

\title{
Black soldier fly larvae as a sustainable animal feed ingredient in Kenya
}

\author{
Shaphan Yong Chia
}




\section{Thesis committee}

\section{Promotors}

Prof. Dr Marcel Dicke

Professor of Entomology

Wageningen University \& Research

Prof. Dr Joop J. A. van Loon

Personal chair at the Laboratory of Entomology

Wageningen University \& Research

\section{Co-promotor}

Dr Chrysantus M. Tanga

International Centre of Insect Physiology and Ecology (icipe), Nairobi, Kenya

\section{Other members}

Prof. Dr W.H. Hendriks, Wageningen University \& Research

Dr H.H.E. van Zanten, Wageningen University \& Research

Dr T. Veldkamp, Wageningen University \& Research

Dr J. Sok, Wageningen University \& Research

This research was conducted under the auspices of the graduate school for Production Ecology \& Resource Conservation 


\title{
Black soldier fly larvae as a sustainable animal feed ingredient in Kenya
}

\author{
Shaphan Yong Chia
}

\section{Thesis}

submitted in fulfilment of the requirements for the degree of doctor

at Wageningen University

by the authority of the Rector Magnificus,

Prof. Dr A.P.J. Mol,

in the presence of the

Thesis Committee appointed by the Academic Board

to be defended in public

on Friday 20 December 2019

at 4 p.m. in the Aula. 
Shaphan Y. Chia

Black soldier fly larvae as a sustainable animal feed ingredient in Kenya, 248 Pages.

$\mathrm{PhD}$ thesis, Wageningen University, Wageningen, the Netherlands (2019) With references, with summary in English

ISBN: 978-94-6395-154-8

DOI: https://doi.org/10.18174/502357 
To my beloved family 



\section{Table of contents}

\section{Chapter 1}

General introduction

\section{Chapter 2}

Insects for sustainable animal feed: inclusive business models involving smallholder farmers

\section{Chapter 3}

Knowledge and willingness of smallholder farmers in Kenya to pay for insect-based feeds

\section{Chapter 4}

Effects of waste stream combinations from brewing industry on performance of black soldier fly Hermetia illucens (Diptera: Stratiomyidae)

\section{Chapter 5}

Threshold temperatures and thermal requirements of black soldier fly Hermetia illucens: Implications for mass production

\section{Chapter 6}

Nutritional composition of black soldier fly larvae feeding on agro-industrial by-products

\section{Chapter 7}

Effect of dietary replacement of fishmeal by insect meal on growth performance, blood profiles and economics of growing pigs in Kenya

\section{Chapter 8}

Black soldier fly larval meal in feed enhances growth performance, carcass yield and meat quality of finishing pigs

Chapter 9

General Discussion

Summary 



\section{Chapter 1}

\section{General introduction}


In low-income countries where the poor rely on agriculture for livelihood, intensification of agricultural production to develop profitable and inclusive fish and livestock enterprises is one way to increase food production and reduce poverty (FAO et al., 2012). Poultry, pig and fish farming are among the fastest growing agribusinesses in Kenya, offering employment and sources of livelihood to the growing population (Bizna, 2019). The poultry sub-sector contributes about 55\% to the livestock sector and accounts for about $30 \%$ of the agricultural gross domestic product (GDP) of Kenya. The sub-sector employs two to three million Kenyans (Omiti \& Okuthe, 2009). Pig keeping is another lucrative business with approximately 350,000 pigs and 7000 pig farmers in Kenya, of which 70\% consists of smallholder farmers (Mburugu-Mosoti, 2014). In addition, fish farming in Kenya employs 67,883 farmers with 69,194 stoked fish ponds. By the end of 2014, the national aquacultural fish production in Kenya was estimated at 24,100 metric tonnes, up from 12,200 metric tonnes in 2010 (FAO, 2016). Therefore, the contribution of these sub-sectors to rural and urban livelihoods as sources of food, income, nutrition and insurance against emergencies are of paramount importance.

Human population growth, rising incomes and urbanization are major drivers of the surge in global demand for highly nutritious protein products such as meat, fish, eggs and milk (Steinfeld et al., 1997). The annual global feed production is estimated at one billion tonnes, representing an annual turnover value of over US $\$ 400$ billion. The FAO projects that feed production will have to increase by $70 \%$ to be able to feed the world in 2050, as meat and fish demands are expected to double (IFIF, 2017; Van Huis et al., 2013). Much of the demand for meat in Kenya can be met through increased poultry, pig and fish production. For example, the rapidly growing urban Kenyan population with higher earnings increasingly spent more on animal products such as dairy products, meat and eggs (FAO, 2017). This growing demand is expected to continue following increased urbanization and income earnings across the population, causing farmers to adopt productivity-enhancing technologies (FAO, 2017). The demand-driven transformation of animal production provides opportunities for the development of the Kenyan economy. Animal producers could improve their livelihoods and the development of the poultry, pig and fish sub-sectors could generate substantial socio-economic benefits, such as job creation and employment for both rural and urban populations (FAO, 2017). However, this transformation in the animal production industry will result in novel interactions between humans, animals, land and the environment (Crist et al., 2017). In Kenya, for instance, 1.8 million urban and peri-urban households currently keep poultry, pigs and dairy cows, but waste management practices remain underdeveloped or inappropriate causing environmental and health problems. This situation is likely to continue and over 6 million households are expected to be involved in livestock production by 2050, representing an unprecedented increase with implications for feed supply, health and the environment (FAO, 2017). 
The challenge in animal nutrition is the availability of sustainable feeds that enable farmers to meet the rising demand for highly nutritious animal products. Ingredients for animal feed include soybeans, fish oil, and several grains, with fishmeal being the major protein source. However, a major constraint to a sustainable production of the increasingly demanded fish and meat products is that land for soybean cultivation is diminishing globally, while the marine overexploitation has continued to reduce the abundance of the small pelagic forage fish, from which fishmeal and fish oil are derived (Masuda \& Goldsmith, 2009; Tacon \& Metian, 2008). The growing demand and scarcity of resources to produce fishmeal and soybean meal have led to increased prices of these ingredients, while feed cost, representing $60-70 \%$ of animal production costs is already prohibitive and cannot be afforded by resource-poor famers (Hilali et al., 2011; Kumar et al., 2017; Van Huis et al., 2013; Villasante et al., 2013). This situation is also affecting the livelihoods of producers in Kenya, especially the smallholder producers. It will therefore, not be a sustainable option to continue to rely on fishmeal and soybean meal as protein sources in feed production (Van Huis et al., 2013). The Kenyan industry is searching for alternative protein sources for its growing poultry, pig and aquaculture sub-sectors and there is much interest in possible replacements for these expensive ingredients (Githigia et al., 2012). Hence there is a need for viable and sustainable alternatives.

Insects are traditional food sources for humans, poultry, pigs and fish and their use as a feed component has long been proposed (DeFoliart, 1989; Farina et al., 1991; Johnson \& Boyce, 1990; Newton et al., 1977; Whitmore et al., 1986). Recently, scientists, academic institutions and policy makers including the FAO have reviewed and recognized the role of insects as food and feed (Van Huis et al., 2013). Most insect amino acid contents are comparable to fishmeal and soybean (Rumpold \& Schluter, 2013). Black soldier fly (BSF) larvae, housefly larvae, and yellow mealworms are promising for industrial animal feed production, among which BSF larvae have superior properties for mass rearing for feed (Van Huis et al., 2013).

\section{The black soldier fly Hermetia illucens}

The black soldier fly Hermetia illucens Linnaeus (Diptera: Stratiomyidae) occurs worldwide in tropical and temperate regions (Cickova et al., 2015; Sheppard et al., 1994). The adult is a black, wasp-like fly, ranging between 13-20 mm in size (May, 1961). There are two translucent cuticular "windows" located on the first abdominal segment and the adult black soldier fly possesses bright, white tarsi. The last abdominal segment of males ends in a plate-like structure while in female BSF the ovipositor protrudes at the last abdominal segment. Adults do not approach or enter human habitats and houses and do not constitute a nuisance. The adult flies only ingest water and flower nectar and this substantially reduces the chances to spread pathogens to humans. The adults are 
pre-occupied with mating and egg-laying (Sheppard et al., 2002). They do not sting and are not considered to be disease vectors (Cickova et al., 2015; Sheppard et al., 2002).

The BSF develops through five developmental stages including: egg, larval, pre-pupal, pupal and adult stages. The BSF larval phase is divided into six instars (Figure 1). An instar refers to the period between two moulting events that involve renewing of the exoskeleton. During the larval period fat reserves are accumulated to meet the nutritional requirements of adult flies (Myers et al., 2008). Kept at $28{ }^{\circ} \mathrm{C}$, the development time from egg to adult typically ranges between 40-43 days (Tomberlin et al., 2002). The female BSF deposits about 500 eggs in cracks and crevices near or in decaying matter (Diclaro \& Kaufman, 2009). The larvae hatch in 3 - 4 days. They feed on organic matter and in about 14 days, they develop to pre-pupae. The pre-pupae disperse from the feeding substrate to sites that are suitable for pupation. The exoskeleton darkens and a pupa develops, from which an adult fly ecloses within approximately 14 days. Approximately two days after adult emergence, the male and female flies are ready to mate (Hall \& Gerhardt, 2002).

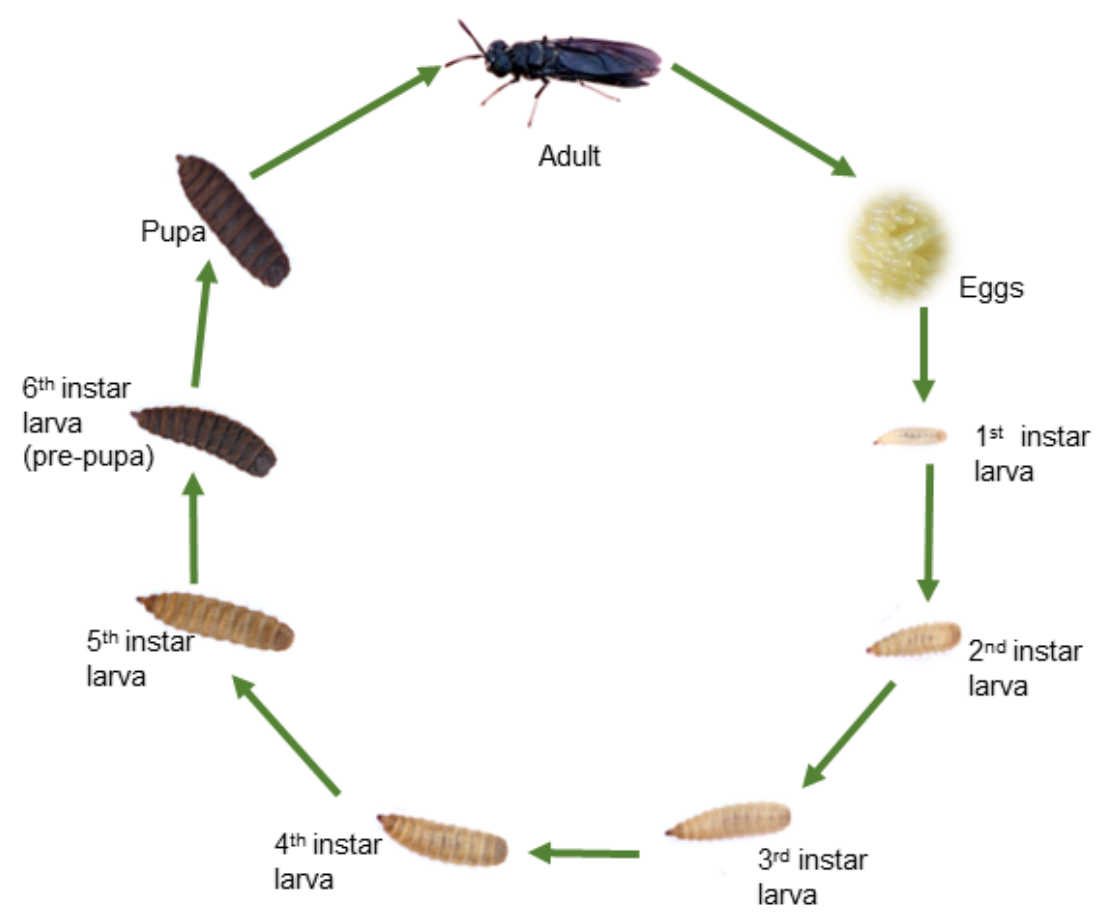

Figure 1. Life cycle of the black soldier fly Hermetia illucens. Sizes of different developmental stages depicted are not proportional. 


\section{Environmental conditions}

Temperature is the most important abiotic factor that influences insect development and overall performance. Insects are particularly sensitive to abiotic conditions due to their small size and proportionately large surface area that increases water loss (Scharf et al., 2015). The BSF has a temperature-dependent pattern of activity. For instance, in tropical regions, the BSF is active throughout the year, while in temperate regions, the insect is only active during the warmer periods of the year (Holmes, 2010). Therefore, modeling its development as function of temperature allows for optimizing their use in waste management and confined animal feeding operations (Holmes et al., 2012). The survival, feeding, development and reproduction of insects are affected by the ambient temperatures. It has been demonstrated that over $95 \%$ of BSF larvae reared on a grainbased diet at $27-30{ }^{\circ} \mathrm{C}$ survive to adults while at $36{ }^{\circ} \mathrm{C}$, less than $1 \%$ of the larvae survive (Tomberlin et al., 2009). In another study, where larvae of BSF were reared on three diets at three different temperatures, i.e. $24.9{ }^{\circ} \mathrm{C}, 27.6{ }^{\circ} \mathrm{C}$ and $32.2{ }^{\circ} \mathrm{C}$, temperature and diet significantly affected all immature stages and the number of degree hours required to complete a particular growth stage as well as the final larval weight varied across diets and temperature regimes. At about 28 and $32{ }^{\circ} \mathrm{C}$, larvae required less degree hours and had approximately $30 \%$ higher final larval weight than at $25^{\circ} \mathrm{C}$ (Harnden \& Tomberlin, 2016). The lower temperature range for BSF egg hatching is reported to be 12 - $16{ }^{\circ} \mathrm{C}$ with egg hatch in 15 days, while the lower range for larval development is 16 - $19{ }^{\circ} \mathrm{C}$ with eggs hatching in about eight days at $19{ }^{\circ} \mathrm{C}$. Mean development time from egg to adult at $19{ }^{\circ} \mathrm{C}$ is 72 days (Holmes et al., 2016). This information is important for understanding growth performance, yet limited to only a few temperature regimes and various diets. Therefore, investigating a wider range of temperatures to determine the optimum as well as minimum and maximum threshold temperatures is crucial for optimal larval production to meet the growing demand for a high-quality protein source and innovative waste management strategies.

\section{Demand for insect-based feed}

An important consideration for research, policy and commercial production is whether the target users of the proposed novel insect products are aware of and willing to pay for them. A proper understanding of the characteristics that influence the consumers' demand for a product will help in the development of a product that targets those most likely to accept and benefit from it (Channa et al., 2019). In this regard, the success of adoption and use of insect-based feed for animal production as well as use of resulting animal products will largely depend on farmers' knowledge and their willingness to pay (Verbeke et al., 2015). However, information on these attitudes is limited, yet necessary for commercial animal production in Africa. 


\section{Research objectives}

The main objective of this thesis is to assess the potential of BSF larvae as a feed component and to investigate farmers' willingness to accept insect-based feed for animal production in Kenya. The specific primary objectives of this thesis are:

1. To assess farmers' knowledge, attitudes towards the use of insects and their willingness to pay for insect-based feed in poultry, pig and fish production in Kenya (Chapter 3)

2. To evaluate the effect of agro-industrial by-products on the performance of BSF (Chapter 4)

3. To determine the threshold temperatures for the development of BSF reared on agro-industrial by-products (Chapter 5)

4. To assess the nutritional quality of BSF larvae reared on agro-industrial by-products (Chapter 6)

5. To evaluate the growth performance, health and carcass yield of growing-finishing pigs fed insect-based feeds (Chapters $7 \& 8$ )

\section{Outline of this thesis}

Chapter 2 presents an overview of the potential of insects as feed and their contribution to sustainably reshaping global food systems into efficient, climate resilient and nutrition-driven models. It also assesses how insects, with a focus on the BSF, can improve livelihoods of smallholder farmers, while mitigating environmental pollution and emphasizes how and why inclusive business involving edible insects aligns with the Sustainable Development Goals (SDGs).

Chapter 3 assesses farmers' knowledge and attitude towards insects as feed, their acceptance of insect species and willingness to pay for insect-based feed by a contingent valuation method using household level data. This chapter provides the first insight into farmers' knowledge of and attitudes to insects as feed and the potential demand for insect-based feed for fish and livestock production in Kenya. Beer and sugar production result in various by-products which typically end up underutilized.

In Chapter 4, a combination of different agro-industrial by-products composed of brewers' spent grains, brewer's yeast and cane molasses was used to evaluate life-history parameters of the BSF such as developmental time and survival of the different life stages. The larval, pre-pupal, pupal, adult biomass, pre-oviposition time, adult fecundity and longevity of starved, water-provided and sugar-fed adults are also presented. The findings reveal that agro-industrial by-products, especially brewers' spent grains, a by-product of beer in Kenya, are suitable for rearing black soldier flies. This has implications for commercial production of high-quality BSF larvae as a suitable alternative to fishmeal in aquaculture and livestock feeds. 
These findings present a new interest in valorizing these side streams due their yearround availability, low competitiveness for food and feed as well as the need for sustainable waste management.

Chapter 5 assesses the development rates of BSF reared on two brewers' spent grain substrates, one supplemented with brewer's yeast and the other not supplemented, at nine constant temperatures using temperature-dependent linear and non-linear day-degree models. The minimum, optimum and maximum threshold temperatures, thermal constants as well as the lifetable parameters for BSF development are presented. The results of mean weight of larvae, pre-pupae, pupae and adult BSF are presented. The results are valuable for optimizing commercial mass rearing procedures of BSF under various environmental conditions.

Chapter $\mathbf{6}$ assesses the effect of the different substrates described in Chapter 4 on the nutritional quality of BSF larvae. The results of proximate, amino acid, fatty acid and mineral compositions of BSF larvae reared on these substrates are presented. High levels of crude protein and predominant saturated fatty acids in larval samples are also presented.

Chapter 7 assesses the potential of substituting fishmeal with BSF larval meal on feed intake, body weight, blood parameters and health of growing pigs as well as economic implications. A conventional level of fishmeal is compared with four dietary inclusion levels of replacement of fishmeal by the BSF larval meal. The findings demonstrate that BSF larval meal is a suitable and cost-effective alternative to fishmeal and present new market opportunities for commercialization of insect-based feed.

Chapter 8 assesses the effect of BSF-based feeds on growth performance and carcass yield of finishing pigs as well as the nutritional value of organ and muscle tissues of pigs. The relationship between live body weight and linear body measurements of finishing pigs and the implication in smallholder pig production are discussed. As indicated in chapter 7 , these findings do not only provide valuable insights into commercial production of insect-based feeds, but also provide important nutritional information for pork consumers.

In Chapter 9, I integrate the findings presented in the different chapters in this thesis and discuss how farmers' knowledge and attitudes influence willingness to pay and how this knowledge can affect the adoption of and demand for insect-based feed in Kenya. I discuss how a combination of different agro-industrial by-products and temperature affect performance of BSF and the implication of this knowledge in mass rearing BSF and waste management operations. I also highlight the need to nutritionally manipulate brewers' spent grains as rearing substrates for BSF larvae in order to improve fatty acid quality of the resulting larvae for feed. Furthermore, I discuss how BSF larval meal in pig feed supports growth and health as well as the economic and nutritional implications 
of this knowledge in commercial production of animal feed and pork consumption in Kenya.

\section{Acknowledgements}

I thank Marcel Dicke and Joop J.A. van Loon for providing helpful comments on an earlier version of this chapter.

\section{References}

Bizna. (2019). Top 10 most profitable farming ideas in Kenya. Retrieved from https://biznakenya.com/most-profitable-farming-ideas-in-kenya/ June, 82019.

Channa, H., Chen, A. Z., Pina, P., Ricker-Gilbert, J., \& Stein, D. (2019). What drives smallholder farmers' willingness to pay for a new farm technology? Evidence from an experimental auction in Kenya. Food Policy, 85, 64-71.

Cickova, H., Newton, G. L., Lacy, R. C., \& Kozanek, M. (2015). The use of fly larvae for organic waste treatment. Waste Management, 35, 68-80.

Crist, E., Mora, C., \& Engelman, R. (2017). The interaction of human population, food production, and biodiversity protection. Science, 356, 260-264.

DeFoliart, G. R. (1989). The human use of insects as food and as animal feed. Bulletin of the Entomological Society of America, 35, 22-36.

Diclaro, J., \& Kaufman, P. E. (2009). Black soldier fly Hermetia illucens linnaeus (Insecta: Diptera: Stratiomyidae) (EENY 461). Florida. Entomology and Nematology; University of Florida/Institute of Food and Agricultural Sciences (IFAS) Extension. Retrieved from: http:/ / citeseerx.ist.psu.edu/viewdoc/download?doi=10.1.1.614.7036\&rep=rep1\&type $=$ pdf, June 8, 2019.

FAO. (2016). FAO Fisheries \& Aquaculture - Fishery and Aquaculture Country Profiles - The Republic of Kenya. Fisheries and Aquaculture country profile. Rome. Food and Agriculture Organization (FAO). Retrieved from: www.fao.org/fishery/facp/KEN/en, June 8, 2019.

FAO. (2017). Africa Sustainable Livestock (ASL) 2050-Country Brief: Kenya (No. I7348EN/1/06.17) - Country brief Kenya. Rome. Food and Agriculture Organization (FAO). Retrieved from: www.fao.org/3/a-i7348e.pdf, June 8, 2019.

FAO, WFP, \& IFAD. (2012). The state of food insecurity in the world 2012. Economic growth is necessary but not sufficient to accelerate reduction of hunger and malnutrition (978-925-107316-2). Rome. Food and Agriculture Organization (FAO). Retrieved from: www.fao. org/3/i2845e/i2845e00.pdf, June 8, 2019.

Farina, L., Demey, F., \& Hardouin, J. (1991). Production de termites pour l'aviculture villageoise au Togo. Tropicultura, 9, 181-187.

Githigia, S. M., Okuthe, S., \& Diop, B. (2012). Pig Sector Kenya. FAO Animal Production and health livestock country reviews. No. 3. Rome. Food and Agriculture Organization (FAO). Retrieved from: www.fao.org/3/a-i2566e.pdf, June 10, 2019. 
Hall, R. D., \& Gerhardt, R. R. (2002). FLIES ( Diptera ). In G. Mullen \& L. Durden (Eds.), Medical and Veterinary Entomology (pp. 127-145): Academic Press.

Harnden, L. M., \& Tomberlin, J. K. (2016). Effects of temperature and diet on black soldier fly, Hermetia illucens (L.) (Diptera: Stratiomyidae), development. Forensic Science International, 266, 109-116.

Hilali, M., Iniguez, L., Knaus, W., Schreiner, M., Rischkowsky, B., Wurzinger, M., \& Mayer, H. K. (2011). Prospects for using nonconventional feeds in diets for Awassi dairy sheep in Syria. Journal of Dairy Science, 94, 3014-3024.

Holmes, L. (2010). Role of abiotic factors on the development and life history of the black soldier fly, Hermetia illucens (L.)(Diptera: Stratiomyidae). Master of Science, University of Windsor, Electronic Theses and Dissertations. 285. Retrieved from htps://scholar.uwindsor.ca/etd/285.

Holmes, L. A., Vanlaerhoven, S. L., \& Tomberlin, J. K. (2012). Relative humidity effects on the life history of Hermetia illucens (Diptera: Stratiomyidae). Environmental Entomology, 41, 971978.

Holmes, L. A., VanLaerhoven, S. L., \& Tomberlin, J. K. (2016). Lower temperature threshold of black soldier fly (Diptera: Stratiomyidae) development. Journal of Insects as Food and Feed, 2 , 255-262.

IFIF. (2017). International Feed Industry Federation (IFIF) Annual report 2016-2017. IFIF. Retrieved from: http://annualreport.ifif.org/wp-content/uploads/IFIF-Annual-Report-2016-2017-download.pdf, June 10, 2019.

Johnson, G. D., \& Boyce, M. S. (1990). Feeding trials with insects in the diet of sage grouse chicks. Journal of Wildlife Management, 54, 89-91.

Kumar, G., Selvakumar, K., Prabu, M., Pandian, A., Valli, C., \& Kannadhasan, M. (2017). Constraints in livestock rearing among resource poor farmers in rural Tamil Nadu. Asian Journal of Agricultural Extension, Economics \& Sociology, 15, 1-5.

Masuda, T., \& Goldsmith, P. D. (2009). World soybean production: Area harvested, yield, and long-term projections. International Food and Agribusiness Management Review, 12, 143-161.

May, B. (1961). The occurrence in New Zealand and the life-history of the soldier fly Hermetia illucens (L.)(Diptera: Stratiomyidae). New Zealand Journal of Science Wellington, 4, 55-65.

Mburugu-Mosoti, C. (2014). The pork value chain: A review of the actors and the business opportunities in the sector in Kenya. Retrieved from: https://agriprofocus.com/upload/ Driving_the_pig_Sector-_Pork_Value_Chain_Report1421660756.pdf, June 10, 2019.

Myers, H. M., Tomberlin, J. K., Lambert, B. D., \& Kattes, D. (2008). Development of black soldier fly (Diptera: Stratiomyidae) larvae fed dairy manure. Environmental Entomology, 37, $11-15$.

Newton, G. L., Booram, C. V., Barker, R. W., \& Hale, O. M. (1977). Dried Hermetia illucens larvae meal as a supplement for swine. Journal of Animal Science, 44, 395-400.

Omiti, J. M., \& Okuthe, S. O. (2009). An overview of the poultry sector and status of highly pathogenic avian influenza (HPAI) in Kenya - background paper. Africa/Indonesia team working paper no. 4. Pro-poor HPAI risk reduction strategy. Washington, D.C. and Nairobi, Kenya: International Food Policy Research Institute and International Livestock 
Research Institute.

Rumpold, B. A., \& Schluter, O. K. (2013). Nutritional composition and safety aspects of edible insects. Molecular Nutrition \& Food Research, 57, 802-823.

Scharf, I., Braf, H., Ifrach, N., Rosenstein, S., \& Subach, A. (2015). The effects of temperature and diet during development, adulthood, and mating on reproduction in the red flour beetle. PLOS ONE, 10, e0136924.

Sheppard, D. C., Newton, G. L., Thompson, S. A., \& Savage, S. (1994). A value added manure management system using the black soldier fly. Bioresource Technology, 50, 275-279.

Sheppard, D. C., Tomberlin, J. K., Joyce, J. A., Kiser, B. C., \& Sumner, S. M. (2002). Rearing methods for the black soldier fly (Diptera: Stratiomyidae). Journal of Medical Entomology, 39, 695-698.

Steinfeld, H., Haan, C. D., \& Blackburn, H. (1997). Livestock-environment interactions: issues and options. Fressingfield. WRENmedia. Retrieved from: www.fao.org/3/x5305e/ x5305e00.htm\#Contents, June 12, 2019.

Tacon, A. G. J., \& Metian, M. (2008). Global overview on the use of fish meal and fish oil in industrially compounded aquafeeds: Trends and future prospects. Aquaculture, 285, 146-158.

Tomberlin, J. K., Adler, P. H., \& Myers, H. M. (2009). Development of the black soldier fly (Diptera: Stratiomyidae) in relation to temperature. Environmental Entomology, 38, 930-934.

Tomberlin, J. K., Sheppard, D. C., \& Joyce, J. A. (2002). Selected life-history traits of black soldier flies (Diptera : Stratiomyidae) reared on three artificial diets. Annals of the Entomological Society of America, 95, 379-386.

Van Huis, A., Van Itterbeeck, J., Klunder, H., Mertens, E., Halloran, A., Muir, G., \& Vantomme, P. (2013). Edible insects: future prospects for food and feed security (No. 171). Rome: Food and Agriculture Organization (FAO).

Verbeke, W., Spranghers, T., De Clercq, P., De Smet, S., Sas, B., \& Eeckhout, M. (2015). Insects in animal feed: Acceptance and its determinants among farmers, agriculture sector stakeholders and citizens. Animal Feed Science and Technology, 204, 72-87.

Villasante, S., Rodríguez-González, D., Antelo, M., Rivero-Rodríguez, S., \& Lebrancón-Nieto, J. (2013). Why are prices in wild catch and aquaculture industries so different? Ambio, 42, 937-950.

Whitmore, R. W., Pruess, K. P., \& Gold, R. E. (1986). Insect food selection by 2-week-old ringnecked pheasant chicks. Journal of Wildlife Management, 50, 223-228. 


\section{Chapter 2}

\section{Insects for sustainable animal feed: inclusive business models involving smallholder farmers}

Shaphan Y. Chia, Chrysantus M. Tanga, Joop J. A. van Loon and Marcel Dicke

Published in

Current Opinion in Environmental Sustainability (2019) 41:23-30, doi:10.1016/j.cosust.2019.09.003 


\section{Abstract}

Global population growth, an increasing demand for animal products and scarcity of conventional feed ingredients drive the search for alternative protein sources for animal feed. Extensive research indicates that insects provide good opportunities as a sustainable, high quality and low-cost component of animal feed. Here, we discuss how insect farming can promote inclusive business for smallholder farmers in the agribusiness value chain. Inclusive business models involving insects as ingredients in feed may contribute to solving socio-economic and environmental problems in developing countries, aligning with the United Nations' Sustainable Development Goals. With low initial capital investments, smallholder insect farmers have good opportunities to increase productivity, improve their livelihood and contribute to food security and a circular economy. 


\section{Introduction}

While smallholder farmers are responsible for the basis of global food production (Poole, 2017), those in low income communities do not necessarily benefit by gaining access to commercial value chains. Integrating smallholder farmers in a circular economy and thus making them stakeholders in the agribusiness value chain can help to improve their quality of life in a sustainable way. Developing this through inclusive business (IB) models (Golja \& Požega, 2012; Kelly et al., 2015) will empower smallholder farmers, and promote their financial viability as well as environmental sustainability.

In the developing world, particularly in Africa where most of the human population increase is expected to occur, economic growth and changing dietary patterns will account for a 70\% increase in the demand for livestock products by 2050 (IFPRI, 2017; United Nations, 2017). Feed costs represent $60-70 \%$ of total costs of livestock production (Van Huis et al., 2013). Important protein sources in feed are soybean meal whose use competes with food production, and fishmeal whose availability is increasingly limited because of marine overexploitation (Masuda \& Goldsmith, 2009; Tacon \& Metian, 2008). Costs of these feed ingredients rapidly increase, especially affecting resource-poor farmers. The search for sustainable alternatives has led to a growing interest in insects as feed component (Van Huis et al., 2013).

Insects contain high levels of protein and their production has a small ecological footprint (Van Huis, 2013). Among the insect species that are mass reared, the black soldier fly (BSF) Hermetia illucens, house fly (HF) Musca domestica and yellow mealworm Tenebrio molitor, have received considerable attention because they can feed on different substrates including organic waste streams (Chia et al., 2018a; Chia et al., 2018b). The ability of these insects to convert organic waste into high-quality nutrients has rapidly opened innovative economic prospects. These include insect-based protein as an alternative to fishmeal or soybean meal for pig (Biasato et al., 2019), poultry (Onsongo et al., 2018) and fish (Iaconisi et al., 2017) feeds. BSF and HF larvae are currently reared exclusively as feed ingredients (van der Fels-Klerx et al., 2018; Van Huis et al., 2013).

This review focusses on how the value of insects as feed component can contribute to improving livelihood of smallholder farmers through IB models and reshaping food systems into efficient, climate resilient and nutrition-driven elements of a circular economy. In doing so, we will emphasize how and why IB models in this area align with the Sustainable Development Goals (SDGs) (Figure 1). 


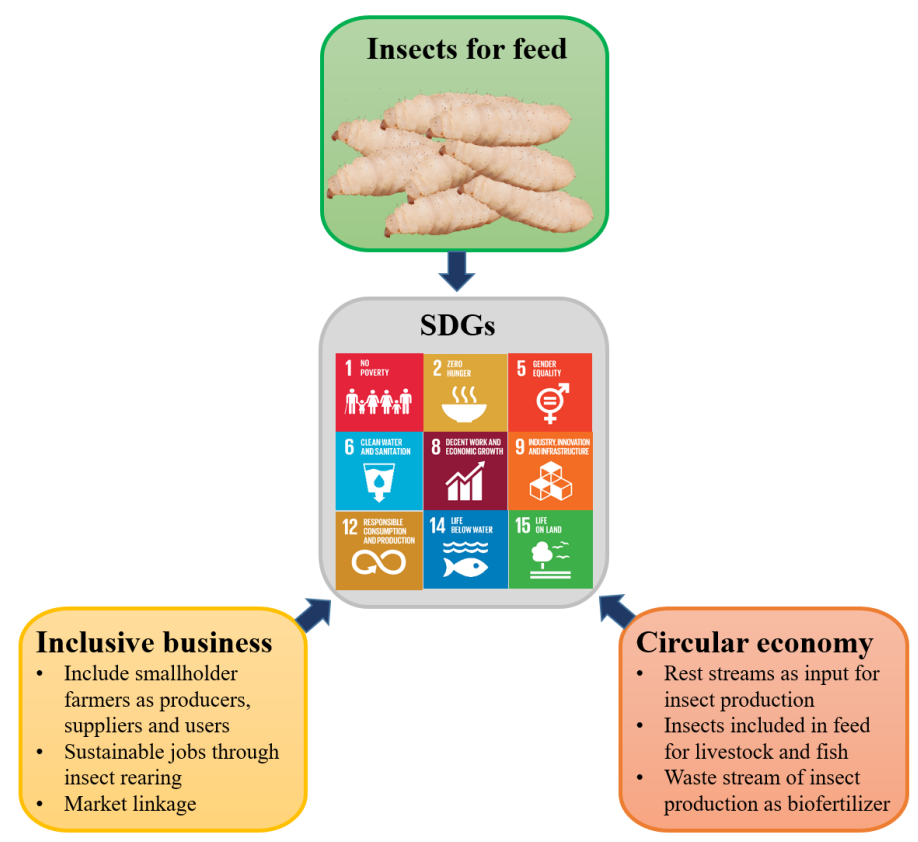

Figure 1. Sustainable production of insects, their use in animal feed, contribution to a circular economy and applying inclusive business models involving smallholder farmers contribute to achieving the Sustainable Development Goals (SDGs) 1, 2, 5, 6, 8, 9, 12, 14 and 15.

\section{Insects as feed}

Recent studies indicate that insect meal can be an excellent replacement of fishmeal or soybean meal in animal feed (Biasato et al., 2019; Iaconisi et al., 2017; Onsongo et al., 2018; van der Fels-Klerx et al., 2018; Van Huis et al., 2013). Insects are rich sources of macro- and micronutrients (Finke \& Oonincx, 2017; Van Huis, 2013). BSF larvae, for example, contain high levels of protein (37-63\%) and fat (20-40\%) that have well-balanced amino acid and fatty acid profiles, respectively (Roos, 2018; Schiavone et al., 2017). Insects are good sources of minerals, such as calcium, iron, potassium, magnesium, phosphorus and zinc as well as vitamins including niacin, vitamin B12, thiamine and riboflavin (Akhtar \& Isman, 2018; Spranghers et al., 2017).

When BSF larval meal replaced soybean and fishmeal in proportions of 10 to $56 \%$, broiler quails and chickens had satisfactory taste, aroma and nutritional composition of the meat, confirming that BSF larval meal is suitable for inclusion in poultry diets (Cullere et al., 2018; Onsongo et al., 2018). Insects have also been implemented as fish feed: nursing Nile tilapia fingerlings with different levels of fishmeal replacement by BSF meal resulted in similar growth performance and feed conversion (Devic et al., 2018). Piglets fed diets with 5-10\% levels of BSF larval meal exhibited satisfactory 
growth performance, with minimal effects on blood profiles (Biasato et al., 2019). Also, at higher inclusion levels, performance similar to the use of conventional feed has been recorded (Chia et al., 2019). Overall, research indicates that BSF larval meal is a suitable component of animal feed (Biasato et al., 2019; Iaconisi et al., 2017; Onsongo et al., 2018; van der Fels-Klerx et al., 2018).

\section{Organic waste reduction and environmental sanitation}

The production of insects as feed has interesting characteristics. Insects can efficiently convert low-grade organic substrates into high-quality protein (Van Huis et al., 2013). BSF and HF larvae can be reared on organic waste, which would otherwise end up in dumpsites, causing environmental pollution. BSF (Box 1) is most commonly utilized. For instance, in one day, BSF larvae can reduce 30 metric tons of food waste to $c a .10$ metric tons (waste reduction 66\%), while producing $930 \mathrm{~kg}$ of dry biomass (Salomone et al., 2017). Waste reduction of $51-80 \%$ by BSF larvae was recorded on pig, chicken and kitchen waste (Nana et al., 2018). Fly larvae can also be used in environmental sanitation programs to improve human health conditions. In Africa, private companies currently convert human waste from slums into organic fertilizer and fly larvae (Dicke, 2018). These initiatives help to sanitize the environment for poor communities. In conclusion, the production of fly larvae as feed component provides high quality feed ingredients while contributing to a circular economy.

\section{Box 1: Black soldier fly (Hermetia illucens)}

The BSF is present in tropical and subtropical regions of the world (Sheppard et al., 1994). Larvae can develop on several waste streams including vegetable and fruit waste, animal manure and human excrements resulting in significant waste reduction and high nutritional quality insect biomass (Chia et al., 2018a; Chia et al., 2018b; Nana et al., 2018; Spranghers et al., 2017). Larvae reach highest biomass after ca. two weeks under optimal diet and temperature conditions (Chia et al., 2018a; Chia et al., 2018b). Content of individual amino acids as percentage of crude protein is high (1.3-12.8\%), which is comparable with fishmeal (2.1-13.1\%) and soybean meal (1.320.7\%) (Liland et al., 2017). BSF is not considered a pest and is not known as a vector of diseases. Adult BSF are not attracted to human habitats and do not constitute a nuisance. These characteristics make BSF an attractive insect species for animal feed.

\section{Environmental sustainability}

Implementing insects in nutrient cycling for feed production is innovative and currently receives ample attention (Chaalala et al., 2018). The production of one metric ton of HF larval meal to replace 0.5 metric ton of fishmeal and 0.5 metric ton of soybean meal, for example, resulted in reduced land use and increased energy use (van Zanten 
et al., 2015). Similar data were reported for mealworm meal production (Oonincx \& de Boer, 2012). Land use is globally under pressure and, thus, production of insects for feed alleviates this. The higher energy consumption was mainly needed to maintain optimal temperatures for larval production (van Zanten et al., 2015). Thus, exploiting environments that match optimal temperatures, such as in tropical regions, may reduce energy use.

Insects convert their feed more efficiently than pigs and cattle (Bosch et al., 2019; Dobermann et al., 2017; Halloran et al., 2018; Rumpold \& Schlüter, 2013), which contributes to their importance for valorizing organic waste streams (Chia et al., 2018b). Sustainability of insect production is highest if the insects are fed with organic resources that are currently not suitable as feed for livestock. Current protein sources in feed are soybean meal and fishmeal whose use is under pressure because of environmental aspects (Dicke, 2018). Therefore, rearing BSF as feed may mitigate environmental impact of feed production (Bosch et al., 2019).

\section{Inclusive business}

For small-scale farmers, the most important costs of livestock production are represented by the costs of feed which amount up to $70 \%$ of all costs and this is especially due to the costs of protein components. Soybean meal and particularly fishmeal prices are rapidly increasing (Dicke, 2018). As a consequence, farmers in low and middle-income countries are in need of alternatives that are both effective and affordable.

A survey among smallholder poultry farmers in four counties in Kenya showed that they are aware of the opportunities of insects as feed component (Figure 2). Female farmers appear to be more informed of the opportunities than male farmers. However, these farmers usually depend on external sources for feed, including national and international feed companies (Figure 2). This makes them economically dependent on imported feeds that are commonly based on fishmeal and soybean meal. Yet, fly larvae may be produced locally by smallholder farmers providing opportunities to become feed suppliers in addition to or instead of being feed buyers. They may rear fly larvae as feed component either to be included in feeds that they formulate themselves or to sell to feed millers (knowledge4food.net/research-project/gcp2-insect-products-feed-africa). This will provide farmers with opportunities to actively engage in the emerging insect agribusiness value chain (Pomalégni et al., 2017). Becoming less dependent on international feed producers and simultaneously gaining income from producing fly larvae as feed component contributes to improving livelihood and food security of smallholder farmers (Pomalégni et al., 2017). 


\begin{tabular}{|l|l|l|l|}
\hline \multirow{2}{*}{} & \multicolumn{2}{|c|}{ Farmers } & \multirow{2}{*}{ Statistical significance } \\
\cline { 2 - 4 } & Female, $\mathrm{n}=243$ & Male, $\mathrm{n}=166$ & $* * *$ \\
\hline $\begin{array}{l}\text { Aware that insects can } \\
\text { be used as feed }\end{array}$ & & & \\
\hline
\end{tabular}

Figure 2. Farmers' perception and use of insects as feed for poultry in Kenya. The blue, green, red and yellow colours represent farmers' responses. Asterisks indicate significant differences between male and female farmers (z-test): ***: $\mathrm{P}<0.001$, ns: not significant.

\section{Economic aspects}

The economics of adopting insects as feed ingredient include the production of the insects as well as incorporating them in feed for livestock. The production costs of fly larvae involve investments in infrastructure such as space and containers. These costs are minor (Roffeis et al., 2018). Additional costs involve resources such as water, electricity and feed substrates for the fly larvae, and labour (Roffeis et al., 2018). Comparing break-even sales prices of feeds that include HF or BSF meal as protein source with prices of conventional feeds in West Africa indicates that insect meals are competitive to feeds based on fishmeal as protein source (Roffeis et al., 2018). Costs of protein ingredients for chicken feed in Kenya are 1.20 and $0.85 \mathrm{US} \$ / \mathrm{kg}$ for fishmeal and BSF meal respectively (Onsongo et al., 2018). Dietary replacement of soybean and fish meal by BSF meal in broiler feed resulted in an improved feed conversion rate leading to higher yield with less feed input. In combination with lower costs for BSF meal than for fishmeal and soybean meal, this resulted in a $25 \%$ higher return on investment when using BSF meal (Onsongo et al., 2018).

The production of fly larvae is based on waste streams as input. Many of these waste streams are currently not valorized and end up in landfills. This leads to environmental damage in terms of e.g. contribution to global warming and limiting of resource recovery (Oyoo et al., 2014). However, the increasing importance of waste streams as input in 
the production of a valuable feed component may result in an increase in costs of this resource of insect production. Reducing labour costs will be important to limit the production costs of BSF and HF for feed (Roffeis et al., 2018). Moreover, an additional benefit of producing insects for feed is that the waste stream remaining after harvesting the fly larvae can be valorized as fertilizer, thus providing an additional financial benefit (Roffeis et al., 2018; Xiao et al., 2018). In conclusion, producing HF or BSF as feed component is competitive with the use of fishmeal and although the price of substrates is likely to rise, other benefits of fly production are likely to outweigh this.

\section{Insect farming in the context of a circular economy}

Insect farming by smallholder farmers can increase local supply of insects as animal feed in an integrated livestock-fish farming system. Farmers may use on-farm waste streams such as crop leftovers as input for BSF production and add the resulting fly larvae to the feed for their livestock. This results in a circular approach that closes the nutrient cycles on farm (Figure 3). With limited space, resource-poor farmers that engage in insect farming may increase their productivity while contributing to waste management (Pomalégni et al., 2017). Smallholders can start up innovative businesses with limited inputs to generate insect meal for animal feed and the waste stream of insect production can be used as organic fertilizer for crop production (Chaalala et al., 2018). Sales from resulting animal products (fish, meat and eggs, insect meal) and crop yields can supplement household income or provide food. Insects can thus effectively close nutrient cycles (Figure 3), avoiding food wasting because waste becomes a resource. One key aspect to consider in closing the loop is the legislative constraints of using insect meal as (ingredient of) livestock feed (van Raamsdonk et al., 2017). Inclusion of insect meal in livestock and fish diets is currently allowed in Kenya and Uganda (Dicke, 2018) and under development in the EU (http://ipiff.org/insects-eu-legislation/). Thus, this promising model is now in the process of being accepted by regulators as well.

\section{Sustainable Development Goals (SDGs)}

IB models enable individuals, households, entrepreneurs, micro-, small-, and medium-sized enterprises to secure access to affordable goods and services relevant to sustainable livelihoods and engaging in value chains in beneficial and sustainable ways (Asia Development Bank, 2016; Beckwith, 2018; Kelly et al., 2015; Likoko \& Kini, 2017). Inclusive business models are sustainable business solutions that expand access to goods, services, and livelihood opportunities for low-income communities in commercially viable ways (Marangu \& Adoyo, 2018). Insect production by smallholder farmers may both disconnect them from expensive external inputs such as fishmeal-based feed as well as connect them to local economies by selling the insects to local livestock farmers as well as feed millers (Figure 3). 


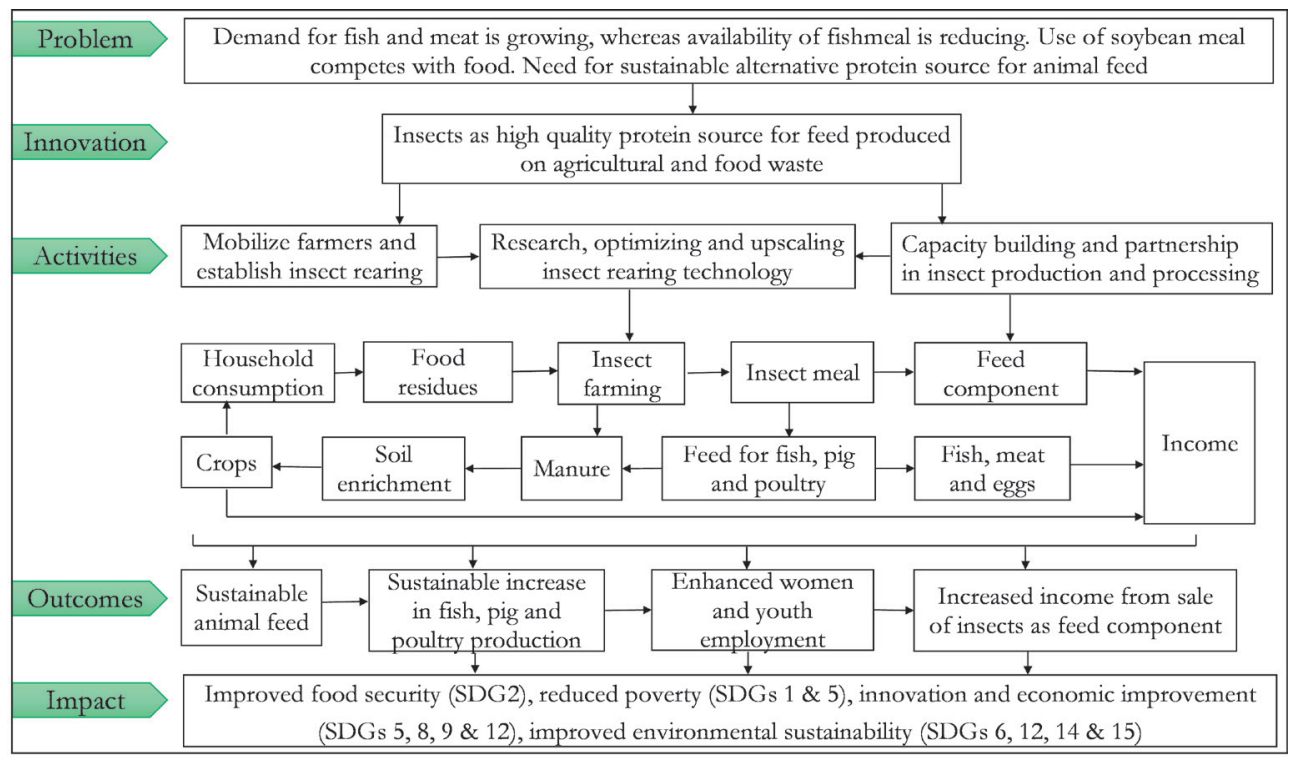

Figure 3. Insect farming for feed in the context of a circular economy can generate income and create employment: innovation, activities, outcome and impact.

In January 2016, the United Nations officially adopted the SDGs and called for a universal action to end all forms of poverty, fight inequalities and tackle climate change within a package of 17 SDGs. Specific for this call is the inclusion of poor, middle- and high-income people. However, efforts towards achieving the SDGs are felt differently among low- and high-income people, men and women, developed and developing countries (Asia Development Bank, 2016). Implementing innovative and sustainable food production strategies such as insect farming for animal feed involving smallholder farmers may contribute substantially to several of the SDGs, which are interconnected (Figure 1) (Dicke, 2018; Poole, 2017; Veglio \& Fiedler, 2016). Access to and control over natural resources globally impact how rural people secure decent livelihoods, escape hunger, participate in decision making and overcome social and economic exclusion (Franco \& Monsalve Suárez, 2018). With minimal inputs, resource-poor people can set up small insect farms to produce for themselves or the local market (Figure 3) hence reducing poverty (SDG 1) and hunger (SDG 2) (Chaalala et al., 2018).

Water scarcity, poor water quality and inadequate sanitation negatively impact food production and livelihoods, thus worsening malnutrition. In South Africa, preliminary trials show that BSF larvae can be effectively used in urine diversion dehydrating toilets to manage human faeces, while conserving water to alleviate sanitation problems faced mainly by the rural poor (SDG 6) (Mutsakatira et al., 2018). Commercial insect farming is becoming a new sector for economic growth and employment opportunities (SDG 8). 
Inclusive insect farming may promote sustainable industrialization, increase employment and local technology development in low-income communities (SDG 9) as well as improve gender equality (SDG 5). Insect bio-conversion can ensure sustainable use and reduction of food waste (SDG 12). Increased insect production as feed may provide a sustainable alternative to fishmeal, thus reducing effects on biodiversity due to overfishing and conversion of forests to agricultural land (SDGs 14 and 15).

In conclusion, IB models align with the SDGs by strengthening stakeholder engagement in agricultural value chains, while mitigating the effects of food production on the environment.

\section{Future prospects}

Changes in feed systems are dependent on several potential drivers, including technological, environmental, political, economic, cultural and demographic drivers (De Brauw et al., 2019). Technological drivers are clearly present for insects as feed (Biasato et al., 2019; Iaconisi et al., 2017; Onsongo et al., 2018; Van Huis et al., 2013). Fly larvae have great prospects for animal feed and waste management (Van Huis et al., 2013). Environmental drivers include the valorization of waste streams as well as mitigation of biodiversity loss and climate change (Dicke, 2018; Van Huis et al., 2013). Producing insect meal requires limited land and water. Insects can sustainably close nutrient cycles while providing animal proteins and useful by-products, creating employment, increasing local productivity and connecting smallholder farmers to the agribusiness value chain. As long as the fly larvae can be reared on substrates that are a true waste stream, the production of fly larvae as feed will not interfere with food production and will provide a sustainable alternative for fishmeal. Future research should focus on the suitability of a diversity of waste streams that effectively support the growth of the fly larvae while not competing with other use. The remaining drivers, including political, economic, cultural and demographic drivers, are institutional and require a multi-stakeholder involvement (De Brauw et al., 2019). The production of fly larvae for on-farm and local use may make smallholder farmers less dependent on feed millers that provide feed based on expensive and unsustainable fishmeal or soybean meal. For smallholder farmers to be able to effectively connect to the agribusiness value chain and supply fly larvae to national feed millers, it is important that they can supply sufficient volume. To do so, farmers likely need to organize in cooperatives. This will not only improve supply volume but can also empower them within the value chain. The novel production of insects as feed ingredient by smallholder farmers aligns with various SDGs: smallholder farmers can benefit from new markets while generating meaningful profits and increasing economic resilience in low-income communities. Developing the institutional drivers will be vital for successfully implementing the use of insects for feed via inclusive business models. 


\section{Acknowledgements}

This study was financially supported by the Netherlands Organization for Scientific Research (NWO)-WOTRO Science for Global Development (ILIPA - W 08.250.202). The authors declare no conflicts of interest.

\section{References}

Akhtar, Y., \& Isman, M. (2018). Insects as an alternative protein source. In Y. Y. Rickey (Ed.), Proteins in food processing (pp. 263-288): Woodhead Publishing.

Asia Development Bank. (2016). How inclusive is inclusive business for women? Examples from Asia and Latin America. Mandaluyong City: Asian Development Bank.

Beckwith, N. (2018). Inclusive business financing: Where commercial opportunity and sustainability converge. Mandaluyong City: Asian Development Bank.

Biasato, I., Renna, M., Gai, F., Dabbou, S., Meneguz, M., Perona, G., .. Gasco, L. (2019). Partially defatted black soldier fly larva meal inclusion in piglet diets: effects on the growth performance, nutrient digestibility, blood profile, gut morphology and histological features. Journal of Animal Science and Biotechnology, 10,12.

Bosch, G., van Zanten, H. H. E., Zamprogna, A., Veenenbos, M., Meijer, N. P., van der FelsKlerx, H. J., \& van Loon, J. J. A. (2019). Conversion of organic resources by black soldier fly larvae: Legislation, efficiency and environmental impact. Journal of Cleaner Production, 222, 355-363.

Chaalala, S., Leplat, A., \& Makkar, H. (2018). Importance of Insects for Use as Animal Feed in Low-Income Countries. In A. Halloran, R. Flore, P. Vantomme, \& N. Roos (Eds.), Edible Insects in Sustainable Food Systems (pp. 303-319). Cham: Springer.

Chia, S. Y., Tanga, C. M., Khamis, F. M., Mohamed, S. A., Salifu, D., Sevgan, S., . . Ekesi, S. (2018a). Threshold temperatures and thermal requirements of black soldier fly Hermetia illucens: Implications for mass production. PLoS ONE, 13, e0206097.

Chia, S. Y., Tanga, C. M., Osuga, I. M., Alaru, A. O., Mwangi, D. M., Githinji, M., . . Dicke, M. (2019). Effect of dietary replacement of fishmeal by insect meal on growth performance, blood profiles and economics of growing pigs in kenya. Animals, 9, 705.

Chia, S. Y., Tanga, C. M., Osuga, I. M., Mohamed, S. A., Khamis, F. M., Salifu, D., . . Ekesi, S. (2018b). Effects of waste stream combinations from brewing industry on performance of Black Soldier Fly, Hermetia illucens (Diptera: Stratiomyidae). PeerJ, 6, e5885.

Cullere, M., Tasoniero, G., Giaccone, V., Acuti, G., Marangon, A., \& Dalle Zotte, A. (2018). Black soldier fly as dietary protein source for broiler quails: meat proximate composition, fatty acid and amino acid profile, oxidative status and sensory traits. Animal, 12, 640-647.

De Brauw, A., Brouwer, I. D., Snoek, H., Vignola, R., Melesse, M. B., Lochetti, G., . . Ruben, R. (2019). Food system innovations for healthier diets in low and middle-income countries (IFPRI Discussion Paper 1816). Washington, DC. International Food Policy Research Institute (IFPRI). Retrieved from: https://doi.org/10.2499/p15738coll2.133156.

Devic, E., Leschen, W., Murray, F., \& Little, D. C. (2018). Growth performance, feed utilization and body composition of advanced nursing Nile tilapia (Oreochromis niloticus) fed diets containing Black Soldier Fly (Hermetia illucens) larvae meal. Aquaculture Nutrition, 24, 416-423. 
Dicke, M. (2018). Insects as feed and the Sustainable Development Goals. Journal of Insects as Food and Feed, 4, 147-156.

Dobermann, D., Swift, J. A., \& Field, L. M. (2017). Opportunities and hurdles of edible insects for food and feed. Nutrition Bulletin, 42, 293-308.

Finke, M., \& Oonincx, D. (2017). Nutrient content of insects. In A. Van Huis \& J. Tomberlin (Eds.), Insects as Food and Feed. From Production to Consumption (pp. 290 - 308). Wageningen: Wageningen Academic Publishers.

Franco, J., \& Monsalve Suárez, S. (2018). Why wait for the state? Using the CFS Tenure Guidelines to recalibrate political-legal struggles for democratic land control. Third World Quarterly, 39, 1386-1402.

Golja, T., \& Požega, S. (2012). Inclusive business-what it is all about? Managing inclusive companies. International Review of Management and Marketing, 2, 22-42.

Halloran, A., Hansen, H. H., Jensen, L. S., \& Bruun, S. (2018). Comparing environmental impacts from insects for feed and food as an alternative to animal production. In A. Halloran, R. Flore, P. Vantomme, \& N. Roos (Eds.), Edible Insects in Sustainable Food Systems (pp. 163-180). Cham: Springer.

Iaconisi, V., Marono, S., Parisi, G., Gasco, L., Genovese, L., Maricchiolo, G., . . . Piccolo, G. (2017). Dietary inclusion of Tenebrio molitor larvae meal: Effects on growth performance and final quality treats of blackspot sea bream (Pagellus bogaraveo). Aquaculture, 476, 49-58.

IFPRI. (2017). 2016 Annual report. International Food Policy Research Institute (IFPRI). Washington, DC. Retrieved from: http://ebrary.ifpri.org/cdm/ref/collection/p15738coll2/ id/131159, April 15, 2019.

Kelly, S., Vergara, N., \& Bammann, H. (2015). Inclusive business models - Guidelines for improving linkages between producer groups and buyers of agricultural produce. Rome: Food and Agriculture Organization.

Likoko, E., \& Kini, J. (2017). Inclusive business—a business approach to development. Current Opinion in Environmental Sustainability, 24, 84-88.

Liland, N. S., Biancarosa, I., Araujo, P., Biemans, D., Bruckner, C. G., Waagbo, R., . . Lock, E. J. (2017). Modulation of nutrient composition of black soldier fly (Hermetia illucens) larvae by feeding seaweed-enriched media. PLOS ONE, 12, e0183188.

Marangu, J., \& Adoyo, L. (2018). Food and business knowledge platform and NWO-WOTRO exchange afternoon on inclusive agribusiness strategies. Food and business knowledge platform (FBKP) and the Netherlands Organisation for Scientific Research (NWO) Retrieved from: https://knowledge4food.net/wp-content/uploads/2018/02/180118_fbkp-wotro-iab-fullreport.pdf, April 9, 2019.

Masuda, T., \& Goldsmith, P. D. (2009). World soybean production: Area harvested, yield, and long-term projections. International Food and Agribusiness Management Review, 12, 143-161.

Mutsakatira, E., Buckley, C., \& Mercer, S. (2018). Potential use of the black soldier fly larvae in faecal sludge management: a study in Durban, South Africa. Paper presented at the 41st WEDC International Conference: Transformation towards sustainable and resilient wash services, Egerton University, Nakuru, Kenya.

Nana, P., Kimpara, J. M., Tiambo, C. K., Tiogue, C. T., Youmbi, J., Choundong, B., \& Fonkou, T. (2018). Black soldier flies (Hermetia illucens Linnaeus) as recyclers of organic waste and 
possible livestock feed. International Journal of Biological and Chemical Sciences, 12, 2004-2015.

Onsongo, V. O., Osuga, I. M., Gachuiri, C. K., Wachira, A. M., Miano, D. M., Tanga, C. M., . . Fiaboe, K. K. M. (2018). Insects for income generation through animal feed: Effect of dietary replacement of soybean and fish meal with black soldier fly meal on broiler growth and economic performance. Journal of Economic Entomology, 111, 1966-1973.

Oonincx, D. G., \& de Boer, I. J. (2012). Environmental impact of the production of mealworms as a protein source for humans - a life cycle assessment. PLOS ONE, 7, e51145.

Oyoo, R., Leemans, R., \& Mol, A. P. J. (2014). Comparison of environmental performance for different waste management scenarios in East Africa: The case of Kampala City, Uganda. Habitat International, 44, 349-357.

Pomalégni, S. C. B., Gbemavo, D. S. J. C., Kpadé, C. P., Kenis, M., \& Mensah, G. A. (2017). Traditional use of fly larvae by small poultry farmers in Benin. Journal of Insects as Food and Feed, 3, 187-192.

Poole, N. (2017). Smallholder agriculture and market participation. Rome: Food and Agriculture Organization and Practical Action Publishing.

Roffeis, M., Wakefield, M. E., Almeida, J., Alves Valada, T. R., Devic, E., Koné, N. G., . . Muys, B. (2018). Life cycle cost assessment of insect based feed production in West Africa. Journal of Cleaner Production, 199, 792-806.

Roos, N. (2018). Insects and Human Nutrition. In A. Halloran, R. Flore, P. Vantomme, \& N. Roos (Eds.), Edible insects in sustainable food systems. Cham: Springer.

Rumpold, B. A., \& Schlüter, O. K. (2013). Potential and challenges of insects as an innovative source for food and feed production. Innovative Food Science \& Emerging Technologies, 17, 1-11.

Salomone, R., Saija, G., Mondello, G., Giannetto, A., Fasulo, S., \& Savastano, D. (2017). Environmental impact of food waste bioconversion by insects: Application of Life Cycle Assessment to process using Hermetia illucens. Journal of Cleaner Production, 140, 890-905.

Schiavone, A., De Marco, M., Martínez, S., Dabbou, S., Renna, M., Madrid, J., . . Gasco, L. (2017). Nutritional value of a partially defatted and a highly defatted black soldier fly larvae (Hermetia illucens L.) meal for broiler chickens: apparent nutrient digestibility, apparent metabolizable energy and apparent ileal amino acid digestibility. Journal of Animal Science and Biotechnology, 8, 51.

Sheppard, D. C., Newton, G. L., Thompson, S. A., \& Savage, S. (1994). A value added manure management system using the black soldier fly. Bioresource Technology, 50, 275-279.

Spranghers, T., Ottoboni, M., Klootwijk, C., Ovyn, A., Deboosere, S., De Meulenaer, B., . . De Smet, S. (2017). Nutritional composition of black soldier fly (Hermetia illucens) prepupae reared on different organic waste substrates. Journal of the Science of Food and Agriculture, 97, 2594-2600.

Tacon, A. G. J., \& Metian, M. (2008). Global overview on the use of fish meal and fish oil in industrially compounded aquafeeds: Trends and future prospects. Aquaculture, 285, 146-158.

United Nations, \& Department of Economic and Social Affairs Population Division. (2017). World population prospects: The 2017 Revision, key findings and advance tables (Working Paper No. ESA/P/WP/248). New York. Retrieved from: https://reliefweb.int/sites/ reliefweb.int/files/resources/WPP2017_KeyFindings.pdf, April 15, 2019.

Van der Fels-Klerx, H. J., Camenzuli, L., Belluco, S., Meijer, N., \& Ricci, A. (2018). Food Safety 
issues related to uses of insects for feeds and foods. Comprehensive Reviews in Food Science and Food Safety, 17, 1172-1183.

Van Huis, A. (2013). Potential of insects as food and feed in assuring food security. Annual Review of Entomology, 58, 563-583.

Van Huis, A., Van Itterbeeck, J., Klunder, H., Mertens, E., Halloran, A., Muir, G., \& Vantomme, P. (2013). Edible insects: future prospects for food and feed security (No. 171). Rome: Food and Agriculture Organization.

van Raamsdonk, L. W. D., van der Fels-Klerx, H. J., \& de Jong, J. (2017). New feed ingredients: the insect opportunity. Food Additives \& Contaminants. Part A: Chemistry, Analysis, Control, Exposure \& Risk Assessment, 34, 1384-1397.

van Zanten, H. H. E., Mollenhorst, H., Oonincx, D. G. A. B., Bikker, P., Meerburg, B. G., \& de Boer, I. J. M. (2015). From environmental nuisance to environmental opportunity: housefly larvae convert waste to livestock feed. Journal of Cleaner Production, 102, 362-369.

Veglio, F., \& Fiedler, D. (2016). Delivering on the Sustainable Development Goals: The inclusive business approach. Geneva, World Business Council for Sustainable Development (WBCSD). Retrieved from: www.wbcsd.org/contentwbc/download/2585/31560, April 5, 2019.

Xiao, X., Mazza, L., Yu, Y., Cai, M., Zheng, L., Tomberlin, J. K., . . Zhang, J. (2018). Efficient co-conversion process of chicken manure into protein feed and organic fertilizer by Hermetia illucens L. (Diptera: Stratiomyidae) larvae and functional bacteria. Journal of Environmental Management, 217, 668-676. 


\section{Chapter 3}

\section{Knowledge and willingness of}

smallholder farmers in Kenya to pay for insect-based feeds

Shaphan Y. Chia, Chrysantus M. Tanga, John Macharia, Gracious M. Diiro, Sunday Ekesi, Joop J. A. van Loon and Marcel Dicke

Submitted 


\section{Abstract}

Edible insects are increasingly considered as sustainable alternatives to fish and soybean meals in animal feed because of their high nutritional quality and environmental benefits. However, the successful introduction of a new product to the market depends on the target user's acceptance. Thus, evaluating the potential demand of insect-based feeds would provide relevant information for policy development. The present study assessed farmers' knowledge of insects as feed, their acceptance of insect utilization as ingredient in animal feeds and willingness to pay (WTP) for insect-based feed (IBF) using a contingent valuation method. A household survey was conducted among 957 randomly selected farmers including: 409 poultry, 241 fish and 307 pig farmers in four counties in Kenya. Results of the study reveal that over 70 and $80 \%$ of poultry and fish farmers, respectively, are aware that insects can be used as a feed ingredient. In addition, over 60 and $75 \%$ of poultry and fish farmers, respectively, consider insects as a good component of feed. Poultry, pig and fish farmers interviewed accepted and showed willingness to pay for IBF. Regression analysis indicated that age, gender, education, marital status, distance to feed trader, awareness of insects as feed, attitude towards insects, acceptance of insect species, availability of agricultural inputs, use of commercial feeds, availability of training and market information had a significant influence on the WTP for IBF. Therefore, increased extension services to educate famers on the nutritional benefits of insect meals in animal feeds and existing market opportunities are expected to improve farmers' attitude towards utilization and consequently enhance WTP for IBF, which in return would significantly reduce the existing pressure on conventional fishmeal feed resources. Our findings provide the first insights into the market opportunities of including insect meals in the animal feed value chain in Kenya.

Keywords: edible insects, alternative protein source, animal feed, willingness to pay, Kenya 


\section{Introduction}

In livestock and aquaculture production, feed is the most important input, representing $60-70 \%$ and $40-80 \%$ of total cost of production, respectively (Kumar et al., 2017; Makkar, 2018; Mosig, 2018). Feed production requires high resource inputs and the current food-feed competition as well as overfishing represent major sustainability issues that need viable solutions. Global demand of feed is increasing and projection by 2050 revealed that over a billion tonnes of cereals will be required in animal feed as opposed to about eight hundred million tonnes currently used. Developing countries will likely experience most of the increase in demand of animal feed (Makkar, 2016; Makkar, 2018). Livestock and aquaculture production provide employment, income generation and food security opportunities especially in vulnerable communities (FAO, 2009; Rajee \& Mun, 2017; Shava \& Gunhidzirai, 2017; Thornton, 2010).

The livestock sector, including poultry and pig production among other livestock species contributes about $42 \%$ of the Kenya's agricultural Gross Domestic Product (GDP), $12 \%$ of the national GDP, $30 \%$ of total marketed agricultural products and employs about $50 \%$ of the agricultural sector labour force (Republic of Kenya Ministry of Agriculture Livestock Fisheries and Irrigation, 2019; Shibia et al., 2017). Kenya's poultry population is estimated at 31 billion birds, $75 \%$ of which are indigenous chicken, $22 \%$ are broilers and layers (Vernooij et al., 2018). The sector produces about 605,000 metric tonnes of meat annually. In pig production, smallholder farms keep 5-100 pigs and make up 70\% of the total pig producers. Feed costs alone represent up to $80 \%$ of total costs of production (Githigia et al., 2012). The Kenyan fisheries and aquaculture sector employs about 20,000 people (FAO, 2016; Kenyan National Bureau of standards (KNBS), 2017). Kenya is the fourth largest producer of freshwater fish in Africa. However, several factors including lack of market information, low levels of extension services and inadequate availability of quality and affordable feeds prevent the sector from realizing its full potential (Kenya Marine and Fisheries Research Institute (KMFRI); Nyandat \& Owiti, 2013).

In Kenya, major poultry feed categories include chick mash, growers' mash, layers' mash, broilers' mash and Kienyeji mash. Pigs are fed with pig starter, creep pellet, sow and weaner and pig finisher feeds. Fish feeds include floating pellets and mash feed. In these feeds, fishmeal and soybean meal are the major protein ingredients. However, reduced availability, high cost and environmental implications of exploiting these resources represent major constraints to achieving optimal production, especially for smallholder producers in the developing countries (Abiodun, 2019; Gordon \& Maurice, 2015; Katende, 2017; Nwokocha \& Nwokocha, 2013; Ssepuuya et al., 2017). In view of the above concerns, researchers, policy makers, private and public institutions including the Food and Agricultural Organization (FAO) have called for diversification and 
innovation towards sustainable feed protein sources such as edible insects (Makkar \& Ankers, 2014; Van Huis et al., 2015; Van Huis et al., 2013).

Edible insects have traditionally been part of livestock diets especially in the tropics and may provide an alternative source of protein and other nutrients in livestock and aquaculture feeds (Henry et al., 2015; Makkar et al., 2014; Van Huis et al., 2015). Insects contain valuable proteins with well-balanced amino acid profiles, fats with rich fatty acid contents as well as micronutrients. The use of insects as an alternative protein source is advantageous because they can be sustainably mass reared on organic side streams and agro-industrial by-products (Rumpold \& Schluter, 2013; Rumpold \& Schlüter, 2013). The black soldier fly (BSF) Hermetia illucens L. (1758) (Diptera: Stratiomyidae) and the synanthropic housefly Musca domestica L. (Diptera: Muscidae) for example, feed on organic side streams and produce nutrient-rich larvae that could be used as ingredients in animal feeds while helping to reduce waste on which the larvae are reared (Chia et al., 2018; Van Huis et al., 2013). Insects contain 40-60\% protein on a dry matter basis and have been found to be a suitable alternative to fishmeal and soybean meal in animal feed. Furthermore, insects release smaller amounts of greenhouse gases per unit of protein produced than cattle, pigs and chickens (Makkar et al., 2014; Mosig, 2018; Oonincx et al., 2010; van Huis, 2013).

Feed manufacturers are willing to include insects in their feed formulation, given favourable legislation and marketplace acceptance (AllaboutFeed, 2015). However, little is known about farmers' perception towards the use of insects in animal feed. Such perception may affect the success of introducing insect-based feed (IBF), as well as the consumer acceptance of products resulting from animals fed IBF (Verbeke et al., 2015). So far, only a few studies have documented consumer acceptance of insects as feed, all in European countries including: Belgium (Verbeke et al., 2015), France (Bazoche \& Poret, 2016), Germany (Ankamah-Yeboah et al., 2018), Poland (Kostecka et al., 2017), Italy (Laureati et al., 2016; Mancuso et al., 2016) and the United Kingdom (Popoff et al., 2017). Overall, these studies found a favourable attitude and willingness to accept insects in animal feed and resulting products from animals fed with IBF among respondents. Furthermore, consumer willingness to pay (WTP) for insects and insect-based products for human consumption has been assessed and results show that consumers who are familiar with the idea of insects as food are more likely to accept insect-based foods. In addition, consumers are willing to accept insect-based products with high nutritional quality. Therefore, information campaigns and identifying suitable target markets are crucial for promoting a new product (Alemu et al., 2016; Lombardi et al., 2019; Tan et al., 2015; Verbeke, 2015).

While the findings from these previous studies are useful, such information is limited or lacking for Africa, particularly for smallholder farmers who make up $70 \%$ of all the producers. The present study aims to provide the first insights into farmers' knowledge 
of insects as feed and the potential demand for IBF for fish and livestock using household level data in major poultry, fish and pig producing counties of Kenya. It is worth noting that the successful introduction of a new product in the market depends on the product's marketplace acceptance by the target users, which ultimately will affect the WTP for the product (Etim \& Benson, 2016; Henson, 1996; Martinez-Carrasco et al., 2015; Rumpold \& Schluter, 2013). Therefore, we evaluated knowledge, attitudes, practices and WTP for IBF among poultry, fish and pig farmers in four counties in Kenya across different agro-ecological zones.

\section{Theoretical framework}

Producers are in a constant search for new technologies or inputs with novel attributes to reduce production costs and increase revenues. However, these products do not have an existing market, making it hard to estimate their demand potential. As a result, the producer demand estimation relies on stated acceptance. One of the stated-preference methods used to elicit demand is known as the contingent valuation method (CVM) (Heinzen \& Bridges, 2008). The CVM is a non-market valuation method used to find the economic value of non-market commodities. It uses hypothetical survey questions in order to elicit peoples' acceptance of public goods. It is used to find out what the people are willing to pay for specified improvements in the goods. In CVM, absence of markets is circumvented by presenting the consumers/producers with hypothetical markets where they can be provided with information about the products and then asked how much they are willing to pay to obtain the good described. There are four commonly utilized elicitation formats in CVM: open-ended, dichotomous choice, payment card, and bidding game (Heinzen \& Bridges, 2008). The bidding game was used in this study. It involves a series of yes/no questions aimed at finding the maximum willingness to pay. The repeated nature of this technique allows a greater amount of time for the respondent to scrutinize their response, and thus gives results that have greater construct validity. Elicitation of contingent valuation employs either of two methods: single or double bounded contingent valuation method.

In the single bound model, the respondents are faced with a single bid value to which their response is either a "yes" or "no" (Heinzen \& Bridges, 2008). "Yes" denotes WTP the proposed amount while "no" denotes refusal to pay the proposed amount. Alternatively, they can be assessed on the likelihood of paying for the product without attaching any price to it. The probability of obtaining either a "yes" or "no" response can be written as follows:

$\operatorname{Prob}(n o)=\pi^{n}=G(B I D ; \theta), \operatorname{Prob}($ yes $)=\pi^{y}=1-G(B I D ; \theta)$

Where $G(B I D ; \theta)$ is the statistical distribution function with parameter $\theta$, which can be estimated using a logit or probit model, a qualitative choice model. Logit or probit 
model for a single bid value can be expressed in two forms; log-logistic or the logistic cumulative distribution.

The log-logistic cumulative distribution is expressed as follows:

$$
\left.\mathrm{G}(\mathrm{Bid})=1 /\left(\left[1+\mathrm{e}^{(\mathrm{a}-\mathrm{b}(\mathrm{n} \mathrm{Bid})}\right)\right]\right)
$$

The logistic cumulative distribution is expressed as follows:

$$
\mathrm{G}(\mathrm{Bid})=1 /\left(\left[1+\mathrm{e}^{(\mathrm{a}-\mathrm{b}(\mathrm{Bid}))}\right]\right)
$$

where $\theta=(a, b), a$ and $b$ are the intercept and slope coefficients to be estimated. The statistical model can be interpreted to mean that an individual whose aim is to maximize utility within a random utility context will say "yes" to a BID only if the BID is less than or equal to his maximum WTP and will say "no" if the BID is greater. Alternatively, for a case that has no bid value attached to the model, the probability of obtaining either a "yes" or "no" response can be written as follows:

$\operatorname{Prob}(n o)=\pi^{n}=G(X ; \theta), \operatorname{Prob}(y e s)=\pi^{y}=1-G(X ; \theta)$

where $X$ represents the control, variables used in the model (Hanemann et al., 1991).

In a double-bound model, the respondents are faced with a two-sequence-bid offer. In the first offer, they are asked whether they will accept or reject the bid, then the second bid is offered depending on the respondent's first bid response, a higher bid if the response was yes and a lower bid if the response was no. This results in four possible responses: (1) both answers are "yes", (2) both answers are "no", (3) a "yes" followed by a "no" and 4) a "no" followed by a "yes" (Herriges, 1999).

This two-sequence-bid provides a bound of the respondent's WTP. The WTP is right censored if the answer to the initial and higher bids is "yes" and left censored if the response to the first and second bids is "no". If both answers are alternate of yes and no, then their WTP is intermediate with the second bid acting as an upper or lower bid. The likelihood of these outcomes is as shown in Fig. 1.

It is assumed that a respondent's maximum WTP is lower than or equal to the lowest

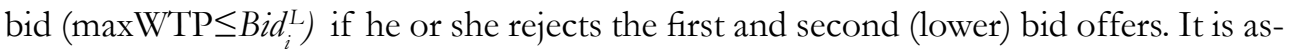
sumed that the respondent's maximum WTP lies between the lower and the first bid offer $\left(B_{i} d_{i}^{L} \leq \operatorname{maxWTP}<\right.$ Bid $)$ ) if the respondent rejects the first bid but accepts the second lower bid offer. If the respondent is willing to accept the first bid but rejects the second higher bid offer, it is assumed that the respondent's maximum WTP lies between the second higher and the first bid offers $\left(\mathrm{Bid}_{i}^{\mathrm{H}}>\operatorname{maxWTP}>\right.$ Bid) $)$. Finally, if the respondent accepts the first and second higher bids, then it is assumed that the respondent's maximum WTP is greater than or equal to the second higher bid offer $\left(\max W T P \geq B i d_{i}^{H}\right)$. 


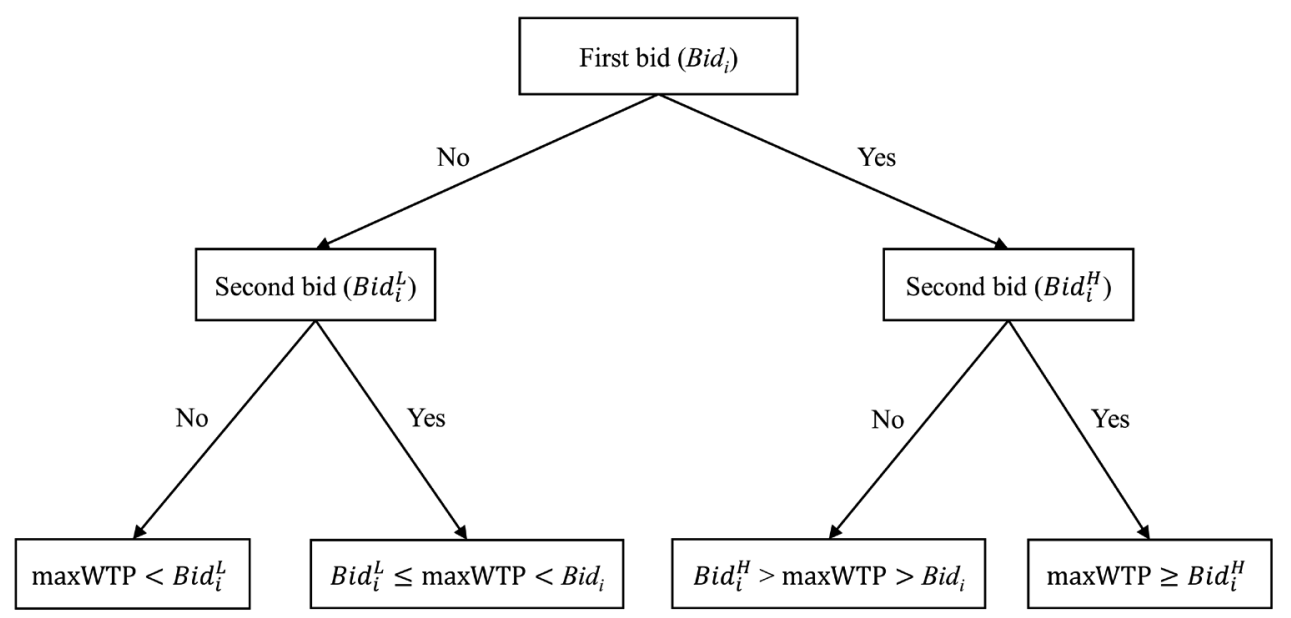

Fig. 1. Double-bound dichotomous choice contingent valuation methods bid sequence. $B i d_{i}^{H}=$ the second bid, which is an amount greater than the first bid $\left(\mathrm{Bid}_{\mathrm{j}}\right) ; \mathrm{Bid}_{i}^{\mathrm{L}}=$ the second bid, which is an amount smaller than the first bid if the individual response is "no" to the first bid.

The double bound dichotomous choice model improves on the single bound dichotomous choice model by providing a two-level bidding process (Hanemann et al., 1991). In this study a double-bound logit model was used to estimate WTP and the factors that influence WTP for IBF among the farmers. A positive correlation between a variable and WTP means that an increase in the variable leads to an increase in the probability of WTP for IBF. Furthermore, a negative correlation with WTP means that an increase in the variable leads to a decrease in the probability of WTP for IBF.

\section{Materials and methods}

\section{Study area and data collection}

This study was conducted in four counties in Kenya, including Kiambu, Nyeri, Kakamega and Uasin Gishu (Fig. 2). A purposive sampling method was employed to select sub-counties in each of four counties, based on the production statistics of the three animal types including pig, poultry and fish. Respondents within each sub-county were randomly selected. The sample frame composed of a census of active smallholder pig farmers, poultry farmers and fish farmers in the survey sites compiled by the respective sub-county agricultural officers for these. In total, 409 poultry famers were interviewed, distributed as follows: Kiambu (79), Nyeri (89), Kakamega (98) and Uasin Gishu (143). A total of 307 pig farmers were interviewed: Kiambu (102), Nyeri (63), Kakamega (96) and Uasin Gishu (46). A total of 241 fish farmers were interviewed: Kiambu (29), Nyeri (68), Kakamega (75) and Uasin Gishu (69). Data were collected at the household level 
by trained enumerators using CSPro version 7.0, data collection software addressing the following aspects: socioeconomic characteristics of the respondents, their knowledge, attitudes, practices and acceptance of different insect species, availability of agricultural support services, feed use and distance to feed market (trader). Farmers' WTP for IBF and prices they are willing to offer per unit of IBF, availability of market and financial institutions were also assessed.

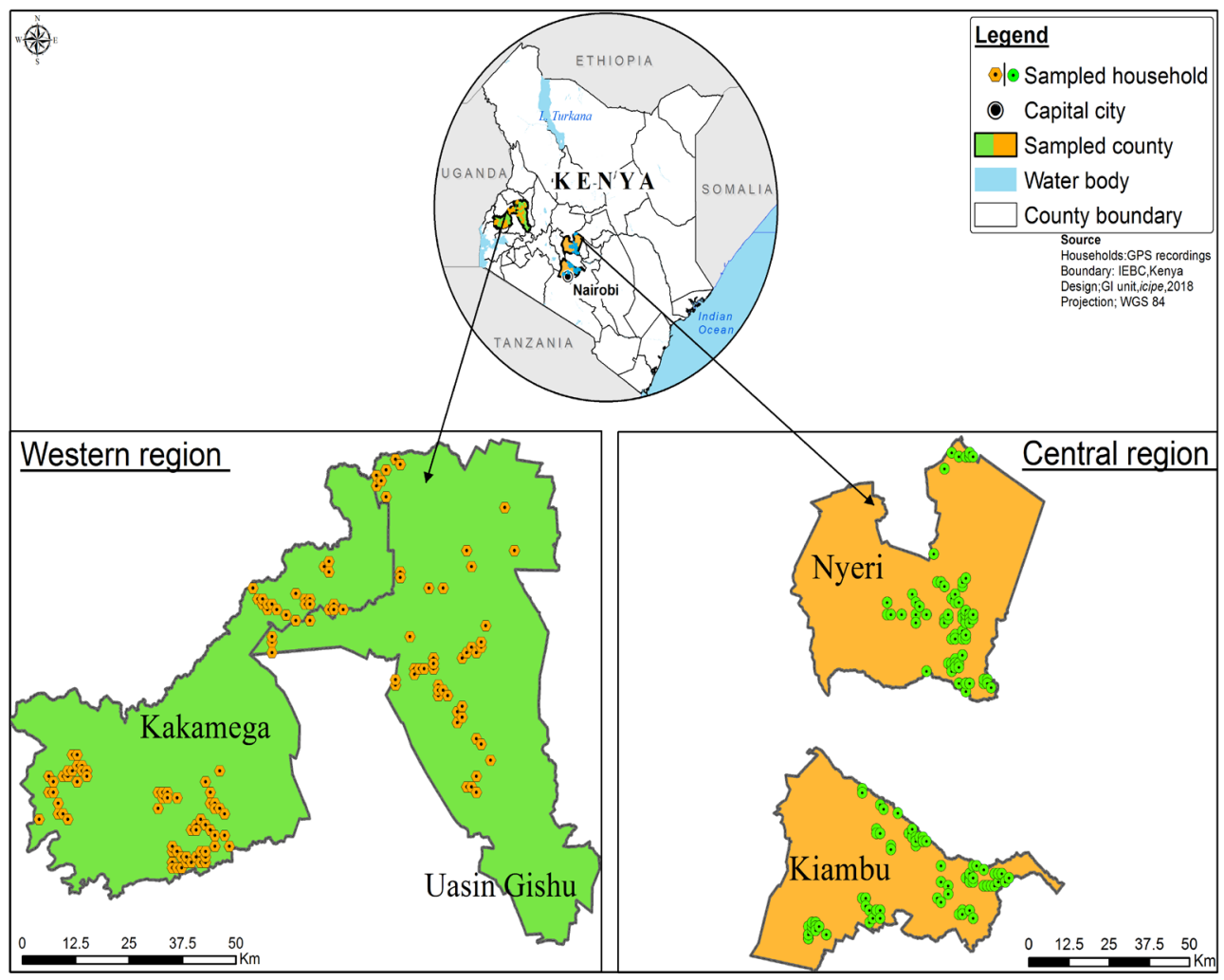

Fig. 2. Map representing the four study areas (counties) in two geographical regions of Kenya. Green colour represents counties sampled in the Western region, orange represents counties sampled in the Central region of Kenya.

\section{Empirical model}

We model a farmer's WTP for IBF using a single-equation logit model of the form:

$Y_{i}=\beta_{0}+\beta_{i} X_{i}+\varepsilon_{j}$

where $Y$ is a binary variable for farmers' WTP (having value of one if farmers are willing to pay for IBF and zero otherwise), $i$ indexes individual farmer's WTP, $\beta_{0}$ is the intercept, $\beta_{i}$ is the regression coefficient, $X$ is a vector of explanatory variables that affect farmers' WTP, $\varepsilon_{j}$ is an error term, which assumes a normal distribution (mean $=0$, 
variance $=1)$. Selection of explanatory variables was guided by a review of theoretical and empirical studies on the determinants of WTP for agricultural products (Alemu et al., 2016; Mancuso et al., 2016; Tan et al., 2015; Verbeke, 2015).

We estimate the empirical model for several categories of poultry, pig, and fish farmers based on the expectation that factors associated with WTP for insect-based feed will vary across farmer type. Poultry farmers were categorized into those rearing Kienyeji (an indigenous type of chicken), Layers (laying chickens aged 19 - 76 weeks), Growers (chickens aged $8-18$ weeks), and Chicks (young birds aged $0-8$ weeks). Fish farmers were grouped according to type of feed currently used: floating pellets (finely ground feed that has been compressed and molded into pellets in a pellet mill and float on the surface of water when served to grower and finisher fish stages) and feed mash (a finely ground feed formulated and used in moist form for farmed juvenile fish). Pig farmers included those raising finisher (pigs weighing over $55 \mathrm{~kg}$ ) or sows and weaners (pigs up to $55 \mathrm{~kg}$ ) and adult breeding pigs.

\section{Results}

\section{Demographic characteristics of the study population}

A total of 957 farmers participated in this study. Fifty nine percent (59\%) of poultry, $34 \%$ of fish and $49 \%$ of pig farmers were females (Table 1). Mean age varied significantly for male and female respondents in poultry, fish and pig production. Fish farmers had the highest (52.5 and 49.2 years) mean age while pig farmers had the lowest (48.5 and 45.7 years) mean age for male and female respondents, respectively. For all categories (poultry, fish and pig), mean number of years of education differed significantly for male and female respondents; male farmers were more educated than the females (Table 1). Household size and distance to feed trader were similar for male- and female-headed households for poultry, fish and pig farmers. There were on average, five members per household (Table 1) across the study locations. 


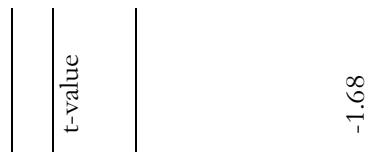
$\stackrel{\substack{* \\ \stackrel{*}{n}}}{\stackrel{m}{m}}$

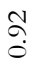

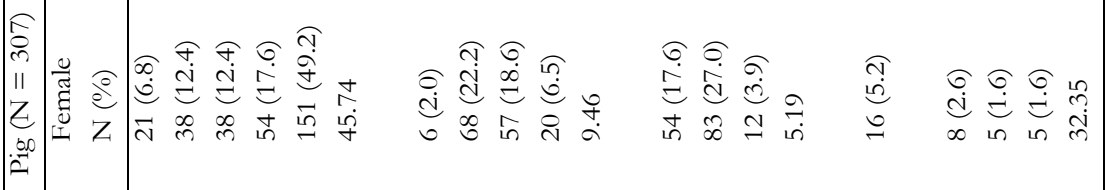

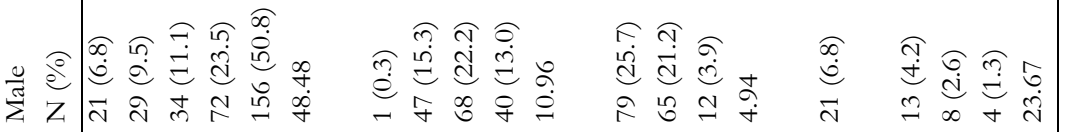

$$
\stackrel{?}{\stackrel{1}{i}}
$$

$\stackrel{*}{\stackrel{*}{N}}$

$\stackrel{2}{0}$

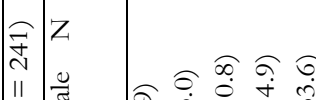

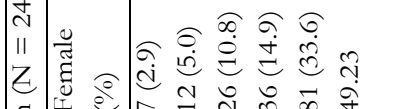

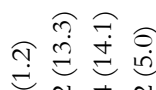

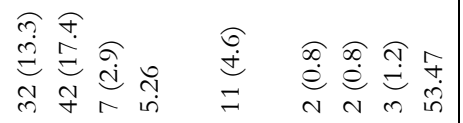
点

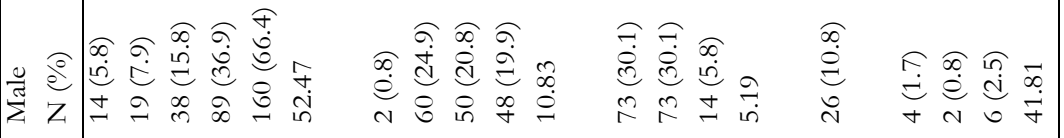

若<smiles>[Te][TeH]</smiles>

in

in

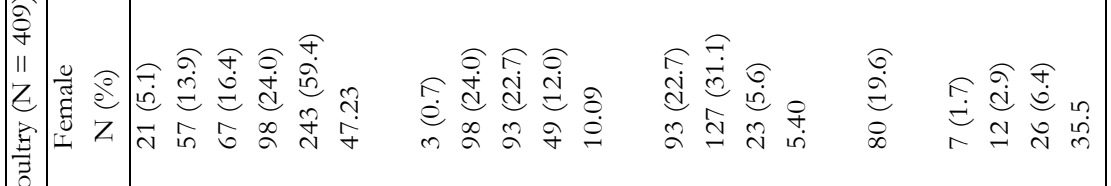
$\stackrel{0}{2}$

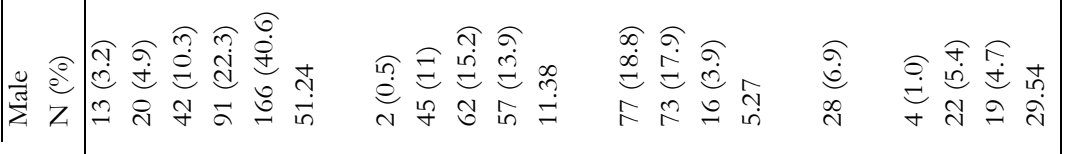

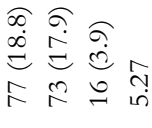

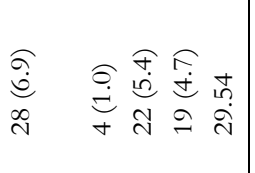

宛

త్రి

.

亮

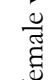




\section{Farmer knowledge, attitudes and practices towards insects as an alternative source of feed for poultry, fish and pigs}

The proportion of female farmers who were aware that insects can be used as feed for poultry was significantly higher than for the males. Male and female fish farmers were similarly aware that insects can be used as feed for fish (Table 2). A significantly higher proportion of female poultry farmers had a positive attitude towards insects as feed than the males. There was no significant difference between proportions of male and female fish farmers with regards to their attitude toward the use of insects in animal feeds. However, only a small proportion of both poultry and fish farmers demonstrated that they had previously used insects to feed their animals (25-38\% of respondents).

The proportion of male famers who previously used insects as feed for their fish was significantly higher than for female fish farmers. It was common to find poultry, fish and pig farmers engaged in the practice of making their own feed as well as using commercial feeds. Feed items (conventional feed) frequently used by the smallholder farmers included: vegetables, grains, food remains. On average, less than $20 \%$ of male and female respondents made their own feed in all animal categories (Table 2). More male than female pig farmers made their own feed while more female poultry farmers than males used conventional feeds (Table 2).

\section{Acceptance of insect species and availability of agricultural support services and inputs}

Similar proportions of male and female farmers accepted cockroaches, housefly, BSF larvae, crickets, termites and grasshoppers as alternative feed components for poultry and fish production (Fig. 3). The proportion of male pig farmers who accepted housefly and BSF larvae was significantly higher than for female pig farmers. However, similar proportions of male and female pig farmers accepted the other insect species investigated (Fig. 3). The acceptance of termites was significantly higher compared to other insect species. 


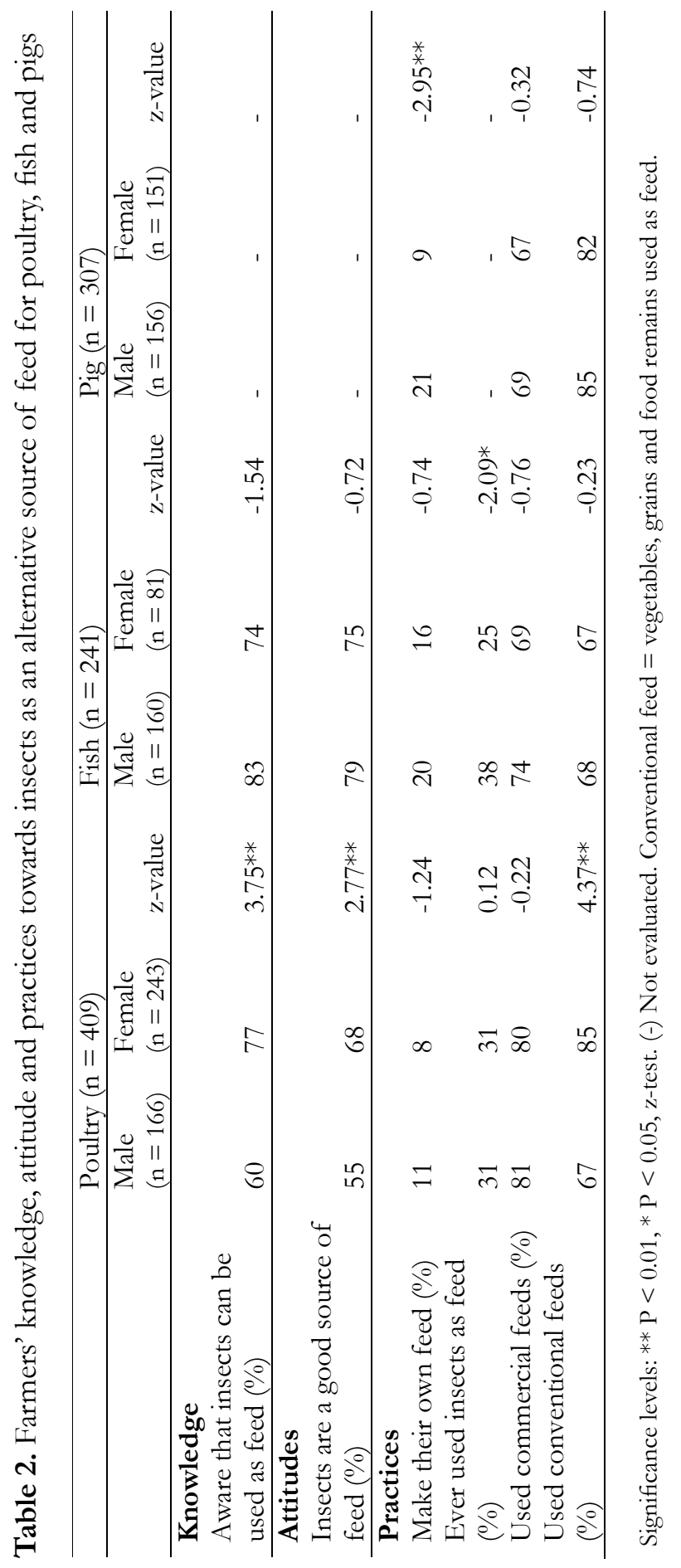




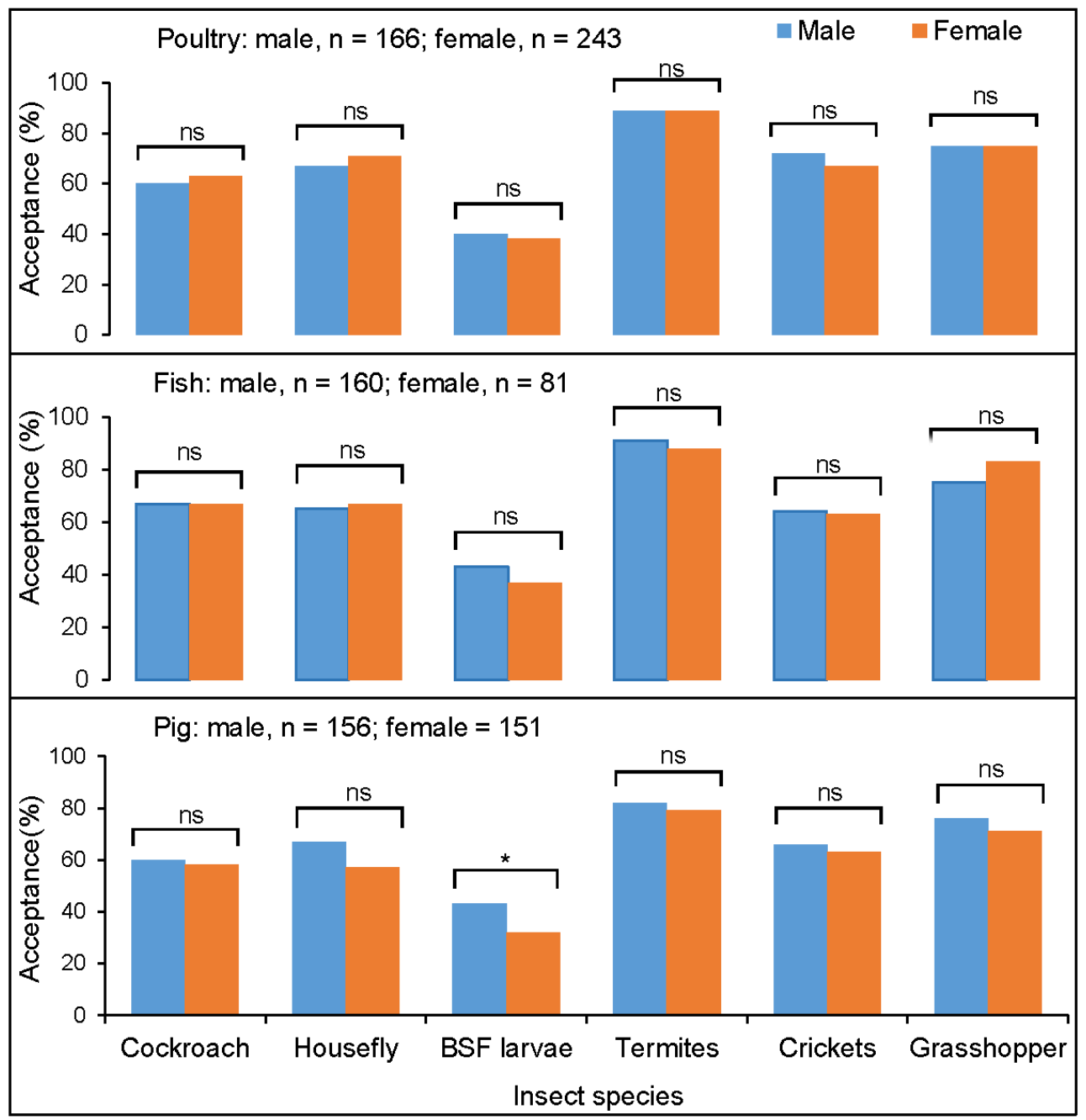

Fig. 3. Percentage farmers that accept insects as feed ingredients among poultry, fish and pig farmers. Bars with asterisk are significantly different for male and female respondents, $\mathrm{P}<0.05$, two-proportion z-test. Bars with " $n s$ " are not significantly different for male and female respondents, $\mathrm{P}<0.05$, two-proportion z-test. BSF = black soldier fly. For additional statistical analyses see Table 3.

The BSF larvae had the lowest acceptance, which differed significantly from other insect species for both male and female poultry, fish and pig farmers (Table 3). Cockroaches, houseflies and crickets were similarly accepted as alternative feed ingredients for poultry fish and pig feed (Table 3). Among support services and inputs, new technologies were the least available: ca $25-35 \%$ of farmers had access to this input (Fig. 4). 


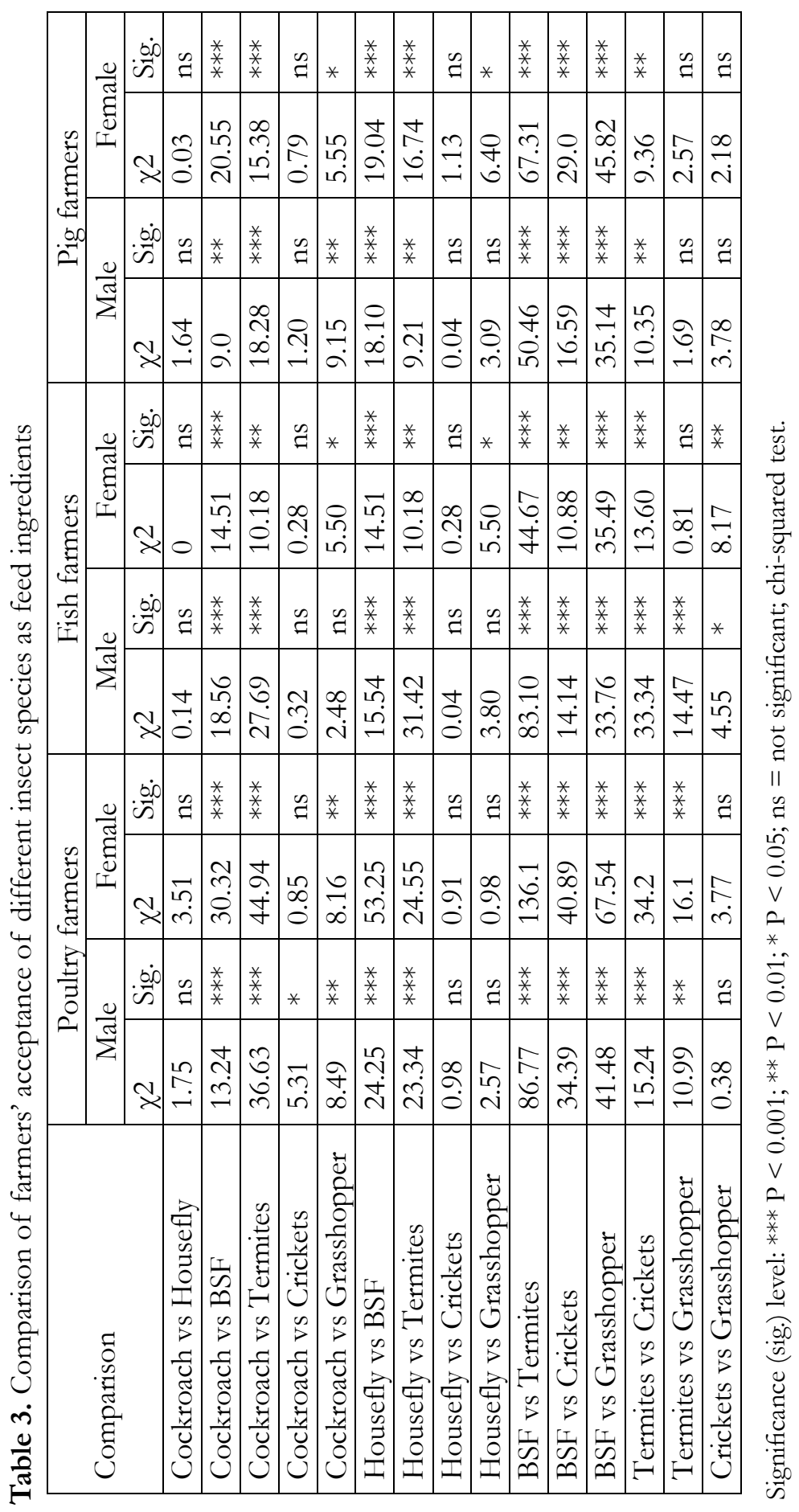




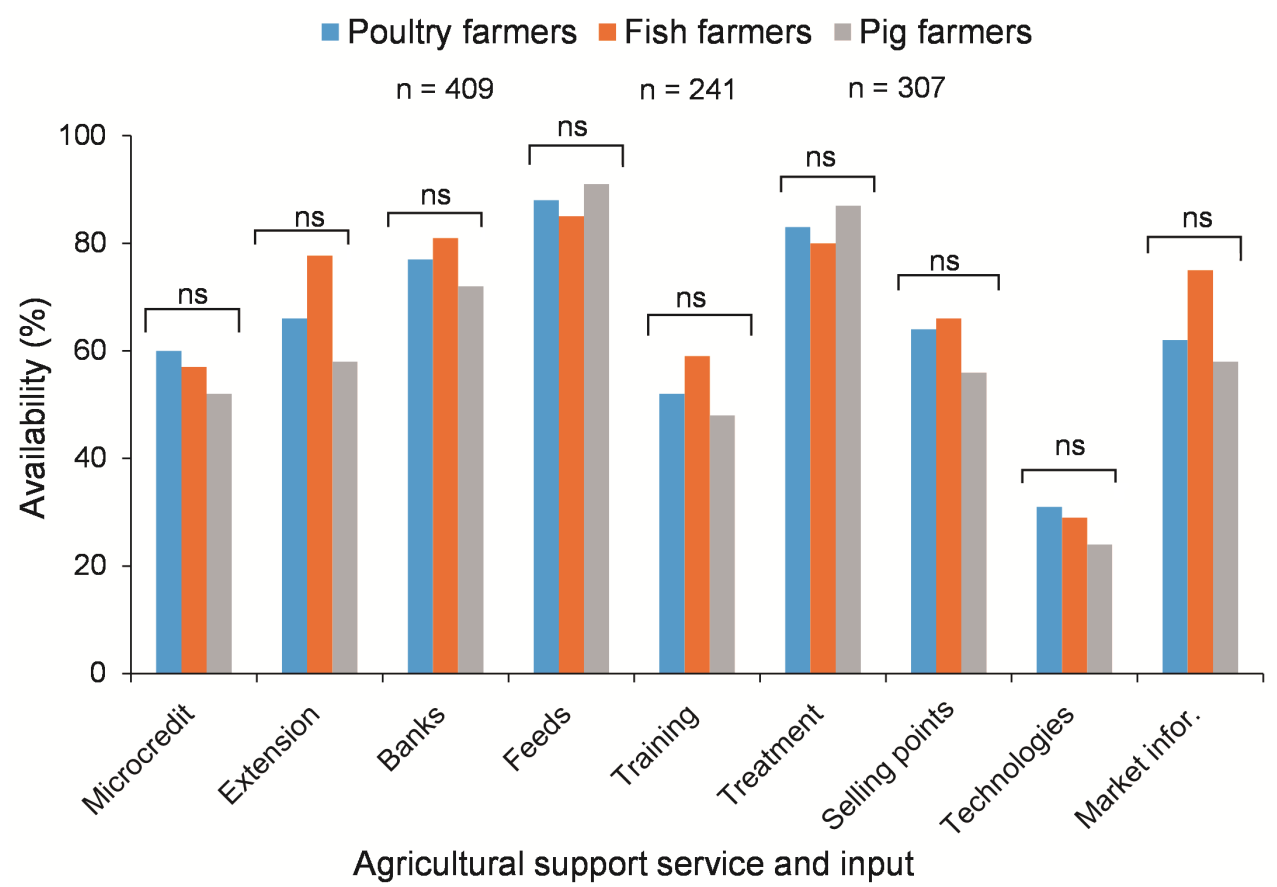

Fig. 4. Percentage availability of agricultural support services and inputs to poultry, fish and pig farmers. Bars with "ns" are not significantly different, $\mathrm{P}<0.05$, Chi-squared test. Microcredit $=$ availability of savings and credit cooperatives that provide saving and credit facilities at low interest rates; Extension = availability of agricultural extension services; Banks = availability of main stream banking services; Feeds $=$ availability of commercial feeds and feed ingredients for the different livestock types; Training $=$ availability of production education programs; Treatment $=$ availability of vaccines and general disease control facilities; Selling points = selling points for poultry, fish and pig products; Technologies $=$ availability of improved feeds, feeding, housing and general production methods; Market infor. = availability of information regarding demand and supply of farm inputs and outputs.

\section{Willingness to pay for insect-based feeds (IBF) among poultry, fish and pig farmers}

A total of 899 respondents were willing to pay for IBF, whereas 58 respondents were not, accounting for $94 \%$ and $6 \%$, respectively. When asked if they would buy IBF (before the introduction of any bidding process), more than $90 \%$ of male and female poultry, fish and pig farmers responded positively (Fig 5).

For each animal category (poultry, fish and pig), more than $70 \%$ of the farmers were willing to buy the different feed types at the market price (Fig. 6, 7 and 8). WTP was high and ranged from 65-88\% (Fig. 6, 7 and 8). Furthermore, 82-100\%, 75-88\% and and $100 \%$ of all poultry, fish and pig farmers, respectively, were willing to buy at a discounted price (Fig. 6, 7 and 8). 


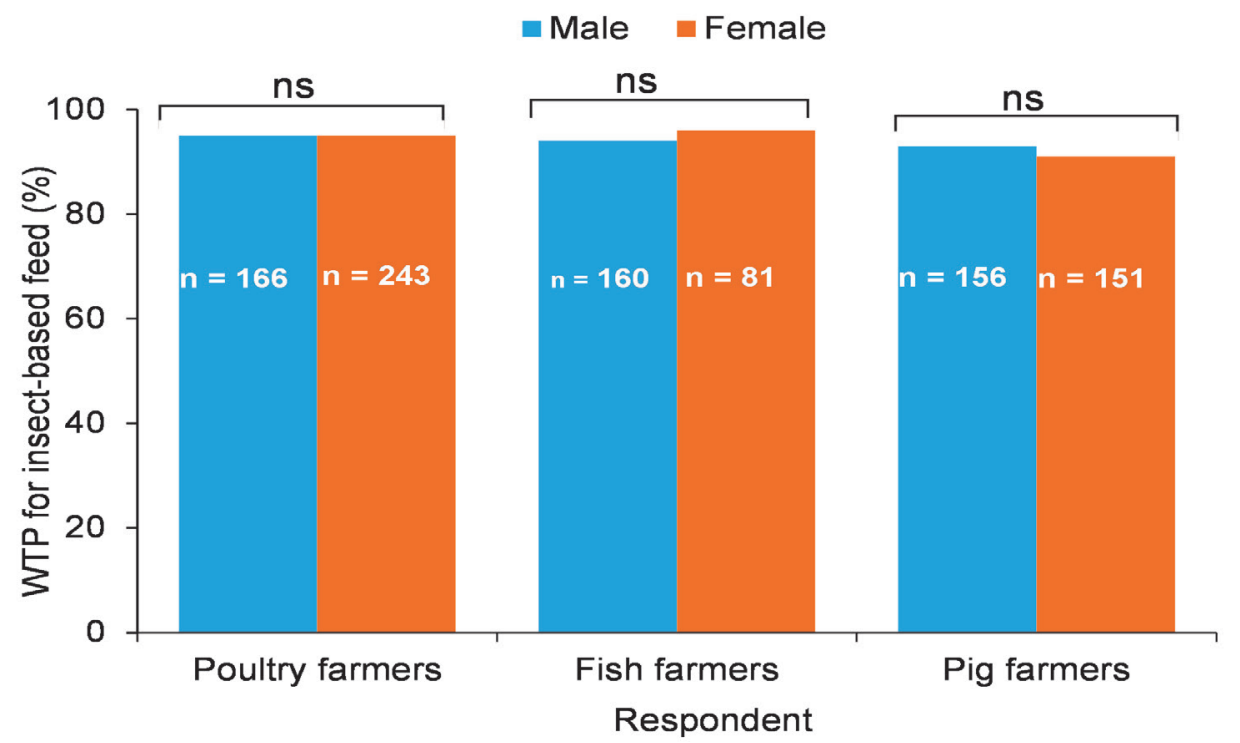

Fig. 5. Percentage farmers willing to pay for insect-based feeds among male and female poultry, fish and pig farmers. Bars with "ns" are not significantly different for male and female respondents, $\mathrm{P}<0.05$, two-proportion z-test.

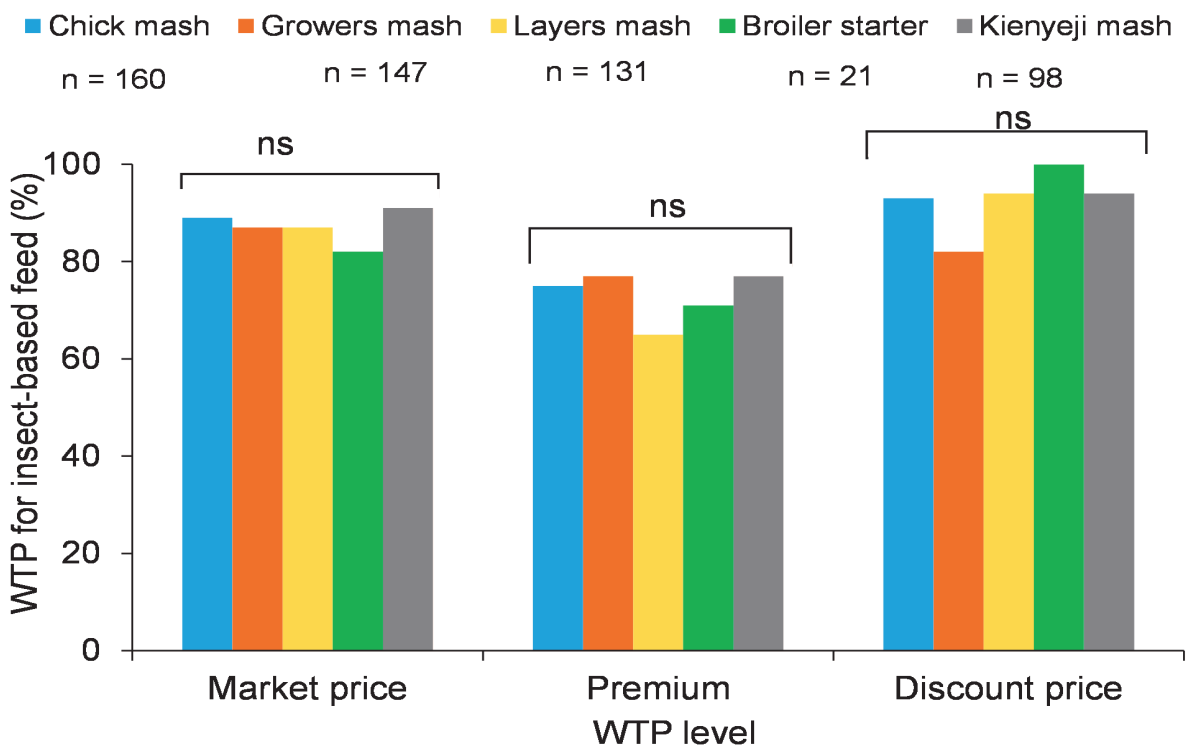

Fig. 6. Percentage farmers willing to pay for insect-based poultry feeds at market price, discount price and premium price. Bars with "ns" are not significantly different, $\mathrm{P}<0.05$, Chi-squared test. Chick mash $=\mathrm{a}$ ground form of feed fed to chicks aged 0-8 weeks. Growers mash $=$ ground form of feed for birds aged 8-18 weeks. Layers mash $=$ ground form of feed for laying birds aged 19-76 weeks. Broiler starter $=$ a protein-dense feed formulated to meet the dietary requirements of young broilers aged approximately 1-21 days and are raised purposely for meat. Kienyeji mash $=$ a ground form of feed for indigenous type of chicken commonly known as "Kienyeji". 


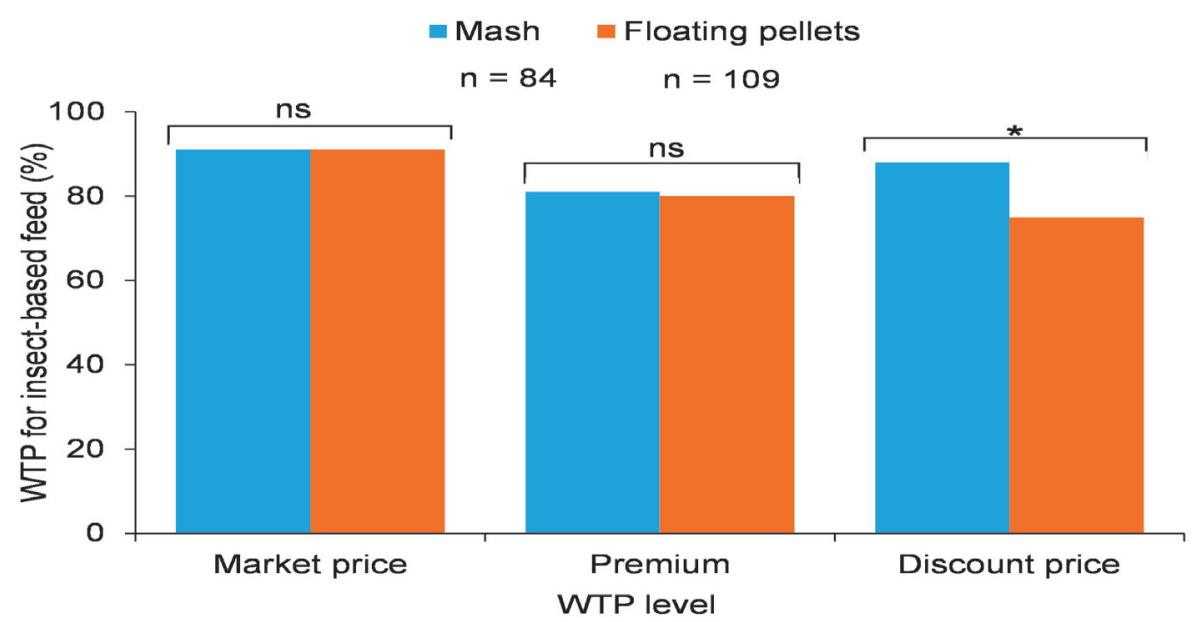

Fig. 7. Percentage farmers willing to pay for insect-based fish feed at market, discount and premium price. Bars with an asterisk are significantly different for mash and floating pellets, $\mathrm{P}<0.05$, z-test. Bars with "ns" are not significantly different, $\mathrm{P}<0.05$, two-proportion $z$-test. Mash $=$ a finely ground feed formulated and used in moist form for farmed juvenile fish. Floating pellets = finely ground feed that has been compressed and molded into pellets in a pellet mill and float on the surface of water when served to grower and finisher fish stages.

- Creep pellet $\quad$ Sow and weaner $\quad$ Pig finisher

$\mathrm{n}=12 \quad \mathrm{n}=135 \mathrm{n}=58 \quad \mathrm{~ns}$

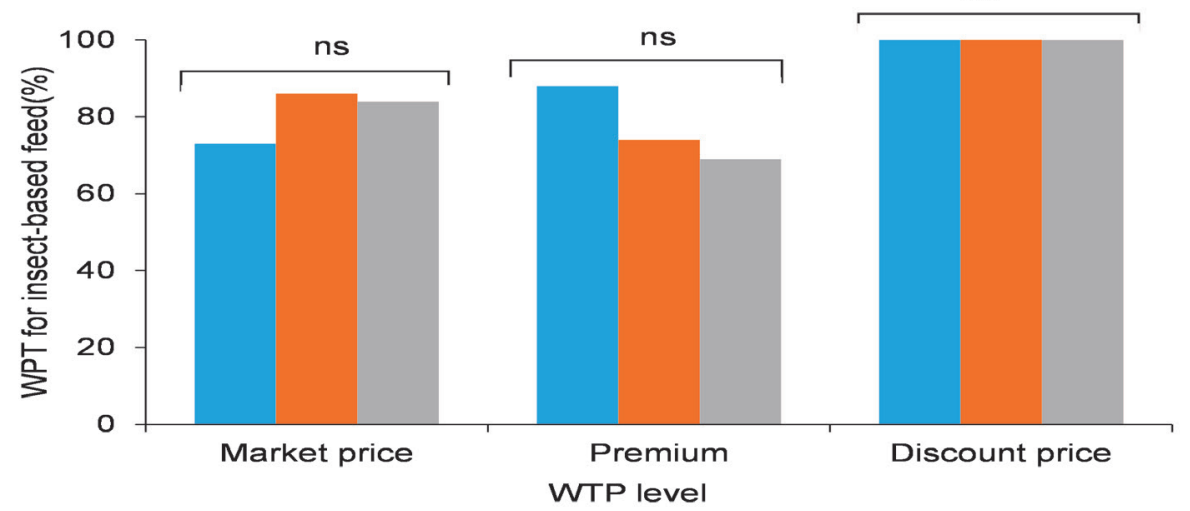

Fig. 8. Farmers' willingness to pay (WTP) for insect-based pig feed at market, discount and premium price. Bars with "ns" are not significantly different, $\mathrm{P}<0.05$, Chi-squared test. Sow and weaner $=$ Feed type for growing pigs up to $55 \mathrm{~kg}$ live body weight and adult breeding pigs. Pig finisher $=$ Feed for pigs weighing over $55 \mathrm{~kg}$ live body weight.

When the market price of feeds was reduced by $5-15 \%$, most (96-100\%) poultry farmers were willing to buy, whereas an increase in the market price resulted in a decrease in the percentage (50-74\%) of poultry farmers willing to buy the different poultry feed types (Fig 9). The majority (94-99\%) of the fish farmers were willing to buy floating pellets at a reduced price, but an increase in the market price resulted in a decrease in the percentage of farmers willing to buy at a premium price (Fig 10). Similarly, reducing 
the market price of sow and weaner feed by 5-15\% resulted in all pig famers willing to buy at the reduced (discount) price (Fig 10). Furthermore, an increase in the price of feed reduced farmers' WTP and less than $60 \%$ of the farmers accepted to buy sow and weaner feed at a premium price (Fig 10). At 15\% increase, less than 50\% of the pig farmers accepted to buy (Fig 10).

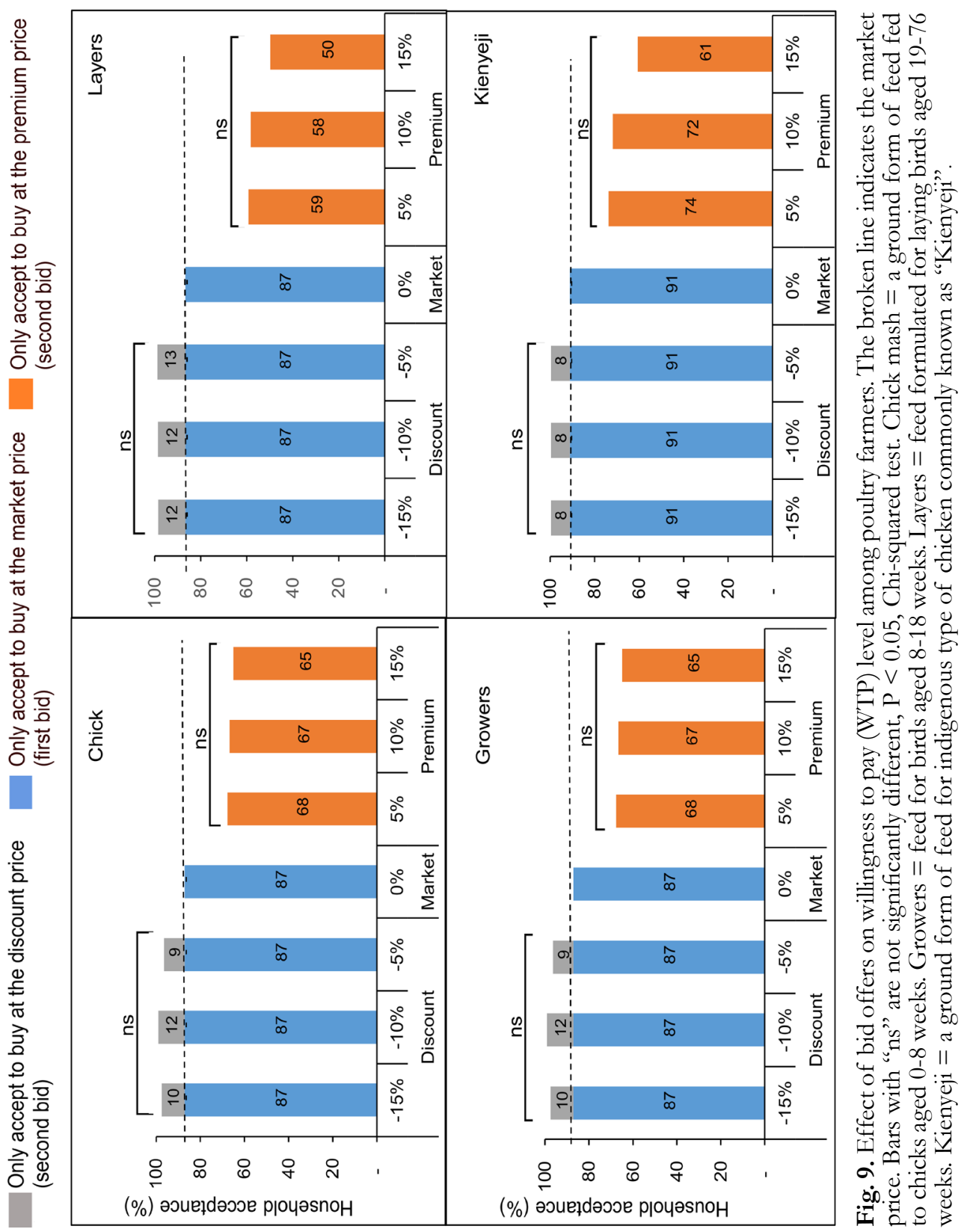




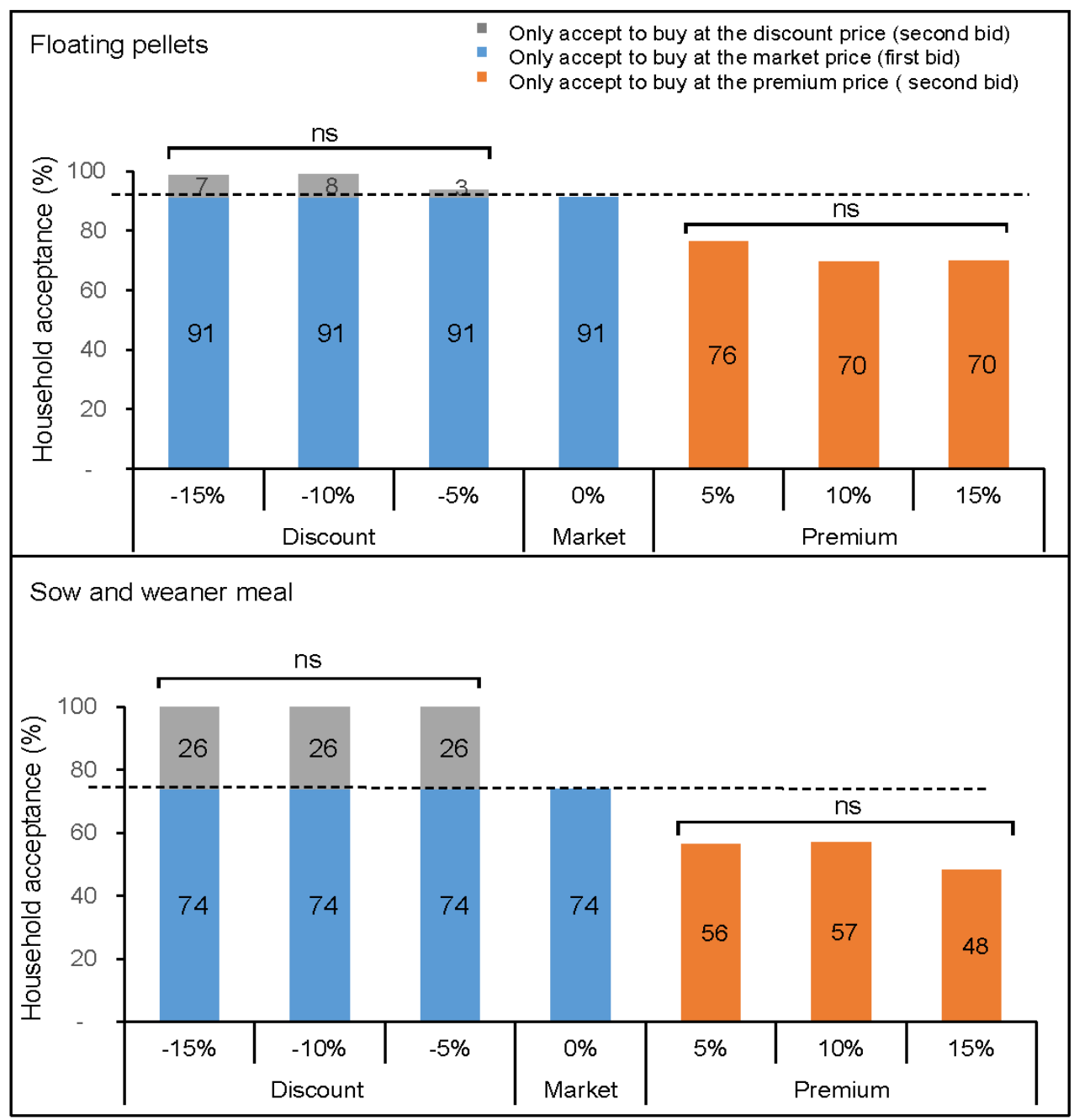

Fig. 10. Effect of bid offers on willingness to pay (WTP) level among fish and pig farmers. The broken line indicates the market price. Bars with "ns" are not significantly different, $\mathrm{P}<0.05$, Chi-squared test. Floating pellets $=$ feed that has been compressed and molded into pellets in a pellet mill and float on the surface of water when served to grower and finisher fish stages. Sow and weaner $=$ Feed type for growing pigs up to $55 \mathrm{~kg}$ live body weight and adult breeding pigs. Pig finisher $=$ Feed for pigs weighing over $55 \mathrm{~kg}$ live body weight.

Farmers were willing to pay a premium price for IBF (Table 4). Poultry farmers were willing to pay Ksh 60-70 per kilogram of IBF, representing 16-57\% increase from the benchmark price (market price) for the different poultry feed types. Kienyeji mash and broiler starter feeds had the highest and lowest percentage change, respectively for poultry farmers. Fish farmers had the lowest percentage change (12-28\%) compared to the other farmers in the study. Pig farmers accepted to pay 30-70\% higher prices for IBF (Table 4). 
Table 4. Farmer's willingness to pay (WTP) level and mean price premium (\% change) for insect-based feed

\begin{tabular}{llllll}
\hline Feed type & $\begin{array}{l}\text { WTP price } \\
(\mathrm{Ksh} / \mathrm{kg})\end{array}$ & $\begin{array}{l}\text { Standard } \\
\text { error }\end{array}$ & $\begin{array}{l}\text { Market price } \\
(\mathrm{Ksh} / \mathrm{kg})\end{array}$ & $\begin{array}{l}\text { Standard } \\
\text { error }\end{array}$ & $\begin{array}{l}\text { Premium } \\
(\%)\end{array}$ \\
\hline Poultry & & & & & \\
Chick mash & 70.05 & 2.54 & 48.92 & 1.04 & 43.19 \\
Growers mash & 63.76 & 2.70 & 46.06 & 1.12 & 38.43 \\
Layers mash & 57.92 & 2.12 & 44.04 & 1.19 & 31.52 \\
Kienyeji mash & 58.47 & 3.54 & 37.34 & 1.21 & 56.59 \\
Broiler starter & 71.11 & 2.10 & 61.32 & 1.91 & 15.97 \\
Broiler finisher & 62.41 & 8.18 & 48.62 & 3.70 & 28.36 \\
\hline Fish & & & & & \\
Mash & 101.92 & 8.84 & 91.12 & 9.98 & 11.85 \\
Pellets & 179.44 & 17.81 & 139.82 & 12.59 & 28.34 \\
\hline Pig & & & & & \\
Creep feed & 84.19 & 30.49 & 49.38 & 10.04 & 70.49 \\
Sow and weaner & 53.47 & 3.06 & 35.69 & 1.42 & 49.82 \\
Pig finisher & 52.83 & 3.73 & 40.65 & 3.48 & 29.96 \\
\hline
\end{tabular}

Premium $(\%)=(($ WTP price - Market price $) /$ Market price $) * 100$, Ksh: Kenyan shillings. WTP = willingness to pay. Chick mash $=$ a ground form of feed fed to chicks aged $0-8$ weeks, Growers mash $=$ feed for birds aged $8-18$ weeks, Layers mash $=$ feed for laying birds aged $19-76$ weeks, Kienyeji mash $=$ feed for indigenous type of chicken commonly known as "Kienyeji". WTP = willingness to pay. Broiler starter and finisher $=$ a protein-dense feed formulated to meet the dietary requirements of young broilers aged approximately 1- 21 days and raised purposely for meat. Broiler finisher $=$ feed formulated to meet the dietary requirements of broilers aged above 21 days. Mash $=$ a finely ground feed formulated and used in moist form for farmed juvenile fish (fry), Floating pellets $=$ finely ground feed that has been compressed and molded into pellets in a pellet mill and float on the surface of water when served to grower and finisher fish stages, Creep feed $=$ high-nutrient feed designed to supplement nursing animals, Sow and weaner $=$ Feed type for growing pigs up to 55 kilograms live body weight and adult breeding pigs, Pig finisher $=$ Feed for pigs weighing over 55 kilograms live body weight.

\section{Factors influencing farmers' WTP for insect-based feed}

Explanatory variables were regressed with WTP for IBF among farmers for the differ nt feed types within the animal categories (Table 5). The regression results showed that awareness that insects can be used as feed, acceptance of BSF larvae as feed, availability of extension services and market information positively influenced WTP, whereas variables such as age, making of their own feed and attitude that insects are a good feed source negatively influenced WTP among farmers using Kienyeji feed (Table 5). For famers using layers feed, availability of training positively influenced WTP, whereas 
marital status, household size, availability of microcredit and market information negatively influenced WTP (Table 5). For farmers using grower feed, acceptance of crickets and the availability of banks positively influenced WTP (Table 5).

For farmers using chick feeds, WTP for IBF was not affected by the variables (Table 5). In fish production, WTP for IBF also varied for the different feed types (Table 5). The use of commercial feeds and acceptance of BSF larvae as feed ingredient positively influenced WTP for farmers using floating pellets, whereas distance to feed trader, acceptance of housefly and availability of treatment negatively influenced WTP. For farmers using mash feed, educational level positively influenced WTP (Table 5).

In pig production, WTP was positively influenced by age, distance to feed trader and availability of new technologies, whereas factors such as making of their own feed, acceptance of cockroaches as feed and market information negatively influenced WTP among farmers using pig finisher feeds (Table 5). For farmers using sow and weaner feeds, WTP was positively influenced by acceptance of BSF larvae as feed whereas the acceptance of housefly maggots negatively influenced WTP (Table 5). 
Table 5: Regression results for factors influencing willingness to pay (WTP) for insect-based feeds among fish, pig and poultry farmers

\begin{tabular}{|c|c|c|c|c|c|c|c|c|}
\hline \multirow{2}{*}{ Variable } & \multicolumn{2}{|c|}{ Fish farmers } & \multicolumn{2}{|c|}{ Pig farmers } & \multicolumn{4}{|c|}{ Poultry farmers } \\
\hline & Pellets & Mash & Finisher & Sow & Kienyeji & Layer & Grower & Chick \\
\hline Gender & - & -37.36 & - & - & - & - & - & - \\
\hline Age & -1.85 & - & $0.59 * *$ & 0.13 & $-0.65^{*}$ & 0.04 & 0.28 & 0.22 \\
\hline Education level & -1.63 & $5.25^{*}$ & - & - & - & - & - & - \\
\hline Marital status & 50.74 & -17.98 & 13.35 & - & -3.56 & $-4.83^{*}$ & - & - \\
\hline Household size & - & - & - & - & -1.55 & $-2.69 * *$ & -1.31 & - \\
\hline Commercial feed & $293.34 * *$ & 26.13 & - & - & - & - & - & - \\
\hline Distance & $-0.27 *$ & & $0.68^{* *}$ & - & - & - & - & - \\
\hline Make own feed & - & - & $-21.77^{*}$ & -9.09 & $-16.42^{*}$ & - & - & - \\
\hline $\begin{array}{l}\text { Aware that poultry feed on } \\
\text { insect }\end{array}$ & - & - & - & - & $35.92^{* *}$ & -10.97 & - & 2.43 \\
\hline $\begin{array}{l}\text { Insect are a good source of } \\
\text { poultry feed }\end{array}$ & - & - & - & - & $-30.79 * *$ & 9.38 & - & - \\
\hline Number of growers owned & - & - & - & - & $-0.16^{*}$ & 0.02 & 0.05 & - \\
\hline Number of chicks owned & - & - & - & - & 0.27 & 0.32 & $0.35^{*}$ & - \\
\hline Ever used insect as feed & -44.50 & - & - & - & - & - & - & - \\
\hline Housefly maggots-acceptance & $-57.29 *$ & - & -6.76 & $-13.58^{*}$ & -13.03 & - & - & -3.83 \\
\hline Crickets-acceptance & - & - & - & - & -7.91 & - & $12.87^{*}$ & 3.18 \\
\hline Black soldier fly-acceptance & $127.54^{* *}$ & - & - & $14.23^{* *}$ & $19.39 * *$ & 5.28 & 3.10 & 9.04 \\
\hline Cockroach-acceptance & - & - & $-14.58^{*}$ & - & - & - & - & - \\
\hline Availability of microcredits & - & - & - & - & -5.40 & $-12.39 * *$ & - & 7.08 \\
\hline Availability of banks & - & - & - & - & 12.60 & - & $11.02 *$ & 2.01 \\
\hline $\begin{array}{l}\text { Availability of extension } \\
\text { services }\end{array}$ & $65.08 *$ & 17.58 & - & - & $24.59^{* *}$ & - & - & - \\
\hline Availability of training & - & - & - & - & -8.36 & $13.86^{* *}$ & -4.72 & - \\
\hline $\begin{array}{l}\text { Availability of agricultural } \\
\text { inputs }\end{array}$ & -112.78 & - & -11.85 & 16.55 & - & & - & - \\
\hline Availability of new technologies & - & - & $21.26^{* *}$ & 6.12 & - & - & - & - \\
\hline Availability of treatment & $-99.83^{*}$ & 20.81 & - & - & 12.58 & - & 6.44 & - \\
\hline $\begin{array}{l}\text { Availability of market } \\
\text { information }\end{array}$ & 62.19 & - & $-14.10^{* *}$ & - & $13.28^{*}$ & $-10.29 *$ & -0.84 & - \\
\hline Constant & 2.49 & 49.64 & -2.53 & 71.02 & 48.82 & 79.74 & 42.86 & 54.31 \\
\hline
\end{tabular}

Significance levels: $* * \mathrm{P}<0.01, * \mathrm{P}<0.05$, logistic regression. $(-)$ variable not included in the model. Floating pellets $=$ finely ground feed that has been compressed and molded into pellets in a pellet mill and float on the surface of water when served to grower and finisher fish stages. Mash $=$ a finely ground feed formulated and used in moist form for farmed juvenile fish. For pig finisher $=$ Feed for pigs weighing over 55 kilograms live body weight. Sow and weaner $=$ Feed type for growing pigs up to 55 kilograms live body weight and adult breeding pigs. For Kienyeji $=$ feed for indigenous type of chicken commonly known as "Kienyeji". Layers = feed for laying birds aged $19-76$ weeks. Growers $=$ feed for birds aged $8-18$ weeks. Chick $=$ a ground form of feed fed to chicks aged between $0-8$ weeks. WTP $=$ willingness to pay. 


\section{Discussion}

In most developing countries, agribusiness is an important component of the economy. Central to its sustainability are consumers' attitudes and market acceptance of the products (Alemu et al., 2016; Etim \& Benson, 2016). One way of ensuring this, is by assessing the hypothetical WTP prior to production (Alemu et al., 2016; Martinez-Carrasco et al., 2015). The present study explored farmers' knowledge of and attitudes towards insects as an alternative feed ingredient, the practice and utilization of local feed formulations, and their WTP for IBF. Socio-demographic characteristics of a household present the ability of the household to produce and consume goods. They affect the household's access to and WTP for farm inputs (Manja et al., 2015). The present study shows that farmers in Kenya are sufficiently educated and thus exposed to information which is important in decision making. In most peasant economies in developing countries, household labour is used to produce either for their own use or for the market (Asaminew, 2014). In the present study, we recorded a mean household size of five, which indicates that family labour is available for production. In addition, farmers generally had a medium to high access to agricultural inputs and support services such as microcredit, extension services, banking services and agricultural inputs such as: feed, training, selling points for livestock products, new technologies and market information.

Information regarding farmers' knowledge, attitude towards insects as feed and the practice of making and using their own feeds may be used in strategies geared towards introducing IBF. Our results show that Kenyan livestock producers are well aware of the potential of insects being used as a feed ingredient. This awareness probably provided farmers with the opportunity to develop a positive attitude. This positive attitude would promote the decision maker taking a risk regarding a novel input while a negative attitude discourages the decision maker from taking risk. This result is similar to previous reports that socio-economic characteristics and farmers' knowledge affect interests in insect as feed (Mancuso et al., 2016). The finding that farmers are well aware of the use of insects as feed ingredient with a positive attitude towards insects as a feed ingredient as well as the finding that farmers have already used insects to feed their animals, provides an enabling environment for implementing IBF.

A key finding in the present study is that farmers are willing to pay more for IBF than for major commercial feeds used in poultry, fish and pig production. This is consistent with the farmers' high knowledge level and positive attitude towards insects as an alternative feed ingredient in this study and agrees with observations from studies in other countries (Mancuso et al., 2016). This provides an indication of a potential market acceptance of IBF among farmers. The high percentage of farmers' WTP recorded in this study is not surprising considering that insects have been part of the natural diet of 
poultry, fish and pigs in their natural environment (Laureati et al., 2016). The socio-demographic variables represent differential influences on farmers' W'TP in this study. The variable 'age' for example, negatively correlated with WTP for farmers using Kienyeji and floating pellets for poultry and fish, respectively, but showed a positive correlation with WTP for pig finisher feed. These results are in agreement with previous reports that the variable 'age' could either negatively or positively influence a farmer's WTP for a new product (Etim \& Benson, 2016; Manja et al., 2015; Oladele, 2008). Similar findings were obtained for variables such as 'aware that insects can be used as feed', which positively and negatively correlated with WTP for Kienyeji and layers feed, respectively.

It is worth noting that for poultry and pig, farmer age and acceptance of insects showed a significant correlation with WTP, in at least one of the feed types for each animal category. A negative correlation of 'farmer age' with WTP indicates that the younger the farmers, the more willing they are to pay for IBF for poultry and fish and vice versa (Laureati et al., 2016). This also agrees with other reports that younger people are more willing to try new products than older people (Lombardi et al., 2019). This also suggests a greater potential adoption of insects as feed ingredient among young farmers compared to older farmers, except for pig farmers where older farmers appear to be more willing to adopt IBF. Furthermore, acceptance of insects as feed ingredients generally showed a significant correlation with WTP, with BSF showing a strong positive correlation with WTP. This means that an increased availability of the BSF would greatly influence farmers' WTP for IBF.

We used household-based data and adopted the contingent valuation method (Etim \& Benson, 2016) and the double bound-logit model to assess farmers' WTP, WTP level and the factors that influence WTP, using market price as a benchmark price for IBF for poultry, fish and pig farmers in Kenya. Our results show that above $90 \%$ of the surveyed male and female farmers are willing to pay for IBF. The farmers are willing to pay at least 16\%,12\% and 30\% extra for IBF for poultry, fish and pigs, respectively. Female poultry farmers are significantly more aware that insects can be used as feed ingredients than males. More female poultry farmers have a positive attitude towards insects as feed than males. Furthermore, the significantly negative correlation between WTP and the variables: "insects are a good feed source" for farmers using Kienyeji feed and "acceptance of housefly maggots" for fish and pig farmers in the present study, may have been due to lack of information on the negative impact of total reliance on the traditional feed ingredients. In one study for example, respondents expressed a strong negative attitude towards fish raised on IBF. When informed of the impacts of overfishing for farmed fish, the result showed a strong positive correlation, indicating that respondents' knowledge can strongly affect acceptance and willingness to accept alternatives (Ankamah-Yeboah et al., 2018). The present study is one of only few studies to assess consumer opinion on insects as feed, and the first to document farmers' knowledge and 
attitude towards insects as feed and their intentions to purchase IBF in sub-Saharan Africa. We conclude that farmers are willing to pay for IBF and understand the benefits of using IBF in animal production. Farmers' WTP for IBF is a function of several socio-demographic factors, especially: age, gender, awareness of insects as feed, acceptance of insect species, availability of agricultural extension services and market information. Therefore, such factors are crucial for designing policy strategies to ensure effective adoption of IBF in Kenya.

The implication of our study is that feed companies can replace fishmeal and soybean meal with insect meal in poultry, fish and pig feeds without major impacts on market demand because most of the farmers are willing to pay for IBF. This, therefore, presents an excellent opportunity for innovative and sustainable use of resources through insect rearing and minimizes the pressure on the agricultural land and marine resources. Our findings provide the first insight into the market opportunities of including insects in the animal feed value chain in Kenya, particularly following the recent authorization of the use of insects in animal feed by the Kenyan government (Kenya Final Approved Standard KS 2711_2017).

To enhance farmer uptake of the innovative technology and WTP for more sustainable and readily available alternatives such as IBF, improvements in extension support services are of paramount importance (Makkar, 2016; Popoff et al., 2017). We therefore recommend the following: First, there is a need to increase farmer's knowledge on the nutritional value of insects, especially the BSF, as well as their use as alternative feed ingredients. From the empirical results of this study, awareness and acceptance of insect species significantly influence farmers' WTP. Developing local insect production systems can increase availability of insect meal and, thus promote local IBF production. In the present study for instance, "distance to feed trader" had a significant influence on WTP. This means that the closer the feed trader is to the farmer, the higher the probability that the farmer will be willing to buy the feed and vice versa. Second, our results indicate that the use of commercial feeds and acceptance of BSF larvae as feed positively influence WTP among fish farmers for floating pellets. This means that an increase in these variables leads to an increase in WTP. So, engaging feed millers and traders and training them with regard to the advantages of insect meal in animal feed, can promote inclusion of insects in commercial feed without affecting demand. Finally, creating linkages between farmers and the markets will further enhance utilization of innovative and locally available feed resources such as insect meal among fish and livestock farmers in Kenya. 


\section{Acknowledgements}

We thank Monica Fisher for helpful comments and suggestions on an earlier version of this chapter. We thank all the farmers drawn from the 4 counties and the trained enumerators for their substantial contribution during the data collection process of the study. This work was financially supported by the Netherlands Organization for Scientific Research (NWO)-WOTRO Science for Global Development (ILIPA - W 08.250.202). The authors declare no conflicts of interest.

\section{References}

Abiodun, E. (2019). Catfish and catfish feed ingredient prices. Retrieved from: www.profitablefishfarming.com/catfish-catfish-feed-ingredient-prices/, May 21, 2019.

Alemu, M. H., Olsen, S. B., Vedel, S. E., Pambo, K. O., \& Owino, V. O. (2016). Consumer acceptance and willingness to pay for edible insects as food in Kenya: the case of white winged termites (IFRO Working Paper 2015/10). Department of Food and Resource Economics (IFRO). Retrieved from: http://okonomi.foi.dk/workingpapers/WPpdf/WP2015/ IFRO_WP_2015_10.pdf, May 17, 2019.

AllaboutFeed. (2015). Why are insects not allowed in animal feed? R. B. Information. Retrieved from: www.allaboutfeed.net/PageFiles/23785/Whitepaper_Insects_2015.pdf, September 24, 2019.

Ankamah-Yeboah, I., Jacobsen, J. B., \& Olsen, S. B. (2018). Innovating out of the fishmeal trap: The role of insect-based fish feed in consumers' preferences for fish attributes. British Food Journal, 120, 2395-2410.

Asaminew, E. (2014). Household production, home consumption and market supply in peasant economies: The case of Ethiopia. African Journal of Agricultural Economics and Rural Development, 2, 155-164.

Bazoche, P., \& Poret, S. (2016). What do trout eat: Acceptance of insects in animal feed. 11èmes Journées de Recherche en Sciences Sociales, 1-14.

Chia, S. Y., Tanga, C. M., Osuga, I. M., Mohamed, S. A., Khamis, F. M., Salifu, D., . . Ekesi, S. (2018). Effects of waste stream combinations from brewing industry on performance of black soldier fly, Hermetia illucens (Diptera: Stratiomyidae). PeerJ, 6, e5885.

Etim, N., \& Benson, D. (2016). Willingness to pay for organic fertilizer by resource poor vegetable farmers in the Humid Tropic. Journal of Agriculture and Ecology Research International, 6, 1-11.

FAO. (2009). The state of food and agriculture: Livestock in the balance. Rome. Food and Agriculture Organization (FAO). Retrieved from: www.fao.org/3/i0680e/i0680e.pdf, May 6, 2019.

FAO. (2016). FAO fisheries \& aquaculture - fishery and aquaculture country profiles - The Republic of Kenya. Fisheries and Aquaculture country profile. Rome. Food and Agriculture Organization (FAO). Retrieved from: www.fao.org/fishery/facp/KEN/en, June 8, 2019.

Githigia, S. M., Okuthe, S., \& Diop, B. (2012). Pig Sector Kenya. FAO animal production and health livestock country reviews. No. 3 (No. 3). Rome. Food and Agriculture Organization (FAO). Retrieved from: www.fao.org/3/a-i2566e.pdf, June 10, 2019. 
Gordon, D. V., \& Maurice, S. (2015). Vertical and horizontal integration in the Uganda fish supply chain: Measuring for feedback effects to fishermen. Aquaculture Economics \& Management, 19, 29-50.

Hanemann, M., Loomis, J., \& Kanninen, B. (1991). Statistical Efficiency of Double-Bounded Dichotomous Choice Contingent Valuation. American Journal of Agricultural Economics, 73, 1255-1263.

Heinzen, R. R., \& Bridges, J. F. (2008). Comparison of four contingent valuation methods to estimate the economic value of a pneumococcal vaccine in Bangladesh. International Journal of Technology Assessment in Health Care, 24, 481-487.

Henry, M., Gasco, L., Piccolo, G., \& Fountoulaki, E. (2015). Review on the use of insects in the diet of farmed fish: Past and future. Animal Feed Science and Technology, 203, 1-22.

Henson, S. (1996). Consumer willingness to pay for reductions in the risk of food poisoning in the UK. Journal of Agricultural Economics, 47, 403-420.

Herriges, J. A. (1999). measuring goodness of fit for the double-bounded logit model: comment. American Journal of Agricultural Economics, 81, 231-234.

Katende, C. (2017). Feeds and quality, major factors in varying egg prices. Daily Monitor. Retrieved from: http://tinyurl.com/y7bva929, May 23, 2019.

Kenya Final Approved Standard KS 2711_2017. Retrieved from: www.feednavigator.com/Article/2017/11/17/Internationally-funded-project-behind-insectfeed-approval-in-Kenya-and-Uganda, June 17, 2019.

Kenya Marine and Fisheries Research Institute (KMFRI). Kenya's aquaculture brief 2017: status, trends, challenges and future outlook. Mombasa. KMFRI. Retrieved from: www.kmfri. co.ke/images/pdf/Kenya_Aquaculture_Brief_2017.pdf, May 6, 2019.

Kenyan National Bureau of standards (KNBS). (2017, October 2, 2018). Revision of the 2017, gross domestic product (GDP). Retrieved from: www.knbs.or.ke/download/revision-ofthe-2017-gross-domestic-product-gdp/\#, May 6, 2019.

Kostecka, J., Konieczna, K., \& Cunha, L. M. (2017). Evaluation of insect-based food acceptance by representatives of polish consumers in the context of natural resources processing retardation. Journal of Ecological Engineering, 18, 166-174.

Kumar, P., Jain, K. K., MunilKumar, S., \& Sudhagar, S. A. (2017). Alternate feeding strategies for optimum nutrient utilization and reducing feed cost for semi-intensive practices in aquaculture system-A review. Agricultural Reviews, 38, 1-7.

Laureati, M., Proserpio, C., Jucker, C., \& Savoldelli, S. (2016). New sustainable protein sources: consumers' willingness to adopt insects as feed and food. Italian Journal of Food Science, 28, 652-668.

Lombardi, A., Vecchio, R., Borrello, M., Caracciolo, F., \& Cembalo, L. (2019). Willingness to pay for insect-based food: The role of information and carrier. Food Quality and Preference, 72, 177-187.

Makkar, H. P. (2016). Smart livestock feeding strategies for harvesting triple gain-the desired outcomes in planet, people and profit dimensions: a developing country perspective. Animal Production Science, 56, 519-534.

Makkar, H. P. S. (2018). Review: Feed demand landscape and implications of food-not feed strategy for food security and climate change. Animal, 12, 1744-1754.

Makkar, H. P. S., \& Ankers, P. (2014). Towards sustainable animal diets: A survey-based study. Animal Feed Science and Technology, 198, 309-322. 
Makkar, H. P. S., Tran, G., Henze, V., \& Ankers, P. (2014). State-of-the-art on use of insects as animal feed. Animal Feed Science and Technology, 197, 1-33.

Mancuso, T., Baldi, L., \& Gasco, L. (2016). An empirical study on consumer acceptance of farmed fish fed on insect meals: the Italian case. Aquaculture International, 24, 1489-1507.

Manja, L. P., Chirwa, G. C., \& Kambewa, P. (2015). Determinants of farmers'willingness to pay for subsidised farm inputs in Malawi. International Journal of Social Sciences and Humanity Studies, 7, 16-35.

Martinez-Carrasco, L., Brugarolas, M., Martinez-Poveda, A., \& Ruiz-Martinez, J. J. (2015). Comparing hypothetical versus non-hypothetical methods for measuring willingness to pay in a food context. Spanish Journal of Agricultural Research, 13, 0109.

Mosig, J. (2018). Is farmed fish becoming more expensive? Retrieved from: www.allaboutfeed. net/Compound-Feed/Articles/2018/4/Is-farmed-fish-becoming-more-expensive267850E/, May 24, 2019.

Nwokocha, J., \& Nwokocha, N. (2013). Development of aquacultural feeds from locally available feedstuff: A giant step towards food security in Nigeria. International Journal of Academic Research in Business and Social Sciences, 3, 2222-6990.

Nyandat, B., \& Owiti, G. (2013). Aquaculture needs assessment mission report. Report/Rapport: SF-FAO/2013/24.FAO-SmartFish Programme of the Indian Ocean Commission Ebene. Retrieved from: www.fao.org/3/a-az041e.pdf, May 7, 2019.

Oladele, O. (2008). Factors determining farmers' willingness to pay for extension services in Oyo State, Nigeria. Agricultura Tropica et Subtropica, 41, 165-170.

Oonincx, D. G., van Itterbeeck, J., Heetkamp, M. J., van den Brand, H., van Loon, J. J. A., \& Van Huis, A. (2010). An exploration on greenhouse gas and ammonia production by insect species suitable for animal or human consumption. PLoS ONE, 5, e14445.

Popoff, M., MacLeod, M., \& Leschen, W. (2017). Attitudes towards the use of insect-derived materials in Scottish salmon feeds. Journal of Insects as Food and Feed, 3, 131-138.

Rajee, O., \& Mun, A. (2017). Impact of aquaculture on the livelihoods and food security of rural communities. International Journal of Fisheries and Aquatic Studies, 5, 278-283.

Republic of Kenya Ministry of Agriculture Livestock Fisheries and Irrigation. (2019). Draft National Livestock Policy-Kenya. Retrieved from: www.kilimo.go.ke/wp-content/uploads/2019/02/Draft-reviewed-National-Livestock-Policy-February-2019.pdf, May 6, 2019.

Rumpold, B. A., \& Schluter, O. K. (2013). Nutritional composition and safety aspects of edible insects. Molecular Nutrition \& Food Research, 57, 802-823.

Rumpold, B. A., \& Schlüter, O. K. (2013). Potential and challenges of insects as an innovative source for food and feed production. Innovative Food Science \& Emerging Technologies, 17, 1-11.

Shava, E., \& Gunhidzirai, C. (2017). Fish farming as an innovative strategy for promoting food security in drought risk regions of Zimbabwe. Jamba: Journal of Disaster Risk Studies, 9, 1-10.

Shibia, M., Rahman, S., \& Chidmi, B. (2017). Consumer demand for meat in Kenya: An examination of the linear approximate almost ideal demand system. Paper presented at the 2017 Annual Meeting, Southern Agricultural Economics Association, Alabama. Retrieved from: https://ideas.repec.org/p/ags/saea17/252789.html\#download.

Ssepuuya, G., Namulawa, V., Mbabazi, D., Mugerwa, S., Fuuna, P., Nampijja, Z., . . Nakimbugwe, D. (2017). Use of insects for fish and poultry compound feed in sub-Saharan Africa-a systematic review. Journal of Insects as Food and Feed, 3, 289-302. 
Tan, H. S. G., Fischer, A. R. H., Tinchan, P., Stieger, M., Steenbekkers, L. P. A., \& van Trijp, H. C. M. (2015). Insects as food: Exploring cultural exposure and individual experience as determinants of acceptance. Food Quality and Preference, 42, 78-89.

Thornton, P. K. (2010). Livestock production: recent trends, future prospects. Philosophical Transactions of the Royal Society B: Biological Sciences, 365, 2853-2867.

Van Huis, A. (2013). Potential of insects as food and feed in assuring food security. Annual Review of Entomology, 58, 563-583.

Van Huis, A., Dicke, M., \& van Loon, J. J. A. (2015). Insects to feed the world. Journal of Insects as Food and Feed, 1, 3-5.

Van Huis, A., Van Itterbeeck, J., Klunder, H., Mertens, E., Halloran, A., Muir, G., \& Vantomme, P. (2013). Edible insects: future prospects for food and feed security (No. 171). Rome: Food and Agriculture Organization.

Verbeke, W. (2015). Profiling consumers who are ready to adopt insects as a meat substitute in a Western society. Food Quality and Preference, 39, 147-155.

Verbeke, W., Spranghers, T., De Clercq, P., De Smet, S., Sas, B., \& Eeckhout, M. (2015). Insects in animal feed: Acceptance and its determinants among farmers, agriculture sector stakeholders and citizens. Animal Feed Science and Technology, 204, 72-87.

Vernooij, A., Masaki, M. N., \& Meijer-Willems, D. (2018). Regionalisation in poultry developmen in Eastern Africa. Wageningen Livestock Research. Retrieved from: http:/ library.wur.nl/ WebQuery/wurpubs/fulltext/458221, May 6, 2019. 


\section{Chapter 4}

\section{Effects of waste stream combinations}

from brewing industry on performance of black soldier fly Hermetia illucens (Diptera: Stratiomyidae)

Shaphan Y. Chia, Chrysantus M. Tanga, Isaac M. Osuga, Samira A. Mohamed, Fathiya M. Khamis, Daisy Salifu, Subramanian Sevgan, Komi K. M. Fiaboe, Saliou Niassy, Joop J. A. van Loon, Marcel Dicke and Sunday Ekesi

Published in PeerJ (2018) 6:e5885, doi:10.7717/peerj.5885 


\section{Abstract}

In recent years, there has been a rapidly growing demand for readily accessible substrates for mass production of black soldier fly, Hermetia illucens Linnaeus. Beer production results in various by-products that typically end up in uncontrolled dumpsites, constituting pollution problems, which merits urgent attention. The present study investigated whether the 12 formulated diets composed of brewers' spent grains (BSGs), brewers' yeast and cane molasses can serve as substrates for $H$. illucens production. Four different BSGs were selected and formulated into 12 diets, aiming at varying protein and net energy levels. The diets were offered to newly hatched ( $\sim 1 \mathrm{~h}$ old) $H$. illucens larvae and the influence on developmental duration, survival, wet weight, pre-oviposition time, fecundity, and longevity were compared. Developmental duration of the larvae (16-21 days) and pre-pupae (8-11 days) differed significantly across the different diets. The developmental duration of the pupae (8.7-9.1 days) was not affected by diet. The larval (86-99.2\%), pre-pupal (71-95\%), and pupal (65-91\%) survival rates varied significantly between flies reared on the different diets. The pre-oviposition time was similar for flies provided with water (7-11 days) and 10\% sugar solution (8-14 days) or across the different diets. The mean fecundity per female ranged from 324-787 eggs and did not differ between females provided with water or sugar solution. However, the number of eggs laid per female varied significantly across the different diets when provided with water. The longevity of starved $H$. illucens adults was significantly lower (5 days) compared to those provided with water (11-14 days) or sugar solution (14-15 days). The implications of these findings as part of a quality control procedure for commercial production of high-quality $H$. illucens larvae as an alternative protein ingredient in livestock and aquaculture feed are discussed.

Keywords: Hermetia illucens, protein, mass rearing, quality control parameters, agro-industrial by-products 


\section{Introduction}

The United Nations figures project global human population growth of almost 50\% since 2000 to 9.5 billion by 2050 (United Nations, 2015). The increase in human population has resulted in an increase in the demand for protein and, consequently, an increase in the production of livestock, which is constrained by the availability of protein-rich feedstuffs (Herrero et al., 2015; Mottet et al., 2017; Tallentire et al., 2018). Commonly used protein sources in livestock and aquaculture feeds include fish-derived and plant-derived protein sources, which are directly and indirectly competing with human nutrition (Shewry \& Halford, 2002; Van der Spiegel et al., 2013), creating an unsustainable pressure on the food value chain (Evans, 2009). Therefore, the development of innovative, cost-effective, and environmentally friendly options such as farming of insects on organic waste streams as alternative protein sources becomes important because they are increasingly considered an attractive, viable, and sustainable alternative to animal and plant protein sources (Henry et al., 2015; Makkar et al., 2014; Van Huis, 2013). Insects are rich in crude protein (35-77\%), carbohydrate, fat, vitamins, and minerals (Ganguly et al., 2013; Henry et al., 2015; Makkar et al., 2014; Van Huis, 2013).

Insects like the black soldier fly Hermetia illucens Linnaeus, offer promising alternatives of nutrient recovery while accumulating high-quality nutrient body biomass with an average of 42-43\% crude protein, 33\% fat and micronutrients such as iron and zinc (Barragán-Fonseca, 2018; Makkar et al., 2014; Oonincx et al., 2015; Rumpold \& Schluter, 2013; Spranghers et al., 2017). However, the nutritional status of insects varies depending on the species and rearing substrates (Liland et al., 2017; Meneguz et al., 2018; Tschirner \& Simon, 2015). The use of H. illucens larvae as an alternative to fishmeal or soybean meal in poultry, pig, and fish feeds has been advocated worldwide (Gasco et al., 2016; Ji et al., 2016; Lock et al., 2016; Makkar et al., 2014; Renna et al., 2017; Schiavone et al., 2017; Veldkamp \& Bosch, 2015) and provides opportunities for income generation (Dobermann et al., 2017; Kelemu et al., 2015; Van Huis et al., 2013). To meet the increasing demand for high-quality $H$. illucens-based protein ingredients, mass production of $H$. illucens on readily available organic waste streams is important (Sanchez-Muros et al., 2014).

Organic waste management is a major challenge in Kenya, especially in Nairobi, the rapidly growing capital. In Nairobi, over 2,400 tons of waste are generated every day (Kasozi \& von Blottnitz, 2010), of which only 38\% is collected and less than $10 \%$ recycled (Japan International Cooperation Agency (JICA), 2010). The remaining 62\% being organic waste largely from households, restaurants, hotels, markets, and agro-industrial manufacturing processes (Hoornweg \& Bhada-Tata, 2012; UN-HABITAT, 2010a). For agro-industrial manufacturing processes in Kenya, Kenya Breweries Limited (KBL) and Mumias Sugar Company Limited generate huge amounts of waste. Only a small proportion of these massive waste streams has occasionally been used as supplements in 
livestock feed, since the advent of beer production in many countries in the world (Aliyu \& Bala, 2011; Calvert, 1991; Farhat et al., 2001; Liguori et al., 2015; McDonald et al., 2002), but this is not the optimal use, as the spent grains are difficult for animals to digest (Newman \& Jennings, 2008).

The use of $H$. illucens larvae to digest a wide range of organic waste streams, including animal manure (Xiao et al., 2018) fruit remains (Nguyen et al., 2013), and vegetable remains (Meneguz et al., 2018), or even some indigestible food such as coffee pulp (Diener et al., 2009) has been well documented. Larvae of H. illucens can convert these organic waste streams to useful nutrients, maintaining a balance between high larval weight and reduction of organic solid matter up to about 42-56\% (Diener et al., 2011; Diener et al., 2009; Li et al., 2011; Nguyen et al., 2015). Interest in the use of these waste streams as a source of value-added products is increasing rapidly due to their availability, year-round accessibility, affordability, low competitiveness for food or feed and the need for sustainable waste management procedures. According to Van Huis et al. (2013), bioconversion of these waste streams using H. illucens will be more sustainable than other waste conversion and handling techniques as the insects are able to utilize massive amounts of organic waste and reduce the unpleasant smells emanating from the waste (Lardé, 1990), reduce efficiently the accumulation of polluting elements (nitrogen, phosphorous) from manure and compost (Beskin et al., 2018; Sanchez-Muros et al., 2014; Van Huis, 2013; Xiao et al., 2018). Larvae of H. illucens also modify the microflora in organic waste thereby reducing the occurrence or abundance of undesirable bacteria (Erickson et al., 2004; Yu et al., 2011). Larvae of H. illucens, thus, add value to the waste (bio-fertilizers) and are efficient converters as they produce a protein and lipid-rich biomass from substrates that can be poorly used by monogastric animals (Gobbi et al., 2013; Tomberlin \& Sheppard, 2002; Tomberlin et al., 2002; Xiao et al., 2018). These characteristics, linked to a short production cycle, make $H$. illucens larvae very good candidates for intensive production. Therefore, waste that would otherwise contaminate the environment and put human and animal health at risk could be a source of income generation and employment creation through well-established recycling and resource recovery (Diener et al., 2011; Diener et al., 2009; Liguori et al., 2015; Nguyen et al., 2013; UN-HABITAT, 2010b).

Although, the economic importance of this fly as a potential candidate for mass rearing is well established, knowledge on important aspects of the reproductive biology of $H$. illucens on agro-industrial waste streams (mixed diets of brewer's spent grains (BSGs), brewers' yeast, and cane molasses) as suitable substrates for mass production remains largely unknown. The process of beer and sugar manufacturing generates various by-products, typically BSGs, brewers' yeast, and molasses. These by-products are produced in large quantities daily, readily available and highly accessible throughout the year and easy to handle. Here, we investigate the suitability of these waste streams as 
substrate for $H$. illucens.

It is well known that the quality of larval diet significantly affects mass rearing of insects, especially growth, survival, and biological traits of adult flies because large females have large ovaries and lay more eggs than small females (Blackmore \& Lord, 2000; Churchill-Stanland et al., 1986; Gobbi et al., 2013; Roper et al., 1996). Thus, larval diet quality and feeding are crucial to overall fitness (Moreau et al., 2006; Tikkanen et al., 2000; Tomberlin et al., 2002). In this study, we combined different agro-industrial waste streams and determined the life-history parameters of $H$. illucens by focusing on the following research questions: how does the quality of the larval diet affect (a) developmental duration of immature life stages, (b) their survival, (c) larval, pre-pupal, pupal, and adult biomass, (d) pre-oviposition duration, (e) adult fecundity, and (f) longevity of starved, water-provided and sugar-fed adults.

\section{Materials and Methods}

\section{Insect culture}

This study was carried out at the Animal Rearing and Containment Unit of the International Centre of Insect Physiology and Ecology (icipe), Nairobi, Kenya. H. illucens colony was established in 2016 from eggs of wild-trapped H. illucens populations in Kasarani, Nairobi County (S 01¹3'14.6"; E 03653'44.5", 1,612 m a.s.l.) following the method described by Booth \& Sheppard (1984) and Sripontan et al. (2017) with slight modifications. The egg clusters were transferred to metal trays $(76 \times 27.5 \times 10 \mathrm{~cm})$ containing $2,000 \mathrm{~g}$ of BSG diluted in 3,200 $\mathrm{ml}$ of water. The diet was hydrated to approximately 70 $\pm 2 \%$ moisture by weight and confirmed using a moisture sensor with two $12 \mathrm{~cm}$ long probes (HydroSense ${ }^{\mathrm{TM}}$ CS620; Campbell Scientific, Inc., Logan, UT, USA). The culture was monitored daily for larval development. The pre-pupal stages after self-dispersal from the substrate were kept in four litre transparent rectangular plastic containers (21 $\times 14 \times 15 \mathrm{~cm})($ Kenpoly Manufacturer Ltd., Nairobi, Kenya) containing moist wood shavings (sawdust) as pupation substrate according to Holmes et al. (2013). An opening $(14.5 \times 8.3 \mathrm{~cm})$ was made in the lid of each container and covered with fine netting organza material capable of retaining emerging adult flies. Conditions in the rearing room were maintained at $28 \pm 1{ }^{\circ} \mathrm{C}, 70 \pm 2 \%$ relative humidity $(\mathrm{RH})$ and a photoperiod of L12:D12. Adults were transferred to outdoor cages where water and sugar solution were provided ad libitum to the flies. When the adult flies in the cage were 7-days-old (Nakamura et al., 2016), moist chicken manure (500 g diluted in $800 \mathrm{ml}$ of water) was provided in plastic containers $(30 \times 15 \mathrm{~cm})$ with the surface covered with wire mesh. Strips of cardboard with flutes along the edges were placed on top of the wire mesh, which provided the flies with sites for laying eggs. The containers were checked daily to collect egg clusters deposited by the flies. The cardboard strips with egg clusters were 
transferred to plastic containers and placed in climate-controlled chambers. The newly hatched larvae were fed ad libitum BSG until full development into pre-pupal stages. The pre-pupal stages were transferred into two 1 transparent rectangular plastic containers containing a $2.5 \mathrm{~cm}$ layer of moist wood shavings and monitored daily for pupal formation. The pupae collected were regularly transferred into four-litre transparent plastic rectangular containers containing a $2.5 \mathrm{~cm}$ layer of moist wood shavings until emergence. The emerged flies were transferred to the outdoor rearing cages designed specifically to hold the adult fly stock populations. The H. illucens colony has been in culture for $\sim 2$ years and once every 6 months, wild-caught flies are added to the colony to prevent inbreeding depression. In addition, adult $H$. illucens populations in the cages were maintained in low numbers (approximately 2,000 adult flies in a $1 \times 1.2 \times 1.8 \mathrm{~m}$ cage) to avoid stressful crowding effects, which is very common in insect mass production (Sørensen \& Loeschcke, 2001).

\section{Experimental substrates and diet formulation}

The BSGs used were sourced once from the KBL, Nairobi, Kenya; main producer of major beer brands in the country: Tusker (malt and corn starch); Guinness (malt and barley); Senator (sorghum and barley), and Pilsner (barley). The liquid form of brewer's yeast from the processing of each of the beer brands was also collected as part of waste streams to be used during the experiments. The fresh BSGs were placed on plastic sheets with moving dry air at ambiant temperature $\left(28.0 \pm 1{ }^{\circ} \mathrm{C}\right)$ for $48 \mathrm{~h}$ using an Xpelair ${ }^{\circledR}$ heater (WH30, 3 KW Wall Fan Heater; Peterborough, UK). Possible fermentation of the BSGs at this temperature was avoided by turning the substrates twice daily to ensure proper aeration and to prevent molding within the substrates. Thereafter, the semi-dried products were oven-dried at $60^{\circ} \mathrm{C}$ for $72 \mathrm{~h}$ to approximately $90 \%$ dry matter (DM) ( 10\% moisture). The dried BSGs were later passed through a three $\mathrm{mm}$ sieve in a Münch hammer mill (Münch, Wuppertal, Germany) to obtain particle size suitable for incorporation into $H$. illucens diet. Molasses was obtained in liquid form from Mumias Sugar Company Limited.

Dried BSGs from the four main beer brands were formulated into 12 different diets as follows: The first group was the "control" for which $50 \mathrm{~g}$ of each BSG was mixed with $80 \mathrm{ml}$ of water only: malt/corn-starch/water; malt/barley/water; sorghum/barley/water, and barley/water. Each diet was hydrated to approximately $70 \pm 2 \%$ moisture content and confirmed using a moisture sensor with two $12 \mathrm{~cm}$ long probes (HydroSense ${ }^{\text {TM }}$ CS620; Campbell Scientific, Inc., Logan, UT, USA). In the second group, each of four BSGs was supplemented with waste brewer's yeast. Fifty grams of each BSG was mixed with $90 \mathrm{ml}$ of brewer's yeast to generate the following treatments: malt/corn-starch/ brewer's yeast; malt/barley/brewer's yeast; sorghum/barley/brewer's yeast, and barley/ brewer's yeast. In the third group, $50 \mathrm{~g}$ of each BSG was supplemented with $45 \mathrm{ml}$ of 
waste brewers' yeast $+45 \mathrm{ml}$ of molasses: malt/corn-starch/brewer's yeast/molasses; malt/barley/brewer's yeast/molasses; sorghum/barley/brewer's yeast/molasses, and barley/brewer's yeast/molasses.

\section{Chemical analysis of experimental diets}

Prior to conducting proximate analysis of the various diets using the method described by AOAC (1990), weighed samples were oven-dried at $60^{\circ} \mathrm{C}$ for $72 \mathrm{~h}$. DM content of each sample was measured by oven drying at $105^{\circ} \mathrm{C}$ for $48 \mathrm{~h}$ until constant weight was achieved (AOAC, 1990; Okedi, 1992; Pen et al., 2013). Moisture content was determined using the oven set at $105^{\circ} \mathrm{C}$ for $24 \mathrm{~h}$ (AOAC, 1990). Nitrogen content was determined using the Kjeldahl method (AOAC), 1990) and later converted to crude protein content by multiplying with factor 6.25 (Finke, 2007). The ash content was determined using a muffle furnace and samples heated at $550{ }^{\circ} \mathrm{C}$ overnight according to the method described by (AOAC, 1990). Velp solvent extractor (SER 148/6) was used to determine fat content (crude fat) with ethyl ether as extractant (AOAC, 1990). All parameters discussed above were determined in triplicate per sample and expressed as a percentage.

\section{Experimental design}

Before the start of the experiment, the rearing room was maintained at $28.0 \pm 1{ }^{\circ} \mathrm{C}$ using an Xpelair heater (WH30, 3 KW Wall Fan Heater; Peterborough, UK). The RH in the experimental room was adjusted and maintained at $70 \pm 2 \%$ using an adiabatic atomizer humidifier (Condair ABS3; Hornsby, Australia), while maintaining 12:12 L:D photoperiod. The condition of the room was monitored daily using a WiFi Sensor (WiFi-TH Corintech Ltd., Fordingbridge, UK; Firmware version 5.1.7/13.3.3G/R4.11). Thereafter, 120 egg batches ( 3 h old) collected from the adult stock culture maintained in the outdoor cages described above were distributed equally in 12 sterilized disposable $100 \times 15 \mathrm{~mm}$ petri dishes and monitored at $6 \mathrm{~h}$ intervals daily for egg eclosion.

According to the method described by Gobbi et al. (2013), 300 neonate larvae ( $1 \mathrm{~h}$ old) were individually counted with the aid of entomological tweezers and a moist fine camel hair brush under a stereomicroscope (Leica MZ 125 Microscope; Leica Microsystems Switzerland Limited, Heerbrugg, Switzerland), fitted with a Toshiba 3CCD camera using the Auto-Montage software (Syncroscopy; Synoptics Group, Cambridge, UK) at magnification of $\times 25$. The larvae were carefully lined on moistened pieces of sterilized black cloth, which were thereafter placed on top of the experimental diet in each of the 12 transparent plastic containers $(12 \times 4.5 \mathrm{~cm})$. The lid of each container was designed with an opening $(8 \times 4 \mathrm{~cm})$ fitted with fine netting material of $1.3 \times 1.3 \mathrm{~mm}$ mesh size for ventilation. Each experimental setup was then maintained in the climate-controlled 
rearing room described above. The larvae in each treatment were provided ample feeding substrate to carry them throughout the larval developmental phase to pre-pupae (non-feeding phase). The larvae generally have a cream-like color but at the fifth instar stage there is a recognizable on-set of exoskeletons (skin) color change to beige (dark brown) before they undergo the last molt to the charcoal-grey colored pre-pupal stage (Dortmans et al., 2017). Once the larvae turned into pre-pupae, they were transferred individually into plastic containers $(3 \times 4 \times 3 \mathrm{~cm})$ with $2.5 \mathrm{~cm}$ layer of moist wood shavings (sawdust). Each container had an opening ( $2.5 \mathrm{~cm}$ diameter) covered with fine netting organza material for ventilation. The containers were checked daily, and pupae formed were recorded. The pupae were collected and maintained individually in similar plastic containers until emergence. Stage-specific developmental time, survival and wet weight were calculated for each treatment. Weight measurements of the different life stages were carried out using a Kern-PCB 350-3 precision balance (0.001-350 g). The experiments were replicated five times for each experimental diet.

Pre-oviposition period, oviposition period, fecundity, and longevity when starved or provided with water or sugar solution

To determine the effect of each of the 12 experimental larval diets on life-history parameters, ninety paired newly emerged $(<24 \mathrm{~h}$ old $)$ adult flies were randomly selected by collecting fully winged male and female flies that emerged from each dietary treatment. The paired adult flies were subdivided into three groups of 30 each. Individual pairs of flies from each group were kept in transparent rectangular Perspex cages $(30 \times$ $16 \times 16 \mathrm{~cm}$ ) with openings covered with breathable material. Two strips of cardboard with holes along the edges were provided for laying eggs. The first group of paired flies from each diet was starved (unfed) throughout the experiment, while the second and third groups were provided with water and 10\% sugar solution on soaked cotton wool, respectively. Each experimental set-up was observed daily to record the number of eggs laid. The pre-oviposition period was calculated from the first day of emergence of an adult female to the first day of oviposition. Eggs laid on each day were collected with the aid of a fine wet black camel hair brush. Each egg clutch collected was physically separated by spreading it on the surface of an electrically powered light box $(2 \times 15 \mathrm{~W}$ 6,500 K, model 44077 B.S.4533; Sasco, London, England) and counted with the help of a tally counter. The light box allowed for easy identification of individual eggs during counting. The experiment was terminated when the female and male flies died. Both longevity and fecundity were calculated for each diet. 


\section{Statistical analysis}

Larval weight, pre-pupal weight, pupal weight, adult weight, development duration, adult longevity, number of eggs (female fecundity), and pre-oviposition period data were subjected to analysis of variance (ANOVA) to evaluate the effect of the waste streams on these variables. Number of eggs was log-transformed prior to ANOVA to stabilize variance. Tukey's honestly significant difference test was used to separate means. A t-test was used to compare the pre-oviposition period between treatments with sugar solution and water within each experimental diet. Further, orthogonal contrasts were created and evaluated using the glht function in the multcomp package (Hothorn, Bretz \& Westfall, 2008) to explore the structure in the treatments, the agro-industrial wastes. The differences among treatment means were considered statistically significant at $\alpha=0.05$. All statistical analyses were implemented using $\mathrm{R}$ version 3.3.3 (R Core Team, 2017).

\section{Results}

\section{Nutrient composition of experimental diets}

Marked variation was observed on the nutritional composition (on DM basis) of the diets used in this study (Table 1). There was a significant difference in crude protein ( $F$ $=194.90 ; \mathrm{df}=11,24 ; \mathrm{P}<0.0001)$, crude fat $(\mathrm{F}=45.09 ; \mathrm{df}=11,24 ; \mathrm{P}<0.0001)$, ash $(\mathrm{F}=8.48 ; \mathrm{df}=11,24 ; \mathrm{P}<0.0001)$ and moisture $(\mathrm{F}=261.90 ; \mathrm{df}=11,24 ; \mathrm{P}<0.0001)$ contents among the experimental diets. Diets supplemented with brewers' yeast only had higher crude protein levels compared to the other diets. The inclusion of brewers' yeast plus molasses in diets (spent grains) resulted in lower crude protein contents compared to diets mixed with water only.

Table 1. Nutrient composition (on dry matter basis) of experimental diets

\begin{tabular}{lllll}
\hline Larval diet & Crude protein $(\%)$ & Crude fat $(\%)$ & Ash $(\%)$ & Moisture $(\%)$ \\
\hline BW & $30.33 \pm 0.24^{\mathrm{bc}}$ & $6.38 \pm 0.17^{\mathrm{c}}$ & $4.15 \pm 0.18^{\mathrm{bcd}}$ & $11.57 \pm 0.10^{\mathrm{cd}}$ \\
MBW & $28.89 \pm 0.23^{\mathrm{cd}}$ & $6.78 \pm 0.25^{\mathrm{c}}$ & $3.80 \pm 0.19^{\mathrm{cd}}$ & $12.38 \pm 0.13^{\mathrm{c}}$ \\
MCW & $27.38 \pm 0.11^{\mathrm{d}}$ & $6.46 \pm 0.41^{\mathrm{c}}$ & $3.03 \pm 0.18^{\mathrm{d}}$ & $12.10 \pm 0.15^{\mathrm{c}}$ \\
SBW & $29.43 \pm 0.30^{\mathrm{c}}$ & $11.8 \pm 1.07^{\mathrm{a}}$ & $3.72 \pm 0.18^{\mathrm{cd}}$ & $10.38 \pm 0.13^{\mathrm{def}}$ \\
BY & $31.99 \pm 0.08^{\mathrm{a}}$ & $5.39 \pm 0.03^{\mathrm{cd}}$ & $4.74 \pm 0.28^{\mathrm{abc}}$ & $11.53 \pm 0.12^{\mathrm{cd}}$ \\
MBY & $30.22 \pm 0.10^{\mathrm{bc}}$ & $6.96 \pm 0.13^{\mathrm{c}}$ & $4.41 \pm 0.34^{\mathrm{bc}}$ & $10.76 \pm 0.26^{\mathrm{de}}$ \\
MCY & $27.72 \pm 0.23^{\mathrm{d}}$ & $6.04 \pm 0.15^{\mathrm{c}}$ & $5.14 \pm 0.2^{\mathrm{ab}}$ & $9.91 \pm 0.11^{\mathrm{ef}}$ \\
SBY & $31.39 \pm 0.17^{\mathrm{ab}}$ & $9.48 \pm 0.15^{\mathrm{b}}$ & $4.32 \pm 0.25^{\mathrm{bc}}$ & $9.17 \pm 0.20^{\mathrm{f}}$ \\
BYMo & $22.14 \pm 0.48^{\mathrm{c}}$ & $3.95 \pm 0.31^{\mathrm{def}}$ & $5.8 \pm 0.19^{\mathrm{a}}$ & $19.51 \pm 0.23^{\mathrm{a}}$ \\
MBYMo & $22.32 \pm 0.71^{\mathrm{c}}$ & $3.23 \pm 0.17^{\mathrm{f}}$ & $4.08 \pm 0.22^{\mathrm{bcd}}$ & $18.24 \pm 0.20^{\mathrm{b}}$ \\
MCYMo & $19.10 \pm 0.35^{\mathrm{f}}$ & $3.42 \pm 0.02^{\mathrm{cf}}$ & $4.31 \pm 0.21^{\mathrm{bc}}$ & $18.79 \pm 0.62^{\mathrm{ab}}$ \\
SBYMo & $21.69 \pm 0.14^{\mathrm{c}}$ & $5.18 \pm 0.15^{\mathrm{cdc}}$ & $4.71 \pm 0.20^{\mathrm{abc}}$ & $18.66 \pm 0.22^{\mathrm{ab}}$ \\
\hline
\end{tabular}

Means in a column followed by different lower-case letter are significantly different $(\mathrm{P}<0.05$, ANOVA plus HSD). BW, Barley/water; MBW, Malt/Barley/water; MCW, Malt/Corn-starch/water; SBW, Sorghum/Barley/water; BY, Barley/ brewer's yeast; MBY, Malt/Barley/brewer's yeast; MCY, Malt/Corn-starch/brewer's yeast; SBY, Sorghum/Barley/ brewer's yeast; BYMo, Barley/brewer's yeast/Molasses; MBYMo, Malt/Barley/brewer's yeast/Molasses; MCYMo, Malt/ Corn-starch/brewer's yeast/Molasses and SBYMo, Sorghum/Barley/Molasses. 


\section{Effect of rearing diet on development of immature stages of $H$. illucens}

There were significant differences in larval $(\mathrm{F}=14.16$; $\mathrm{df}=11,48 ; \mathrm{P}<0.001)$ and prepupal ( $\mathrm{F}=12.45 ; \mathrm{df}=11,48 ; \mathrm{P}<0.001)$ developmental time among experimental diets (Table 2). Pupal development time did not differ significantly between diets $(F=0.89$; $\mathrm{df}=11,48 ; \mathrm{P}=0.55)$. Total developmental time (larva-adult) was significantly different among diets $(\mathrm{F}=40.57$; $\mathrm{df}=11,96 ; \mathrm{P}<0.001)$. Development time was similar for males and females from the same diet (Table 2) and there was no significant interaction $(\mathrm{F}=0.09 ; \mathrm{df}=11,96 ; \mathrm{P}=1.0)$ between diet and sex. Larval developmental time did not differ significantly between non-supplemented diets vs. diets supplemented with brewers' yeast only.

Table 2. Development time (mean number of days \pm SE) of H. illucens stages and comparison between treatment (diet) groups using orthogonal contrasts

\begin{tabular}{|c|c|c|c|c|c|c|c|}
\hline \multirow{2}{*}{ Diet } & \multirow{2}{*}{ Larva } & \multirow{2}{*}{\multicolumn{2}{|c|}{ Pre-pupa }} & \multirow{2}{*}{\multicolumn{2}{|c|}{ Pupa }} & \multicolumn{2}{|c|}{ Larva-adult } \\
\hline & & & & & & Male & Female \\
\hline $\mathrm{BW}$ & $17.2 \pm 0.5^{\text {cde }}$ & \multicolumn{2}{|c|}{$8.8 \pm 0.1^{\mathrm{bcd}}$} & \multicolumn{2}{|l|}{$9.1 \pm 0.1^{\mathrm{a}}$} & $35.0 \pm 0.5^{\mathrm{cdA}}$ & $35.2 \pm 0.5^{\mathrm{cdA}}$ \\
\hline MBW & $16.4 \pm 0.2^{\mathrm{e}}$ & \multicolumn{2}{|c|}{$9.5 \pm 0.1 \mathrm{abc}$} & \multicolumn{2}{|l|}{$8.7 \pm 0.2^{\mathrm{a}}$} & $34.5 \pm 0.4^{\mathrm{dA}}$ & $34.7 \pm 0.3^{\mathrm{dA}}$ \\
\hline $\mathrm{MCW}$ & $18.3 \pm 0.4$ bcd & \multicolumn{2}{|c|}{$8.3 \pm 0.1^{\mathrm{cd}}$} & \multicolumn{2}{|l|}{$8.8 \pm 0.1^{\mathrm{a}}$} & $35.5 \pm 0.6 \mathrm{cdA}$ & $35.5 \pm 0.6 \mathrm{cdA}$ \\
\hline SBW & $20.6 \pm 0.3^{\mathrm{a}}$ & \multicolumn{2}{|c|}{$8.8 \pm 0.3^{\mathrm{bcd}}$} & \multicolumn{2}{|l|}{$9.0 \pm 0.0^{\mathrm{a}}$} & $38.3 \pm 0.5^{\mathrm{abA}}$ & $38.4 \pm 0.4 \mathrm{abA}$ \\
\hline BY & $17.9 \pm 0.5^{\text {bcde }}$ & \multicolumn{2}{|c|}{$10.2 \pm 0.3^{\mathrm{a}}$} & \multicolumn{2}{|l|}{$8.9 \pm 0.1^{\mathrm{a}}$} & $37.0 \pm 0.3^{\mathrm{bcA}}$ & $37.0 \pm 0.3^{\mathrm{bcA}}$ \\
\hline MBY & $19.1 \pm 0.4^{\mathrm{ab}}$ & \multicolumn{2}{|c|}{$10.3 \pm 0.3^{\mathrm{a}}$} & \multicolumn{2}{|c|}{$8.8 \pm 0.1^{a}$} & $38.2 \pm 0.6^{\mathrm{abA}}$ & $38.3 \pm 0.4 \mathrm{abA}$ \\
\hline MCY & $19.0 \pm 0.3^{\mathrm{ab}}$ & \multicolumn{2}{|c|}{$10.5 \pm 0.4^{\mathrm{a}}$} & \multicolumn{2}{|c|}{$9.0 \pm 0.1^{\mathrm{a}}$} & $38.5 \pm 0.7^{\mathrm{abA}}$ & $38.5 \pm 0.5^{\mathrm{abA}}$ \\
\hline SBY & $16.6 \pm 0.4^{\mathrm{de}}$ & \multicolumn{2}{|c|}{$8.5 \pm 0.2^{\mathrm{cd}}$} & \multicolumn{2}{|l|}{$8.8 \pm 0.1^{\mathrm{a}}$} & $34.1 \pm 0.4^{\mathrm{dA}}$ & $33.7 \pm 0.4^{\mathrm{dA}}$ \\
\hline BYMo & $19.4 \pm 0.3^{\mathrm{ab}}$ & \multicolumn{2}{|c|}{$10.9 \pm 0.4 \mathrm{a}$} & \multicolumn{2}{|c|}{$9.0 \pm 0.1^{\mathrm{a}}$} & $39.3 \pm 0.4 \mathrm{aA}$ & $39.3 \pm 0.5^{\mathrm{aA}}$ \\
\hline MBYMo & $19.5 \pm 0.3^{\mathrm{ab}}$ & \multicolumn{2}{|c|}{$10.0 \pm 0.3^{\mathrm{ab}}$} & $8.8 \pm 0.1^{2}$ & & $38.3 \pm 0.4^{\mathrm{abA}}$ & $38.2 \pm 0.4^{\mathrm{abA}}$ \\
\hline MCYMo & $20.2 \pm 0.2^{\mathrm{a}}$ & 10.4 & $0.4^{a}$ & $9.0 \pm 0.2$ & & $39.4 \pm 0.3^{\mathrm{aA}}$ & $39.8 \pm 0.2^{\mathrm{aA}}$ \\
\hline SBYMo & $18.5 \pm 0.2^{\mathrm{bc}}$ & $8.1=$ & & $8.9 \pm 0.1$ & & $35.4 \pm 0.3^{\mathrm{cd} A}$ & $35.4 \pm 0.2^{\mathrm{cdA}}$ \\
\hline & & & & trasts & & & \\
\hline & & & & & & Larva-adult & \\
\hline Comparison & Larva & & Pre- & & Pupa & Male & Female \\
\hline & $\mathrm{df}=1,48$ & & $\mathrm{df}=$ & & & $\mathrm{df}=1,48$ & $\mathrm{df}=1,48$ \\
\hline NonSup. vs YM-Yeast & $\mathrm{F}=8.768$ & & $\mathrm{~F}=$ & 0.0001 & ns & $\mathrm{F}=35.83, \mathrm{P}<0.0001$ & $\mathrm{~F}=38.53, \mathrm{P}<0.0001$ \\
\hline NonSup vs Yeast only & $\mathrm{F}=0.008$ & & $\mathrm{~F}=$ & $<0.0001$ & ns & $\mathrm{F}=11.83, \mathrm{P}=0.012$ & $\mathrm{~F}=10.06, \mathrm{P}=0.025$ \\
\hline Yeast vs Molasses/yeast & $\mathrm{F}=24.5$ & 0001 & $\mathrm{~F}=$ & 1.000 & ns & $\mathrm{F}=12.17, \mathrm{P}=0.010$ & $\mathrm{~F}=19.42, \mathrm{P}<0.0001$ \\
\hline Barley vs Corn-starch & $\mathrm{F}=12.62$ & & $\mathrm{~F}=$ & 0.98 & ns & $\mathrm{F}=3.24, \mathrm{P}=0.49$ & $\mathrm{~F}=5.11, \mathrm{P}=0.22$ \\
\hline Barley vs Sorghum & $\mathrm{F}=1.83 \mathrm{C}$ & & $\mathrm{F}=$ & $<0.0001$ & ns & $\mathrm{F}=9.97, \mathrm{P}=0.026$ & $\mathrm{~F}=15.77, \mathrm{P}=0.003$ \\
\hline
\end{tabular}

Means in a column followed by the same lower-case letter are not significantly different $(\mathrm{P}<0.05$, ANOVA plus HSD). Means for both sexes within a treatment followed by the same upper-case letter are not significantly different. ns, not significantly different $(\mathrm{P}<0.05)$. BW, Barley/water; MBW, Malt/ Barley/water; MCW, Malt/Corn-starch/water; SBW, Sorghum/Barley/water; BY, Barley/brewer's yeast; MBY, Malt/Barley/brewer's yeast; MCY, Malt/Corn-starch/brewer's yeast; SBY, Sorghum/Barley/brewer's yeast; BYMo, Barley/brewer's yeast/Molasses; MBYMo, Malt/Barley/brewer's yeast/Molasses; MCYMo, Malt/Corn-starch/brewer's yeast/Molasses and SBYMo, Sorghum/Barley/Molasses. Non-supplemented diets = BW, MBW, MCW, and SBW; Yeast/Molasses + yeast-supplemented diets = BY, MBY, MCY, SBY, BYMo, MBYMo, MCYMo, and SBYMo; Yeast-based diets = BY, MBY, MCY, and SBY; Molasses-based diets = BYMo, MBYMo, MCYMo, and SBYMo; Barley-based diets = BW, BY, and BYMo; Corn-starchbased diets = MCW, MCY, and MCYMo; Sorghum-based diets = SBW, SBY, and SBYMo. NonSup. = Non-supplemented diets; YM-Yeast $=$ diets supplemented with a mixture of yeast and molasses + diets supplemented with yeast only. 


\section{Effect of diet on the larval survival, pre-pupal survival, and pupal survival of $H$. illucens}

Larval survival $(\mathrm{F}=2.13 ; \mathrm{df}=11,48 ; \mathrm{P}=0.036)$, pre-pupal survival $(\mathrm{F}=3.67 ; \mathrm{df}=11$, $48 ; \mathrm{P}=0.001)$, and pupal survival $(\mathrm{F}=2.54 ; \mathrm{df}=11,48 ; \mathrm{P}=0.013)$ were significantly affected by diet type (Fig. 1). Orthogonal contrasts between treatment groups showed no significant differences in larval survival, pre-pupal survival, and pupal survival between diets supplemented with brewers' yeast and the non-supplemented diets (Table $3)$.

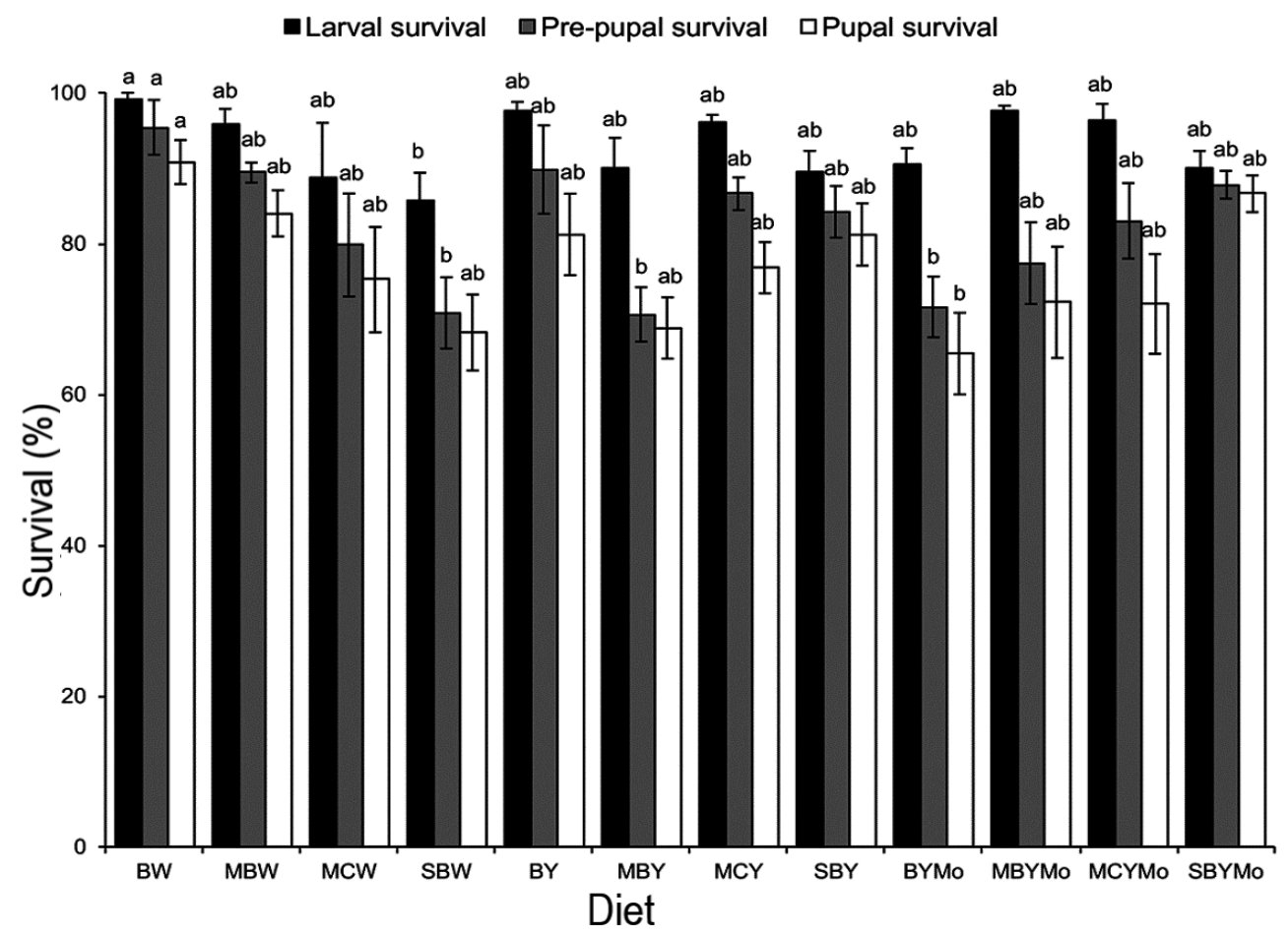

Fig. 1. Stage-specific survival of $H$. illucens reared on various larval diets. Means $( \pm$ SE) followed by the same lower-case letter for a given life stage are not significantly different across diets $(\mathrm{P}<0.05$, ANOVA, HSD). BW, Barley/water; MBW, Malt/Barley/water; MCW, Malt/Corn-starch/water; SBW, Sorghum/Barley/water; BY, Barley/brewer's yeast; MBY, Malt/Barley/brewer's yeast; MCY, Malt/Corn-starch/brewer's yeast; SBY, Sorghum/Barley/brewer's yeast; BYMo, Barley/brewer's yeast/Molasses; MBYMo, Malt/ Barley/brewer's yeast/Molasses; MCYMo, Malt/Corn-starch/brewer's yeast/Molasses and SBYMo, Sorghum/Barley/Molasses. 
Table 3. Comparison of stage-specific survival between treatment groups using orthogonal contrasts for $H$. illucens

\begin{tabular}{llll}
\hline Contrast & Larva & Pre-pupa & Pupa \\
\cline { 2 - 4 } & $\mathrm{df}=1,48$ & $\mathrm{df}=1,48$ & $\mathrm{df}=1,48$ \\
Non-supplemented vs YM-Yeast & $\mathrm{F}=0.58, \mathrm{P}=0.99$ & $\mathrm{~F}=0.88, \mathrm{P}=0.97$ & $\mathrm{~F}=1.73, \mathrm{P}=0.82$ \\
Non-supplemented vs. Yeast & $\mathrm{F}=0.36, \mathrm{P}=1.0$ & $\mathrm{~F}=0.12, \mathrm{P}=1.0$ & $\mathrm{~F}=0.52, \mathrm{P}=0.99$ \\
Yeast vs. molasses + yeast & $\mathrm{F}=0.01, \mathrm{P}=1.0$ & $\mathrm{~F}=0.88, \mathrm{P}=0.97$ & $\mathrm{~F}=0.70, \mathrm{P}=0.99$ \\
Barley vs. Corn-starch & $\mathrm{F}=0.69, \mathrm{P}=0.99$ & $\mathrm{~F}=0.49, \mathrm{P}=1.0$ & $\mathrm{~F}=1.20, \mathrm{P}=0.92$ \\
Barley vs. Sorghum & $\mathrm{F}=7.46, \mathrm{P}=0.078$ & $\mathrm{~F}=1.77, \mathrm{P}=0.81$ & $\mathrm{~F}=0.01, \mathrm{P}=1.0$ \\
\hline
\end{tabular}

Non-supplemented diets = BW, MBW, MCW, and SBW; YM-Yeast (all diets supplemented with a mixture of yeast and molasses or yeast only) = BY, MBY, MCY, SBY, BYMo, MBYMo, MCYMo, and SBYMo; Yeast-based diets = BY, MBY, MCY, and SBY; Molasses/yeast diets = BYMo, MBYMo, MCYMo, and SBYMo; Barley-based diets = BW, BY, and BYMo; Corn-starch = MCW, MCY, and MCYMo; Sorghum-based diets = SBW, SBY, and SBYMo.

\section{Effect of larval diet on pre-oviposition period, fecundity, and longevity of $\mathrm{H}$. illucens}

Pre-oviposition time of adult $H$. illucens provided with a $10 \%$ sugar solution $(\mathrm{F}=2.36$; $\mathrm{df}=1,75 ; \mathrm{P}=0.08)$ or water $(\mathrm{F}=0.38 ; \mathrm{df}=1,75 ; \mathrm{P}=0.46)$ was not significantly affected by larval diet (Table 4). On all diets, starved adult female flies failed to reach oviposition age as the female could only survive for a maximum of 6 days.

Table 4. Pre-oviposition period (mean \pm SE) of female H. illucens fed on sugar solution or water

\begin{tabular}{lcc}
\hline \multirow{2}{*}{ Larval diet } & \multicolumn{2}{c}{ Pre-oviposition period (days) } \\
\cline { 2 - 3 } & Sugar solution & Water \\
\hline BW & $9.5 \pm 0.5^{\text {aA }}$ & $9.2 \pm 1.1^{\mathrm{aA}}$ \\
MBW & $8.8 \pm 0.5^{\mathrm{aA}}$ & $9.6 \pm 0.9^{\mathrm{aA}}$ \\
MCW & $10.0 \pm 1.5^{\mathrm{aA}}$ & $11.0 \pm 2.0^{\mathrm{aA}}$ \\
SBW & $8.0 \pm 0.0^{\mathrm{aA}}$ & $7.3 \pm 0.8^{\mathrm{aA}}$ \\
BY & $13.5 \pm 3.5^{\mathrm{aA}}$ & $8.2 \pm 0.7^{\mathrm{aB}}$ \\
MBY & $9.8 \pm 0.3^{\mathrm{aA}}$ & $10.2 \pm 2.4^{\mathrm{aA}}$ \\
MCY & $9.0 \pm 0.6^{\mathrm{aA}}$ & $7.8 \pm 0.5^{\mathrm{aA}}$ \\
BYMo & $10.5 \pm 0.5^{\mathrm{aA}}$ & $7.5 \pm 0.5^{\mathrm{aA}}$ \\
MBYMo & $10.2 \pm 1.1^{\mathrm{aA}}$ & $8.0 \pm 1.1^{\mathrm{aA}}$ \\
MCYMo & $10.2 \pm 1.0^{\mathrm{aA}}$ & $8.4 \pm 0.4^{\mathrm{aA}}$ \\
SBYMo & $10.7 \pm 3.7^{\mathrm{aA}}$ & $7.0 \pm 0.3^{\mathrm{aA}}$ \\
\hline
\end{tabular}

Means within a column followed by the same lower-case superscript are not significantly different $(\mathrm{P}<$ $0.05, \mathrm{HSD})$. Means within a row followed by the same upper-case superscript are not significantly different between sugar- and water-fed female H. illucens for each diet $(\mathrm{P}<0.05$, t-test). 
The fecundity of female flies provided with sugar solution was similar $(\mathrm{F}=0.73$; $\mathrm{df}=$ $10,27 ; \mathrm{P}=0.69)$ across dietary treatments but varied significantly from diets provided with water $(\mathrm{F}=2.89 ; \mathrm{df}=10,38 ; \mathrm{P}=0.010)$ (Fig. 2). The fecundity of female flies was higher for almost all the diets supplemented with brewers' yeast or molasses/brewers' yeast than for the non-supplemented diets (Fig. 2). Egg production was similar $(\mathrm{F}=0.88 ; \mathrm{df}=1,85 ; \mathrm{P}=0.35)$ for female flies provided with water or sugar solution (Fig. 2). There was a significant interaction between adult food and sex of $H$. illucens $(\mathrm{F}=5.99 ; \mathrm{df}=2,806 ; \mathrm{P}=0.004)$. However, no significant interaction was observed between larval diet and sex on adult fly longevity $(\mathrm{F}=0.80 ; \mathrm{df}=11,806, \mathrm{P}=0.64)$. The longevity of both starved (unfed) male and female H. illucens was significantly lower ( $\mathrm{F}=208.79$; $\mathrm{df}=2$, 806; $\mathrm{P}<0.001)$ compared to flies that were provided with sugar solution or water (Fig. 3).

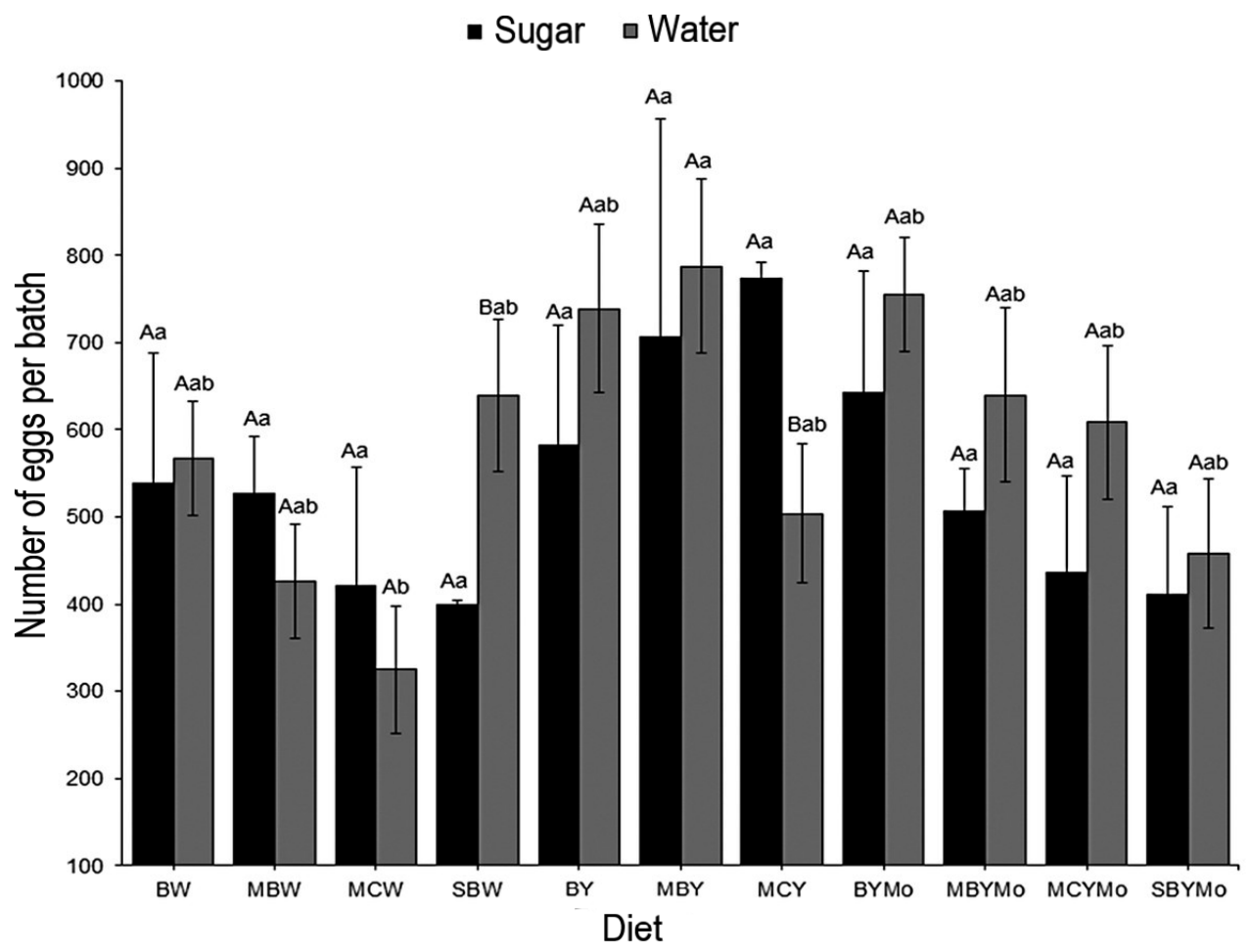

Fig. 2. Mean number of eggs laid per adult female $H$. illucens reared on different larval diets. Bars $( \pm \mathrm{SE})$ followed by different upper-case letters are significantly different between sugar- and water-fed flies for each diet. Bars followed by different lower-case letters are significantly different among diets $(P<0.05$, HSD). BW, Barley/water; MBW, Malt/Barley/water; MCW, Malt/Corn-starch/water; SBW, Sorghum/ Barley/water; BY, Barley/brewer's yeast; MBY, Malt/Barley/brewer's yeast; MCY, Malt/Corn-starch/ brewer's yeast; BYMo, Barley/brewer's yeast/Molasses; MBYMo, Malt/Barley/brewer's yeast/Molasses; MCYMo, Malt/Corn-starch/brewer's yeast/Molasses and SBYMo, Sorghum/Barley/Molasses. 

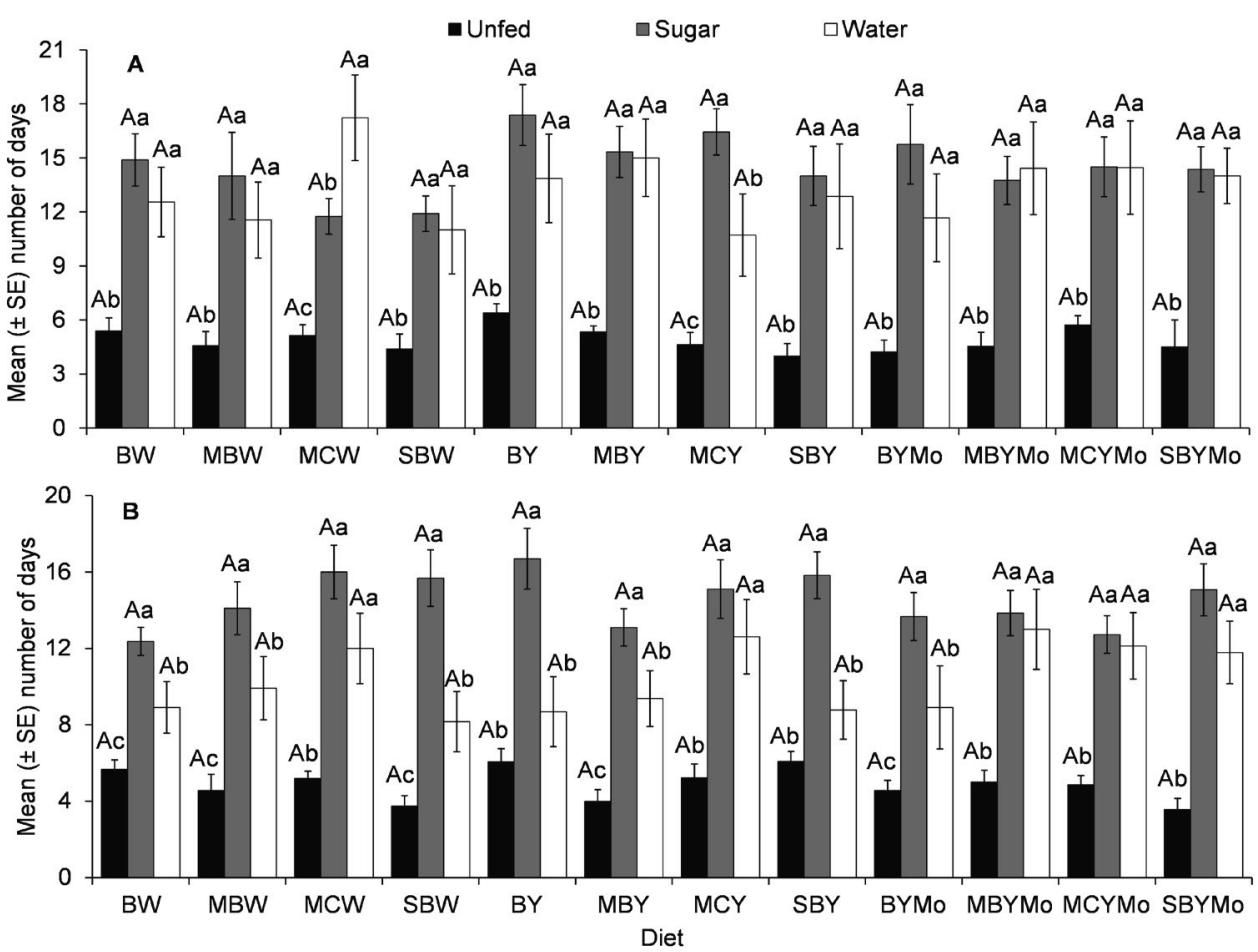

Fig. 3. Longevity (mean \pm SE) of adult male (A) and female (B) H. illucens fed on different diets as larvae and provided with sugar solution or water or remaining unfed as adults. Bars followed by the same upper-case letter are not significantly different among diets $(\mathrm{P}<0.05$, HSD). Bars followed by different lower-case letters are significantly different among unfed, sugar-fed, and water-fed flies for each diet $(\mathrm{P}<0.05$, HSD). BW, Barley/water; MBW, Malt/Barley/water; MCW, Malt/Corn-starch/water; SBW, Sorghum/ Barley/water; BY, Barley/brewer's yeast; MBY, Malt/Barley/brewer's yeast; MCY, Malt/Corn-starch/ brewer's yeast; SBY, Sorghum/Barley/brewer's yeast; BYMo, Barley/brewer's yeast/Molasses; MBYMo, Malt/Barley/brewer's yeast/Molasses; MCYMo, Malt/Corn-starch/brewer's yeast/Molasses and SBYMo, Sorghum/Barley/Molasses.

\section{Effect of larval diet on wet weight of $H$. illucens life stages}

Fifth instar larval weight of $H$. illucens was significantly different $(\mathrm{F}=5.46$; $\mathrm{df}=11,48$; $\mathrm{P}<0.001)$ among diets tested. Larval diet significantly affected weight of pre-pupa $(\mathrm{F}=$ 8.004; $\mathrm{df}=11,48 ; \mathrm{P}<0.001)$, pupa $(\mathrm{F}=9.08 ; \mathrm{df}=11,48 ; \mathrm{P}<0.001)$, adult male $(\mathrm{F}=$ 39.40; $\mathrm{df}=1,96 ; \mathrm{P}<0.001)$, and female $(\mathrm{F}=89.40 ; \mathrm{df}=1,96 ; \mathrm{P}<0.001)$ (Figs. 4 and 5). Larvae fed on non-supplemented diets weighed significantly $(\mathrm{F}=106.3$; $\mathrm{df}=1,57$; $\mathrm{P}<0.001$ ) less than those fed on diets supplemented with brewers' yeast (Table 5). The weight of larvae fed on diets supplemented with brewer's yeast or molasses/brewers' yeast was not significantly different, whereas weight of pre-pupae differed significantly between non-supplemented diets and diets supplemented with either brewer's yeast or molasses/brewers' yeast ('Table 5). 

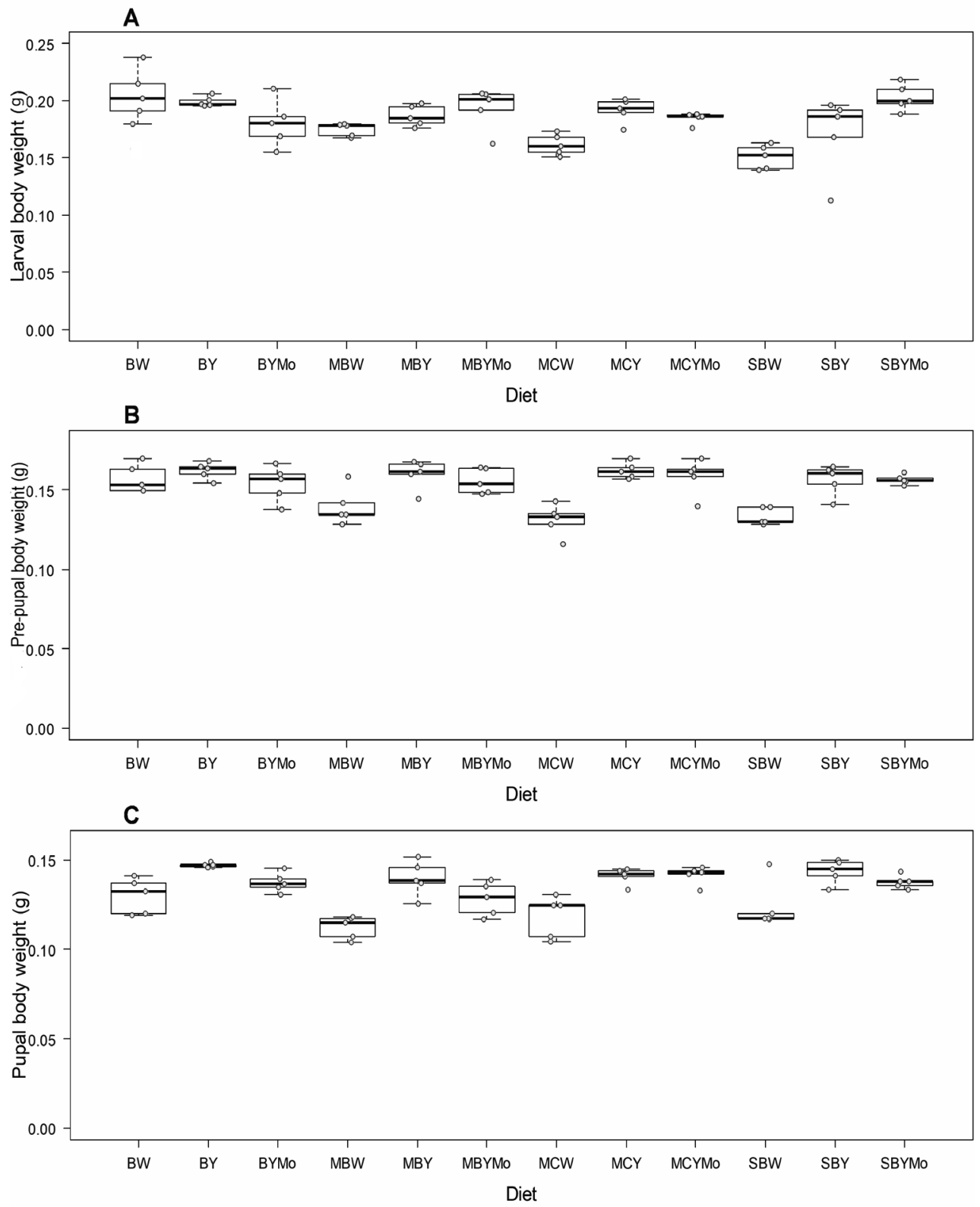

Fig. 4. Boxplots showing wet weight (g) of larval (A), pre-pupal (B), and pupal (C) stages of H. illucens reared on different diets. The middle quartile or median (the line that divides the box into two parts) marks the midpoint of the data. The middle box (inter-quartile range) represents $50 \%$ of the data for each diet. BW, Barley/water; MBW, Malt/Barley/water; MCW, Malt/Corn-starch/water; SBW, Sorghum/Barley/water; BY, Barley/brewer's yeast; MBY, Malt/Barley/brewer's yeast; MCY, Malt/Corn-starch/brewer's yeast; SBY, Sorghum/Barley/brewer's yeast; BYMo, Barley/brewer's yeast/Molasses; MBYMo, Malt/Barley/ brewer's yeast/Molasses; MCYMo, Malt/Corn-starch/brewer's yeast/Molasses and SBYMo, Sorghum/ Barley/Molasses. 


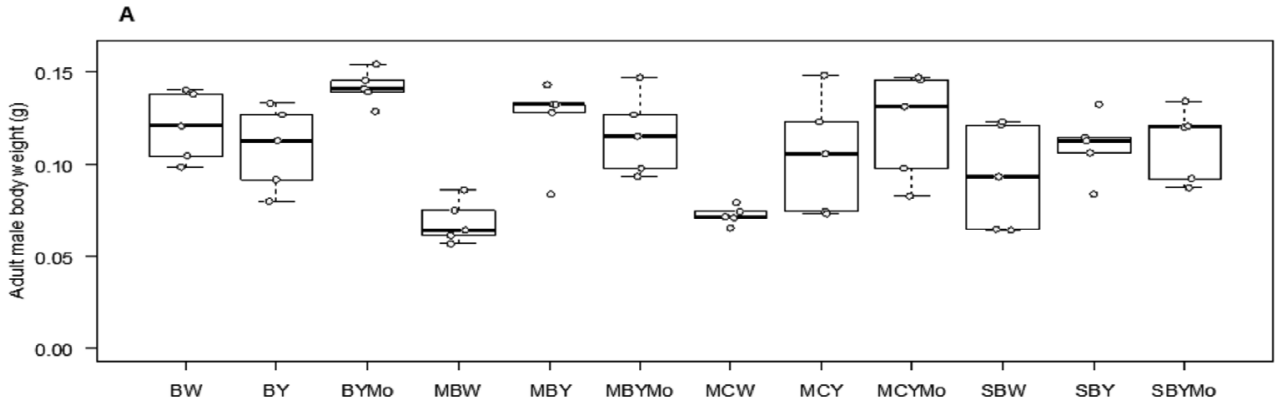

B

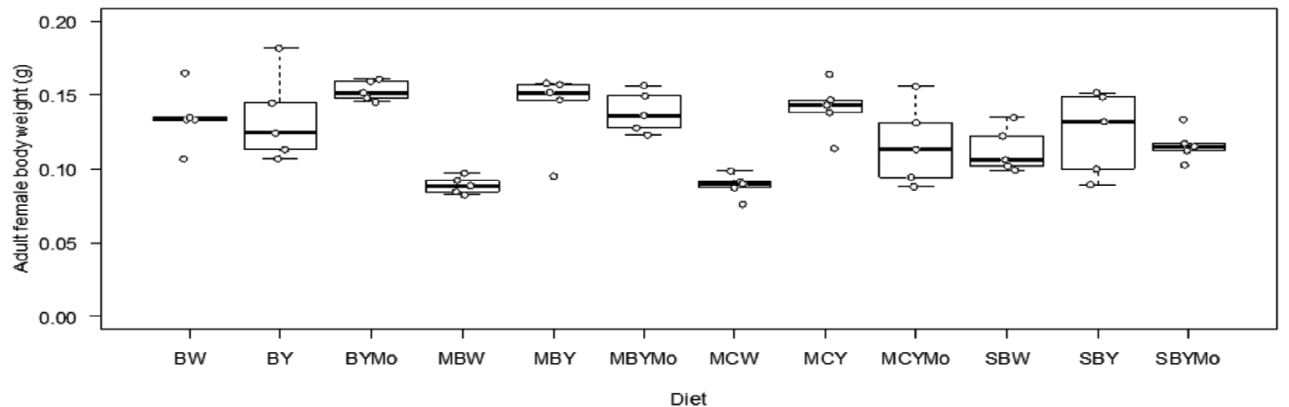

Fig. 5. Boxplots showing wet weight (g) of adult male (A) and female (B) H. illucens reared on various diets. The middle quartile or median (the line that divides the box into two parts) marks the midpoint of the data. The middle box (inter-quartile range) represents $50 \%$ of the data for each diet. BW, Barley/water; MBW, Malt/Barley/water; MCW, Malt/Corn-starch/water; SBW, Sorghum/Barley/water; BY, Barley/brewer's yeast; MBY, Malt/Barley/brewer's yeast; MCY, Malt/Corn-starch/brewer's yeast; SBY, Sorghum/Barley/ brewer's yeast; BYMo, Barley/brewer's yeast/Molasses; MBYMo, Malt/Barley/brewer's yeast/Molasses; MCYMo, Malt/Corn-starch/brewer's yeast/Molasses and SBYMo, Sorghum/Barley/Molasses.

Table 5. Comparison of mean wet weight for different life stages of $H$. illucens between treatment groups using orthogonal contrasts

\begin{tabular}{llllll}
\hline \multirow{2}{*}{ Contrast } & Larva & Pre-pupa & Pupa & Male adult & Female adult \\
\cline { 2 - 5 } & $\mathrm{df}=1,48$ & $\mathrm{df}=1,48$ & $\mathrm{df}=1,48$ & $\mathrm{df}=1,48$ & $\mathrm{df}=1,48$ \\
\hline Non-supplemented vs YM- & $\mathrm{F}=12.80$, & $\mathrm{F}=56.19$, & $\mathrm{F}=69.92$, & $\mathrm{F}=23.33$, & $\mathrm{F}=24.88$, \\
Yeast & $\mathrm{P}=0.001$ & $\mathrm{P}<0.0001$ & $\mathrm{P}<0.0001$ & $\mathrm{P}<0.0001$ & $\mathrm{P}<0.0001$ \\
Non-supplemented vs & $\mathrm{F}=7.78$, & $\mathrm{F}=52.33$, & $\mathrm{F}=72.92$, & $\mathrm{F}=11.66$, & $\mathrm{F}=21.76$, \\
Yeast only & $\mathrm{P}=0.07$ & $\mathrm{P}<0.0001$ & $\mathrm{P}<0.0001$ & $\mathrm{P}=0.013$ & $\mathrm{P}<0.0001$ \\
Yeast vs Molasses/yeast & $\mathrm{F}=0.38$, & $\mathrm{F}=2.20$, & $\mathrm{F}=6.73$, & $\mathrm{F}=2.36$, & $\mathrm{F}=0.48$, \\
& $\mathrm{P}=1.0$ & $\mathrm{P}=0.71$ & $\mathrm{P}=0.10$ & $\mathrm{P}=0.68$ & $\mathrm{P}=1.0$ \\
Barley vs Corn-starch & $\mathrm{F}=7.07$, & $\mathrm{F}=5.03$, & $\mathrm{F}=2.37$, & $\mathrm{F}=9.47$, & $\mathrm{F}=12.11$, \\
& $\mathrm{P}=0.09$ & $\mathrm{P}=0.23$ & $\mathrm{P}=0.67$ & $\mathrm{P}=0.038$ & $\mathrm{P}=0.012$ \\
Barley vs Sorghum & $\mathrm{F}=11.83$, & $\mathrm{F}=7.77$, & $\mathrm{F}=1.12$, & $\mathrm{F}=5.75$, & $\mathrm{F}=9.99$, \\
& $\mathrm{P}=0.013$ & $\mathrm{P}=0.07$ & $\mathrm{P}=0.94$ & $\mathrm{P}=0.17$ & $\mathrm{P}=0.022$ \\
\hline
\end{tabular}

Non-supplemented diets = BW, MBW, MCW and SBW; YM-Yeast (All diets supplemented with a mixture of yeast and molasses or yeast only) = BY, MBY, MCY, SBY, BYMo, MBYMo, MCYMo, and SBYMo; Yeast-based diets = BY, MBY, MCY, and SBY; Molasses/yeast diets = BYMo, MBYMo, MCYMo, and SBYMo; Barley = BW, BY, and BYMo; Corn-starch-based diets = MCW, MCY, and MCYMo; Sorghum-based diets = SBW, SBY, and SBYMo. 


\section{Discussion}

This study provides insight into the effects of mixing different waste types on $H$. illucens growth performance. We observed a shorter larval developmental duration in $H$. illucens reared on the 12 diet types compared to that documented in the literature (Cammack \& Tomberlin, 2017; Myers et al., 2008; Nguyen et al., 2013; Oonincx et al., 2015). The larval developmental time in our study was 5-25 days shorter (17-21 days) than recorded in the studies mentioned above (21-46 days), a record similar to that reported by (Barragán-Fonseca, 2018). Differences in developmental time between studies may have been due to variation in the quantity and/or quality of the larval diet. A reduction in larval food supply could delay $H$. illucens larval development up to 4 months (Furman et al., 1959). Other factors that affect larval development include larval density, larval feeding rate, and $\mathrm{pH}$ of the feeding medium (Barragán-Fonseca, 2018; Morrison \& King, 1977; Paz et al., 2015) as well as the physical texture of the feeding medium (Gobbi et al., 2013). Pre-pupal recovery, pupal recovery, and adult emergence of $H$. illucens reared on diets supplemented with brewers' yeast or molasses/brewery yeast compared favorably with, and sometimes exceeded, those obtained on the non-supplemented BSG diets. Percentage pupal recovery obtained for H. illucens was well within the range reported by several authors on a variety of rearing substrates (Myers et al., 2008; Nguyen et al., 2013; Oonincx et al., 2015). Percentage emergence of adults for the different diet types in our study was high, which agrees with previous studies (Cammack \& Tomberlin, 2017; Tomberlin et al., 2002). Considerably variable patterns have been reported for other dipterans like Bactrocera dorsalis (Hendel) and Zeugodacus cucurbitae (Coquillett) (Diptera: Tephritidae) that successfully completed development in diets containing the local waste stream, brewers' yeast (Chang et al., 2007; Chang et al., 2004).

In our study, supplementation of BSGs with either brewers' yeast or molasses/brewers' yeast outperformed the spent grain diets mixed with water only in terms of increased larval, pre-pupal, pupal, and adult weight. The weight measurements of the different life stages observed in our study were comparable to those reported in previous research (Nguyen et al., 2013, 2015; Tomberlin et al., 2009; Tomberlin et al., 2002). These studies report means of larval weight ranging from 0.11 to $0.23 \mathrm{~g}$, pre-pupal weight of $0.07-0.22 \mathrm{~g}$ and adult weight of $0.04-0.11 \mathrm{~g}$, which are all similar to our findings. The stage-specific weight increase observed in our study has been viewed as a useful quality control criterion in insect mass-rearing since it is correlated with mating success. This result may be useful in the management of waste in a traditional brewing system which often generates very little (if any) value and may have negative impacts if the brewery must pay to get rid of waste water and spent grains. Adult flies from heavy pupae experience higher mating success than those from lower-weight pupae (Churchill-Stanland et al., 1986). Large flies exhibit greater flight ability than small flies (Sharp et al., 1983). 
The difference in body weight observed in our study may be explained by the quality of diet and the resulting critical weight, one of the physiological factors that regulate variation in body size. The critical weight has been defined as the minimal mass at which further growth is not necessary for a normal time course to pupation (Davidowitz et al., 2003). Previous studies show that insects reared on low quality diets have low critical weight values (Davidowitz et al., 2003; Davidowitz \& Nijhout, 2004).

Unlike the development of immature life stages, adult parameters (fecundity and adult longevity) were clearly affected by diet type on which the larvae were reared except for pre-oviposition duration. Previous studies have shown that in females, the nutritional quality of the diet (especially higher protein-based diets) ingested during the immature phase improves adult performance and affects ovarian development leading to higher fecundity rates (Cangussu \& Zucoloto, 1993, 1997; Cangussu \& Zucoloto, 1995) (Fernandes-da-Silva \& Zucoloto, 1997). Large protein-fed insect males are more likely to have their sperm stored in the females (Taylor \& Yuval, 1999).

Dietary effects on body size could be mediated through alterations in the quantity of nutrients stored as lipids and as proteins prior to pupariation (Nestel \& Nemny-Lavy, 2008; Nestel et al., 2004). Nutrient composition of the brewers' yeast (Saccharomyces cerevisiae) is about $45 \%$ crude protein (Raven \& Walker, 1980) with an excellent lysine (amino acid) profile (Huige, 2006). BSGs contain $21-31 \%$ crude protein, and approximately 2,080 kcal/kg metabolizable energy on DM basis (National Research Council, 1994; Westendorf \& Wohlt, 2002), but it is a poor source of other minerals (Hussain et al., 2010; Westendorf \& Wohlt, 2002). Molasses is a source of readily available dietary energy (Van Niekerk, 1981), niacin, and pantothenic acid (Cleasby, 1963). We observed that diets supplemented with brewers' yeast or molasses/brewers' yeast resulted in slightly higher number of eggs produced than the non-supplemented diets, a trend similar to that observed by (Barragán-Fonseca, 2018) who recorded heavier H. illucens adults and higher egg production for diets with higher dietary protein contents.

Adult longevity of male and female flies was similar across diets when flies were starved. This implies that the nutritional quality of the larval diets appears to have had minimal effects on life span of the flies and significant impact on egg production (no eggs were laid). Water, unlike food, is essential for adult H. illucens to reproduce (Sheppard et al., 2002), which might explain why less vigorous and dehydrated adults were unable to lay eggs. In our experiment, adult longevity increased with $10 \%$ sugar solution or water supply as food in separate treatments. The longevity of male and female flies varied on each diet type when adult flies were subjected to water only or 10\% sugar solution treatments. Although we did not evaluate the effects of protein and carbohydrate on adult $H$. illucens longevity, previous research has indicated that dietary protein and carbohydrate contents are important and affect both larval and adult performance of H. illucens (Barragán-Fonseca, 2018). 


\section{Conclusion}

The successful development of $H$. illucens on all 12 diet types clearly indicates the high nutrient quality of the brewery by-products. Based on quality control parameters of $H$. illucens reared on the combination of these agro-industrial waste streams, our values are comparable to, and sometimes higher than, those documented in literature on other organic wastes. Thus, the study at hand confirms the application potential of the black soldier fly in industrial solid waste management and the importance to investigate future large-scale mass rearing possibilities. The combination of waste treatment capacity together with generation of a valuable product, that is, a high-quality cheap alternative protein source for animal feeds, instead of discarding the waste into open plots, makes the black soldier fly technology a highly promising tool for waste management and feed production. The conversion of organic waste into high nutritional biomass has now opened new economic opportunities for municipalities and offers small entrepreneurs the possibility of income generation without high investment costs. Concurrently, this reduces the environmental impact of organic waste stream considered as one of the serious environmental problems confronting urban governments in low- and middleincome countries in Sub-Saharan Africa. Hence, composting by utilizing black soldier fly larvae should be recommended in Kenya and other African countries as a sustainable method of dealing with organic municipal waste that embraces the concept of a circular economy. Being a financially more attractive option for municipal waste management, private sectors, with stronger focus in business opportunities and marketing approaches should be in the center of attention (Wang et al., 2008).

\section{Acknowledgments}

We thank Joshua Wambua, Rachami Isaiah E. and Faith Nyamu Wamurango for their substantial contribution and technical support during data collection. This study was financially supported by the Netherlands Organization for Scientific Research (NWO)WOTRO Science for Global Development (ILIPA - W 08.250.202). Authors declare no conflicts of interest. 


\section{References}

Aliyu, S., \& Bala, M. (2011). Brewer's spent grain: A review of its potentials and applications. African Journal of Biotechnology, 10, 324-331.

Association of Official Analytical Chemists (AOAC). (1990). Official methods of analysis of the AOAC International: Association of Official Analytical Chemists.

Barragán-Fonseca, K. B. (2018). Flies are what they eat: Tailoring nutrition of black soldier fly (Hermetia illucens L.) for larval biomass production and fitness. PhD thesis, Wageningen University, Wageningen.

Beskin, K. V., Holcomb, C. D., Cammack, J. A., Crippen, T. L., Knap, A. H., Sweet, S. T., \& Tomberlin, J. K. (2018). Larval digestion of different manure types by the black soldier fly (Diptera: Stratiomyidae) impacts associated volatile emissions. Waste Management, 74, 213-220.

Blackmore, M. S., \& Lord, C. C. (2000). The relationship between size and fecundity in Aedes albopictus. Journal of Vector Ecology, 25, 212-217.

Booth, D. C., \& Sheppard, C. (1984). Oviposition of the black soldier fly, Hermetia illucens (Diptera, Stratiomyidae) - eggs, masses, timing, and site characteristics. Environmental Entomology, 13, 421-423.

Calvert, C. (1991). Fiber utilization by swine. In E. Miller, D. Ullrey, \& A. Lewis (Eds.), Swine nutrition (pp. 285-296). Stoneham: Butterworth-Heinemann.

Cammack, J. A., \& Tomberlin, J. K. (2017). The impact of diet protein and carbohydrate on select life-history traits of the black soldier fly Hermetia illucens (L.) (Diptera: Stratiomyidae). Insects, 8, 56.

Cangussu, J., \& Zucoloto, F. (1993). Influence of partial malnutrition on egg production by Ceratitis capitata (Diptera, Tephritidae). Revista Brasileira de Biologia, 53, 155-158.

Cangussu, J., \& Zucoloto, F. (1997). Effect of protein sources on fecundity, food acceptance, and sexual choice by Ceratitis capitata (Diptera, Tephritidae). Revista Brasileira de Biologia, 57, 611-618.

Cangussu, J. A., \& Zucoloto, F. S. (1995). Self-selection and perception threshold in adult females of Ceratitis capitata (Diptera, Tephritidae). Journal of Insect Physiology, 41, 223-227.

Chang, C. L., Caceres, C., \& Ekesi, S. (2007). Life history parameters of Ceratitis capitata (Diptera: Tephritidae) reared on liquid diets. Annals of the Entomological Society of America, 100, 900906.

Chang, C. L., Caceres, C., \& Jang, E. B. (2004). A novel liquid larval diet and its rearing system for melon fly, Bactrocera cucurbitae (Diptera : Tephritidae). Annals of the Entomological Society of America, 97, 524-528.

Churchill-Stanland, C., Stanland, R., Wong, T. T., Tanaka, N., McInnis, D. O., \& Dowell, R. V. (1986). Size as a factor in the mating propensity of Mediterranean fruit flies, Ceratitis capitata (Diptera: Tephritidae), in the laboratory. Journal of Economic Entomology, 79, 614-619.

Cleasby, T. (1963). The feeding value of molasses. South African Sugar Journal, 47, 360.

Davidowitz, G., D’Amico, L. J., \& Nijhout, H. F. (2003). Critical weight in the development of insect body size. Evolution and Development 5, 188-197.

Davidowitz, G., \& Nijhout, H. F. (2004). The physiological basis of reaction norms: The interaction among growth rate, the duration of growth and body size. Integrative and Comparative Biology, 44, 443-449. 
Diener, S., Zurbrügg, C., Gutiérrez, F. R., Nguyen, D. H., Morel, A., Koottatep, T., \& Tockner, K. (2011). Black soldier fly larvae for organic waste treatment-prospects and constraints. Paper presented at the 2nd international conference on solid waste management in the developing countries, Khulna, Bangladesh.

Diener, S., Zurbrugg, C., \& Tockner, K. (2009). Conversion of organic material by black soldier fly larvae: establishing optimal feeding rates. Waste Management \& Research, 27, 603-610.

Dobermann, D., Swift, J. A., \& Field, L. M. (2017). Opportunities and hurdles of edible insects for food and feed. Nutrition Bulletin, 42, 293-308.

Dortmans, B., Diener, S., Bart, V., \& Zurbrügg, C. (2017). Black soldier fly biowaste processing: a Step-by-Step Guide. Dübendorf, Switzerland: Eawag - Swiss Federal Institute of Aquatic Science and Technology.

Erickson, M. C., Islam, M., Sheppard, C., Liao, J., \& Doyle, M. P. (2004). Reduction of Escherichia coli $\mathrm{O} 157$ : $\mathrm{H} 7$ and Salmonella enterica serovar enteritidis in chicken manure by larvae of the black soldier fly. Journal of Food Protection, 67, 685-690.

Evans, A. (2009). The Feeding of the Nine Billion: Global Food Security for the 21st Century. London: Royal Institute of International Affairs (Chatham House).

Farhat, A., Normand, L., Chavez, E. R., \& Touchburn, S. P. (2001). Comparison of growth performance, carcass yield and composition, and fatty acid profiles of Pekin and Muscovy ducklings fed diets based on food wastes. Canadian Journal of Animal Science, 81, 107-114.

Fernandes-da-Silva, P. G., \& Zucoloto, F. S. (1997). Effect of host nutritive value on egg production by Ceratitis capitata (Diptera, Tephritidae). Journal of Insect Physiology, 43, 939-943.

Finke, M. D. (2007). Estimate of chitin in raw whole insects. Zoo Biology, 26, 105-115.

Furman, D. P., Young, R. D., \& Catts, E. P. (1959). Hermetia illucens (Linnaeus) as a factor in the natural control of Musca domestica Linnaeus. Journal of Economic Entomology, 52, 917-921.

Ganguly, A., Chakravorty, R., Das, M., Gupta, M., Mandal, D. K., Haldar, P., . . Moreno, J. M. P. (2013). A preliminary study on the estimation of nutrients and anti-nutrients in Oedaleus abruptus (Thunberg)(Orthoptera: Acrididae). International Journal of Nutrition and Metabolism, $5,50-56$.

Gasco, L., Henry, M., Piccolo, G., Marono, S., Gai, F., Renna, M., . . Chatzifotis, S. (2016). Tenebrio molitor meal in diets for European sea bass (Dicentrarchus labrax L.) juveniles: Growth performance, whole body composition and in vivo apparent digestibility. Animal Feed Science and Technology, 220, 34-45.

Gobbi, P., Martinez-Sanchez, A., \& Rojo, S. (2013). The effects of larval diet on adult life-history traits of the black soldier fly, Hermetia illucens (Diptera: Stratiomyidae). European Journal of Entomology, 110, 461-468.

Henry, M., Gasco, L., Piccolo, G., \& Fountoulaki, E. (2015). Review on the use of insects in the diet of farmed fish: Past and future. Animal Feed Science and Technology, 203, 1-22.

Herrero, M., Wirsenius, S., Henderson, B., Rigolot, C., Thornton, P., Havlík, P., . . Gerber, P. J. (2015). Livestock and the environment: what have we learned in the past decade? Annual Review of Environment and Resources, 40, 177-202.

Holmes, L. A., Vanlaerhoven, S. L., \& Tomberlin, J. K. (2013). Substrate effects on pupation and adult emergence of Hermetia illucens (Diptera: Stratiomyidae). Environmental Entomology, $42,370-374$.

Hoornweg, D., \& Bhada-Tata, P. (2012). What a waste: a global review of solid waste management (Vol. 15). Washington, DC: World Bank. 
Huige, N. J. (2006). Brewery by-products and effluents. In G. Stewart, G \& F. G. Priest (Eds.), Handbook of brewing (2nd Edition, pp. 656-713). Boca Raton: CRC Press.

Hussain, J., Ullah, R., Rehman, N. U., Khan, A. L., Muhammad, Z., Khan, F. U., . . Anwar, S. (2010). Endogenous transitional metal and proximate analysis of selected medicinal plants from Pakistan. Journal of Medicinal Plants Research, 4, 267-270.

Japan International Cooperation Agency (JICA). (2010). Preparatory survey for integrated solid waste management in Nairobi City in the Republic of Kenya: final report. Japan International Cooperation Agency (JICA). Retrieved from: http://open_jicareport.jica.go.jp/ pdf/12005443.pdf, July 8, 2018.

Ji, Y. J., Liu, H. N., Kong, X. F., Blachier, F., Geng, M. M., Liu, Y. Y., \& Yin, Y. L. (2016). Use of insect powder as a source of dietary protein in early-weaned piglets. Journal of Animal Science, 94, 111-116.

Kasozi, A., \& von Blottnitz, H. (2010). Solid waste management in Nairobi: A situation analysis technical document accompanying the integrated solid waste management plan University of Cape Town. Retrieved from: www.ecopost.co.ke/assets/pdf/nairobi_solid_waste.pdf, July 8, 2018.

Kelemu, S., Niassy, S., Torto, B., Fiaboe, K., Affognon, H., Tonnang, H., . . Ekesi, S. (2015). African edible insects for food and feed: inventory, diversity, commonalities and contribution to food security. Journal of Insects as Food and Feed, 1, 103-119.

Lardé, G. (1990). Recycling of coffee pulp by Hermetia illucens (Diptera, Stratiomyidae) larvae. Biological Wastes, 33, 307-310.

Li, Q., Zheng, L., Qiu, N., Cai, H., Tomberlin, J. K., \& Yu, Z. (2011). Bioconversion of dairy manure by black soldier fly (Diptera: Stratiomyidae) for biodiesel and sugar production. Waste Management, 31, 1316-1320.

Liguori, R., Soccol, C., Porto de Souza Vandenberghe, L., Woiciechowski, A., \& Faraco, V. (2015). Second generation ethanol production from brewers' spent grain. Energies, 8, 2575-2586.

Liland, N. S., Biancarosa, I., Araujo, P., Biemans, D., Bruckner, C. G., Waagbo, R., . . Lock, E. J. (2017). Modulation of nutrient composition of black soldier fly (Hermetia illucens) larvae by feeding seaweed-enriched media. PLOS ONE, 12, e0183188.

Lock, E., Arsiwalla, T., \& Waagbø, R. (2016). Insect larvae meal as an alternative source of nutrients in the diet of A tlantic salmon (Salmo salar) postsmolt. Aquaculture Nutrition, 22, 1202-1213.

Makkar, H. P. S., Tran, G., Henze, V., \& Ankers, P. (2014). State-of-the-art on use of insects as animal feed. Animal Feed Science and Technology, 197, 1-33.

McDonald, P., Edwards, R., Greenhalgh, J., \& Morgan, C. (2002). Animal nutrition (6th Ed.). Harlow: Pearson education.

Meneguz, M., Schiavone, A., Gai, F., Dama, A., Lussiana, C., Renna, M., \& Gasco, L. (2018). Effect of rearing substrate on growth performance, waste reduction efficiency and chemical composition of black soldier fly (Hermetia illucens) larvae. Journal of the Science of Food and Agriculture, 98, 5776-5784.

Moreau, J., Benrey, B., \& Thiéry, D. (2006). Grape variety affects larval performance and also female reproductive performance of the European grapevine moth Lobesia botrana (Lepidoptera: Tortricidae). Bulletin of Entomological Research, 96, 205-212.

Morrison, R. K., \& King, E. G. (1977). Mass production of natural enemies. In R. L. Ridgway \& S. B. Vinson (Eds.), Biological control by augmentation of natural enemies (pp. 183-217). 
Boston, MA: Springer.

Mottet, A., de Haan, C., Falcucci, A., Tempio, G., Opio, C., \& Gerber, P. (2017). Livestock: On our plates or eating at our table? A new analysis of the feed/food debate. Global Food Security, 14, 1-8.

Myers, H. M., Tomberlin, J. K., Lambert, B. D., \& Kattes, D. (2008). Development of black soldier fly (Diptera: Stratiomyidae) larvae fed dairy manure. Environmental Entomology, 37, $11-15$.

Nakamura, S., Ichiki, R. T., Shimoda, M., \& Morioka, S. (2016). Small-scale rearing of the black soldier fly, Hermetia illucens (Diptera: Stratiomyidae), in the laboratory: low-cost and yearround rearing. Applied Entomology and Zoology, 51, 161-166.

National Research Council. (1994). Nutrient requirements of poultry: National Academies Press.

Nestel, D., \& Nemny-Lavy, E. (2008). Nutrient balance in medfly, Ceratitis capitata, larval diets affects the ability of the developing insect to incorporate lipid and protein reserves. Entomologia Experimentalis et Applicata, 126, 53-60.

Nestel, D., Nemny-Lavy, E., \& Chang, C. L. (2004). Lipid and protein loads in pupating larvae and emerging adults as affected by the composition of Mediterranean fruit fly (Ceratitis capitata) meridic larval diets. Archives of Insect Biochemistry and Physiology: Published in Collaboration with the Entomological Society of America, 56, 97-109.

Newman, P., \& Jennings, I. (2008). Cities as sustainable ecosystems: Principles and practices: Island Press.

Nguyen, T. T., Tomberlin, J. K., \& Vanlaerhoven, S. (2013). Influence of resources on Hermetia illucens (Diptera: Stratiomyidae) larval development. Journal of Medical Entomology, 50, 898906.

Nguyen, T. T., Tomberlin, J. K., \& Vanlaerhoven, S. (2015). Ability of black soldier fly (Diptera: Stratiomyidae) larvae to recycle food waste. Environmental Entomology, 44, 406-410.

Okedi, J. (1992). Chemical evaluation of Lake Victoria lakefly as nutrient source in animal feeds. International Journal of Tropical Insect Science, 13, 373-376.

Oonincx, D. G., van Broekhoven, S., van Huis, A., \& van Loon, J. J.A. (2015). Feed conversion, survival and development, and composition of four insect species on diets composed of food by-products. PLoS ONE, 10, e0144601.

Paz, A. S. P., Carrejo, N. S., \& Rodríguez, C. H. G. (2015). Effects of larval density and feeding rates on the bioconversion of vegetable waste using black soldier fly larvae Hermetia illucens (L.) (Diptera: Stratiomyidae). Waste and Biomass Valorization, 6, 1059-1065.

Pen, M., Savage, D. B., Nolan, J. V., \& Seng, M. (2013). Effect of Stylosanthes guianensis supplementation on intake and nitrogen metabolism of Bos indicus cattle offered a basal diet of mixed rice straw and tropical grass. Animal Production Science, 53, 453-457.

R Core Team. (2017). R: A language and environment for statistical computing. Vienna.

Raven, P., \& Walker, G. (1980). Ingredients for fish feed manufacture in the United States. Paper presented at the FAO/UNDP Training Course in Fish Feed Technology. Seattle, Wash. (USA). 9 Oct 1978.

Renna, M., Schiavone, A., Gai, F., Dabbou, S., Lussiana, C., Malfatto, V., . . Gasco, L. (2017). Evaluation of the suitability of a partially defatted black soldier fly (Hermetia illucens L.) larvae meal as ingredient for rainbow trout (Oncorbynchus mykiss Walbaum) diets. Journal of Animal Science and Biotechnology, 8, 57.

Roper, C., Pignatelli, P., \& Partridge, L. (1996). Evolutionary responses of Drosophila melanogaster 
life history to differences in larval density. Journal of Evolutionary Biology, 9, 609-622.

Rumpold, B. A., \& Schluter, O. K. (2013). Nutritional composition and safety aspects of edible insects. Molecular Nutrition \& Food Research, 57, 802-823.

Sanchez-Muros, M. J., Barroso, F. G., \& Manzano-Agugliaro, F. (2014). Insect meal as renewable source of food for animal feeding: a review. Journal of Cleaner Production, 65, 16-27.

Schiavone, A., De Marco, M., Martínez, S., Dabbou, S., Renna, M., Madrid, J., . . Gasco, L. (2017). Nutritional value of a partially defatted and a highly defatted black soldier fly larvae (Hermetia illucens L.) meal for broiler chickens: apparent nutrient digestibility, apparent metabolizable energy and apparent ileal amino acid digestibility. Journal of Animal Science and Biotechnology, 8, 51.

Sharp, J. L., Boller, E. F., \& Chambers, D. L. (1983). Selection for flight propensity of laboratory and wild strains of Anastrepha suspensa and Ceratitis capitata (Diptera, Tephritidae). Journal of Economic Entomology, 76, 302-305.

Sheppard, D. C., Tomberlin, J. K., Joyce, J. A., Kiser, B. C., \& Sumner, S. M. (2002). Rearing methods for the black soldier fly (Diptera: Stratiomyidae). Journal of Medical Entomology, 39, 695-698.

Shewry, P. R., \& Halford, N. G. (2002). Cereal seed storage proteins: structures, properties and role in grain utilization. Journal of Experimental Botany, 53, 947-958.

Sørensen, J., \& Loeschcke, V. (2001). Larval crowding in Drosophila melanogaster induces Hsp70 expression, and leads to increased adult longevity and adult thermal stress resistance. Journal of Insect Physiology, 47, 1301-1307.

Spranghers, T., Ottoboni, M., Klootwijk, C., Ovyn, A., Deboosere, S., De Meulenaer, B., . . De Smet, S. (2017). Nutritional composition of black soldier fly (Hermetia illucens) prepupae reared on different organic waste substrates. Journal of the Science of Food and Agriculture, 97, 2594-2600.

Sripontan, Y., Juntavimon, T., Songin, S., \& Chiu, C. (2017). Egg-trapping of black soldier fly, Hermetia illucens (L.) (Diptera: Stratiomyidae) with various wastes and the effects of environmental factors on egg-laying. Khon Kaen Agricultural Journal, 45, 179-184.

Tallentire, C., Mackenzie, S., \& Kyriazakis, I. (2018). Can novel ingredients replace soybeans and reduce the environmental burdens of European livestock systems in the future? Journal of Cleaner Production, 187, 338-347.

Taylor, P. W., \& Yuval, B. (1999). Postcopulatory sexual selection in Mediterranean fruit flies: advantages for large and protein-fed males. Animal Behaviour, 58, 247-254.

Tikkanen, O. P., Niemela, P., \& Keranen, J. (2000). Growth and development of a generalistinse ct herbivore, Operophtera brumata, on original and alternative host plants. Oecologia, 122, 529-536.

Tomberlin, J. K., Adler, P. H., \& Myers, H. M. (2009). Development of the black soldier fly (Diptera: Stratiomyidae) in relation to temperature. Environmental Entomology, 38, 930-934.

Tomberlin, J. K., \& Sheppard, D. C. (2002). Factors influencing mating and oviposition of black soldier flies (Diptera : stratiomyidae) in a colony. Journal of Entomological Science, 37, 345-352.

Tomberlin, J. K., Sheppard, D. C., \& Joyce, J. A. (2002). Selected life-history traits of black soldier flies (Diptera : Stratiomyidae) reared on three artificial diets. Annals of the Entomological Society of America, 95, 379-386.

Tschirner, M., \& Simon, A. (2015). Influence of different growing substrates and processing on the nutrient composition of black soldier fly larvae destined for animal feed. Journal of 
Insects as Food and Feed, 1, 249-259.

UN-HABITAT. (2010a). Solid waste management in the world's cities. London and Washington, D.C: United Nations Human Settlements Programme (UN-HABITAT).

UN-HABITAT. (2010b). The state of African cities 2010: governance, inequality and urban land markets: United Nations Human Settlements Programme (UN-HABITAT).

United Nations, \& Department of Economic and Social Affairs Population Division. (2015). World Population Prospects: The 2015 Revision, Key Findings and Advance Tables. Working Paper No. ESA/P/WP.241 Retrieved from: https://population.un.org/wpp/ Publications/Files/Key_Findings_WPP_2015.pdf.

Van der Spiegel, M., Noordam, M., \& Van der Fels-Klerx, H. (2013). Safety of novel protein sources (insects, microalgae, seaweed, duckweed, and rapeseed) and legislative aspects for their application in food and feed production. Comprehensive Reviews in Food Science and Food Safety, 12, 662-678.

Van Huis, A. (2013). Potential of insects as food and feed in assuring food security. Annual Review of Entomology, 58, 563-583.

Van Huis, A., Van Itterbeeck, J., Klunder, H., Mertens, E., Halloran, A., Muir, G., \& Vantomme, P. (2013). Edible insects: future prospects for food and feed security (No. 171). Rome: Food and Agriculture Organization.

Van Niekerk, B. (1981). Byproducts of the sugar industry as animal feeds. South African Journal of Animal Science, 11, 119-137.

Veldkamp, T., \& Bosch, G. (2015). Insects: a protein-rich feed ingredient in pig and poultry diets. Animal Frontiers, 5, 45-50.

Wang, J., Han, L., \& Li, S. (2008). The collection system for residential recyclables in communiies in Haidian District, Beijing: a possible approach for China recycling. Waste Management, 28, 1672-1680.

Westendorf, M. L., \& Wohlt, J. E. (2002). Brewing by-products: their use as animal feeds. Veterinary Clinics of North America-Food Animal Practice, 18, 233-252.

Xiao, X. P., Mazza, L., Yu, Y. Q., Cai, M. M., Zheng, L. Y., Tomberlin, J. K., . . . Zhang, J. B. (2018). Efficient co-conversion process of chicken manure into protein feed and organic fertilizer by Hermetia illucens L. (Diptera: Stratiomyidae) larvae and functional bacteria. Journal of Environmental Management, 217, 668-676.

Yu, G., Cheng, P., Chen, Y., Li, Y., Yang, Z., Chen, Y., \& Tomberlin, J. K. (2011). Inoculating poultry manure with companion bacteria influences growth and development of black soldier fly (Diptera: Stratiomyidae) larvae. Environmental Entomology, 40, 30-35. 


\section{Chapter 5}

\section{Threshold temperatures and ther-}

mal requirements of black soldier fly Hermetia illucens: Implications for mass production

Shaphan Y. Chia, Chrysantus M. Tanga, Fathiya M. Khamis, Samira A. Mohamed, Daisy Salifu, Subramanian Sevgan, Komi K. M. Fiaboe, Saliou Niassy, Joop J. A. van Loon, Marcel Dicke and Sunday Ekesi

Published in PLoS ONE (2018)

13:e020609, doi:10.1371/journal.pone.0206097 


\section{Abstract}

Efforts to recycle organic wastes using black soldier fly (BSF) Hermetia illucens into high nutrient biomass that constitutes a sustainable fat and high-quality protein ingredient in animal feeds have recently gained momentum worldwide. However, there is little information on the most suitable rearing conditions for growth, development and survivorship of these flies, which is a prerequisite for mass production technologies. We evaluated the physiological requirements for growth and reproduction of H. illucens on two diets [spent grains supplemented with brewers' yeast (D1) and un-supplemented (D2)]. Development rates at nine constant temperatures $\left(10-42^{\circ} \mathrm{C}\right)$ were fitted to temperature-dependent linear and non-linear day-degree models. Thereafter, life history parameters were determined within a range of favourable temperatures. The thermal maximum (TM) estimates for larval, pre-pupal and pupal development using non-linear model ranged between $37.2 \pm 0.3$ and $44.0 \pm 2.3^{\circ} \mathrm{C}$. The non-linear and linear day-degree model estimates of lower developmental temperature threshold for larvae were $11.7 \pm 0.9$ and $12.3 \pm 1.4^{\circ} \mathrm{C}$ for $\mathrm{D} 1$, and $10.4 \pm 1.7$ and $11.7 \pm 3.0^{\circ} \mathrm{C}$ for $\mathrm{D} 2$, respectively. The estimated thermal constant of immature life stages of development of BSF was higher for the larval stage $(250 \pm 25 \mathrm{DD}$ for $\mathrm{D} 1$ and $333 \pm 51$ for D2) than the other stages evaluated. Final larval wet weight was higher on D1 compared to D2. The population growth rate was most favourable at 30-degree Celsius $\left({ }^{\circ} \mathrm{C}\right)$ with higher intrinsic rate of natural increase $\left(\mathrm{r}_{\mathrm{m}}=0.127\right.$ for D1 and 0.122 for D2) and shorter doubling time (5.5 days for $\mathrm{D} 1$ and 5.7 days for D2) compared to the other temperatures. These results are valuable for the optimization of commercial mass rearing procedures of BSF under various environmental conditions and prediction of population dynamics using computer simulation models. 


\section{Introduction}

The black soldier fly (BSF) Hermetia illucens L. (Diptera: Stratiomiydae) (Fig. 1) is an indigenous saprophagous fly of the Neotropics. However, the distributional range of these fly has widely changed over time to include the warmer parts of the world (Marshall et al., 2015). There has been substantial interest in the last decades to use these flies in organic waste management, given that their larvae are voracious eaters of organic waste (detritivores in compost heaps) (Diener et al., 2009; Lalander et al., 2015; Newton et al., 2005; Nguyen et al., 2013; Sheppard et al., 1994). The ability of BSF to convert waste into high-quality nutrient biomass has rapidly opened innovative economic prospects for municipal solid waste management. Also, the larvae of BSF after waste management are nutrient-rich consisting of an average of $42.1-43.2 \%$ crude protein, 33\% fat, and micronutrients (Bonso, 2013; Makkar et al., 2014; Newton et al., 2005; Rumpold \& Schluter, 2013; St-Hilaire et al., 2007), thus advocated as an appropriate alternative to fishmeal or soybean meal in poultry, pig and fish feeds (Barragan-Fonseca et al., 2017; Makkar et al., 2014; Van Huis et al., 2013), and provides opportunities for income generation (Newton et al., 2005; Sheppard et al., 1994). Therefore, there has been an increasing interest in developing novel methods of mass producing BSF as an agent of organic waste management and composting as well as sustainable novel protein-rich ingredients in animal feeds. However, the paucity of scientific data and the reluctance of commercial producers to share detailed information impairs up-scaling BSF production technology among smallholder farmers (Sanchez-Muros et al., 2014). As such many important aspects related to mass production technologies of BSF remains poorly studied, especially temperature. Among these factors, temperature remains one of the most important factors (Goulson et al., 2005; Saska et al., 2013) that considerably impacts behaviour, distribution, development rate, immature survival and reproduction, thus hampering the establishment of successful rearing systems across the world (Bale et al., 2002). To understand the dynamics and ecological system-specific BSF mass production strategies, data on temperature-driven population growth parameters of this insect become crucial, especially when dealing with small to medium-scale enterprises. Although information on development time, egg eclosion and adult emergence of BSF is reported for limited sets of temperature (Harnden \& Tomberlin, 2016; Holmes et al., 2016; Tomberlin et al., 2009), no information is available on temperature-driven effects on the life history parameters including mortality and reproduction at an extensive range of temperatures. Several nonlinear models have been used (Briere \& Pracros, 1998; Briere et al., 1999) to define the developmental and survivorship rates of different insects (Baek et al., 2014; Fand et al., 2014; Tanga et al., 2018; Tanga et al., 2015) over a varied array of temperatures but this has never been applied to BSF. Studies have shown that temperature significantly impacts the development of life stages, thus directly impacting the quality and quantity of insects produced in rearing facilities 
(Brevault \& Quilici, 2000; Duyck \& Quilici, 2002; Liu \& Ye, 2009; Rwomushana et al., 2008; Salum et al., 2014; Trudgill et al., 2005; Vargas et al., 2000; Vayssieres et al., 2008). Although studies have shown that below and above the optimal temperature range of insect development, which is commonly limited by upper and lower developmental thresholds, survival does not occur but there are indications that this can vary depending on the insect-specific life stage or geographical origin of the insect species (Honěk \& Kocourek, 1990). Thus, knowledge on developmental thermal requirements of insects provides strong basis for estimation of optimal response (Dixon et al., 2009). There is a deficiency of information on temperature-driven development of BSF which is needed to maximize production. Thus, to enhance mass production technologies, additional studies are warranted on temperature requirements of BSF. In the present study, we evaluated the stage-specific developmental time, survival, wet weight, pre-oviposition time, fecundity and adult longevity at nine constant temperatures $\left(10-42^{\circ} \mathrm{C}\right)$ for BSF larvae reared on spent grains with or without supplementation with brewer's yeast. The present work has implications for the mass production of BSF larvae as high-quality protein ingredient for animal feed.

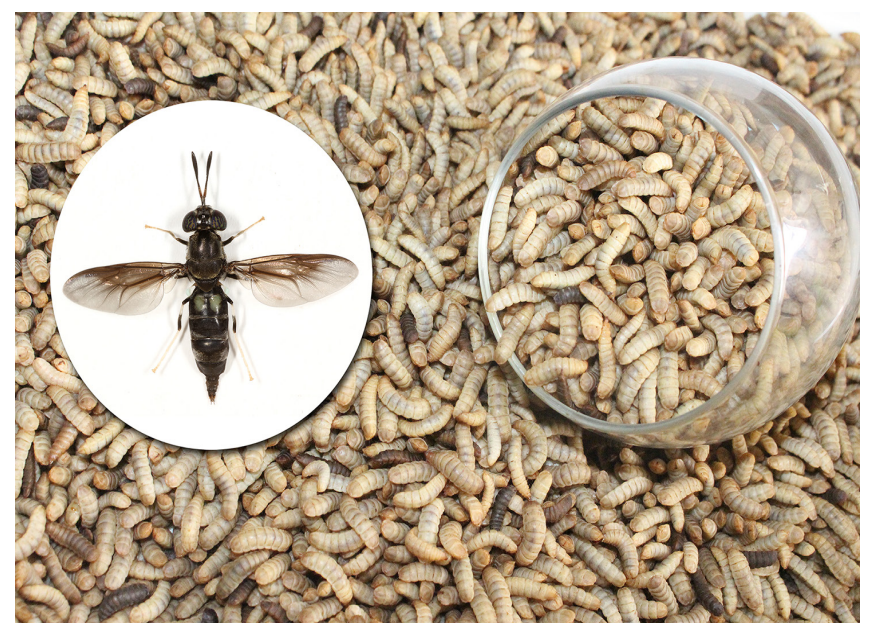

Fig. 1. Illustration of black soldier fly (BSF) Hermetia illucens (Diptera: Stratiomyidae) and high-quality larvae. Sizes of larvae and adult fly are not proportional.

\section{Materials and methods}

\section{Origin of $H$. illucens population and colony maintenance}

A stock culture of the wild-caught fly population was established following the methodology described by (Booth \& Sheppard, 1984) and (Sripontan et al., 2017) with slight modifications. Egg-trapping of wild BSF was carried out in Kasarani, Nairobi County, Kenya (S 01 '13' 14.6”; E 036 53' 44.5”, $1612 \mathrm{~m}$ above sea level). Chicken manure, rabbit 
manure, mixed fruit wastes and household food wastes were used as baiting materials for adult flies. The baiting materials were placed separately inside 6-L plastic buckets (22 $\mathrm{cm}$ high by $18 \mathrm{~cm}$ bottom diameter by $23 \mathrm{~cm}$ top diameter) designed with six openings (10 cm diameter each), $5 \mathrm{~cm}$ from the lid to facilitate entry of adult flies. The bait inside each container was maintained at approximately $70 \%$ moisture level. In cases where household food waste or mixed fruit waste were used, four-five holes were made at the bottom of the containers to allow excess fluid to drain out during the decomposition process. Three-five corrugated cardboard flutes ( $\sim 10 \mathrm{~cm}$ length by $5 \mathrm{~cm}$ width) were attached vertically to the walls of the containers over the bait to serve as oviposition sites for adult flies. The lids of the containers were fastened to prevent desiccation or interference from heavy rainfall. Traps were labelled with date, location, time and GPS coordinates. Thereafter, the traps were hung on wooden or metallic stands $(1 \mathrm{~m}$ above the ground) under shades around homesteads or close to garbage dump sites. We ensured that the wooden or metallic stands holding the traps were smeared with Tanglefoot1 (Tangle-trap) (Tanglefoot1 Company, Grand Rapids, MI) insect paste, which served as a barrier to stop intrusion by predators (ants, reptiles, etc). These traps were checked regularly, and available egg clusters deposited by BSF in the cardboard flutes were harvested. The egg clusters were immediately transferred into other rearing containers holding a diet specifically formulated for the newly hatched neonates, hatching took approximately 4 days at $28 \pm 1^{\circ} \mathrm{C}$. Ten days after hatching the young larvae were transferred to bigger metal rearing trays containing wet brewer's spent grains sourced from Kenya Breweries Limited, Nairobi, Kenya. The top surface of the rearing trays measured $76 \mathrm{~cm}$ length by $27.5 \mathrm{~cm}$ width, $10 \mathrm{~cm}$ height while the bottom of the tray measured $52 \mathrm{~cm}$ length by $27.5 \mathrm{~cm}$ width. In the rearing facility, conditions were maintained at $28 \pm 1{ }^{\circ} \mathrm{C}, 65 \pm 5 \% \mathrm{RH}$ and L12:D12 photoperiod. User-friendly thermo-hygrometers (TH-812E) were maintained in each rearing room to allow us track slight changes in temperature and RH. Pre-pupal stages harvested from the rearing trays were kept in 4-L transparent rectangular plastic containers $(21$ x 14 x $15 \mathrm{~cm}$ ) (Kenpoly Manufacturer Ltd., Nairobi, Kenya) containing moist wood shavings (sawdust) until eclosion. On the lid of each container, an opening $(14.5 \times 8.3 \mathrm{~cm})$ was introduced and screened with fine netting organza material. Emerging flies were transferred to an outdoor cage $(1 \times 1 \times 1.8 \mathrm{~m})$. The flies were provided ad libitum $60 \%$ sugar solution on cotton wool or soaked pumice granules in 2-L rectangular transparent plastic containers (21 x 14 x 7 cm) (Kenpoly Manufacturers Ltd., Nairobi, Kenya). Some of the flies (15 males and 15 females) were rendered inactive by freezing them $\left(-20^{\circ} \mathrm{C}\right)$ for $20 \mathrm{~min}$ and later preserved in $90 \%$ alcohol for taxonomic identification based on morphological features (Oliveira et al., 2016; Roy et al., 2016). Thereafter, the preserved specimens were identified at the Biosystematics unit of icipe, which also holds reference materials of the specimens. BSF has been in culture for $\sim 2$ years. In addition, BSF was kept at high numbers (2000-2500 
adults per cage) to avoid inbreeding depression while also avoiding stressful crowding effects (Sørensen \& Loeschcke, 2001).

\section{Sources of experimental substrates and diet formulation}

Before the commencement of the experiment, fresh brewer's spent grains (BSGs) (malt/corn starch) and brewer's yeast, both by-products of brewing beer were sourced from the Kenya Breweries Limited, Nairobi, Kenya. The fresh BSGs were subsequently dried using moving dry air at $28.0 \pm 2{ }^{\circ} \mathrm{C}$ (using Xpelair1 heater: WH30, 3KW Wall Fan Heater, United Kingdom) for two days (48 h). Afterwards, the semi-dried products were maintained in the oven for 3-days $(72 \mathrm{~h})$ at $60{ }^{\circ} \mathrm{C}$ to dry properly to achieve approximately $90 \% \mathrm{DM}$ ( $\sim 10 \%$ moisture). The dried BSGs were later passed through the Münch hammer mill (Münch, Wuppertal, Germany) to reduce the materials to a $3 \mathrm{~mm}$ particle size, suitable for incorporation into BSF diet when needed. Two experimental diets were then formulated for the BSF larvae, which consisted of diet one (D1) (50 $\mathrm{g}$ BSGs mixed in $90 \mathrm{ml}$ of brewer's yeast) and diet two (D2) (50 g BSGs mixed in $80 \mathrm{ml}$ of water (Control). Each diet was hydrated to approximately $70.0 \pm 2 \%$ moisture by weight according to the protocol described by Cammack \& Tomberlin (2017) and confirmed using a moisture sensor with two 12-cm-long probes (HydroSenseTM CS620, Campbell Scientific, Inc., Logan, UT, USA). Five replicates were conducted for each experimental diet fed ad libitum until the late larval stage.

\section{Temperature effect on the development and survivorship rate of H. illucens life stages}

Thermostatically controlled incubators (MIR-554-PE, Sanyo/Panasonic cooled incubators, Japan) were used to conduct the experiments set at one of the nine constant temperatures conditions $\left[\left(10,15,20,25,30,35,37,40\right.\right.$ or $\left.42{ }^{\circ} \mathrm{C}\left( \pm 0.03{ }^{\circ} \mathrm{C}\right)\right]$. The relative humidity in each incubator was maintained at $70 \pm 2.0 \%$ and photoperiod of $12: 12 \mathrm{~L}$ : D. In each incubator, the effect of temperature on the developmental time and survival of the different life stages were assessed. EasyLog USB data loggers (EL-USB-2, RH/ Temp data logger; MicroDAQ.com, Ltd. USA, 603-746-5524) were placed inside each incubator, which recorded the inside temperature at 15 minutes interval. Eggs of BSF were obtained by providing the adult flies with oviposition media that consisted of corrugated cardboard with flutes (cut into sizes as described above). The cardboards were attached to the wall of cages near the baiting materials and on top of the substrates (baiting material). Freshly laid egg clusters were obtained from the stock colony $\sim 1 \mathrm{~h}$ after the eggs were laid.

Egg. Camel hair brush with a fine tip was used to collect 300 eggs ( 1 h old), which were carefully transferred unto sterilized Petri dishes (150 x 25 × $20 \mathrm{~mm})$. The Petri 
dishes containing eggs were transferred to the nine incubators described above. The experimental setup with the eggs were monitored at regular interval of $6 \mathrm{~h}$ daily until they hatched. All egg eclosion at each temperature regime was recorded with the help of entomological tweezers under the microscope (Leica MZ 125 Microscope; Leica Microsystems Switzerland Limited). The stereomicroscope used for counting the emerged neonates was fitted with Toshiba 3CCD camera and an auto-montage software (Syncroscopy, Synoptics Group, Cambridge, UK) at 25X magnification to ensure no damage was observed. Time until hatching of larvae and percentage egg hatch was determined. The experiments were replicated five times per temperature treatment.

Larva. Per temperature treatment, 300 newly hatched larval BSF ( $\sim 1 \mathrm{~h}$ old) were randomly obtained from the clusters of hatched eggs maintained at each experimental temperature and transferred onto square $\left(5 \mathrm{~cm}^{2}\right)$ sterile filter papers. The square filter papers with the young BSF larvae were transferred onto a $50 \mathrm{~g}$ formulated diets; D1 or D2 placed in 2-L rectangular plastic rearing containers. The plastic containers containing the neonates were then maintained in respective thermostatically controlled incubators. The opening made on the lids of the containers were covered with a netting of $1.3 \times 1.3 \mathrm{~mm}$ mesh size to allow for sufficient ventilation. The larvae were then fed ad libitum, until pre-pupal stage. Fifty 5 th instar larvae were randomly selected from each diet in the different temperature treatments and separated into ten replicate groups of five and weighed to determine the wet weight. Stage-specific developmental time and survival was recorded for each temperature treatment. For each experiment in the different temperature regimes, five replications were achieved.

Pre-pupa. A total of 300 newly formed pre-pupae were selected randomly from the experimental culture maintained on each diet at each temperature treatment. The pre-pupae used for the experiment were maintained individually in small plastic containers with a top and bottom diameter of 5 and $4 \mathrm{~cm}$, respectively and a height of $4 \mathrm{~cm}$. The containers were provided with breathable lids. Each container had a $2.5 \mathrm{~cm}$-deep moist sawdust, which served as pupation substrates. The containers used for the experiment were monitored daily for the development and survival of the pre-pupal stage. Each experiment was replicated five times.

Pupa. From experimental cultures maintained on each diet at each temperature, 300 pupae were randomly selected and transferred individually into plastic containers with a $2.5 \mathrm{~cm}$ layer of moist sterile sawdust for emergence. Pupae that failed to emerge within the anticipated period were allowed for an addition 1-month period before pronouncing them dead. Emerged adults were recorded by sex, and their adult weight (50 individuals) recorded. Each experiment was replicated five times for each diet and temperature treatment. 


\section{Temperature effect on adult $H$. illucens fecundity, oviposition and longevity}

Upon emergence, one female and one male adult $H$. illucens ( $\sim 1 \mathrm{~h}$ old $)$ were paired. The individual BSF adult pairs were placed in well ventilated Perspex cages $(15 \times 15 \times 10$ $\mathrm{cm})$. In each cage, the paired flies were provided sugar water on soaked cotton balls. Thereafter, the flies were provided with two corrugated cardboard flutes stocked on the walls of the container. The corrugated cardboards were maintained in the cages throughout the lifespan of the flies. Egg clusters produced daily were checked and counted, while the longevity of individual flies was also recorded. In each egg cluster collected, total number of eggs laid per female was counted and recorded. Thirty pairs of $H$. illucens were monitored for each temperature treatment and diet. Pre-oviposition duration was calculated based on the days required for a newly emerged female BSF to start ovipositing. Adult longevity was calculated based on the length of time lived by an adult fly from the date of emergence until death. Fecundity was considered as the number of eggs laid per female.

\section{Life history parameters}

The net reproductive rate $\left(R_{0}\right)$, intrinsic rate of natural increase $\left(r_{m}\right)$, generation time $(G)$, and doubling time (DT) were estimated using the method described by Carey (1993) using the modified spreadsheet of (Portilla et al., 2014). $R_{o}$, which is an indication of the number of offspring that an individual female fly can produce during its life span was calculated as:

$$
R_{o}=\sum_{x=0}^{w} l_{x} m_{x}
$$

The maximum population growth, $r_{m}$ was assessed using the iterative bisection approach from the Euler-Lotka equation with age indexed starting from zero. Life table with data on the $r_{m}$ at different temperature regimes provide insight into the characteristic life patterns of BSF:

$$
\sum_{x=0}^{w} e^{-r(x+1)} l_{x} m_{x}=1
$$

The finite rate of increase $(\lambda)$, which represents overall female offspring per female per day, was calculated using the formula:

$$
\lambda=e^{r_{m}}
$$


The mean generation time $(G)$, which is defined as the length of time that a population requires to increase to $R_{o}$-fold of its population size at the stable age-stage distribution was estimated using the formula:

$$
G=\frac{\ln R_{o}}{r_{m}}
$$

The gross reproductive rate $(G R R)$ was calculated as:

$$
G R R=\sum_{x=0}^{w} m_{x}
$$

The doubling time $(D T)$ is defined as the number of days required by a population to double and was calculated as shown below:

$$
D T=\frac{\ln (2)}{r_{m}}
$$

where $l x$ is the female survival rate from egg to age $x, w$ is the oldest surviving age, $x$ is the age class in days and $m x$ is mean female progeny occurring during age $x$.

\section{Temperature-dependent models}

For temperature dependent models, both linear (Campbell et al., 1974) and nonlinear models were fitted to developmental rate stage-specific data of the insect. The linear model expressed below evaluated the relationship between $H$. illucens developmental rate and temperature:

$$
r(T)=a+b T
$$

In the model, $T$ is the ambient temperature $\left({ }^{\circ} \mathrm{C}\right), r$ is an indication of the development rate [1/ developmental duration presented in days], while the intercept $(a)$ and slope $(b)$ are model parameters. The minimum temperature $\left(T_{\text {min }}\right)$ and standard error were calculated using the following equations (Campbell et al., 1974):

$$
\begin{gathered}
T_{\min }=\frac{-a}{b} \\
S E_{T_{\text {min }}}=\frac{y_{m}}{b} \sqrt{\frac{S^{2}}{N \times y_{m}^{2}}+\left[\frac{S E_{b}}{b}\right]^{2}}
\end{gathered}
$$


where $y_{m}$ is the average value of the developmental rate, $b$ is estimated slope of the fitted line, $S^{2}$ is the residual mean square of the linear model, and $N$ is the sample size (Andreadis et al., 2013). The total thermal energy (heat units) necessary to complete development, which is considered to be above the low temperature development threshold (LTDT) and referred to as the thermal constant $K$, is represented in degree-days (DDs). The value of $K$, and its standard error were calculated using the following equations (Campbell et al., 1974):

$$
\begin{gathered}
K=\frac{1}{b} \\
S E_{k}=\frac{S E_{b}}{b^{2}}
\end{gathered}
$$

Many empirical non-linear models fitted to developmental rate stage-specific data have been used to determine minimum temperature thresholds $\left(T_{\text {min }}\right)$, optimal temperatures $\left(T_{o p}\right)$ and upper temperature thresholds $\left(T_{\max }\right)$. Optimum temperature $\left(T_{o p}\right)$ is defined as the temperature when developmental rate is observed to be maximal, while $T_{\max }$ is referred to as threshold temperatures above which temperatures are lethal. Between the different non-linear models evaluated, Brière 1 model provided a better explanation of the temperature effect on the development of $H$. illucens life stages in comparison to other models tested. Brière 1 model is expressed as below:

$$
r(T)=n * T *\left(T-T_{\min }\right) * \sqrt{T_{\max }-T}
$$

Here, $r$ is considered as the developmental rate, derived as a function of temperature $T$, $n$ being an empirical constant, $T_{\text {min }}$ the lower development temperature threshold, and $T_{\max }$ the upper temperature threshold. The optimal temperature of H. illucens development rate was estimated using the following equation (Briere et al., 1999):

$$
T_{o p t}=\frac{2 m T_{\max }+(m+1) T_{\min }+\sqrt{\left(4 m^{2} T_{\max }^{2}+(m+1)^{2} T_{\min }^{2}-4 m^{2} T_{\min } T_{\max }\right)}}{4 m+2}
$$

where $m=2$ (Briere et al., 1999). 


\section{Statistical analysis}

A two-way analysis of variance (ANOVA) was used to analyze the data on development time, survival of immature life stages, adult longevity, fecundity and pre-oviposition period (dependent variables) to evaluate the effect of temperature and rearing substrate (independent factors) and their interaction. Percentage of survival and average wet weight for the different life stages of BSF at different temperatures and rearing substrates were also analysed using a two-way ANOVA. In the event of a significant F test $(\mathrm{P}<0.05)$, the Student Newman Keuls $(\mathrm{SNK})$ test was used to compare means. Prior to ANOVA, all proportion data (percentage survival and adult emergence) were transformed using angular transformation to stabilize variance. All statistical analyses were performed using $\mathrm{R}$ version 3.4.1 (R Core Team, 2017).

\section{Results}

\section{Temperature effect on developmental and survival rate of $H$. illucens immature life stages and adults}

The time to egg eclosion differed significantly $(\mathrm{F}=117.3$; $\mathrm{df}=6,19 ; \mathrm{P}<0.0001)$ among the different temperatures (Fig. 2). The eclosion time of the eggs incubated at $15^{\circ} \mathrm{C}$ was 14 -days, compared to those incubated at $35^{\circ} \mathrm{C}$, which eclosed in 2.60 days. After monitoring the egg experimental set-up for over 40 days, eggs at 10 and $42^{\circ} \mathrm{C}$ were observed to have completely collapsed and deemed not viable. Larval development time differed significantly among temperatures $(\mathrm{F}=843.1 ; \mathrm{df}=6,28 ; \mathrm{P}<0.0001$ for $\mathrm{D} 1$ and $\mathrm{F}=153.5 ; \mathrm{df}=6,28 ; \mathrm{P}<0.0001$ for $\mathrm{D} 2)$ and between rearing substrates $(\mathrm{F}=114.1 ; \mathrm{DF}=1,56 ; \mathrm{P}<0.0001)$. There was a significant interaction $(\mathrm{F}=20.2 ; \mathrm{df}$ $=6,56 ; \mathrm{P}<0.0001)$ between the effect of temperature and rearing substrate on larval developmental time.

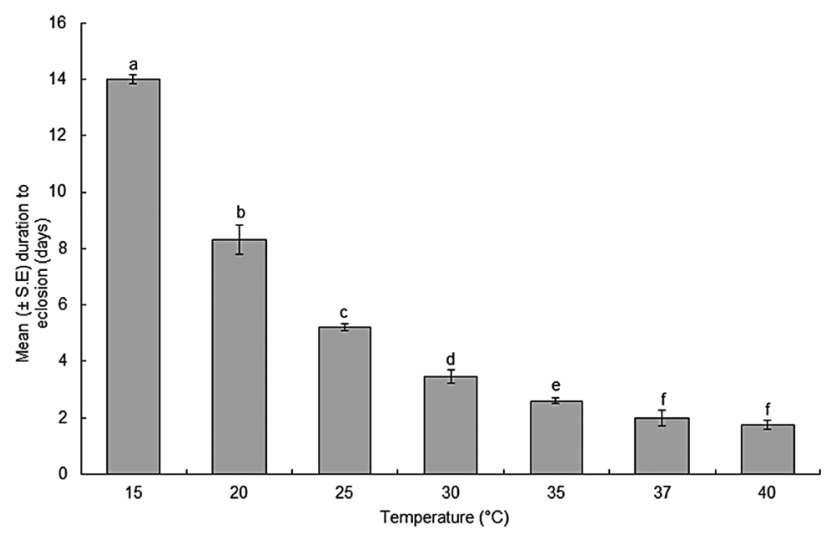

Fig. 2. Duration of H. illucens egg eclosion at different temperatures. Bars with different letters are significantly different $(\mathrm{P}<0.05$, SNK test). 
Larval developmental time on D1 ranged between $12.8 \pm 0.34$ days at $30{ }^{\circ} \mathrm{C}$ and $61.6 \pm$ 0.91 days at $15{ }^{\circ} \mathrm{C}$ (Fig. 3). The longest larval developmental time was recorded at $15{ }^{\circ} \mathrm{C}$ (65 days), while the shortest developmental time was at $30{ }^{\circ} \mathrm{C}(13$ days $)$ and $35{ }^{\circ} \mathrm{C}(16$ days) when reared on D1 and D2, respectively (Fig 3). Larvae reared on D1 and D2 had significantly different developmental time at 20,25 and $30{ }^{\circ} \mathrm{C}$ but similar developmental time at 15, 35, 37 and $40{ }^{\circ} \mathrm{C}$ (Fig. 3). The pre-pupae from larvae fed on D1 and D2 failed to complete development to the pupa at $40{ }^{\circ} \mathrm{C}$. The pre-pupal development time differed significantly among temperatures tested $(\mathrm{F}=61.22 ; \mathrm{df}=5,22 ; \mathrm{P}<0.0001$ for $\mathrm{D} 1$ and $\mathrm{F}=349.3 ; \mathrm{df}=5,22 ; \mathrm{P}<0.0001$ for $\mathrm{D} 2)$ and between the different $\operatorname{diets}(\mathrm{F}=$ 4.743; $\mathrm{df}=1,44 ; \mathrm{P}=0.0350)$. The interaction $(\mathrm{F}=12.35 ; \mathrm{df}=5,44 ; \mathrm{P}<0.0001)$ between the effect of temperature and diet was significant. Pre-pupae from larvae reared on $\mathrm{D} 1$, showed significant variation in developmental times at $15,20,25,30$ and $35^{\circ} \mathrm{C}$, but similar values at 20 and $37{ }^{\circ} \mathrm{C}$ (Fig. 3). The longest pre-pupal developmental durations were 86 days and 83 days for $\mathrm{D} 1$ and $\mathrm{D} 2$, respectively at $15^{\circ} \mathrm{C}$, while the developmental time was shortest at $30^{\circ} \mathrm{C}(10$ and 8 days for D1 and D2, respectively) (Fig. 3).

The development time of pupae obtained from larvae fed on D1 and D2, displayed significant variation between the different temperatures $(\mathrm{F}=175.4 ; \mathrm{df}=5,22 ; \mathrm{P}<0.0001$ and $\mathrm{F}=304.5 ; \mathrm{df}=5,22 ; \mathrm{P}<0.0001$, respectively). The effect of larval diets (D1 and D2) on pupal developmental time did not differ significantly ( $\mathrm{F}=2.002$; $\mathrm{df}=1,44$; $\mathrm{P}=0.1640)$ across the different temperature. No significant interaction was observed between the effect of temperature and diet on pupal development $(\mathrm{F}=2.272$; $\mathrm{df}=5$, $44 ; \mathrm{P}=0.0642)$. Overall developmental duration from larva to adult flies showed a significant difference among the temperature regimes $(\mathrm{F}=209.3$; $\mathrm{df}=5,22 ; \mathrm{P}<0.0001$ and $\mathrm{F}=885.4 ; \mathrm{df}=5,22 ; \mathrm{P}<0.0001$ when reared on $\mathrm{D} 1$ and $\mathrm{D} 2$, respectively) and between diets $(\mathrm{F}=5.25 ; \mathrm{df}=1,44 ; \mathrm{P}=0.0274)$. The effect of temperature and diet on developmental time showed a significant interaction $(\mathrm{F}=26.54 ; \mathrm{df}=5,44 ; \mathrm{P}<0.0001)$. For D1, the developmental time from larva to adult ranged between 28 days at $30{ }^{\circ} \mathrm{C}$ to 184 days at $15^{\circ} \mathrm{C}$, whereas those reared on $\mathrm{D} 2$, completed development to adult stage in 31 days at $30^{\circ} \mathrm{C}$ and 181 days at $15{ }^{\circ} \mathrm{C}$ (Fig. 3). 

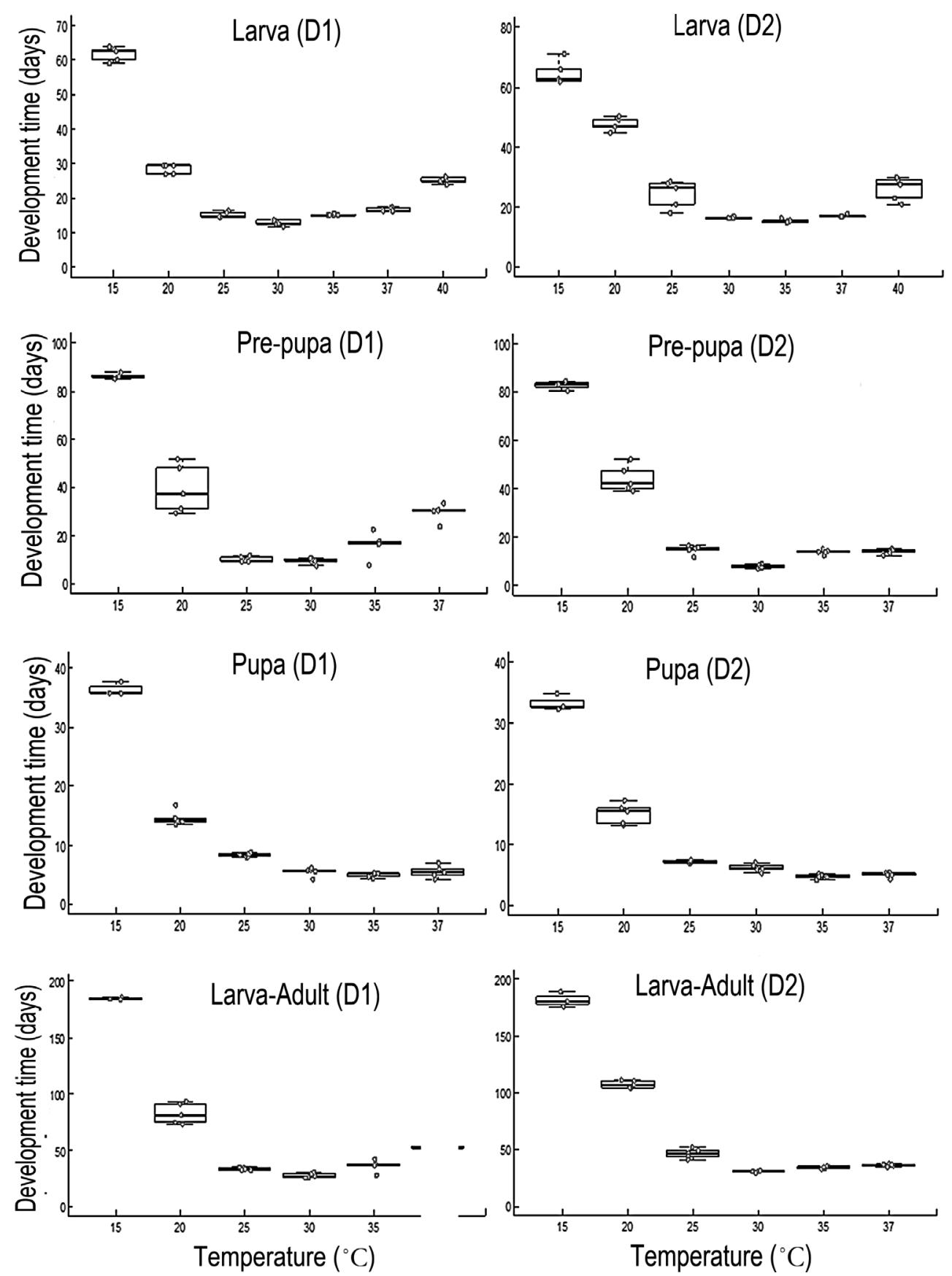

Fig. 3. Development time of different life stages of H. illucens fed on two diets at constant temperatures. The middle quartile or the median (line that divides the box into two parts) marks midpoint of the data. Middle box represents $50 \%$ of the scores for each treatment and the middle $50 \%$ values fall within the inter-quartile range. $\mathrm{D} 1=\operatorname{diet} 1 ; \mathrm{D} 2=\operatorname{diet} 2$. 


\section{Most favourable temperature range of $H$. illucens}

The stage-specific survival of BSF at nine constant temperatures is presented in Table 1. Egg viability was extremely low $(<11 \%)$ at 15,37 and $40{ }^{\circ} \mathrm{C}$ compared to the other temperatures evaluated. The highest percentage of egg eclosion was recorded at 30 ${ }^{\circ} \mathrm{C}(80 \%)$ and $35{ }^{\circ} \mathrm{C}(75 \%)$ (Table 1). Percentage larval survival differed significantly $(\mathrm{F}=7.68 ; \mathrm{df}=6,28 ; \mathrm{P}<0.0001$ for $\mathrm{D} 1$ and $\mathrm{F}=19.79 ; \mathrm{df}=6,28 ; \mathrm{P}<0.0001$ for D2) among the different temperature treatments. The interaction between the effects of temperature and diet was significant $(\mathrm{F}=2.60$; $\mathrm{df}=6,56 ; \mathrm{P}=0.0217)$. However, survival rate was comparable at $15,20,25,30,35$ and $37^{\circ} \mathrm{C}$, whereas it was lower at 40 ${ }^{\circ} \mathrm{C}$ (Table 1). For D2, larval survival rate was high at $35{ }^{\circ} \mathrm{C}(92 \%)$ and $30{ }^{\circ} \mathrm{C}(90 \%)$ and low at $40{ }^{\circ} \mathrm{C}(28 \%)$. Pre-pupal survival was significantly influenced by temperature when larvae were reared on $\mathrm{D} 1(\mathrm{~F}=26.58 ; \mathrm{df}=5,22 ; \mathrm{P}<0.0001)$ and $\mathrm{D} 2(\mathrm{~F}=4.08 ; \mathrm{df}=5$, $22 ; \mathrm{P}=0.0090)$. There was a significant interaction $(\mathrm{F}=11.91 ; \mathrm{df}=5,44 ; \mathrm{P}<0.0001)$ between temperature and diet on pre-pupal survival. For D1, the highest pre-pupal survival rate was recorded at $25^{\circ} \mathrm{C}(83 \%)$ and $30^{\circ} \mathrm{C}(82 \%)$, while the lowest value was recorded at $37^{\circ} \mathrm{C}(24 \%)$. For D2, the highest percentage of survival was observed at $35{ }^{\circ} \mathrm{C}(79 \%)$ and $30{ }^{\circ} \mathrm{C}(77 \%)$, whereas at $25{ }^{\circ} \mathrm{C}$ the survival rate was the lowest $(54 \%)$. However, the survival rate across the different temperatures was similar, except at 25

${ }^{\circ} \mathrm{C}$. The pupal survival rate differed significantly between temperatures when the larvae were reared on D1 $(F=42.28=\mathrm{df}=5,22 ; \mathrm{P}<0.0001)$ or D2 $(\mathrm{F}=25.96$; $\mathrm{df}=5,22 ; \mathrm{P}$ $<0.0001)$. The interaction between the effect of rearing diet and temperature on pupal survival was significant $(\mathrm{F}=6.67$; $\mathrm{df}=5,44 ; \mathrm{P}<0.0001)$. The percentage of survival recorded for the pupal stage was observed to decrease from $77 \%$ at $30{ }^{\circ} \mathrm{C}$ to $5 \%$ at 37 ${ }^{\circ} \mathrm{C}$ for D1 and from $75 \%$ at $30{ }^{\circ} \mathrm{C}$ to $20 \%$ at $37{ }^{\circ} \mathrm{C}$ for D2 (Table 1 ). 


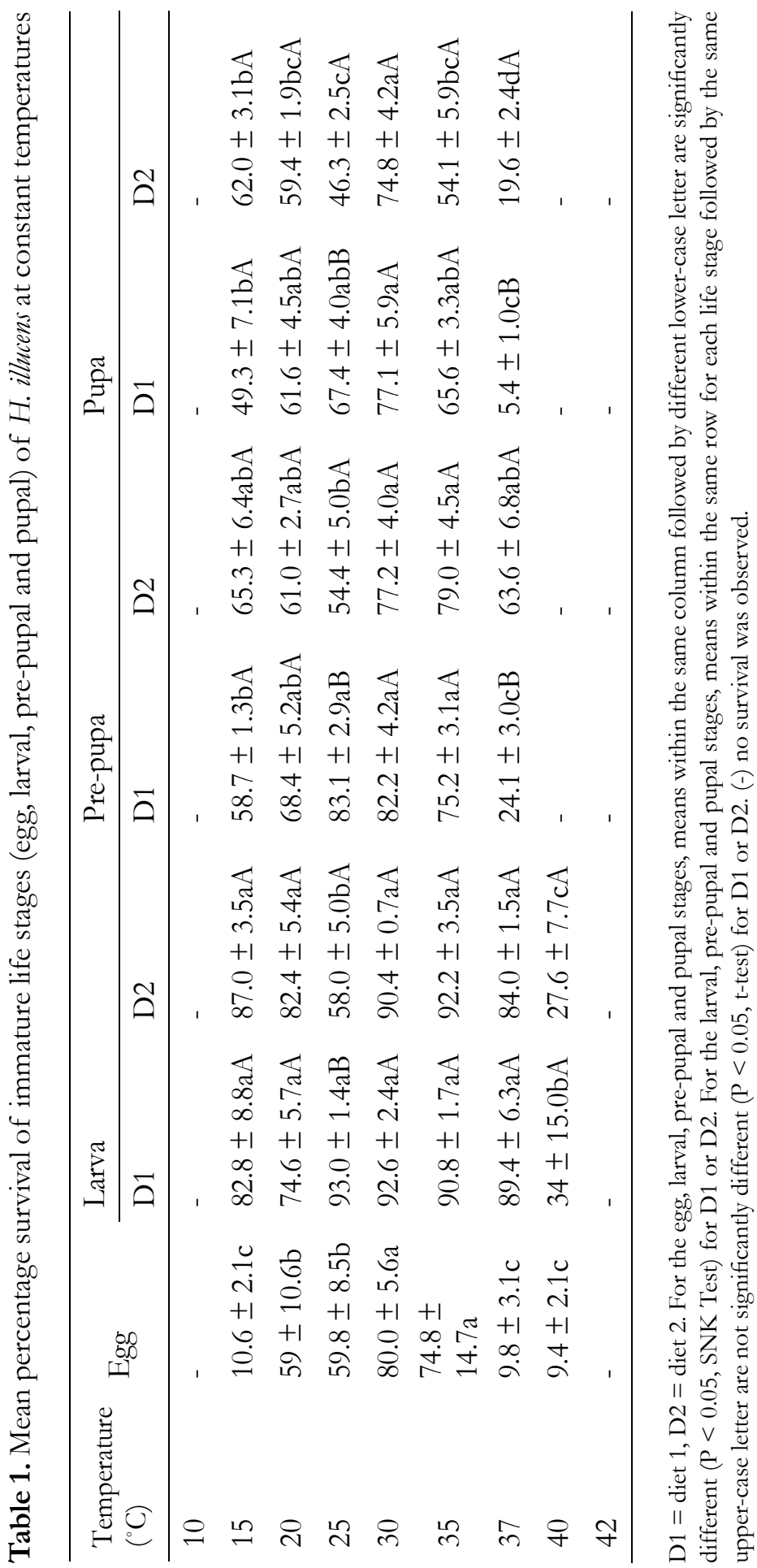




\section{Longevity and reproduction of $H$. illucens at different tempera- tures}

The longevity of adult BSF was significantly affected by temperature for both females $(\mathrm{F}=52.48 ; \mathrm{df}=5,29 ; \mathrm{P}<0.0001)$ and males $(\mathrm{F}=53.27 ; \mathrm{df}=5,29 ; \mathrm{P}<0.0001)$. Fig 4 indicates that adult flies live longer at intermediate temperatures than at upper extreme temperatures as further illustrated by the quadratic model fitted to longevity (Fig. 5) for both sexes when their larvae were reared on D1 or D2. Average pre-oviposition period was observed to vary significantly across the different temperatures, being longest at $20^{\circ} \mathrm{C}$ (16 days) and shortest at $35^{\circ} \mathrm{C}$ (5 days) when larvae were reared on D1 and D2 (Fig. 6). Fecundity was significantly affected by temperature, especially at the lower (15 $\left.{ }^{\circ} \mathrm{C}\right)$ and upper $\left(37^{\circ} \mathrm{C}\right)$ temperatures evaluated. The highest fecundity of BSF was observed at $30{ }^{\circ} \mathrm{C}$ (516 and 475 eggs when flies were reared on D1 and D2, respectively) (Fig. 6).
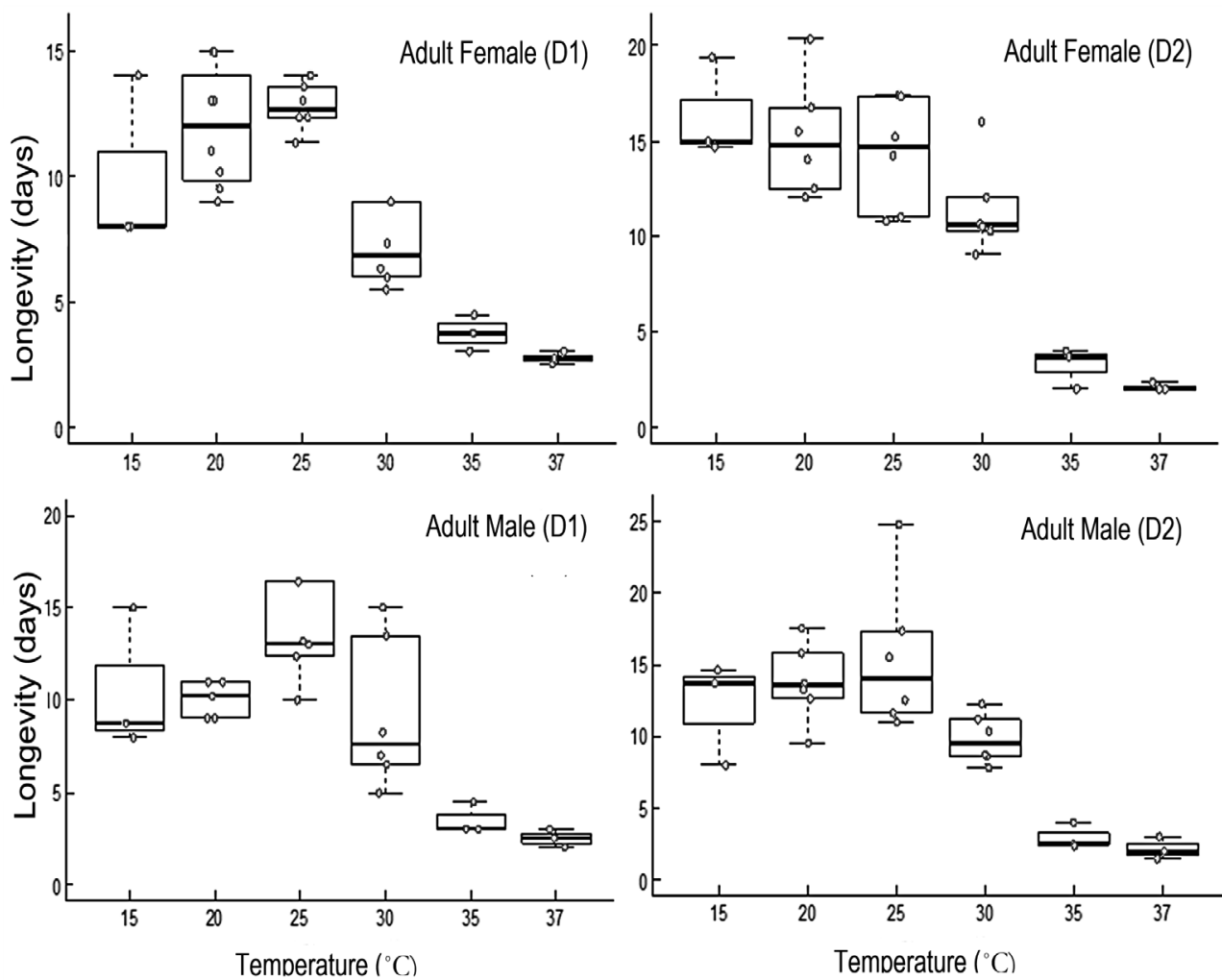

Fig. 4. Boxplots showing longevity of adult female and male H. illucens at constant temperatures. Middle quartile (line that divides the box into two parts) shows midpoint of the data. Middle box represents $50 \%$ of the scores for each treatment and the middle $50 \%$ values fall within the inter-quartile range. D1 = diet 1; D2 $=\operatorname{diet} 2$ 

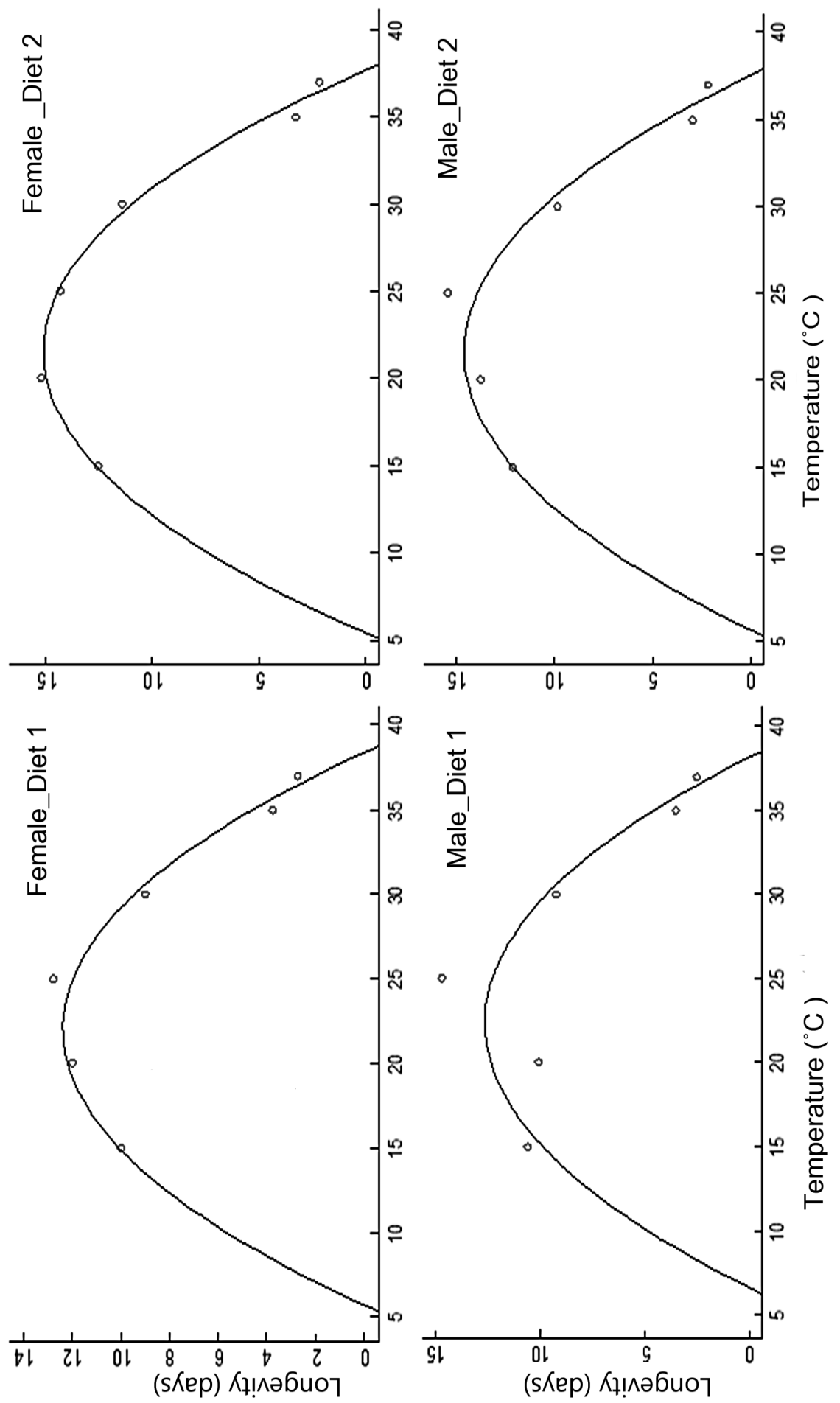

5 


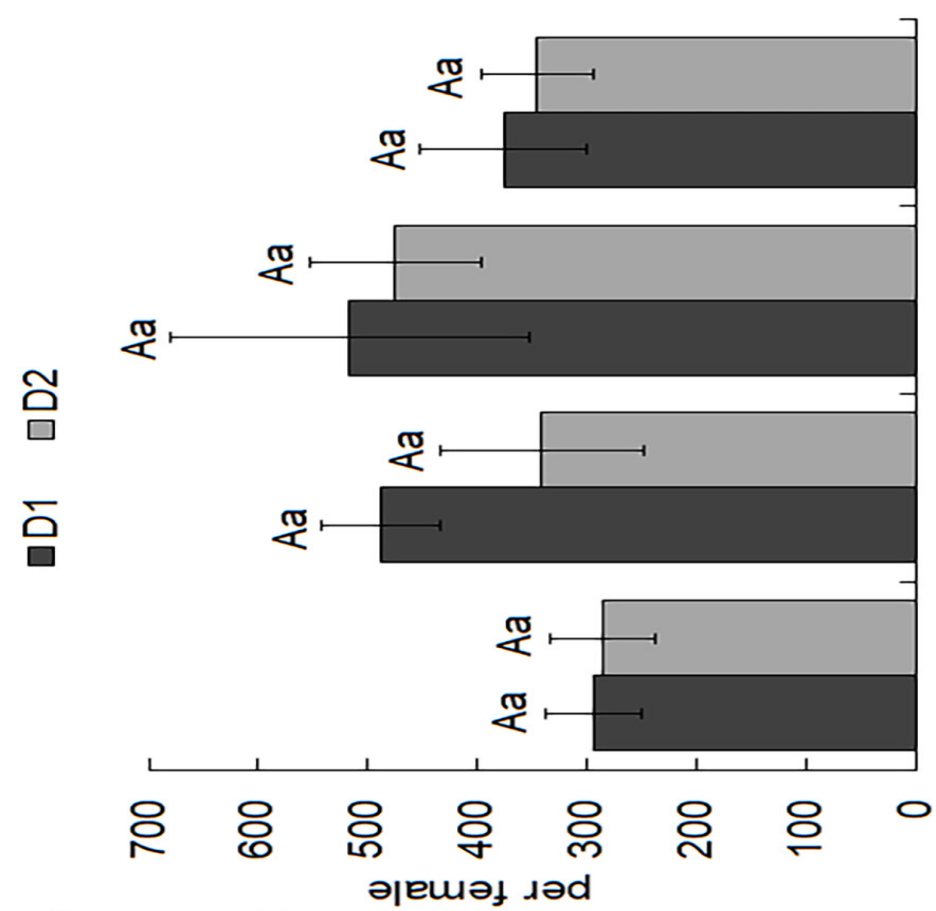

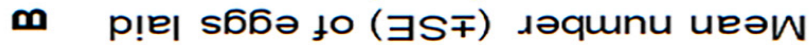

ปิ

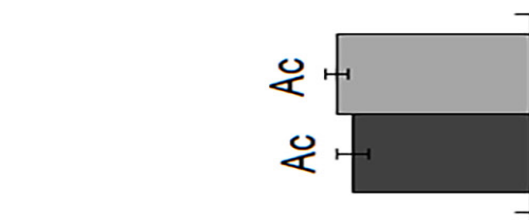

Б

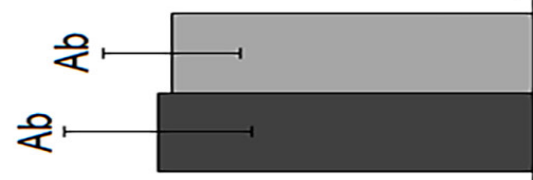

ก)

ฉ

m

○

岂

壳

กิ

急

○

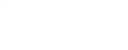




\section{Body weight of $H$. illucens life stages reared on two diets at constant temperatures}

The mean wet weight for the different life stages of BSF reared on two diets is presented in Fig. 7. The estimated mean wet weight was higher for all BSF life stages reared on D1 compared to D2 across the different temperature regimes. Body weight of $5^{\text {th }}$ instar larvae varied significantly among the different temperature regimes $(\mathrm{F}=6.26$; $\mathrm{df}=6$, 26; $\mathrm{P}<0.0001$ for $\mathrm{D} 1$ and $\mathrm{F}=25.8$; $\mathrm{df}=6,26 ; \mathrm{P}<0.0001$ for $\mathrm{D} 2)$ and between rearing diets $(\mathrm{F}=267.81 ; \mathrm{df}=1,52 ; \mathrm{P}<0.0001)$. The interaction between the temperature and diet was found to be significant $(\mathrm{F}=9.52 ; \mathrm{df}=6,52 ; \mathrm{P}<0.0001)$. Mean larval weight was highest $(0.216 \mathrm{~g})$ at $37{ }^{\circ} \mathrm{C}$ and lowest $(0.159 \mathrm{~g})$ at $15{ }^{\circ} \mathrm{C}$ when reared on D1 while on D2, mean larval weight was highest $(0.168 \mathrm{~g})$ at $35^{\circ} \mathrm{C}$ and lowest $(0.084 \mathrm{~g})$ at $15{ }^{\circ} \mathrm{C}$.

Pre-pupal weight differed significantly across the temperature treatments $(\mathrm{F}=31.59$; $\mathrm{df}$ $=6,26 ; \mathrm{P}<0.0001$ for $\mathrm{D} 1$ and $\mathrm{F}=15.94 ; \mathrm{df}=6,26 ; \mathrm{P}<0.0001)$. A significant interaction was observed $(\mathrm{F}=6.78 ; \mathrm{df}=6,52 ; \mathrm{P}<0.0001)$ between temperature and diet for pre-pupal weight. The highest mean pre-pupal weight when the larvae were fed on D1 $(0.186 \mathrm{~g})$ or D2 $(0.152 \mathrm{~g})$ was recorded at $35^{\circ} \mathrm{C}$ and the lowest at $20{ }^{\circ} \mathrm{C}(0.121 \mathrm{~g})$ and 15 ${ }^{\circ} \mathrm{C}(0.087 \mathrm{~g})$ for D1 and D2, respectively. Pupal weight was significantly different among temperature regimes $(\mathrm{F}=6.63 ; \mathrm{df}=5,22 ; \mathrm{P}<0.0001$ for $\mathrm{D} 1$ and $\mathrm{F}=17.22$; $\mathrm{df}=5,22$; $\mathrm{P}<0.0001$ for $\mathrm{D} 2)$ and between the rearing diets $(\mathrm{F}=77.28 ; \mathrm{df}=1,44 ; \mathrm{P}<0.0001)$. There was a significant interaction ( $\mathrm{F}=4.56$; $\mathrm{df}=5,44 ; \mathrm{P}=0.002)$ between the effects of temperature and rearing diet on pupal weight. The highest mean pupal weight was recorded at $35{ }^{\circ} \mathrm{C}$ for either D1 (0.145 g) or D2 (0.126 g) while the lowest weight was recorded at $15{ }^{\circ} \mathrm{C}$ for either D1 $(0.122 \mathrm{~g})$ or D2 (0.087 g). Adult weight varied across the temperature treatments for each diet $(\mathrm{F}=113.2$; df $=6,26 ; \mathrm{P}<0.0001$ for D1 and $\mathrm{F}$ $=245.2 ; \mathrm{df}=6,26 ; \mathrm{P}<0.0001)$. The highest mean adult body weight was recorded at $35{ }^{\circ} \mathrm{C}$ for either D1 (0.078 g) or D2 (0.077 g). 
-Diet $1 \quad \square$ Diet 2
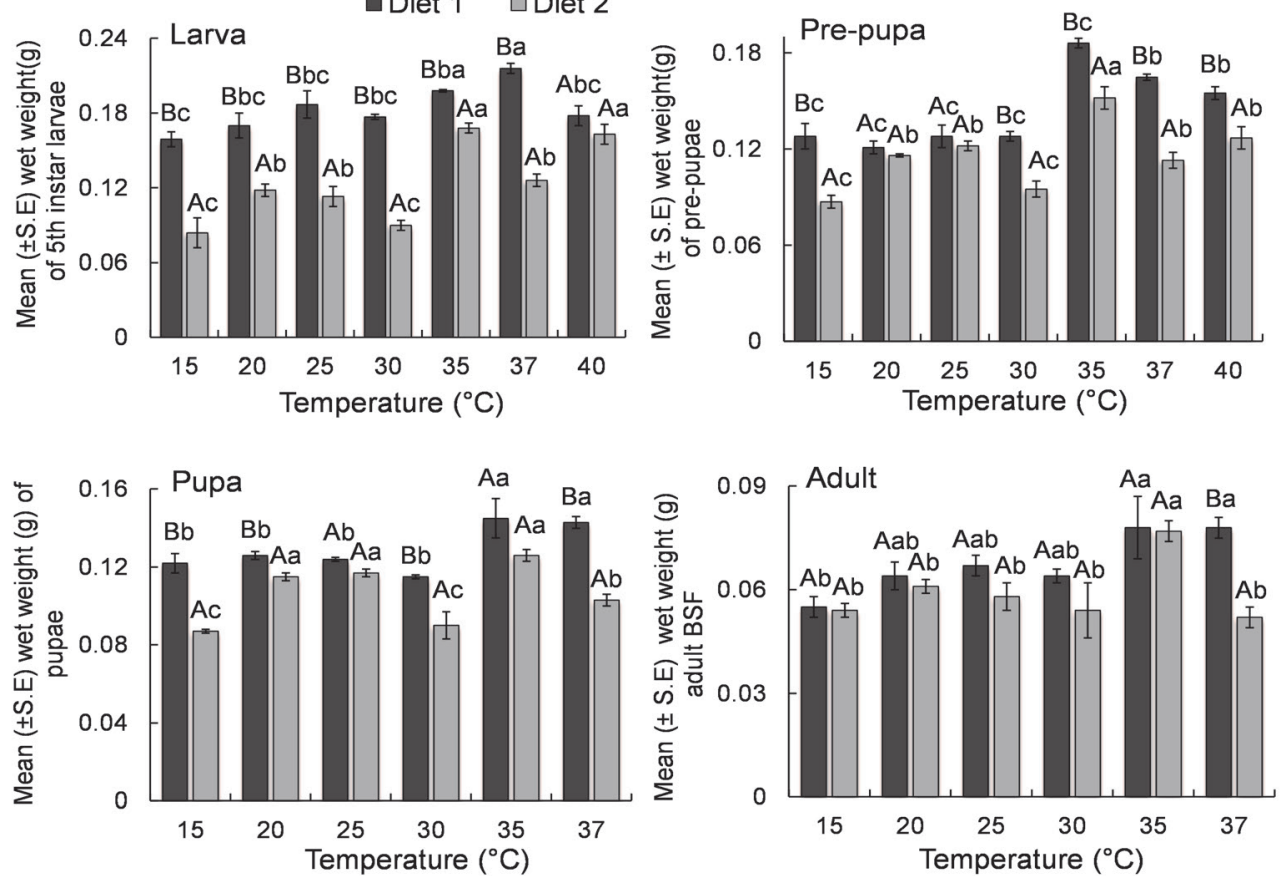

Fig. 7. Mean wet weight of $H$. illucens stages reared on two diets at constant temperatures. Bars within the same dietary treatment with the same lower-case letter are not significantly different. Bars within the same temperature treatment with the same uppercase letter are not significantly different $(\mathrm{P}<0.05, \mathrm{SNK})$.

\section{Temperature-dependent developmental models of $H$. illucens}

Table 2 and Table 3 present the parameter estimates for BSF eggs and immature life stages, respectively, obtained from the non-linear Brière-1 model and linear models fitted to developmental rate. The fitted models for developmental rates $(1 / \mathrm{d})$ versus temperature for all the different life stages are presented in Fig. 8 (egg) and Fig. 9 (larval, pre-pupal and pupal stages). The lower temperature threshold $\left(T_{\text {min }}\right)$ for larval, pre-pupal and pupal stages estimated using Brière- 1 model were lower as compared to estimates of the linear regression model on both diets. Using the linear model, $T_{\text {min }}$ of BSF eggs was estimated at $13.6{ }^{\circ} \mathrm{C}$. For the larvae, pre-pupae and pupae, $T_{\min }$ was estimated as 12.3, 13.3 and $13.3{ }^{\circ} \mathrm{C}$, respectively, for $\mathrm{D} 1$, and $11.7,14.6$ and $12.2^{\circ} \mathrm{C}$, respectively, for D2 (Table 3), which were all similar to that of Brière-1 model estimates. The optimal temperature threshold for larval, pre-pupal and pupal developmental stages reared on D1 were estimated as $31.3-36.0{ }^{\circ} \mathrm{C}$, and $32.3-36.4{ }^{\circ} \mathrm{C}$ for $\mathrm{D} 2$. The upper temperature thresholds were estimated to range from $37.2-44.0^{\circ} \mathrm{C}$ for the different life stages (Table 2 and Table 3). The BSF egg required 50.74 degree-days (DD) for the successful com pletion of eclosion, whereas the larval, pre-pupal and pupal stages required 250.2, 142.9 and 142.9 DD for D1; and 333.3, 125.0 and 111.1 DD for D2, respectively. 
Table 2. Estimates of linear model parameters describing the relationship between temperature and developmental rate of the H. illucens eggs

\begin{tabular}{ll}
\hline Model parameters & Estimate $( \pm$ SE $)$ \\
\hline$a$ & $-0.269 \pm 0.067$ \\
$b$ & $0.011 \pm 0.002$ \\
$T_{\text {min }}$ & $13.647 \pm 1.98$ \\
$k$ & $50.736 \pm 5.751$ \\
$R S S$ & 0.013 \\
$R^{2}$ & 0.940 \\
\hline
\end{tabular}

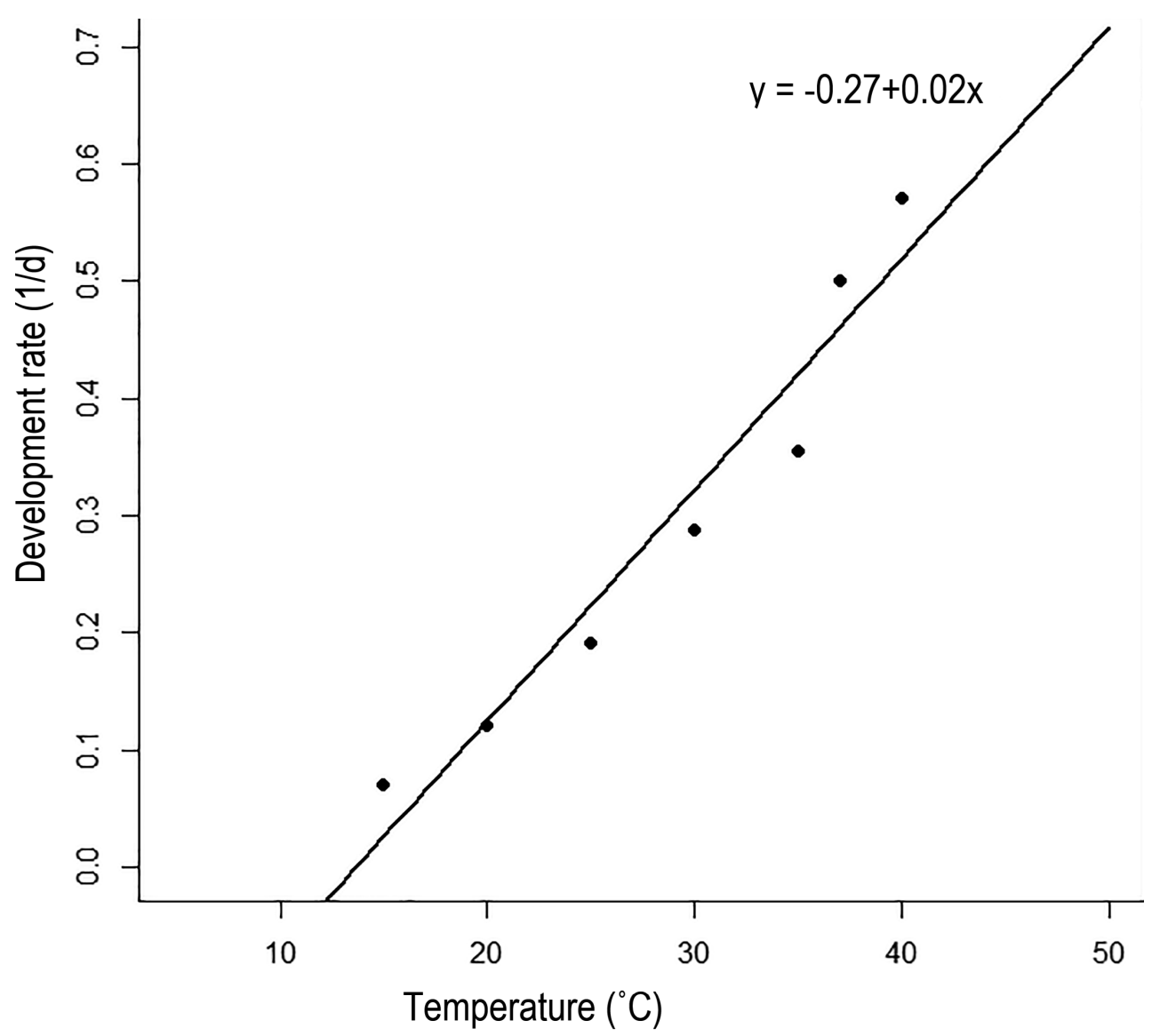

Fig. 8. Linear model fitted to observed values of development rate of $H$. illucens eggs at constant temperatures. 
Table 3. Estimates of model parameters describing the relationship between temperature and developmental rate of $H$. illucens life stages on two diets (D1 and D2)

\begin{tabular}{|c|c|c|c|c|}
\hline Model & $\begin{array}{l}\text { Model } \\
\text { parameters }\end{array}$ & Larva & Pre-pupa & Pupa \\
\hline \multicolumn{5}{|c|}{ D1 } \\
\hline \multirow[t]{6}{*}{ Linear } & $a$ & $-0.049 \pm 0.011$ & $-0.093 \pm 0.042$ & $-0.093 \pm 0.015$ \\
\hline & $b$ & $0.004 \pm 0.001$ & $0.007 \pm 0.002$ & $0.007 \pm 0.001$ \\
\hline & $T_{\min }$ & $12.25 \pm 1.41$ & $13.29 \pm 2.65$ & $13.29 \pm 1.92$ \\
\hline & $k$ & $250.2 \pm 25.50$ & $142.86 \pm 39.17$ & $142.86 \pm 39.17$ \\
\hline & RSS & $5.83 \times 10^{-5}$ & $8.20 \times 10^{-4}$ & $8.20 \times 10^{-4}$ \\
\hline & $R^{2}$ & 0.976 & 0.876 & 0.876 \\
\hline \multirow[t]{4}{*}{ Brière-1 } & $n$ & $2.09 \times 10^{-5}$ & $6.77 \times 10^{-5}$ & $9.59 \times 10^{-5}$ \\
\hline & $T_{\min }$ & $11.74 \pm 0.94$ & $12.17 \pm 3.90$ & $11.75 \pm 1.08$ \\
\hline & $T_{\max }$ & $43.23 \pm 0.47$ & $37.18 \pm 0.29$ & $41.21 \pm 0.81$ \\
\hline & $T_{o p t}$ & 35.99 & 31.26 & 34.39 \\
\hline \multicolumn{5}{|c|}{ D2 } \\
\hline \multirow[t]{6}{*}{ Linear } & $a$ & $-0.035 \pm 0.011$ & $-0.117 \pm 0.036$ & $-0.110 \pm 0.024$ \\
\hline & $b$ & $0.003 \pm 0.001$ & $0.008 \pm 0.002$ & $0.009 \pm 0.001$ \\
\hline & $T_{\min }$ & $11.67 \pm 3.00$ & $14.63 \pm 1.83$ & $12.22 \pm 1.67$ \\
\hline & $k$ & $333.33 \pm 50.59$ & $125.00 \pm 25.88$ & $111.11 \pm 11.90$ \\
\hline & $R S S$ & $5.80 \times 10^{-5}$ & $5.91 \times 10^{-4}$ & $2.58 \times 10^{-4}$ \\
\hline & $R^{2}$ & 0.954 & 0.926 & 0.976 \\
\hline \multirow[t]{4}{*}{ Brière-1 } & $n$ & $2.93 \times 10^{-5}$ & $7.50 \times 10^{-5}$ & $7.92 \times 10^{-5}$ \\
\hline & $T_{\min }$ & $10.39 \pm 1.68$ & $14.28 \pm 3.41$ & $10.66 \pm 1.96$ \\
\hline & $T_{\max }$ & $41.22 \pm 0.34$ & $38.02 \pm 0.97$ & $43.99 \pm 2.34$ \\
\hline & $T_{o p t}$ & 34.20 & 32.25 & 36.44 \\
\hline
\end{tabular}



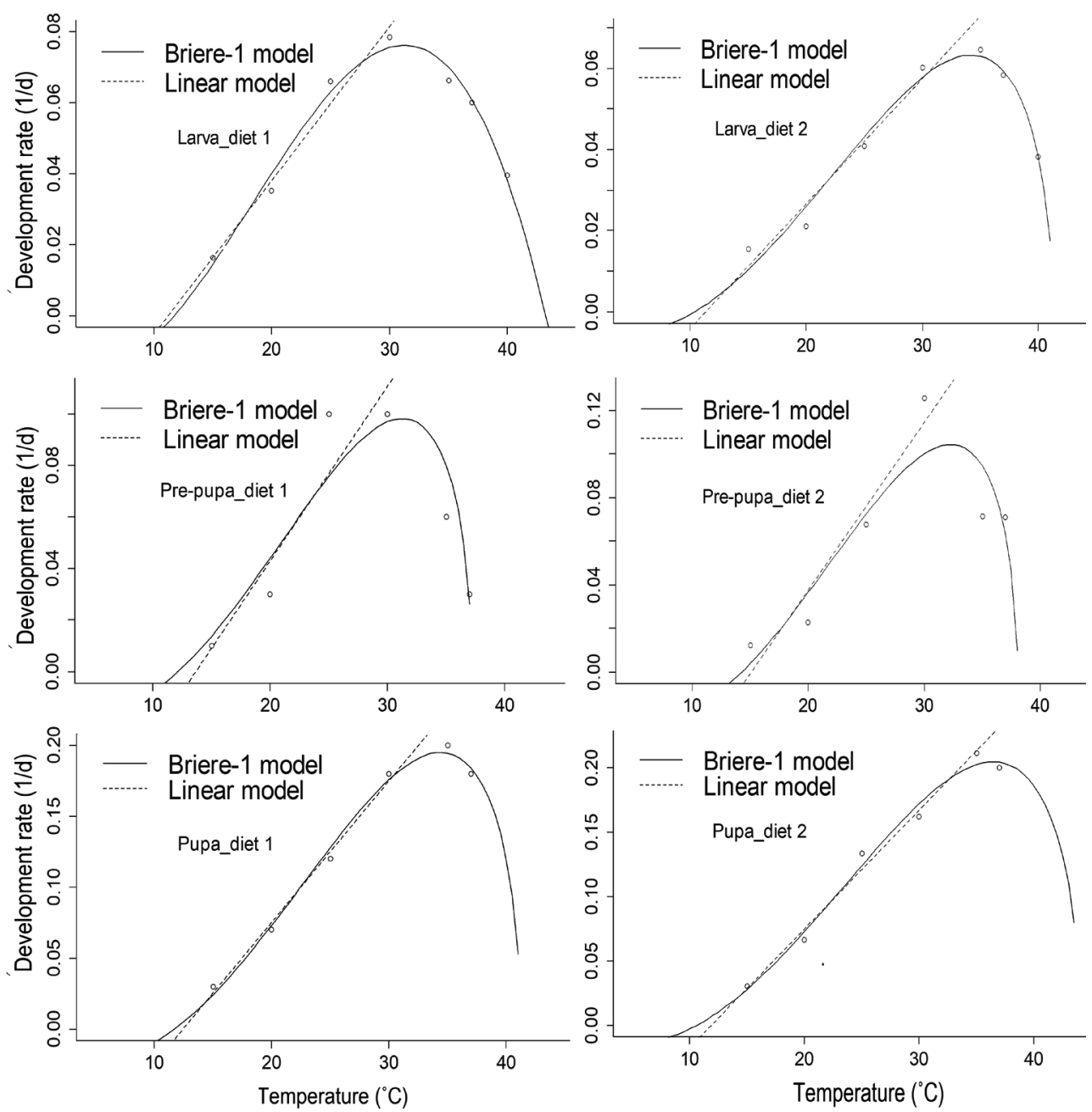

Fig. 9. Linear and non-linear models fitted to observed values of the development rate of H. illucens life stages at constant temperatures.

\section{Estimated life table parameters of $H$. illucens reared on two diets at different temperatures}

The net reproductive rate $\left(\mathrm{R}_{\alpha}\right)(\mathrm{F}=4.57 ; \mathrm{df}=3,13 ; \mathrm{P}=0.021$ for $\mathrm{D} 1$ and $\mathrm{F}=5.79 ; \mathrm{df}=$ $3,13 ; \mathrm{P}=0.010$ for $\mathrm{D} 2)$, intrinsic rate of increase $(\mathrm{rm})(\mathrm{F}=26.91 ; \mathrm{df}=3,13 ; \mathrm{P}<0.0001$ for $\mathrm{D} 1$ and $\mathrm{F}=30.68 ; \mathrm{df}=3,13 ; \mathrm{P}<0.0001$ for $\mathrm{D} 2)$, gross reproductive rate (GRR) $(\mathrm{F}=3.33 ; \mathrm{df}=3,13 ; \mathrm{P}=0.053$ for $\mathrm{D} 1$ and $\mathrm{F}=3.86 ; \mathrm{df}=3,13 ; \mathrm{P}=0.036$ for $\mathrm{D} 2)$ and finite rate of increase $(\lambda)(F=25.36$; df $=3,13 ; \mathrm{P}<0.0001$ for $\mathrm{D} 1$ and $\mathrm{F}=28.95$; $\mathrm{df}=$ $3,13 ; \mathrm{P}<0.0001$ for $\mathrm{D} 2)$ values were significantly higher at $30^{\circ} \mathrm{C}$, when compared to the 
other temperature treatments evaluated (Table 4). The doubling time $\left(\mathrm{T}_{\mathrm{d}}\right)(\mathrm{F}=28.14$; $\mathrm{df}=3,13 ; \mathrm{P}<0.0001$ for $\mathrm{D} 1$ and $\mathrm{F}=29.64$; $\mathrm{df}=3,13 ; \mathrm{P}<0.0001$ for $\mathrm{D} 2)$ and mean generation time $(G)(\mathrm{F}=751.60$; $\mathrm{df}=3,13 ; \mathrm{P}=0.0001$ for $\mathrm{D} 1$ and $\mathrm{F}=11.84$; $\mathrm{df}=3$, 13 ; $\mathrm{P}=0.0001$ for $\mathrm{D} 2)$ at $30{ }^{\circ} \mathrm{C}$ was significantly shorter compared to the other temperature treatments evaluated. The values of $R_{o}$ generated for all the temperatures and diets indicated significant growth of $H$. illucens population rather than a decline. In addition, for all temperature treatments and diets, analysis of life table and fecundity parameters yielded positive values of intrinsic rate of increase. 


\section{Discussion}

The rate of black soldier fly growth and development was considerably influenced by temperature and diet, which are the two most critical environmental factors. Previous studies have shown that insects including the BSF are sensitive to several environmental factors, especially temperature, which is considered the most important abiotic factor (Ratte, 1984) that can impact not only insect developmental rate, seasonal and daily cycles (Logan et al., 1976) but also, indirectly effect different aspects of the insect biology, such as immature survival, adult life span, growth, fecundity, fertility and population growth parameters (Gabre et al., 2005; Schneider, 2009; Summers et al., 1984). As such, temperature would profoundly influence the behaviour, abundance, colonization, distribution, life table parameters and fitness of the insect species. Thus, knowledge generated on thermal requirements of $H$. illucens' development will have significant implications for production programs. Life history studies would provide successful ways of following up changes in a population's growth and several other important aspects of the insect's life cycle that are temperature-dependent (Golizadeh et al., 2009; Karimi-Malati et al., 2014a; Karimi-Malati et al., 2014b; Khanamani et al., 2013; Park et al., 2014; Schneider, 2009). Here, we used nine different constant temperatures to evaluate the influence that different temperature regimes would have on black soldier fly development. The lower $\left(10{ }^{\circ} \mathrm{C}\right)$ temperature was lethal to the insects given that all the eggs completely failed to hatch at this temperature.

Our results confirmed the sensitivity of BSF to extremely low and high temperatures as indicated in previous studies (Holmes et al., 2016; Tomberlin et al., 2009). Egg viability and hatchability observed in this study occurred between $15-40{ }^{\circ} \mathrm{C}$. Our observation at lower temperature threshold concurs with that presented by Holmes et al. (2016) at 16 ${ }^{\circ} \mathrm{C}$. The levels of egg viability at 15 and $40{ }^{\circ} \mathrm{C}$ were extremely low $(<12 \%)$, which is consistent with the report by Holmes et al. (2016) at $16^{\circ} \mathrm{C}$. The present result is consistent with the results obtained by Holmes et al. (2013). Contrary to observations by Holmes et al. (2016), who reported that newly hatched larvae of BSF failed to survive at $16{ }^{\circ} \mathrm{C}$, we found that BSF young larvae at $15{ }^{\circ} \mathrm{C}$ did not die after hatching, suggesting that the lower developmental threshold for BSF eggs could be at $15{ }^{\circ} \mathrm{C}$. Thus, hatchability or egg eclosion could be a pointer to colony efficiency in any mass-rearing systems (Vantomme et al., 2012). According to previous studies, nutrient quality of larval food has been shown to have considerable influence on the amount and quality of emerged adult flies, which indirectly affects the developmental duration, survival and growth of the black soldier larvae (Ekesi et al., 2007; Kaspi et al., 2002; Krainacker et al., 1987; Tomberlin et al., 2009; Vargas et al., 1994). The two types of diet tested in this study supported the development of $H$. illucens larvae. All BSF life stages (larval, pre-pupal and pupal) completed development to adults in the range of $15-37^{\circ} \mathrm{C}$. Survivorship rates of BSF 
immature life stages differed remarkably at different temperature regimes. Temperature treatments below $15{ }^{\circ} \mathrm{C}$ and above $40{ }^{\circ} \mathrm{C}$ were unfavourable with complete mortality of H. illucens life stages observed. The present study showed that the upper temperature for larval survival was $40{ }^{\circ} \mathrm{C}$, with survival of 34 and $28 \%$ on D1 and D2, respectively. Only 5 and $20 \%$ of the flies from D1 and D2, respectively, at $37{ }^{\circ} \mathrm{C}$ emerged as adults; many of the flies showed signs of crippling malformations (i.e. could neither walk nor fly normally and were unable to feed).

At $40{ }^{\circ} \mathrm{C}$, none of the pre-pupal stages successfully completed development to proceed to pupal stage on the various diets. These findings slightly deviate from those reported by Tomberlin et al. (2009), who showed that although $73 \%$ of $H$. illucens larvae were able to develop and survive to pre-pupae (post-feeding stage) at $36^{\circ} \mathrm{C}$, only $0.1 \%$ of pupae successfully developed and emerged as adults, thus implying an upper developmental temperature threshold at $36^{\circ} \mathrm{C}$. The reasons for these differences between the two studies are unknown but nutrient content of diet types, geographical strains of the two populations (Kenyan and Texas, USA populations) and adaptations of both populations of $H$. illucens might have contributed to the observed variation. Furthermore, this is supported by other studies in the literature (Diamantidis et al., 2011; Vargas \& Carey, 1989), which revealed that insect populations from various geographical landscapes may vary in their reproductive fitness and life table traits (Nedvěd \& Honĕk, 2012). The linear relationship between the developmental rates and temperature for rearing BSF life was positive. The estimated lower temperature developmental threshold (LTDT) of BSF eggs according to the linear model was $13.65{ }^{\circ} \mathrm{C}$. Here, we publish the first report on LTDT of BSF immature life stages, which is consistent with reports of other dipteran species like tephritid fruit flies (Duyck \& Quilici, 2002; Tanga et al., 2015). The divergence observed between the different reported LTDTs may be attributed to variations in rearing conditions and possible feedstocks utilized as food for the BSF larvae (Xue et al., 2010). The optimum developmental temperature range for $H$. illucens life stages reared on D1 was $31.3-36.0{ }^{\circ} \mathrm{C}$ and $32.3-36.4{ }^{\circ} \mathrm{C}$ on $\mathrm{D} 2$. In literature, there are no studies reported with regards to upper developmental threshold or lethal upper temperature thresholds of BSF, which according to the present study were estimated to range between $37.2-44.0^{\circ} \mathrm{C}$ for the various developmental stages. Lethal temperature thresholds established in the current study may be applicable for future mass production technology programs for BSF. The present findings revealed that the eggs required 50.74 degree-days (DD) to complete development to the next stage (larval stage). Total degree days required for BSF larval stages to successfully change to the pre-pupal stage was recorded at developmental temperature threshold of $10.4-14.3^{\circ} \mathrm{C}$, which was higher (250-333 DD) compared to the other BSF life stages investigated (<150 DD). Several authors have also reported discrepancies in thermal requirements for different insect species and immature life 
stages, which can be ascribed to differences in methodological approaches or aspects related to larval food quality and quantity as well as larval density in the rearing facilities (Duyck \& Quilici, 2002; Fletcher, 1989; Trudgill et al., 2005; Vargas et al., 1996). It is worth noting that insects require fewer degree days for development when fed on high quality food resources compared to low quality resources (Amalraj et al., 2005), which explains the considerable variation observed when the larvae were provided the two types of diet in the present study. Pronounced quality control parameters observed in this study included high pupal recovery and heavier puparia when the fly larvae fed on $\mathrm{D} 1$, which was supplemented with brewers' yeast compared with those fed on D2 (not supplemented). It is important to note that the pupal mass of insects have been demonstrated to be a practical quality control benchmark in insect mass rearing facilities, where size has been observed to show strong correlation with male fly mating successes (Churchill-Stanland et al., 1986). Furthermore, the insect pupal weight has been used as an estimate of size, (Churchill-Stanland et al., 1986) and revealed that adult flies eclosing from heavy pupae showed higher mating success than those resulting from lower weight pupae. Also, large flies have been shown to demonstrate better flight capability than smaller flies (Sharp et al., 1983). Heavy female insects have also been shown to have a proportionately higher lifetime fecundity compared to less heavier females (Karlsson \& Wickman, 1990). This implies that increased pupal weights will produce larger individuals (adults). Thus, from a commercial point of view, this highlights the significance of safeguarding maximum pupation while optimizing female-to-male ratio to promote healthy mating behaviour within the insect stock colony (Singh, 1982; Tch-uinkam et al., 2011; Vantomme et al., 2012). Black soldier fly fecundity recorded is an important parameter, which was observed to be directly related to differences in the temperature regimes. This attribute has been documented in different insects, where an increase in rearing temperature frequently results in visible decrease in female fly productivity or complete cessation of egg production (Mehrparvar \& Hatami, 2007; Vasicek et al., 2002), as realized fecundity could have been restricted by both temperature dependency of egg maturation and oviposition (Berger et al., 2008). The present study demonstrates that adult female BSF reared on the two diets were capable of reproducing between the temperature range of $20-35^{\circ} \mathrm{C}$. We also observed increased physical inactivity of larvae and reduced feed intake followed by death with increase in temperature $\left(>35^{\circ} \mathrm{C}\right)$. The male and female flies' lifespan gradually decreased with increased temperature from 15 to $37^{\circ} \mathrm{C}$. Thus, at temperatures above $35^{\circ} \mathrm{C}$, the longevity of adult female flies was $4-5$ times less compared to those at $15{ }^{\circ} \mathrm{C}$. The life time fecundity of black soldier flies was temperature-dependent revealing a curvilinear response curve for fecundity to reach its maximum at $30{ }^{\circ} \mathrm{C}$ with a decrease at temperature levels below and above this temperature. This implies that the prevailing optimal temperature recorded in the present study can play a major role in defining climatic fitness for mating and oviposition of adult black soldier flies. The phenomenon of decreased female fecundity has become 
noticeable in different insects in the face of temperature increase (Mehrparvar \& Hatami, 2007; Vasicek et al., 2002). A comparable trend in temperature-dependent fecundity has been observed for different insects with temperatures between $25-30{ }^{\circ} \mathrm{C}$ reported as suitable for reproduction, whereas temperatures above $35{ }^{\circ} \mathrm{C}$ remained extremely unfavourable (Tanga et al., 2018).

Our study reports for the first time the effect of temperature on $H$. illucens' fecundity with slightly higher number of eggs oviposited per female throughout its lifespan in comparison to that documented in literature (Tomberlin et al., 2002). This could be attributed to the dissimilar ovipositional behavioural response of BSF when fed on various diets (Tomberlin et al., 2002). Oviposition pattern of insects is an important life table component, thus information on temperature-driven, age-specific off-spring production is critical for generating models that forecast BSF population growth (Wagner et al., 1984). However, fecundity is affected by many factors, which include larval and adult density, availability of feedstock, nutrition of immature life stages, and several environmental factors, which need to be studied further to improve BSF mass-production. Life-table data offer readily available means of tracking population growth as well as other changes (Khanamani et al., 2013), and remain the most powerful tool for analyzing and understanding the impact that abiotic factors have upon the growth, survival, reproduction and rate of increase of an insect population (Bellows et al., 1992). The impact of temperature on BSF life table parameters is reported here for the first time and describes a series of temperature regimes, which are within the ecological niche suitability limits related to BSF development, establishment and colonization. These findings provide answers to the optimum developmental threshold temperature conditions of $\mathrm{BSF}$ mass production with $30^{\circ} \mathrm{C}$ being the most favourable temperature with higher intrinsic rate of natural increase and shorter doubling time. Thus, the implication of using life table information to improve mass rearing conditions has been reported for many insect species by assessing the variations in their reproductive rate and the total number of female offspring produced per female per generation (Birch, 1948). The intrinsic rate of natural increase is extremely essential as it describes the population increase of insects in an unrestricted environment, basically addressing the differences between birth rate and death rate (Birch, 1948) when the insects are exposed to various food sources (Fouly et al., 1995; Hansen et al., 1999; Hodek \& Honek, 1996; Richards \& Evans, 1998; Souissi \& Le Ru, 1997; Valicente \& Oneil, 1995). 


\section{Acknowledgments}

We thank Joshua Wambua, Rachami Isaiah E. and Faith Nyamu Wamurango for their substantial contribution and technical support during data collection. This study was financially supported by the Netherlands Organization for Scientific Research (NWO)WOTRO Science for Global Development (ILIPA - W 08.250.202). Authors declare no conflicts of interest.

\section{References}

Amalraj, D. D., Sivagnaname, N., \& Das, P. (2005). Effect of food on immature development, consumption rate, and relative growth rate of Toxorbynchites splendens (Diptera: Culicidae), a predator of container breeding mosquitoes. Memorias do Instituto Oswaldo Cru₹, 100, 893902.

Andreadis, S. S., Kagkelaris, N. K., Eliopoulos, P. A., \& Savopoulou-Soultani, M. (2013). Temperature-dependent development of Sesamia nonagrioides. Journal of Pest Science, 86, 409-417.

Baek, S., Son, Y., \& Park, Y. L. (2014). Temperature-dependent development and survival of Podisus maculiventris (Hemiptera: Pentatomidae): implications for mass rearing and biological control. Journal of Pest Science, 87, 331-340.

Bale, J. S., Masters, G. J., Hodkinson, I. D., Awmack, C., Bezemer, T. M., Brown, V. K., ... . Whittaker, J. B. (2002). Herbivory in global climate change research: direct effects of rising temperature on insect herbivores. Global Change Biology, 8, 1-16.

Barragan-Fonseca, K. B., Dicke, M., \& van Loon, J. J. A. (2017). Nutritional value of the black soldier fly (Hermetia illucens L.) and its suitability as animal feed-a review. Journal of Insects as Food and Feed, 3, 105-120.

Bellows, J. T., Van Driesche, R., \& Elkinton, J. (1992). Life-table construction and analysis in the evaluation of natural enemies. Annual Review of Entomology, 37, 587-612.

Berger, D., Walters, R., \& Gotthard, K. (2008). What limits insect fecundity? Body size-and temperature-dependent egg maturation and oviposition in a butterfly. Functional Ecology, 22, 523-529.

Birch, L. C. (1948). The intrinsic rate of natural increase of an insect population. Journal of $A n$ imal Ecology, 17, 15-26.

Bonso, N. K. (2013). Bioconversion of organic fraction of solid waste using the larvae of the black soldier fly (Hermentia illucens). Master of Science, Kwame Nkrumah University of Science and Technology, Kumasi-Ghana.

Booth, D. C., \& Sheppard, C. (1984). Oviposition of the black soldier fly, Hermetia illucens (Diptera, Stratiomyidae) - eggs, masses, timing, and site characteristics. Environmental Entomology, 13, 421-423.

Brevault, T., \& Quilici, S. (2000). Relationships between temperature, development and survival of different life stages of the tomato fruit fly, Neoceratitis cyanescens. Entomologia Experimentalis et Applicata, 94, 25-30.

Briere, J. F., \& Pracros, P. (1998). Comparison of temperature-dependent growth models with the development of Lobesia botrana (Lepidoptera: Tortricidae). Environmental Entomology, 27, 94-101. 
Briere, J. F., Pracros, P., Le Roux, A. Y., \& Pierre, J. S. (1999). A novel rate model of temperature-dependent development for arthropods. Environmental Entomology, 28, 22-29.

Cammack, J. A., \& Tomberlin, J. K. (2017). The impact of diet protein and carbohydrate on select life-history traits of the black soldier fly Hermetia illucens (L.) (Diptera: Stratiomyidae). Insects, 8, 56.

Campbell, A., Frazer, B. D., Gilbert, N., Gutierrez, A. P., \& Mackauer, M. (1974). Temperature requirements of some aphids and their parasites. Journal of Applied Ecology, 11, 431-438.

Carey, J. R. (1993). Applied demography for biologists: with special emphasis on insects. New York: Oxford University Press.

Churchill-Stanland, C., Stanland, R., Wong, T. T., Tanaka, N., McInnis, D. O., \& Dowell, R. V. (1986). Size as a factor in the mating propensity of Mediterranean fruit flies, Ceratitis capitata (Diptera: Tephritidae), in the laboratory. Journal of Economic Entomology, 79, 614-619.

Diamantidis, A. D., Carey, J. R., Nakas, C. T., \& Papadopoulos, N. T. (2011). Population-specific demography and invasion potential in medfly. Ecology and Evolution, 1, 479-488.

Diener, S., Zurbrugg, C., \& Tockner, K. (2009). Conversion of organic material by black soldier fly larvae: establishing optimal feeding rates. Waste Management \& Research, 27, 603-610.

Dixon, A. F. G., Honek, A., Keil, P., Kotela, M. A. A., Sizling, A. L., \& Jarosik, V. (2009). Relationship between the minimum and maximum temperature thresholds for development in insects. Functional Ecology, 23, 257-264.

Duyck, P. F., \& Quilici, S. (2002). Survival and development of different life stages of three Ceratitis spp. (Diptera : Tephritidae) reared at five constant temperatures. Bulletin of Entomological Research, 92, 461-469.

Ekesi, S., Nderitu, P. W., \& Chang, C. L. (2007). Adaptation to and small-scale rearing of invasive fruit fly Bactrocera invadens (Diptera : Tephritidae) on artificial diet. Annals of the Entomological Society of America, 100, 562-567.

Fand, B. B., Tonnang, H. E. Z., Kumar, M., Kamble, A. L., \& Bal, S. K. (2014). A temperature-based phenology model for predicting development, survival and population growth potential of the mealybug, Phenacoccus solenopsis Tinsley (Hemiptera: Pseudococcidae). Crop Protection, 55, 98-108.

Fletcher, B. (1989). Temperature-development rate relationships of the immature stages and adults of Tephritid fruit flies. In A. S. Robinson \& G. Hooper (Eds.), Fruit Flies: Their biology, natural enemies and control (pp. 273-289). Amsterdam: Elsevier.

Fouly, A. H., Abousetta, M. M., \& Childers, C. C. (1995). Effects of diet on the biology and life-tables of Typhlodromalus peregrinus (Acari, Phytoseiidae). Environmental Entomology, 24, 870-874.

Gabre, R. A., Adham, F. K., \& Chi, H. (2005). Life table of Chrysomya megacephala (Fabricius) (Diptera : Calliphoridae). Acta Oecologica-International Journal of Ecology, 27, 179-183.

Golizadeh, A., Kamali, K., Fathipour, Y., \& Abbasipour, H. (2009). Effect of temperature on life table parameters of Plutella xylostella (Lepidoptera: Plutellidae) on two brassicaceous host plants. Journal of Asia-Pacific Entomology, 12, 207-212.

Goulson, D., Derwent, L. C., Hanley, M. E., Dunn, D. W., \& Abolins, S. R. (2005). Predicting calyptrate fly populations from the weather, and probable consequences of climate change. Journal of Applied Ecology, 42, 795-804.

Hansen, D. L., Brodsgaard, H. F., \& Enkegaard, A. (1999). Life table characteristics of Macrolophus caliginosus preying upon Tetranychus urticae. Entomologia Experimentalis et Applicata, 
93, 269-275.

Harnden, L. M., \& Tomberlin, J. K. (2016). Effects of temperature and diet on black soldier fly, Hermetia illucens (L.) (Diptera: Stratiomyidae), development. Forensic Science International, 266, 109-116.

Hodek, I., \& Honek, A. (1996). Ecology of Coccinellidae. Dordrecht Springer.

Holmes, L. A., Vanlaerhoven, S. L., \& Tomberlin, J. K. (2013). Substrate effects on pupation and adult emergence of Hermetia illucens (Diptera: Stratiomyidae). Environmental Entomology, 42, 370-374.

Holmes, L. A., VanLaerhoven, S. L., \& Tomberlin, J. K. (2016). Lower temperature threshold of black soldier fly (Diptera: Stratiomyidae) development. Journal of Insects as Food and Feed, 2, 255-262.

Honěk, A., \& Kocourek, F. (1990). Temperature and development time in insects: a general relationship between thermal constants. Zoologische Jahrbücher, Abteilung für Systematik, Ökologie und Geographie der Tiere, 117, 401-439.

Karimi-Malati, A., Fathipour, Y., \& Talebi, A. A. (2014a). Development response of Spodoptera exigua to eight constant temperatures: Linear and nonlinear modeling. Journal of Asia-Pacific Entomology, 17, 349-354.

Karimi-Malati, A., Fathipour, Y., Talebi, A. A., \& Bazoubandi, M. (2014b). Life table parameters and survivorship of Spodoptera exigua (Lepidoptera: Noctuidae) at constant temperatures. Environmental Entomology, 43, 795-803.

Karlsson, B., \& Wickman, P. O. (1990). Increase in reproductive effort as explained by body size and resource-allocation in the speckled wood butterfly, Pararge aegeria (L). Functional Ecology, 4, 609-617.

Kaspi, R., Mossinson, S., Drezner, T., Kamensky, B., \& Yuval, B. (2002). Effects of larval diet on development rates and reproductive maturation of male and female Mediterranean fruit flies. Physiological Entomology, 27, 29-38.

Khanamani, M., Fathipour, Y., \& Hajiqanbar, H. (2013). Population growth response of Tetranychus urticae to eggplant quality: application of female age-specific and age-stage, two-sex life tables. International Journal of Acarology, 39, 638-648.

Krainacker, D. A., Carey, J. R., \& Vargas, R. I. (1987). Effect of larval host on life history traits of the Mediterranean fruit fly, Ceratitis capitata. Oecologia, 73, 583-590.

Lalander, C. H., Fidjeland, J., Diener, S., Eriksson, S., \& Vinneras, B. (2015). High waste-to-biomass conversion and efficient Salmonella spp. reduction using black soldier fly for waste recycling. Agronomy for Sustainable Development, 35, 261-271.

Liu, X. F., \& Ye, H. (2009). Effect of temperature on development and survival of Bactrocera correcta (Diptera: Tephritidae). Scientific Research and Essays, 4, 467-472.

Logan, J. A., Wollkind, D. J., Hoyt, S. C., \& Tanigoshi, L. K. (1976). An analytic model for description of temperature dependent rate phenomena in arthropods. Environmental Entomology, 5, 1133-1140.

Makkar, H. P. S., Tran, G., Henze, V., \& Ankers, P. (2014). State-of-the-art on use of insects as animal feed. Animal Feed Science and Technology, 197, 1-33.

Marshall, S., Woodley, N., \& Hauser, M. (2015). The historical spread of the black soldier fly, Hermetia illucens (L.)(Diptera, Stratiomyidae, Hermetiinae), and its establishment in Canada. The Journal of the Entomological Society of Ontario, 146, 51-54.

Mehrparvar, M., \& Hatami, B. (2007). Effect of temperature on some biological parameters of 
an Iranian population of the rose aphid, Macrosiphum rosae (Hemiptera: Aphididae). European Journal of Entomology, 104, 631-634.

Nedvěd, O., \& Honĕk, A. (2012). Life history and development. In I. Hodek, A. Honek, \& H. F. van Emden (Eds.), Ecology and Behaviour of the Ladybird Beetles (Coccinellidae) (pp. 54-109). West Sussex, United Kingdom: John Wiley \& Sons.

Newton, L., C. Sheppard, D., W. Watson, D., Burtle, G., R. Dove, C., Tomberlin, J., \& E. Thelen, E. (2005). The black soldier fly, Hermetia illucens, as a manure management/resource recovery tool Retrieved from: https://pdfs.semanticscholar.org/5aa5/81bf66145ee15551c0a86df6436b9183fd05.pdf.

Nguyen, T. T., Tomberlin, J. K., \& Vanlaerhoven, S. (2013). Influence of resources on Hermetia illucens (Diptera: Stratiomyidae) larval development. Journal of Medical Entomology, 50, 898906.

Oliveira, F., Doelle, K., \& Smith, R. (2016). External Morphology of Hermetia illucens Stratiomyidae: Diptera (L.1758) based on electron microscopy. Annual Research \& Review in Biology, 9, 1-10.

Park, H.-H., Ahn, J. J., \& Park, C.-G. (2014). Temperature-dependent development of Cnaphalo crocis medinalis Guenée (Lepidoptera: Pyralidae) and their validation in semi-field condition. Journal of Asia-Pacific Entomology, 17, 83-91.

Portilla, M., Morales-Ramos, J. A., Rojas, M. G., \& Blanco, C. A. (2014). Life tables as tools of evaluation and quality control for arthropod mass production. In J. A. Morales-Ramos, M. Guadalupe Rojas, \& D. I. Shapiro-Ilan (Eds.), Mass production of beneficial organisms (pp. 241-275): Academic Press.

R Core Team. (2017). R: A language and environment for statistical computing. Vienna.

Ratte, H. T. (1984). Temperature and insect development. In K. H. Hoffmann (Ed.), Environmental physiology and biochemistry of insects (pp. 33-66). Berlin, Heidelberg: Springer.

Richards, D. R., \& Evans, E. W. (1998). Reproductive responses of aphidophagous lady beetles (Coleoptera : Coccinellidae) to nonaphid diets: An example from alfalfa. Annals of the Entomological Society of America, 91, 632-640.

Roy, S., Chakraborty, S. K., Parui, P., \& Mitra, B. (2016). Taxonomy of soldier flies (Diptera: Stratiomyidae) of Sunderban Biosphere Reserve, India. Proceedings of the Zoological Society, 71, 121-126.

Rumpold, B. A., \& Schluter, O. K. (2013). Nutritional composition and safety aspects of edible insects. Molecular Nutrition \& Food Research, 57, 802-823.

Rwomushana, I., Ekesi, S., Ogol, C. K. P. O., \& Gordon, I. (2008). Effect of temperature on development and survival of immature stages of Bactrocera invadens (Diptera: Tephritidae). Journal of Applied Entomology, 132, 832-839.

Salum, J., Mwatawala, M., Kusolwa, P., \& Meyer, M. (2014). Demographic parameters of the two main fruit fly (Diptera: Tephritidae) species attacking mango in Central Tanzania. Journal of Applied Entomology, 138, 441-448.

Sanchez-Muros, M. J., Barroso, F. G., \& Manzano-Agugliaro, F. (2014). Insect meal as renewable source of food for animal feeding: a review. Journal of Cleaner Production, 65, 16-27.

Saska, P., van der Werf, W., Hemerik, L., Luff, M. L., Hatten, T. D., Honek, A., \& Pocock, M. (2013). Temperature effects on pitfall catches of epigeal arthropods: a model and method for bias correction. Journal of Applied Ecology, 50, 181-189.

Schneider, J. C. (2009). Environmental biology of insect rearing. In J. C. Schneider (Ed.), 
Principles and procedures for rearing high quality insects (pp. 97-120): Mississippi State University.

Sharp, J. L., Boller, E. F., \& Chambers, D. L. (1983). Selection for flight propensity of laboratory and wild strains of Anastrepha suspensa and Ceratitis capitata (Diptera, Tephritidae). Journal of Economic Entomology, 76, 302-305.

Sheppard, D. C., Newton, G. L., Thompson, S. A., \& Savage, S. (1994). A value added manure management system using the black soldier fly. Bioresource Technology, 50, 275-279.

Singh, P. (1982). The Rearing of Beneficial Insects. New Zealand Entomologist, 7, 304-310.

Sørensen, J., \& Loeschcke, V. (2001). Larval crowding in Drosophila melanogaster induces Hsp70 expression, and leads to increased adult longevity and adult thermal stress resistance. Journal of Insect Physiology, 47, 1301-1307.

Souissi, R., \& Le Ru, B. (1997). Comparative life table statistics of Apoanagyrus lopezi reared on pression, and leads to increased adult longevity and adult thermal stress resistance. Journal of the cassava mealybug Phenacoccus manihoti fed on four host plants. Entomologia Experimentalis et Applicata, 85, 113-119.

Sripontan, Y., Juntavimon, T., Songin, S., \& Chiu, C. (2017). Egg-trapping of black soldier fly, Hermetia illucens (L.)(Diptera: Stratiomyidae) with various wastes and the effects of. Khon Kaen Agricultural Journal, 45, 179-184.

St-Hilaire, S., Sheppard, C., Tomberlin, J. K., Irving, S., Newton, L., McGuire, M. A., . . Sealey, W. (2007). Fly pre-pupae as a feedstuff for rainbow trout, Oncorbynchus mykiss. Journal of the World Aquaculture Society, 38, 59-67.

Summers, C. G., Coviello, R. L., \& Gutierrez, A. P. (1984). Influence of constant temperatures on the development and reproduction of Acyrthosiphon-Kondoi (Homoptera, Aphididae). Environmental Entomology, 13, 236-242.

Tanga, C. M., Khamis, F. M., Tonnang, H. E. Z., Rwomushana, I., Mosomtai, G., Mohamed, S. A., \& Ekesi, S. (2018). Risk assessment and spread of the potentially invasive Ceratitis rosa Karsch and Ceratitis quilicii De Meyer, Mwatawala \& Virgilio sp Nov using life-cycle simulation models: Implications for phytosanitary measures and management. PLOS ONE, 13, e0189138.

Tanga, C. M., Manrakhan, A., Daneel, J. H., Mohamed, S. A., Fathiya, K., \& Ekesi, S. (2015). Comparative analysis of development and survival of two Natal fruit fly Ceratitis rosa Karsch (Diptera, Tephritidae) populations from Kenya and South Africa. ZooKeys, 467-487.

Tchuinkam, T., Mpoame, M., Make-Mveinhya, B., Simard, F., Lele-Defo, E., Zebaze-Togouet, S., . . Fontenille, D. (2011). Optimization of breeding output for larval stage of Anopheles gambiae (Diptera: Culicidae): prospects for the creation and maintenance of laboratory colony from wild isolates. Bulletin of Entomological Research, 101, 259-269.

Tomberlin, J. K., Adler, P. H., \& Myers, H. M. (2009). Development of the black soldier fly (Diptera: Stratiomyidae) in relation to temperature. Environmental Entomology, 38, 930-934.

Tomberlin, J. K., Sheppard, D. C., \& Joyce, J. A. (2002). Selected life-history traits of black soldier flies (Diptera : Stratiomyidae) reared on three artificial diets. Annals of the Entomological Society of America, 95, 379-386.

Trudgill, D., Honek, A., Li, D., \& Van Straalen, N. (2005). Thermal time-concepts and utility. Annals of Applied Biology, 146, 1-14.

Valicente, F. H., \& Oneil, R. J. (1995). Effects of host plants and feeding regimes on selected life-history characteristics of Podisus maculiventris (Say) (Heteroptera, Pentatomidae). 
Biological Control, 5, 449-461.

Van Huis, A., Van Itterbeeck, J., Klunder, H., Mertens, E., Halloran, A., Muir, G., \& Vantomme, P. (2013). Edible insects: future prospects for food and feed security (No. 171). Rome: Food and Agriculture Organization.

Vantomme, P., Mertens, E., Van Huis, A., \& Klunder, H. (2012). Technical consultation meeting: Assessing the potential of insects as food and feed in assuring food security-Summary report. Rome.

Vargas, R., Mitchell, S., Hsu, C.-L., \& Walsh, W. A. (1994). Laboratory evaluation of diets of processed corncob, torula yeast, and wheat germ on four developmental stages of Mediterranean fruit fly (Diptera: Tephritidae). Journal of Economic Entomology, 87, 91-95.

Vargas, R. I., \& Carey, J. R. (1989). Comparison of demographic parameters for wild and labora tory-adapted Mediterranean fruit fly (Diptera, Tephritidae). Annals of the Entomological Society of America, 82, 55-59.

Vargas, R. I., Walsh, W. A., Jang, E. B., Armstrong, J. W., \& Kanehisa, D. T. (1996). Survival and development of immature stages of four Hawaiian fruit flies (Diptera: Tephritidae) reared at five constant temperatures. Annals of the Entomological Society of America, 89, 64-69.

Vargas, R. I., Walsh, W. A., Kanehisa, D., Stark, J. D., \& Nishida, T. (2000). Comparative demog-raphy of three Hawaiian fruit flies (Diptera : Tephritidae) at alternating temperatures. Annals of the Entomological Society of America, 93, 75-81.

Vasicek, A., La Rossa, R., \& Paglioni, A. (2002). Biological and populational aspects of Nasonovia ribisnigri and Aulacorthum solani on lettuce. Pesquisa Agropecuaria Brasileira, 37, 407-414.

Vayssieres, J. F., Carel, Y., Coubes, M., \& Duyck, P. F. (2008). Development of immature stages and comparative demography of two cucurbit-attacking fruit flies in Reunion Island: Bactrocera cucurbitae and Dacus ciliatus (Diptera Tephritidae). Environmental Entomology, 37, 307-314.

Wagner, T. L., Wu, H. I., Sharpe, P. J. H., \& Coulson, R. N. (1984). Modeling distributions of insect development time - a literature-review and application of the Weibull function. Annals of the Entomological Society of America, 77, 475-487.

Xue, J., Bao, Y. Y., Li, B. L., Cheng, Y. B., Peng, Z. Y., Liu, H., . . Zhang, C. X. (2010). Transcriptome analysis of the brown planthopper Nilaparvata lugens. PLOS ONE, 5, e14233. 


\section{Chapter 6}

\section{Nutritional composition of black soldier fly larvae feeding on agro-industrial by-products}

Shaphan Y. Chia, Chrysantus M. Tanga, Isaac M. Osuga, Xavier Cheseto, Sunday Ekesi, Joop J. A. van Loon and Marcel Dicke

Submitted 


\section{Abstract}

Black soldier fly (BSF) larvae Hermetia illucens (Linnaeus) (Diptera: Stratiomyidae) bio-convert organic side streams into high quality biomass, the composition of which largely depends on the side stream used. In the present study, BSF larvae were reared on twelve substrates, composed of brewers' spent grains supplemented by either water, waste brewer's yeast or a mixture of waste brewer's yeast and cane molasses. The nutritional composition (proximate, minerals, amino acids, and fatty acids) of the BSF larvae fed each feedstock was determined. The effect of substrate, supplementation and their interaction on crude protein, fat and ash contents of BSF larvae was significant. Calcium, phosphorus and potassium were the most abundant macrominerals. Differences in amino acid profiles of the larvae were small. Lysine, histidine and arginine were the most abundant essential amino acids. The larval fatty acid profiles predominantly consisted of saturated fatty acids, of which lauric acid, palmitic acid and stearic acid were generally the most abundant. These findings provide important information to support the use of BSF larval meal as potential new source of highly suitable nutrient-rich and sustainable animal feed ingredients to substitute expensive and scarce protein sources such as fishmeal and soya bean meal. The implications of BSF larval meal in animal nutrition are discussed.

Key words: insect meal, brewers' spent grains, protein, minerals, amino acids, fatty acids, animal feed ingredients 


\section{Introduction}

Animal feed is composed of major ingredients such as corn meal, wheat, rice, soybean, fishmeal, and fish oil, therefore competing with human food requirements (Rana et al., 2009; Van Huis et al., 2013). The growing human population and demand for food and feed places continuous pressure on the environment (Foley et al., 2011). The increasing demand for fishmeal and soybean meal, as major protein sources in animal feeds has led to their scarcity and increasing market prices. Furthermore, feed costs represent about $70 \%$ of total aquaculture and livestock production (Ssepuuya et al., 2017; Van Huis et al., 2013). It is, therefore, a matter of utmost urgency to search for alternative and sustainable sources of protein for aquaculture and livestock. The potential of insect-based protein and other nutrients has attracted much interest from scientists and public organisations (Dicke, 2018; Van Huis, 2013; Van Huis, 2015; Van Huis, 2016; Van Huis et al., 2015; Van Huis et al., 2013; van Huis \& Vantomme, 2014). Among several insect species recommended for animal feed, the black soldier fly (BSF) Hermetia illucens L. (Diptera: Stratiomyidae) has the highest potential for large-scale production (Rumpold et al., 2018; Van Huis et al., 2013). Larvae of BSF convert low-grade organic side streams into high-quality protein and provide an innovative strategy for waste valorization (Meneguz et al., 2018; Nguyen et al., 2015; Nyakeri et al., 2017; Spranghers et al., 2017; Surendra et al., 2016). The Food and Agriculture Organization recommends that insect species suitable for feed are those that can be mass-reared on a large industrial scale, with a minimum reach of 1 tonne per day of insect fresh weight (Van Huis et al., 2013). However, meeting this recommendation requires a considerable amount of substrate for insect feeding. Moreover, nutritional composition of BSF larvae is influenced by the substrate used (Barragán-Fonseca et al., 2018; Diener et al., 2009; Liland et al., 2017; Spranghers et al., 2017; Wong et al., 2019).

Availability of sufficient amounts of feedstock is of paramount importance for sustainable insect production. Brewers' spent grain (BSG) is a by-product from beer production and a suitable protein source utilized as feed for livestock. However, the composition of BSG varies greatly depending on the grains used and the industrial processes and conditions such as fermentation, preservation and temperature employed. Moreover, wet BSG contains 75-80\% water and deteriorates rapidly because of bacterial and fungal growth restricting their utilization as animal feed to the first few days after collection. Previous studies have demonstrated that feeding pigs on BSG stored for more than one week results in decreased feed intake and body weight loss (Aguilera-Soto et al., 2008; Thomas et al., 2010). Palatability of feed mixed with BSG has also been shown to decrease with storage time and any uneaten feed rapidly deteriorates resulting in feed wasting. Fresh BSG left in open space spoils quickly and constitutes an environmental nuisance (Heuzé et al., 2017). Dehydrating or ensiling wet BSG can help to prevent 
spoilage, but these are time- and energy-consuming processes (Heuzé et al., 2017). Beer production results in more brewer's yeast than required for beer brewing. This is the second most common by-product of beer production, which is also used as a protein supplement in animal feed (Huige, 2006). Brewer's yeast has a short shelf life and its use as a feed supplement is limited. For prolonged use, drum-drying is required or it is mixed with BSG and then dried in a steam-tube drier. Again, these processes require machinery, energy and are therefore not economical (Heuzé et al., 2018).

Refining sugarcane results in a black syrup called molasses, which is rich in carbohydrates and minerals. In Kenya, this by-product is mainly used as a supplement in animal feed. It can cause environmental pollution, especially in water bodies if major spills or factory effluents drain into rivers or streams (M'Ndegwa, 2016). In the context of the above concerns on utilizing BSG, brewer's yeast and molasses in animal feeding, it is therefore important to consider alternative ways of utilizing these by-products. There is limited information on the nutritional quality of BSF larvae reared on BSG (Meneguz et al., 2018; www.entocycle.com/process). An in-depth study of the nutritional quality of BSF larvae reared on brewery and sugar by-products can fill this important knowledge gap. Therefore, in the present study, we reared BSF larvae on BSG, supplemented with either water, brewer's yeast or brewer's yeast plus cane molasses, which are generated by the beer brewers and sugar companies in Kenya. In order to assess the nutritional quality for animal diets, the proximate, mineral, amino acid and fatty acid contents of BSF larvae were analyzed.

\section{Materials and methods}

\section{Insect rearing and harvesting}

Black soldier fly eggs were collected from the BSF colony at Animal Rearing and Containment Unit of the International Centre of Insect Physiology and Ecology (icipe), Nairobi, Kenya.

As substrate for the BSF larvae, four BSGs, resulting from the production of major beer brands such as: Tusker, Guinness, Senator and Pilsner as well as liquid brewer's yeast were obtained from the Kenya Brewery Limited, Nairobi, Kenya. The BSGs obtained were generated from: barley (B), malted barley (MB), malted corn (MC), and sorghum plus barley (SB). Liquid cane molasses was obtained from Mumias Sugar Company Limited, Kakamega, Kenya. Drying and preparation of substrates and their proximate compositions were previously described by Chia et al. (2018). In the present study, substrates for rearing BSF larvae were formulated as follows: Five hundred grams of each BSG (moisture content 10\%; Chia et al., 2018) were mixed with $800 \mathrm{~mL}$ of water (W) to provide optimal moisture for larval feeding and growth. Another group of substrates consisted of $500 \mathrm{~g}$ of each BSG, mixed with $900 \mathrm{~mL}$ of liquid brewer's yeast (Y). 
The last group of substrates consisted of $500 \mathrm{~g}$ of each BSG, mixed with $450 \mathrm{~mL}$ of liquid brewer's yeast plus $450 \mathrm{~mL}$ of liquid cane molasses (YM).

Twenty batches of freshly laid BSF eggs were placed on the surface of each substrate in a $7 \mathrm{~L}$ plastic container in a temperature-controlled room at $28 \pm 1{ }^{\circ} \mathrm{C}$ and $70 \pm 2 \%$ relative humidity, as previously described by Chia et al. (2018). The experimental containers were screened with fine mesh and eggs hatched after 3-4 days. Larvae were provided with $500 \mathrm{~g}$ of freshly prepared substrates every three days until the fifth instar larval stage, recognisable by a beige colour of the larvae; this occurred 2-3 weeks after egg hatching. At harvest, larvae were sieved and then manually separated from the substrate using forceps according to Spranghers et al. (2017). Harvested larvae were washed with water and frozen at $0{ }^{\circ} \mathrm{C}$ until further analysis. Before analysis, larvae were oven-dried at $60-70{ }^{\circ} \mathrm{C}$, then ground to powder using a blender (Preethi Trio Mixer Grinder 500W, India).

\section{Proximate composition analysis}

Larval samples were subjected to proximate analysis to determine their dry matter (DM), crude protein, fat and ash according to AOAC (1990). Dry matter content of larval samples was assessed by oven drying the samples at $105^{\circ} \mathrm{C}$ until constant weight and water content was determined as the weight difference before and after oven-drying. For the crude protein content, the nitrogen content was determined following the Kjeldahl method and the value was multiplied by a conversion factor of 4.76 (Janssen et al., 2017) to obtain the crude protein value. Fat content of larvae was determined by diethyl ether extraction in a fat extraction unit (VELP SER 148) following the Randall technique, which involves: immersion of samples in a hot solvent (diethyl ether) to ensure rapid solubility; washing off the solvent after boiling and the recovery by evaporation and condensation of the solvent. Ash content was determined by ignition of samples at $550{ }^{\circ} \mathrm{C}$ in a muffle furnace. These analyses were performed in triplicate.

\section{Analysis of minerals}

Mineral composition of BSF larvae was assessed by inductively coupled plasma emission spectrometry (ICP-AES). Sample preparation for mineral analysis involved incineration at $450{ }^{\circ} \mathrm{C}$ until a grey to reddish brown colour of the ash was observed. The ash was then dissolved in a mixture of nitric acid (65\%), hydrochloric acid (37\%), and hydrogen peroxide (30\%) (Manditsera et al., 2019). For each treatment, three subsamples from one biological replicate were analysed for: iron $(\mathrm{Fe})$, copper $(\mathrm{Cu})$, zinc $(\mathrm{Zn})$, manganese $(\mathrm{Mn})$, sodium $(\mathrm{Na})$, sulphur $(\mathrm{S})$, magnesium $(\mathrm{Mg})$, potassium $(\mathrm{K})$, aluminium (Al), phosphorus $(\mathrm{P})$, and calcium $(\mathrm{Ca})$ contents. The $\mathrm{Ca} / \mathrm{P}$ ratio was calculated as the ratio of the concentration of $\mathrm{Ca}$ to the concentration of $\mathrm{P}$ in the $\mathrm{BSF}$ larval samples. 


\section{Analysis of amino acids}

Samples of BSF larvae were analysed for their amino acid composition by liquid chromatography coupled to a mass spectrometer (LC-MS) following acid hydrolysis of the samples. The specification of the LC-MS system and column conditions are given in Appendix A. Approximately $100 \mathrm{mg}$ of each sample were weighed to the nearest 0.01 $\mathrm{mg}$, placed into a Pyrex tube to which $5 \mathrm{~mL}$ of $6 \mathrm{~N} \mathrm{HCl}$ was added carefully. The tubes were capped immediately and placed in boiling water for 10 minutes and then transferred to an oven at $110^{\circ} \mathrm{C}$ for 24 hours. After this period, samples were removed from the oven and allowed to cool, and then vortexed for 10 seconds. The hydrolyzed samples were filtered through Whatman No. 1 filter paper into $10 \mathrm{~mL}$ falcon tubes, while rinsing the Pyrex tubes with double distilled water. Three microliters of the filtrate for each sample were then injected into an LC-MS for chromatographic separation, identification and quantification of amino acids. For each treatment, two subsamples from one biological replicate were analysed. Amino acids were identified based on molecular weight, mass-to-charge ratio $(\mathrm{m} / \mathrm{z})$ and the retention time using a standard mixture of amino acids (see below) and Enhanced ChemStation, Agilent technologies.

A standard mixture of amino acids, which contained Ala, Pro, Lys, Tyr, His, Ser, Arg, Val, Met, Ile, Leu, Gly, Glu, Thr, Phe and Asp in the concentration of $2.5 \mathrm{mmol} \mathrm{L}^{-1}$ and Cys in the concentration of $1.25 \mathrm{mmol} \mathrm{L}^{-1}$ (Sigma-Aldrich, St. Louis, Missouri, USA), were also analysed by LC-MS. Column conditions: as shown in Appendix A. Calibration curves for quantification of the amino acids were constructed through the injection of different volumes of this standard solution (0.1-5 $\mu \mathrm{L}$ ) (Appendix A, Table A2).

\section{Analysis of fatty acids}

Fatty acid methyl ester (FAME) composition of BSF larvae was determined on oven-dried, ground samples by gas chromatography-mass spectrometry (GC-MS). The GC machine specifications and column conditions are described in Appendix A. A methyl esterification reaction was performed on each sample according to Musundire et al. (2016). Five hundred microliters of $15 \mathrm{mg} / \mathrm{mL}$ of methanolic sodium methoxide were added to $50 \mathrm{mg}$ of dried BSF larval sample and incubated for one hour at $60{ }^{\circ} \mathrm{C}$. After this period, $100 \mu \mathrm{L}$ of deionised water was added to the sample and vortexed for one minute. The resulting methyl esters were extracted using GC-grade hexane (Sigma-Aldrich, St. Louis, USA) and then centrifuged at 14,000 rpm for 5 minutes and the supernatant was dried over anhydrous $\mathrm{Na}_{2} \mathrm{SO}_{4}$ (Musundire et al., 2016). One microliter of extract was injected into the GC-MS. For each treatment, two subsamples from one biological replicate were analysed. Fragment ions were generated by McLafferty Rearrangement ion. Fatty acids were identified as methyl esters by comparison of gas chromatographic fragmentation patterns with those of reference spectra published by library-MS databases: National Institute of Standards and Technology 05, 08, and 11. 


\section{Statistical analysis}

Average crude protein, fat, ash, water and the mineral contents of larvae were compared among substrates and supplements through a two-way analysis of variance (ANOVA) $(\alpha=0.05)$, with least significant difference test (LSD) as post-hoc test. The relationship between the rearing substrates and proximate, and mineral contents of BSF larvae was evaluated using principal component analysis (PCA). All statistical analyses of the data were implemented using $\mathrm{R}$ software (version 3.5.1).

\section{Results}

\section{Proximate composition}

The main effects of substrate and supplementation on protein, fat and ash contents were significant (Table 1). There was a significant interaction between substrate and supplementation (Table 1). Larvae reared on SB supplemented with brewer's yeast had the highest protein content followed by those reared on SB supplemented with brewer's yeast plus molasses, whereas larvae reared on MB supplemented with brewer's yeast plus molasses had the lowest protein content. Overall, larvae reared on substrates supplemented with brewer's yeast had a higher protein content compared to those reared on water- or yeast plus molasses-supplemented substrates. Fat content of larvae reared on $\mathrm{B}, \mathrm{MB}$ and $\mathrm{MC}$ supplemented with brewer's yeast plus molasses was higher than when supplemented with water only or brewer's yeast only. Larvae reared on SB supplemented with brewer's yeast or brewer's yeast plus molasses had the lowest fat content (Table 1). There were no significant effects of substrate and supplementation on larval water content. However, their interaction was significant (Table 1).

Regarding the PCA, the first two principal components (PC) accounted for most $(86.2 \%)$ of the variance in the data. The first PC accounted for $64.6 \%$ while the second PC accounted for $21.6 \%$ of the variance in the data (Figure 1). The PCA results revealed a positive correlation between the crude protein and ash contents, whereas the fat content was negatively correlated to the crude protein content (Figure 1). Larvae reared on $\mathrm{B}, \mathrm{MB}$ and $\mathrm{MC}$ and supplemented by a mixture of brewer's yeast and molasses had a higher fat content than for the other substrates, whereas SB supplemented by either brewer's yeast or a mixture of brewer's yeast and molasses resulted in higher values for larval crude protein and ash contents. Overall, larvae grown on brewer's yeast-based substrates had higher crude protein and ash contents, whereas larvae fed on brewer's yeast plus molasses-based substrates had higher fat contents compared to larvae fed on water-based substrates (Figure 1). 


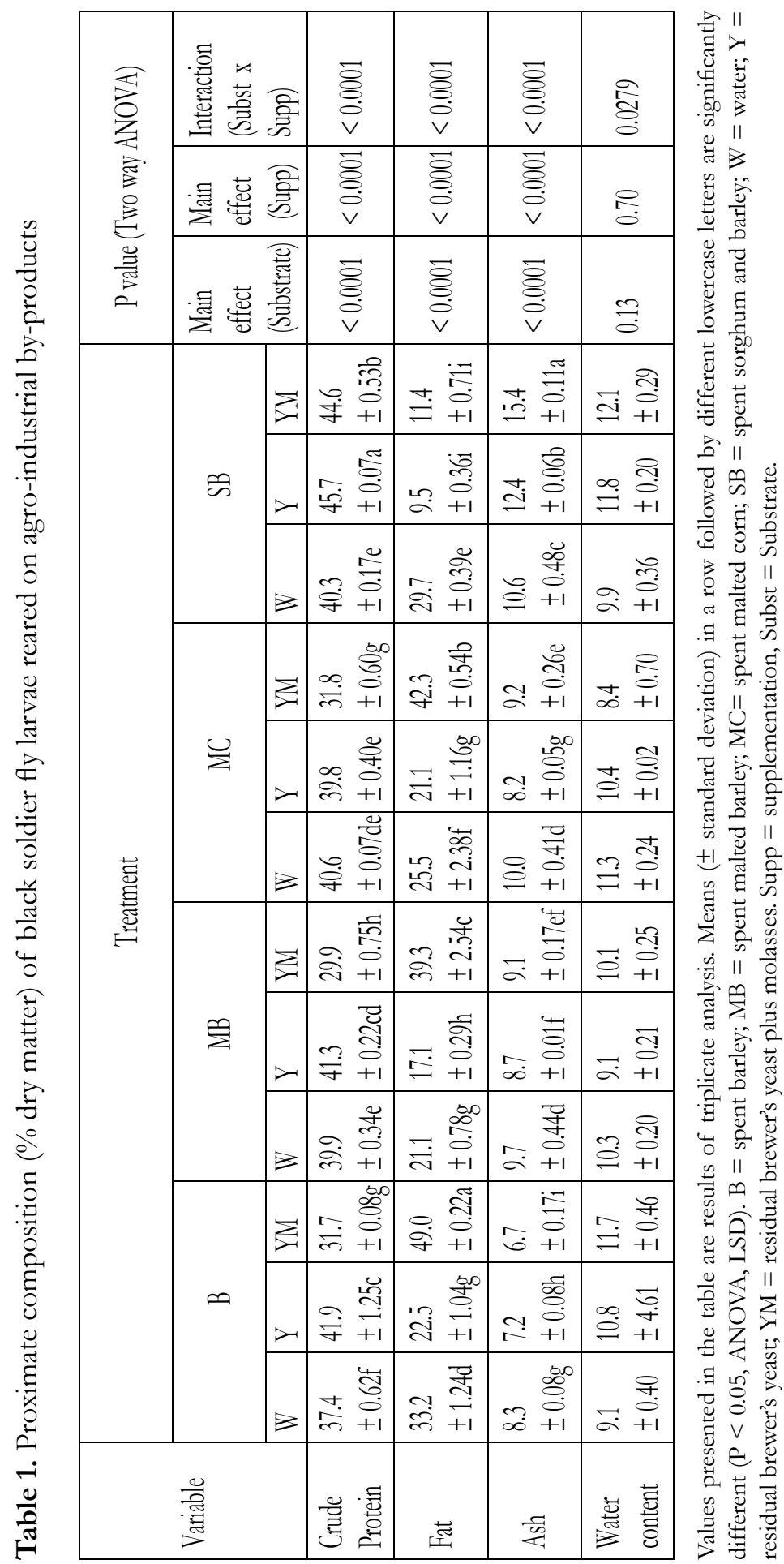




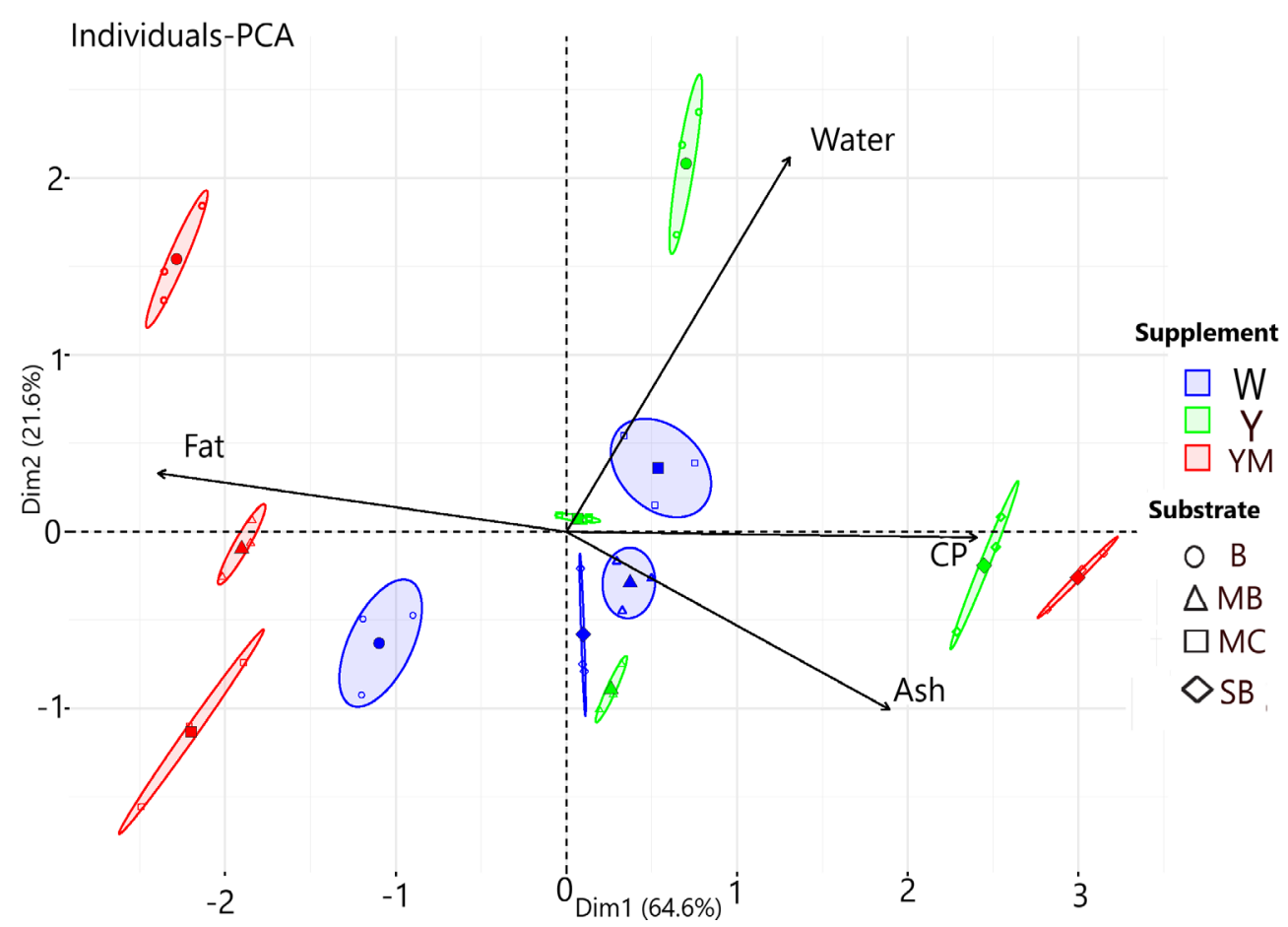

Figure 1. Principal component analysis of proximate composition of black soldier fly larvae reared on substrates composed of agro-industrial by-products. Substrates that are on the same side of a given variable have a high value for this variable while substrates that are on the opposite side of a given variable have a low value for this variable. $\mathrm{CP}=$ crude protein. $\mathrm{B}=$ spent barley; $\mathrm{MB}=$ spent malted barley; $\mathrm{MC}$ $=$ spent malted corn; $\mathrm{SB}=$ spent sorghum and barley; $\mathrm{W}=$ water; $\mathrm{Y}=$ brewer's yeast; $\mathrm{YM}=$ brewer's yeast plus molasses.

\section{Mineral composition}

There were significant effects of substrate, supplementation and their interaction on average concentration of macrominerals and microminerals in the larvae (Table 2). Ca was the most abundant mineral in larvae across all substrates, followed by $\mathrm{P}, \mathrm{K}, \mathrm{S}$ and $\mathrm{Mg}$. All other minerals such as $\mathrm{Na}, \mathrm{Fe}, \mathrm{Mn}$ and $\mathrm{Zn}$ were present at low concentrations. The concentration of $\mathrm{Cu}$ was lowest of all minerals in the larvae, independent of substrate on which they had been reared. Additionally, larvae reared on SB supplemented with brewer's yeast or brewer's yeast plus molasses had significantly higher concentrations of all minerals compared to the rest of the substrates investigated here (Table 2). A similar result was obtained based on the principal component analysis. 


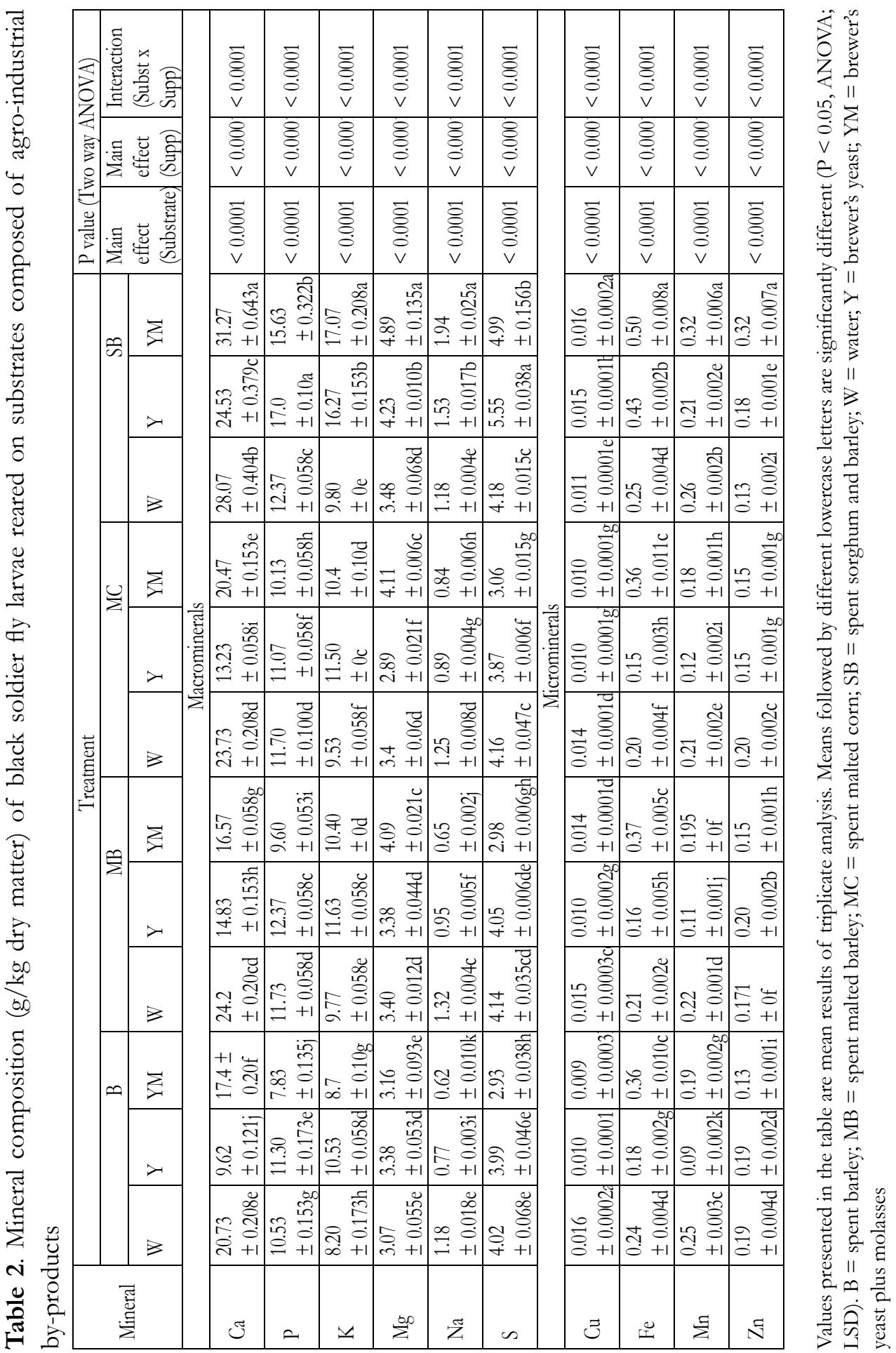


The first two PCs accounted for most of the variance in the data. The first PC explained $56.9 \%$ of the variance, while the second PC accounted for $17.9 \%$ of the variation (Figure 2). There was a positive relationship between the mineral content of larvae and, the substrate SB supplemented with brewer's yeast or brewer's yeast plus molasses (Figure 2). Most other substrates, particularly B, MB and MC supplemented with brewer's yeast or brewer's yeast plus molasses resulted in lower larval mineral contents. The PCA clearly separates mineral content of larvae reared on water-supplemented, brewer's yeast-supplemented and brewer's yeast plus molasses-supplemented substrates, except for SB supplemented with brewer's yeast and brewer's yeast plus molasses (Figure 2). Substrate $(\mathrm{P}<0.0001)$, supplementation $(\mathrm{P}<0.0001)$ and their interaction $(\mathrm{P}<0.0001)$ significantly affected $\mathrm{Ca} / \mathrm{P}$ ratio in larvae. Larvae reared on substrates supplemented with brewer's yeast only, had lower $\mathrm{Ca} / \mathrm{P}$ ratio than those reared on substrates supplemented with water or brewer's yeast plus molasses (Figure 3).

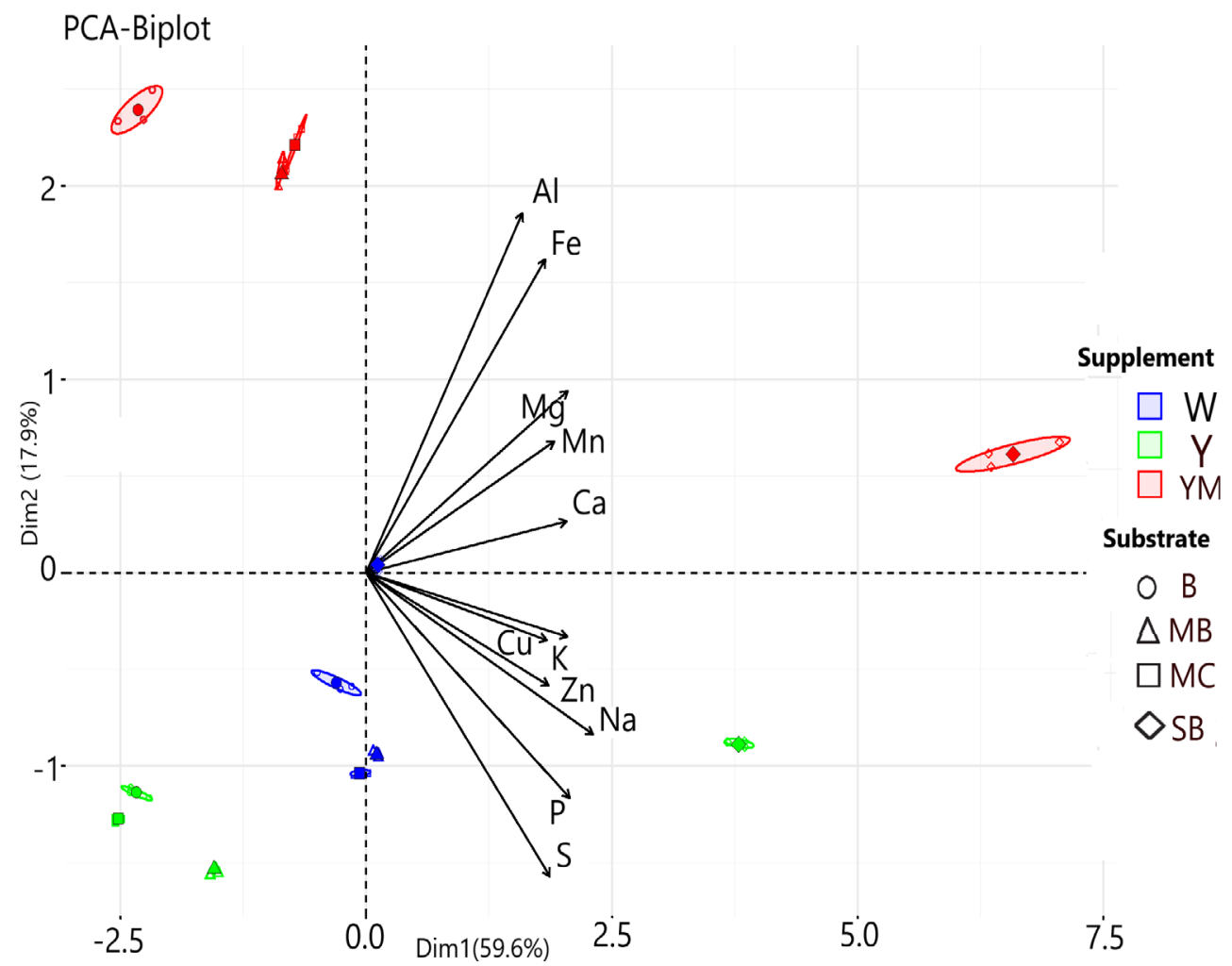

Figure 2. Principal component analysis of mineral composition of black soldier fly larvae reared on substrates composed of agro-industrial by-products. Substrates that are on the same side of a given variable have a high value for this variable while substrates that are on the opposite side of a given variable have a low value for this variable. $\mathrm{B}=$ spent barley; $\mathrm{MB}=$ spent malted barley; $\mathrm{MC}=$ spent malted corn; $\mathrm{SB}=$ spent sorghum and barley; $\mathrm{W}=$ water; $\mathrm{Y}=$ brewer's yeast; $\mathrm{YM}=$ brewer's yeast plus molasses. 


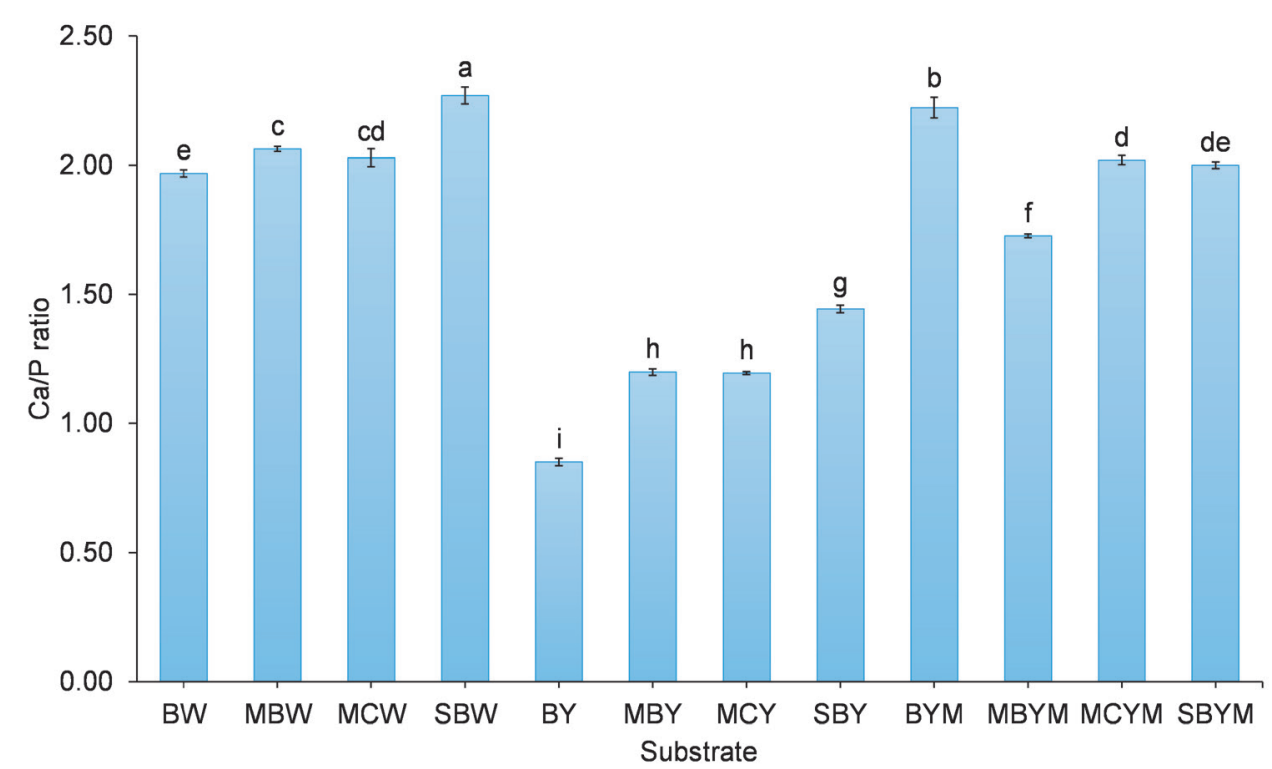

Figure 3. Calcium to phosphorus ratio $(\mathrm{Ca} / \mathrm{P})$ in black soldier fly larvae reared on substrates composed of agro-industrial by-products. Bars followed by different letters are significantly different $(\mathrm{P}<0.05$, LSD, mean \pm standard deviation, $\mathrm{n}=3$ ). $\mathrm{BW}=$ Barley/water; $\mathrm{MBW}=$ Malted barley/water; $\mathrm{MCW}=$ Malted corn/water; SBW = Sorghum/Barley/water; BY = Barley/brewer's yeast; $\mathrm{MBY}=$ Malted barley $/$ brewer's yeast; $\mathrm{MCY}=$ Malted corn $/$ brewer's yeast; $\mathrm{SBY}=$ Sorghum $/$ Barley $/$ brewer's yeast; $\mathrm{BYM}=$ Barley $/$ brewer's yeast/Molasses; MBYM = Malted barley/brewer's yeast/Molasses; MCYM = Malted corn/brewer's yeast/Molasses and SBYM = Sorghum/Barley/brewer's yeast/Molasses.

\section{Amino acid composition}

A total of 17 amino acids were recorded in the BSF larval samples. Of these, nine were essential amino acids while the remaining eight were non-essential amino acids (Figure 4; Table A3). The most prevalent essential amino acids were lysine, histidine and arginine, followed by: methionine, phenylalanine, isoleucine and leucine (Figure 4A). Valine was present in smaller concentration while threonine had the smallest concentration. For the non-essential amino acids, tyrosine was the most abundant amino acid, followed by proline and then glycine and alanine, whereas, aspartic acid, cystine, glutamic acid and serine were present in smaller concentrations (Figure 4B). No major differences were observed among larvae fed on the different four BSG-substrates and the three supplements. 
A

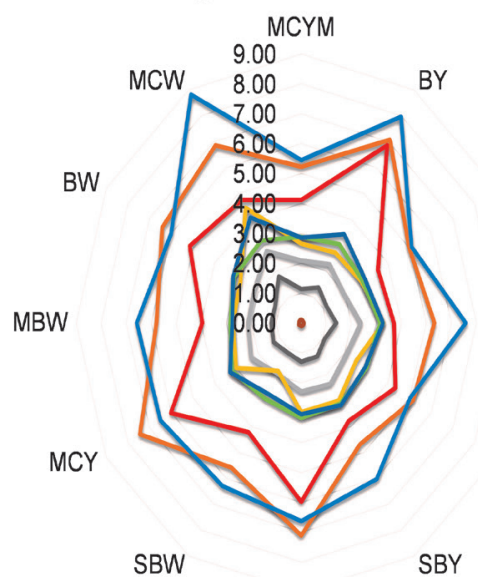

MBY

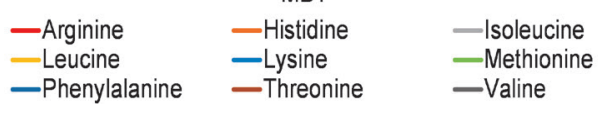

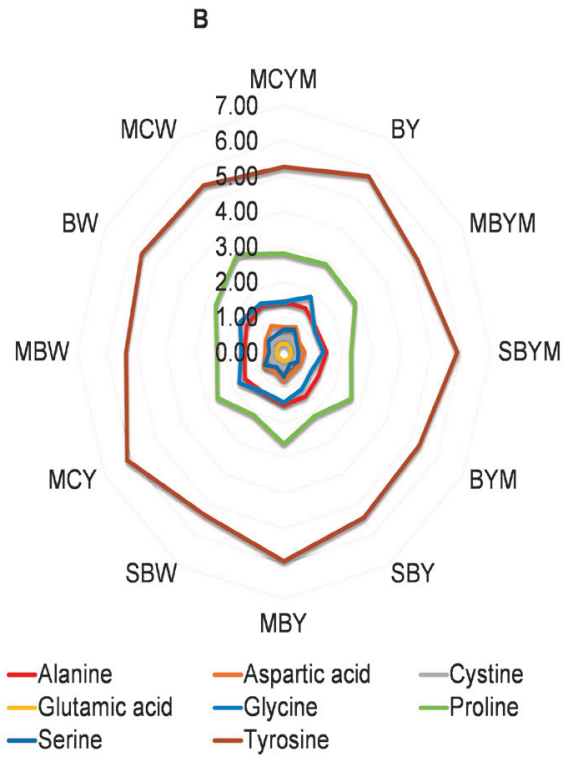

Figure 4. Concentration ( $\mathrm{mg} / \mathrm{g}$ dry matter) of essential and non-essential amino acids in black soldier fly larvae reared on substrates composed of agro-industrial by-products. $\mathrm{A}=$ essential amino acids, $\mathrm{B}=$ non-essential amino acids. BW = Barley/water; $\mathrm{MBW}=$ Malted barley/water; $\mathrm{MCW}=$ Malted corn/water; $\mathrm{SBW}=$ Sorghum $/$ Barley $/$ water; $\mathrm{BY}=$ Barley $/$ brewer's yeast; $\mathrm{MBY}=$ Malted barley $/$ brewer's yeast; $\mathrm{MCY}$ $=$ Malted corn $/$ brewer's yeast; $\mathrm{SBY}=$ Sorghum $/$ Barley $/$ brewer's yeast BYM = Barley $/$ brewer's yeast $/$ Molasses; MBYM = Malted barley/brewer's yeast/Molasses; MCYM = Malted corn/brewer's yeast $/$ Molasses and SBYM $=$ Sorghum $/$ Barley/brewer's yeast/Molasses.

\section{Fatty acid composition}

A total of 10 FAMEs were identified from the BSF larval samples. Of these, seven were saturated fatty acid derivatives, while the remaining three were unsaturated fatty acid derivatives (Figure 5). Lauric acid (C12:0), palmitic acid (C16:0) and stearic acid (C18:0) were the most abundant saturated fatty acids (5.9-39.4\%), followed by myristic acid (C14:0) whereas, capric acid (C10:0), margaric acid (C17:0) and arachidic acid (C20:0) were detected in low proportions $(\leq 1.5 \%, \leq 2.0 \%$ and $\leq 2.5 \%$, respectively) (Figure $5 A)$. Larvae reared on SBY and SBYM had higher proportions of C18:0 than obtained for other substrates investigated (Figure 5A). The three unsaturated fatty acids detected were: linoleic acid (C18:2n-6), which is a polyunsaturated essential fatty acid and two monounsaturated fatty acids (palmitoleic acid (C16:1n-7) and oleic acid (C18:1n-9), the latter two being the most abundant unsaturated fatty acids in the present study (Figure $5 B)$. 

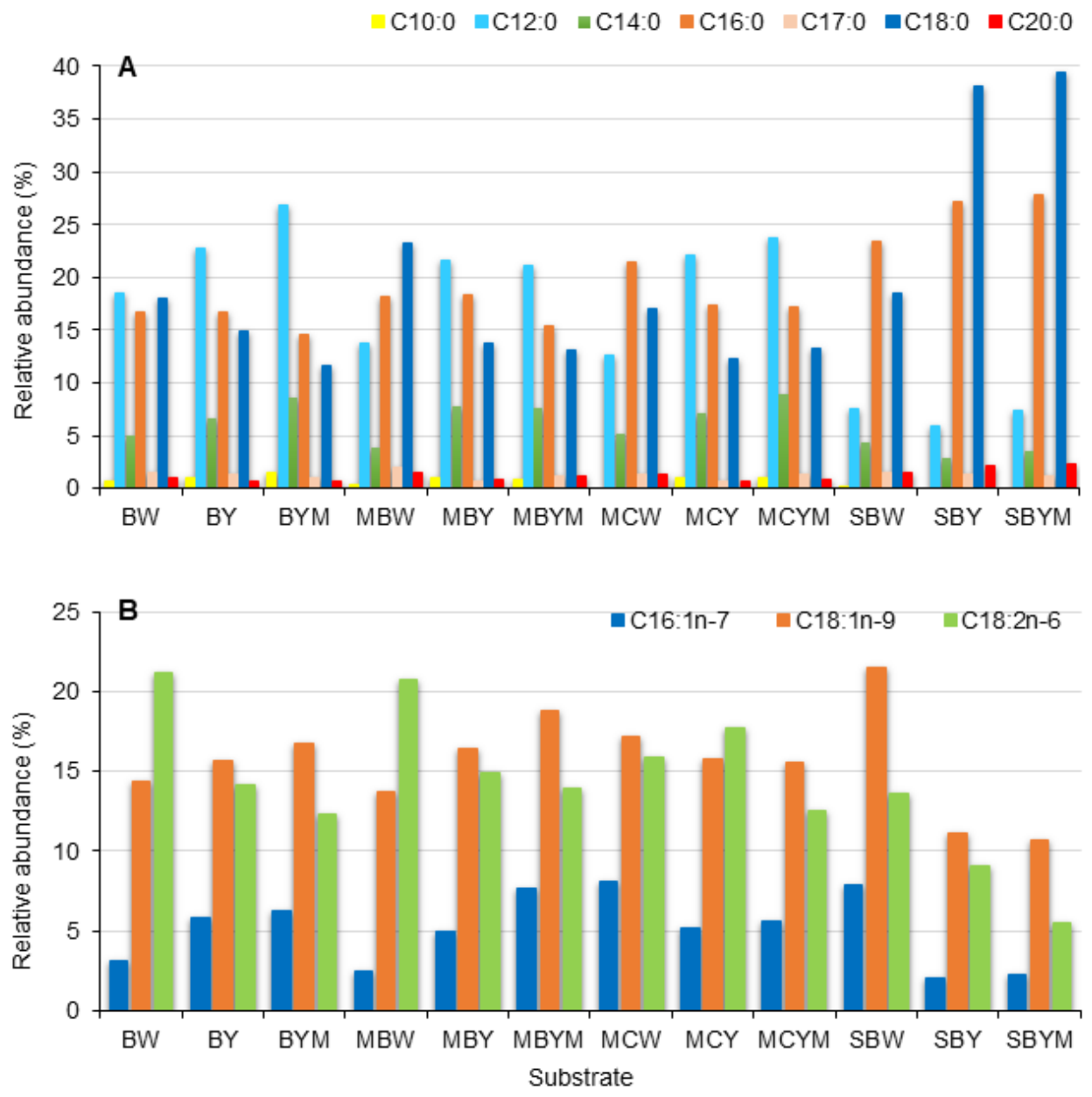

Figure 5. Relative abundance (\% of total fatty acids) of fatty acids in black soldier fly larvae reared on substrates composed of agro-industrial by-products. Bars represent average $(n=2)$ proportion of total fatty acids in larvae for each substrate. $\mathrm{A}=$ saturated fatty acids, $\mathrm{B}=$ unsaturated fatty acids. BW = Barley/ water; $\mathrm{MBW}=$ Malted barley/water; $\mathrm{MCW}=$ Malted corn $/$ water; $\mathrm{SBW}=$ Sorghum $/$ Barley $/$ water; $\mathrm{BY}=$ Barley $/$ brewer's yeast; MBY = Malted barley/brewer's yeast; $\mathrm{MCY}=$ Malted corn $/$ brewer's yeast; SBY = Sorghum $/$ Barley $/$ brewer's yeast; BYM $=$ Barley/brewer's yeast $/$ Molasses; MBYM $=$ Malted barley $/$ brewer's yeast/Molasses; MCYM = Malted corn/brewer's yeast/Molasses and SBYM = Sorghum/Barley/ brewer's yeast/Molasses. 


\section{Discussion}

Our findings revealed that black soldier fly larvae readily fed and grew on all the organic side streams (Chia et al., 2018) and converted them into nutrient-rich biomass. However, the composition of larvae grown on each substrate combination was significantly influenced by the substrate type. The nutrient-rich larvae are suitable for several purposes, one of which is animal feeding (Liland et al., 2017; Spranghers et al., 2017; Van Huis, 2013).

Our results agree with previous reports that rearing substrate influences the nutritional composition of BSF larvae (Barragán-Fonseca et al., 2018; Spranghers et al., 2017; Tan et al., 2015; Wang \& Shelomi, 2017). The supplementation of substrates with brewer's yeast, brewer's yeast plus molasses or water had significant effects on several of the recorded nutritional parameters (protein, fat, amino acid, minerals and ash contents). The significant interaction between substrate and supplementation shows that the main effect of substrate on the nutrient content of the larvae is dependent on the type of supplementation. The main effects of substrate and supplementation on water content were not significant, but their interaction was significant. This shows that there was no overall effect of either substrate or supplementation on water content of the larvae, but there was a crossover interaction by which the effect of supplementation on water content was opposite and depends on the nutritional value of the substrate (Karen, 2019).

The crude protein content of larvae in our study ranged between 30 and $46 \%$. These values are within the range of crude protein values for BSF larvae reported in the literature (Liland et al., 2017; Meneguz et al., 2018; Spranghers et al., 2017; www.entocycle. $\mathrm{com} /$ process). When larvae were reared on SB supplemented with brewer's yeast or brewer's yeast plus molasses, the resulting crude protein values were higher than obtained for the rest of the substrates investigated here. The lowest fat content values were also recorded on these substrates. Furthermore, the addition of brewer's yeast, which contains high crude protein and ash (Chollom et al., 2017) might have contributed to the high nutritional content of the larvae reared on SB. This indicates that these substrates are most suitable for rearing BSF larvae. Low fat contents have previously been reported in BSF larvae with high crude protein contents (Finke, 2013; Meneguz et al., 2018; Musundire et al., 2016).

Minerals play structural, physiological, catalytic and regulatory functions in the body (Andrieu, 2008; Suttle, 2010). The levels of Ca, Cu, Mg, Na, Mn, Fe and $\mathrm{Zn}$ in BSF larvae from our study are comparable to the levels reported by Spranghers et al. (2017), whereas, the levels of $\mathrm{P}, \mathrm{K}$ and $\mathrm{S}$ were higher than the levels reported by Spranghers et al. (2017). The mineral levels in BSF larvae from our study are also similar to the levels reported by Tschirner \& Simon (2015) for BSF larvae reared on different substrates. Furthermore, Makkar et al. (2014) reported higher and similar levels of Ca and P, 
respectively in BSF larvae compared to our study. The difference between studies might be due to differences in life stage of the BSF analysed. For instance, Spranghers et al. (2017) reported values for BSF pre-pupae, whereas we analysed fifth instar BSF larvae. Interestingly, Ca levels in BSF larvae from the present study are comparable to the levels in fishmeal and higher than levels in soybean meal according to Makkar et al. (2014).

Micronutrients, though required in trace amounts are important for the growth, health and immunity, and reproduction of animals. For instance, Fe is an essential component of the respiratory pigments and enzymes involved in tissue oxidation and therefore plays an important role in oxygen and electron transport within the body. $\mathrm{Zn}$ is a component of enzyme systems and plays essential roles in lipid, protein, and carbohydrate metabolism. It plays an active role in the synthesis and metabolism of proteins (Tacon, 1987; Vallee \& Falchuk, 1993). A deficiency in Zn decreases leukocyte function and increases susceptibility to bacterial infections (Sordillo et al., 1997). Copper is a component of the enzyme ferroxidase and plays a vital role in Fe metabolism, and therefore haemoglobin synthesis and red blood cell production and maintenance (Tacon, 1987). Deficiency of $\mathrm{Cu}$ decreases neutrophil killing capability of mammary gland immunity and increases susceptibility to bacterial infection (Sordillo et al., 1997). Manganese is an essential micro-mineral required for bone formation, regeneration of red blood cells, metabolism of carbohydrates and the reproductive cycle in animals (Tacon, 1987).

Overall, the mineral levels in BSF larvae in the present study are in compliance with the requirements of poultry and pigs (NRC, 1994, 1998). Therefore, BSF larvae reared on agro-industrial substrates used in the present study are promising alternatives to fishmeal and soybean meal in terms of mineral content. While all macrominerals are important, $\mathrm{Ca}$ and $\mathrm{P}$ are the most abundant and functionally related macrominerals in the body. These minerals are particularly implicated in bone formation and eggshell formation (Li et al., 2017; Pelicia et al., 2009; Yang, 2019; Zotte et al., 2019). A deficiency or an excess of either of these minerals affects the utilization of the other. Animal feed is often deficient of these two minerals (Mcdowell, 2003; Suttle, 2010) and requires supplementation to meet dietary requirements of the animals. In the present study, $\mathrm{Ca}$ and $\mathrm{P}$ were the predominant macrominerals recorded in BSF larvae. An ideal Ca/P ratio is important in reducing nutritional secondary hyperparathyroidism in insectivorous animals such as cattle egrets, reptiles, amphibians and cats. This is a metabolic bone disease that results from insufficient dietary intake of Ca or excessive intake of $\mathrm{P}$ in the diet (Boykin, 2019; Krook et al., 1963; Lock, 2017; Phalen et al., 2005). The Ca/P ratio in the present study is lower than the 8.4 value for BSF larvae reported by Makkar et al. (2014). However, the values found in our study largely fall within the recommended range (1-2) for animal diets (IPNI-International Plant Nutrition Institute, 1999; Li et al., 2017; Makkar, 2014; Olson \& Hale, 2001; Pelicia et al., 2009; Stewart, 2017; Zotte et al., 2019). In addition, our values are similar to the $\mathrm{Ca} / \mathrm{P}$ ratio in fishmeal and higher than 
values for soybean meal, housefly maggot meal, mealworm, locust meal, house cricket, Mormon cricket, silkworm and pupae meal (Makkar et al., 2014). Our data agree with previous reports that BSF larvae contain a higher concentration of Ca than P (Boykin, 2019; Dierenfeld \& King, 2008; Finke, 2013; Klaphake, 2010). Larvae reared on BSGs supplemented with brewer's yeast showed significantly lower $\mathrm{Ca} / \mathrm{P}$ values compared to those reared on substrates supplemented with water or brewer's yeast plus molasses. Brewer's yeast has been shown to contain lower levels of Ca than of P (Onofre et al., 2017). This might have contributed to lower concentrations of $\mathrm{Ca}$ and high $\mathrm{P}$ concentrations in the larvae and may explain the low $\mathrm{Ca} / \mathrm{P}$ ratio. However, $\mathrm{Ca} / \mathrm{P}$ values are within the recommended range, indicating that the addition of brewer's yeast to the substrates can still result in the production of high-quality BSF larvae with well-balanced $\mathrm{Ca} / \mathrm{P}$ ratio, which will contribute to the total dietary $\mathrm{Ca} / \mathrm{P}$ requirement of farmed animals. Furthermore, our results show that calcium is the most abundant essential mineral in the larvae. This is consistent with previous reports (Liu et al., 2017; Makkar et al., 2014; Schmitt et al., 2019; Spranghers et al., 2017; Wang \& Shelomi, 2017). Overall, our data show that larvae reared on these substrates represent a promising alternative source of minerals for animal feeds.

The amino acid profiles of BSF larvae in the present study are similar to those previously reported in the literature (Makkar, 2014; Sealey et al., 2011). However, information on the amino acid profiles of BSF larvae reared on BSGs is limited. Although statistical analysis was not possible due to limited number of replicates, the results of the present study show that substrates on which the larvae were reared did not influence the amino acid concentrations of the BSF larvae. Overall, lysine, which is one of the most limiting essential amino acids in pigs and poultry was most prevalent in the BSF larvae. Histidine and arginine were also abundant in the BSF larvae in this study. In line with the literature (Makkar, 2014), cystine had the lowest concentration in larvae independent of the substrates we studied. However, the variation in the concentration of amino acids across different substrates was largely within narrow limits. Therefore, we conclude that all substrates used in the present study are suitable for producing BSF larvae that contain balanced amino acids for animal feed.

Analyses of fatty acids in the present study indicate that fatty acid composition of the larvae was influenced by the rearing substrate. For instance, larvae reared on SBY and SBYM had high proportions of C16:0 and C18:0 and low proportions of unsaturated fatty acids, which is consistent with the low crude fat contents of the larvae recorded for these substrates in the proximate analysis. This further indicates that these substrates could be used to produce protein-rich BSF larvae, with reduced fat contents for animal feeds. Consistent with previous studies, the fatty acid profiles of larvae in the present study revealed a composition of mostly saturated fatty acids (seven out of ten fatty acids detected) (Meneguz et al., 2018; Ramos-Bueno et al,, 2016; Surendra et al., 
2016; Makkar, 2014). Of the saturated fatty acids, the high proportion of C12:0 in BSF larvae corresponds to earlier reports for larvae reared on other side streams. For instance, when reared on fruit waste, palm decanter cake and treated sewage sludge, BSF larvae were richest in C12:0 compared to the rest of the saturated fatty acids (Leong et al., 2015).

Studies have demonstrated antimicrobial properties of C12:0 on gastrointestinal bacteria and the ability to supply energy for piglets. The use of BSF larval meal in animal feed therefore represents a nutraceutical advantage.

This means that the BSF larval meal in animal feed not only plays a nutritional role but also a therapeutic role in the health of the animal and, thus offers an excellent opportunity for reduced use of antibiotics in animal production, which is currently a major concern (Devi \& Kim, 2014; Lee \& Chiang, 1994; Skřivanová et al., 2006; Spranghers et al., 2018). It has also been reported that increased inclusion of BSF larval meal in broiler diets led to increased saturated fatty acid content of resulting edible meat products (Schiavone et al., 2017). Meat with a higher ratio of polyunsaturated to saturated fatty acids is more desirable for human consumption (Wood et al., 2003). Therefore, while the saturated fatty acid content of the BSF larvae could benefit the animal in terms of energy and antimicrobial activity (Çetingül \& Yardımc1, 2008; Devi \& Kim, 2014; Lee \& Chiang, 1994; Skrivanová et al., 2006), these fats could be more useful in applications other than animal feed, for example in the production of cosmetic products (www. protenga.com/products/;www.bangkokpost.com/business/1168653/lord-of-the-flies; http://sflyproteins.com/).

Furthermore, unsaturated fatty acids are the most important fatty acids in animal diets, two of which are essential and required in animal diets (Çetingül \& Yardımc1, 2008; Makkar, 2014; Syadati et al., 2012). In particular, C16:1n-7 and C18:1n-9 detected in BSF larvae in the present study are important for animal health. For example; studies have shown that C16:1n-7 plays a vital role in preventing apoptosis as well as promote growth and proliferation of pancreatic $\beta$-cells (Diakogiannaki et al., 2007). In addition, monounsaturated fatty acids and polyunsaturated fatty acids play a role in reducing serum low density lipoprotein cholesterol levels (Grundy, 1989).

While fatty acids are generally important for human and animal health, the composition of omega 3 (n-3) and omega 6 (n- 6 ) fatty acids, as well as the n- $6 / n-3$ ratio are crucial. A high $n-6 / n-3$ ratio is associated with cardiovascular diseases, inflammatory and autoimmune diseases. A ratio of $n-6 / n-3$ fatty acids smaller than five is more desirable and considered optimal for human health (Simopoulos, 2002). In the present study, only $n-6$ (C18:2n-6) was detected in the larval samples. As reported in the literature, C18:1n-9 was the only polyunsaturated fatty acid detected in the present study (Meneguz et al., 2018). The limited unsaturated fatty acids, particularly the polyunsaturated fatty acids detected in the present study agrees with previous reports, which showed that BSF 
larvae contain far lower levels of polyunsaturated fatty acids compared to housefly larvae, mealworms, and adult crickets (Leong et al., 2015; Makkar et al., 2014). Furthermore, BSF larvae reared on household waste were deficient in essential fatty acids in favour of saturated fatty acids (Kawasaki et al., 2019). To compensate for this deficiency in essential fatty acids, varying the fatty acid contents in the substrates used to rear BSF larvae could help improve the polyunsaturated fatty acids (Barroso et al., 2017; Oonincx et al., 2019). The inclusion of fish offal in BSF larval diets can enhance the unsaturated fatty acid content of the larvae. Fat deposition in BSF larvae is largely dependent on the substrate they feed on (Barragan-Fonseca et al., 2019; Sheppard et al., 1994; Spranghers et al., 2017; St-Hilaire et al., 2007).

In livestock feed formulation, ingredients are selected based on their nutrient content, availability, palatability and cost (www.poultryhub.org/nutrition/feed-formulation/). Key nutrients in feed ingredients are amino acids (contained in proteins), vitamins and minerals. Fats and protein provide energy needed to support metabolic processes and growth, whereas minerals are needed for bone formation, enzyme activation and egg shell development in laying hens. Against this background and from an overall evaluation of our data, BSF larvae reared on BSGs can successfully provide protein-rich meal for feed. Dietary essential and non-essential amino acids are necessary for the survival, development, growth, health and reproduction of animals. In poultry diet, methionine and lysine are two most limiting amino acids. In pigs, lysine, threonine, methionine, tryptophan and valine are the limiting amino acids in feed (Dalibard et al., 2014; Toride, 2004; Wu, 2014). Our data demonstrate a high nutritional value of BSF larvae containing most of the limiting amino acids in livestock diets.

Furthermore, the high content of $\mathrm{Ca}, \mathrm{P}$ and other essential microminerals such as $\mathrm{Fe}$ and $\mathrm{Zn}$ recorded in the present study represents a high potential of the larvae as a feed component in livestock feed. The inclusion of BSF larval meal can therefore minimise the additional use of external Ca supplementation in diets (Dierenfeld \& King, 2008).

\section{Conclusions}

This study provides insight into the effects of different agro-industrial side streams, especially BSGs on the nutritional value of BSF larvae and demonstrates that BSF larvae reared on these substrates are nutrient-rich and suitable for animal feed. While the different substrate combinations would generally produce high quality larvae in terms of nutrient composition, SB supplemented with brewer's yeast or brewer's yeast plus molasses appear to be more suitable as a rearing substrates and result in larvae with higher levels of crude protein and minerals. Overall, these findings confirm that BSGs are a valuable resource for rearing BSF larvae. Supplementing these substrates with residual brewers' yeast and cane molasses can enhance the larval quality for animal feed. 
However, the unsaturated fatty acid profile of the larvae needs to be enhanced by ensuring that substrate nutrient content meets the nutritional requirements of the larvae. Our findings show that BSF larvae can be mass-produced on these substrates, while providing an alternative strategy for managing brewery waste streams, when the conventional uses of these substrates such as direct feeding to livestock are not sufficient.

\section{Acknowledgements}

We thank Njowe K.B. Yisa, David M. Marikah and Isaiah E. Rachami for help in nutritional analysis of insect samples. We thank Alexandre Villela for help in data processing. The study was financially supported by the Netherlands Organization for Scientific Research, WOTRO Science for Global Development (NWO-WOTRO) (ILIPA - W 08.250.202). Authors declare no conflicts of interest.

\section{References}

Aguilera-Soto, J., Ramirez, R., Arechiga, C., Mendez-Llorente, F., Lopez-Carlos, M., Silva-Ramos, J., . . . Duran-Roldan, F. (2008). Effect of feed additives in growing lambs fed diets containing wet brewers grains. Asian-Australasian Journal of Animal Sciences, 21, 1425-1434.

Andrieu, S. (2008). Is there a role for organic trace element supplements in transition cow health? The Veterinary Journal, 176, 77-83.

Association of Official Analytical Chemists (AOAC). (1990). Official methods of analysis of the AOAC International: Association of Official Analytical Chemists.

Barragán-Fonseca, K., Pineda-Mejia, J., Dicke, M., \& van Loon, J. J. A. (2018). Performance of the black soldier fly (Diptera: Stratiomyidae) on vegetable residue-based diets formulated based on protein and carbohydrate contents. Journal of Economic Entomology, 111, 2676-2683.

Barragan-Fonseca, K. B., Gort, G., Dicke, M., \& van Loon, J. J. A. (2019). Effects of dietary protein and carbohydrate on life-history traits and body protein and fat contents of the black soldier fly Hermetia illucens. Physiological Entomology, 44, 148-159.

Barroso, F. G., Sánchez-Muros, M.-J., Segura, M., Morote, E., Torres, A., Ramos, R., \& Guil, J.-L. (2017). Insects as food: Enrichment of larvae of Hermetia illucens with omega 3 fatty acids by means of dietary modifications. Journal of Food Composition and Analysis, 62, 8-13.

Boykin, K. L. (2019). Assessing the nutritional value of black soldier fly larvae (Hermetia illucens) used for reptile foods. Master of Science, Louisiana State University and Agricultural and Mechanical College, (4927).

Çetingül, İ. S., \& Yardımc1, M. (2008). The importance of fats in farm animal nutrition. Kocatepe Veterinary Journal, 1, 77-81.

Chia, S. Y., Tanga, C. M., Osuga, I. M., Mohamed, S. A., Khamis, F. M., Salifu, D., . . Ekesi, S. (2018). Effects of waste stream combinations from brewing industry on performance of Black Soldier Fly, Hermetia illucens (Diptera: Stratiomyidae). PeerJ, 6, e5885.

Chollom, P., Agbo, E., Doma, U., Okojokwu, O., \& Yisa, A. (2017). Nutritional value of spent brewers' yeast (Saccharomyces cerevisiae): A potential replacement for soya bean in poultry 
feed formulation. Researcher, 9, 70-74.

Dalibard, P., Hess, V., Tutour, L., Peisker, M., Peris, S., Gutierrez, A., \& Redshaw, M. (2014). Amino acids in animal nutrition. Brussels. FEFANA. Retrieved from: www.aquafeed. com/documents/1430685417_1.pdf, July 5, 2019.

Devi, S. M., \& Kim, I. (2014). Effect of medium chain fatty acids (MCFA) and probiotic (Enterococcus faecium) supplementation on the growth performance, digestibility and blood profiles in weanling pigs. Veterinarni Medicina, 59, 527-535.

Diakogiannaki, E., Dhayal, S., Childs, C. E., Calder, P. C., Welters, H. J., \& Morgan, N. G. (2007). Mechanisms involved in the cytotoxic and cytoprotective actions of saturated versus monounsaturated long-chain fatty acids in pancreatic beta-cells. Journal of Endocrinology and Reproduction, 194, 283-291.

Dicke, M. (2018). Insects as feed and the Sustainable Development Goals. Journal of Insects as Food and Feed, 4, 147-156.

Diener, S., Zurbrugg, C., \& Tockner, K. (2009). Conversion of organic material by black soldier fly larvae: establishing optimal feeding rates. Waste Management \& Research, 27, 603-610.

Dierenfeld, E. S., \& King, J. (2008). Digestibility and mineral availability of Phoenix worms, Hermetia illucens, ingested by mountain chicken frogs, Leptodactylus fallax. Journal of Herpetological Medicine and Surgery, 18, 100-105.

Finke, M. D. (2013). Complete nutrient content of four species of feeder insects. Zoo Biology, 32, 27-36.

Foley, J. A., Ramankutty, N., Brauman, K. A., Cassidy, E. S., Gerber, J. S., Johnston, M., ... Zaks, D. P. (2011). Solutions for a cultivated planet. Nature, 478, 337-342.

Grundy, S. M. (1989). Monounsaturated fatty acids and cholesterol metabolism: implications for dietary recommendations. The Journal of Nutrition, 119, 529-533.

Heuzé, V., Thiollet, H., Tran, G., Edouard, N., Lessire, M., \& Lebas, F. (2018). Brewers yeast. Feedipedia, a programme by INRA, CIRAD, AFZ and FAO. Retrieved from: www.feedipedia.org/node/72, May 25, 2019.

Heuzé, V., Tran, G., Sauvant, D., \& Lebas, F. (2017). Brewer's grains. Feedipedia, a programme by INRA, CIRAD, AFZ and FAO. Retrieved from: www.feedipedia.org/node/74, May $25,2019$.

Huige, N. J. (2006). Brewery by-products and effluents. In G. Stewart, G \& F. G. Priest (Eds.), Handbook of brewing (2nd Edition ed., pp. 670-729). Boca Raton: CRC Press.

IPNI-International Plant Nutrition Institute. (1999). Phosphorus for Agriculture. Better crops with plant food, 83, 1-40.

Janssen, R. H., Vincken, J. P., van den Broek, L. A., Fogliano, V., \& Lakemond, C. M. (2017). Nitrogen-to-protein conversion factors for three edible insects: Tenebrio molitor, Alphitobius diaperinus, and Hermetia illucens. Journal of Agricultural and Food Chemistry, 65, 2275-2278.

Karen, G. (2019). Interpreting interactions when main effects are not significant. The Analysis Factor Retrieved from: www.theanalysisfactor.com/interactions-main-effects-not-significant/, August 29, 2019.

Kawasaki, K., Hashimoto, Y., Hori, A., Kawasaki, T., Hirayasu, H., Iwase, S.-i., . . . Miura, T. (2019). Evaluation of black soldier fly (Hermetia illucens) larvae and pre-pupae raised on household organic waste, as potential ingredients for poultry feed. Animals, 9, 98.

Klaphake, E. (2010). A fresh look at metabolic bone diseases in reptiles and amphibians. Veterinary Clinics: Exotic Animal Practice, 13, 375-392. 
Krook, L., Barrett, R. B., Usui, K., \& Wolke, R. E. (1963). Nutritional secondary hyperparathyroidism in the cat. Cornell Veterinarian, 53, 224-240.

Lee, H., \& Chiang, S. (1994). Energy value of medium-chain triglycerides and their efficacy in improving survival of neonatal pigs. Journal of Animal Science, 72, 133-138.

Leong, S., Kutty, S., Tan, C., \& Tey, L. (2015). Comparative study on the effect of organic waste on lauric acid produced by Hermetia illucens larvae via bioconversion. Journal of Engineering Science and Technology, 10, 52-63. Li, X., Zhang, D., \& Bryden, W. (2017). Calcium and phosphorus metabolism and nutrition of poultry: are current diets formulated in excess? Animal Production Science, 57, 2304-2310.

Liland, N. S., Biancarosa, I., Araujo, P., Biemans, D., Bruckner, C. G., Waagbo, R., . . Lock, E. J. (2017). Modulation of nutrient composition of black soldier fly (Hermetia illucens) larvae by feeding seaweed-enriched media. PloS ONE, 12, e0183188.

Liu, X., Chen, X., Wang, H., Yang, Q., Ur Rehman, K., Li, W., . . Zheng, L. (2017). Dynamic changes of nutrient composition throughout the entire life cycle of black soldier fly. PloS ONE, 12, e0182601.

Lock, B. (2017). Nutritional secondary hyperparathyroidism in reptiles. Veterinary Partner. Retrieved from: https://veterinarypartner.vin.com/default.aspx?pid=19239\&catId=102919\&id=8012396, July 5, 2019.

M'Ndegwa, J. (2016). Diversifying the use of molasses towards improving the infrastructure and economy of Kenya Civil and Environmental Research, 8, 37-42.

Makkar, H. (2014). Insect meals as animal feed. Broadening Horizons No. 12. Feedipedia - Animal Feed Resources Information System - INRA CIRAD AFZ and FAO. Retrieved from: www.feedipedia.org/content/insect-meals-animal-feed, May 28, 2019.

Makkar, H. P. S., Tran, G., Henze, V., \& Ankers, P. (2014). State-of-the-art on use of insects as animal feed. Animal Feed Science and Technology, 197, 1-33.

Manditsera, F. A., Luning, P. A., Fogliano, V., \& Lakemond, C. M. M. (2019). The contribution of wild harvested edible insects (Eulepida mashona and Henicus whellani) to nutrition security in Zimbabwe. Journal of Food Composition and Analysis, 75, 17-25.

Mcdowell, L. (2003). Calcium and phosphorus. In L. Mcdowell (Ed.), Minerals in animal and human nutrition (pp. 33-100). Amsterdam: Elsevier.

Meneguz, M., Schiavone, A., Gai, F., Dama, A., Lussiana, C., Renna, M., \& Gasco, L. (2018). Effect of rearing substrate on growth performance, waste reduction efficiency and chemical composition of black soldier fly (Hermetia illucens) larvae. Journal of the Science of Food and Agriculture, 98, 5776-5784.

Musundire, R., Osuga, I. M., Cheseto, X., Irungu, J., \& Torto, B. (2016). Aflatoxin contamination detected in nutrient and anti-oxidant rich edible stink bug stored in recycled grain containers. PloS ONE, 11, e0145914.

National Research Council. (1994). Nutrient requirements of poultry: National Academies Press.

National Research Council. (1998). Nutrient requirements of swine: 10th revised edition. Washington, DC: The National Academies Press.

Nguyen, T. T., Tomberlin, J. K., \& Vanlaerhoven, S. (2015). Ability of black soldier fly (Diptera: Stratiomyidae) larvae to recycle food waste. Environmental Entomology, 44, 406-410.

Nyakeri, E., Ogola, H., Ayieko, M., \& Amimo, F. (2017). Valorisation of organic waste material: growth performance of wild black soldier fly larvae (Hermetia illucens) reared on different organic wastes. Journal of Insects as Food and Feed, 3, 193-202. 
Olson, K., \& Hale, C. (2001). Mineral supplements for beef cattle. University of Missouri-Columbia (Mu Extension). Retrieved from: www.semanticscholar.org/paper/Mineral-Sup ple ments-for-Beef-Cattle-Olson-Hale/b5e8a1dd7616fcf8270a19115158bc1045a8654c, May 21, 2019.

Onofre, S. B., Bertoldo, I. C., Abatti, D., \& Refosco, D. (2017). Chemical composition of the biomass of Saccharomyces cerevisiae-(Meyen ex EC Hansen, 1883) yeast obtained from the beer manufacturing process. International Journal of Environment, Agriculture and Biotechnology, 2, 558-562.

Oonincx, D., Laurent, S., Veenenbos, M. E., \& van Loon, J. J. A. (2019). Dietary enrichment of edible insects with omega 3 fatty acids. Insect Science in press.

Pelicia, K., Garcia, E. A., Faitarone, A., Silva, A., Berto, D., Molino, A., \& Vercese, F. (2009). Calcium and available phosphorus levels for laying hens in second production cycle. Brazilian Journal of Poultry Science, 11, 39-49.

Phalen, D. N., Drew, M. L., Contreras, C., Roset, K., \& Mora, M. (2005). Naturally occurring secondary nutritional hyperparathyroidism in cattle egrets (Bubulcus ibis) from central Texas. Journal of Wildlife Diseases, 41, 401-415.

Rana, K., Siriwardena, S., \& Hasan, M. (2009). Impact of rising feed ingredient prices on aquafeeds and aquaculture production. FAO fisheries and aquaculture, technical paper no. 541 Rome. Food and Agriculture Organization (FAO). Retrieved from: www.fao.org/3/ i1143e/i1143e00.pdf, May 22, 2019.

Rumpold, B. A., Speckmann, H., Schlüter, O., Kloas, W., \& Prochnow, A. (2018). Potentials of a biogenic residue-based production of Hermetia illucens as fish meal replacement in aquafeed for Oncorbynchus mykiss in Germany. Journal of Insects as Food and Feed, 4, 5-18.

Schiavone, A., De Marco, M., Martínez, S., Dabbou, S., Renna, M., Madrid, J., . . . Gasco, L. (2017). Nutritional value of a partially defatted and a highly defatted black soldier fly larvae (Hermetia illucens L.) meal for broiler chickens: apparent nutrient digestibility, apparent metabolizable energy and apparent ileal amino acid digestibility. Journal of Animal Science and Biotechnology, 8, 51.

Schmitt, E., Belghit, I., Johansen, J., Leushuis, R., Lock, E. J., Melsen, D., . . Paul, A. (2019). Growth and safety assessment of feed streams for black soldier fly larvae: a case study with aquaculture sludge. Animals, 9, 189.

Sealey, W. M., Gaylord, T. G., Barrows, F. T., Tomberlin, J. K., McGuire, M. A., Ross, C., \& St-Hilaire, S. (2011). Sensory analysis of rainbow trout, Oncorbynchus mykiss, fed enriched black soldier fly pre-pupae, Hermetia illucens. Journal of the World Aquaculture Society, 42, 3445.

Sheppard, D. C., Newton, G. L., Thompson, S. A., \& Savage, S. (1994). A value added manure management system using the black soldier fly. Bioresource Technology, 50, 275-279.

Simopoulos, A. P. (2002). The importance of the ratio of omega-6/omega-3 essential fatty acids. Biomedicine and Pharmacotherapy, 56, 365-379.

Skřivanová, E., Marounek, M., Benda, V., \& Březina, P. (2006). Susceptibility of Escherichia coli, Salmonella sp and Clostridium perfringens to organic acids and monolaurin. Veterinarni Medicina, 51, 81-88

Sordillo, L. M., Shafer-Weaver, K., \& DeRosa, D. (1997). Immunobiology of the mammary gland. Journal of Dairy Science, 80, 1851-1865.

Spranghers, T., Michiels, J., Vrancx, J., Ovyn, A., Eeckhout, M., De Clercq, P., \& De Smet, S. (2018). Gut antimicrobial effects and nutritional value of black soldier fly (Hermetia illucens L.) 
prepupae for weaned piglets. Animal Feed Science and Technology, 235, 33-42.

Spranghers, T., Ottoboni, M., Klootwijk, C., Ovyn, A., Deboosere, S., De Meulenaer, B., . . De

Smet, S. (2017). Nutritional composition of black soldier fly (Hermetia illucens) prepupae reared on different organic waste substrates. Journal of the Science of Food and Agriculture, 97, 2594-2600.

Ssepuuya, G., Namulawa, V., Mbabazi, D., Mugerwa, S., Fuuna, P., Nampijja, Z., . . Nakimbugwe, D. (2017). Use of insects for fish and poultry compound feed in sub-Saharan Africa-a systematic review. Journal of Insects as Food and Feed, 3, 289-302.

St-Hilaire, S., Sheppard, C., Tomberlin, J. K., Irving, S., Newton, L., McGuire, M. A., . . Sealey, W. (2007). Fly pre-pupae as a feedstuff for rainbow trout, Oncorbynchus mykiss. Journal of the World Aquaculture Society, 38, 59-67.

Stewart, L. (2017). Mineral supplement for beef cattle. University of Georgia (UGA). UGA Cooperative Extension-Bulletin 895. Retrieved from: https://secure.caes.uga.edu/extension/publications/files/pdf/B\%20895_4.pdf, May 29, 2019.

Surendra, K. C., Olivier, R., Tomberlin, J. K., Jha, R., \& Khanal, S. K. (2016). Bioconversion of organic wastes into biodiesel and animal feed via insect farming. Renewable Energy, 98, 197-202.

Suttle, N. F. (2010). Mineral Nutrition of Livestock (4 ed.): Centre for Agriculture and Bioscience International (CABI).

Syadati, S., Mirzaei-Aghsaghali, A., Fathi, H., \& Davuodi, J. (2012). Importance essential fatty acids (n-6 and n-3) in animal nutrition: I: ruminant. Annals of Biological Research, 3, 1161-1176.

Tacon, A. G. (1987). The nutrition and feeding of farmed fish and shrimp; a training manual. 1: The essential nutrients. Brazil. Food and Agriculture Organization. Retrieved from: www. fao.org/3/ab470e/ab470e06.htm, May 30, 2019.

Tan, H. S. G., Fischer, A. R. H., Tinchan, P., Stieger, M., Steenbekkers, L. P. A., \& van Trijp, H. C. M. (2015). Insects as food: Exploring cultural exposure and individual experience as determinants of acceptance. Food Quality and Preference, 42, 78-89.

Thomas, M., Hersom, M., Thrift, T., \& Yelich, J. (2010). Wet Brewers' Grains for Beef Cattle (AN241). University of Florida. A. Institute of Food and Agricultural Sciences (IFAS) Extension. Retrieved from: http://edis.ifas.ufl.edu/pdffiles/AN/AN24100.pdf, July 3, 2019.

Toride, Y. (2004). Lysine and other amino acids for feed: production and contribution to protein utilization in animal feeding. In: Protein sources for the animal feed industry- Expert consultation and workshop, Bangkok, 29 April-3 May 200229 April-3 May 2002. Rome. Food and Agriculture Organization. Retrieved from: www.fao.org/3/y5019e/y5019e00. htm\#Contents, July 3, 2019.

Tschirner, M., \& Simon, A. (2015). Influence of different growing substrates and processing on the nutrient composition of black soldier fly larvae destined for animal feed. Journal of Insects as Food and Feed, 1, 249-259.

Vallee, B. L., \& Falchuk, K. H. (1993). The biochemical basis of zinc physiology. Physiological Reviews, 73, 79-118.

Van Huis, A. (2013). Potential of insects as food and feed in assuring food security. Annual Review of Entomology, 58, 563-583.

Van Huis, A. (2015). Edible insects contributing to food security? Agriculture \& Food Security, 4, 20. 
Van Huis, A. (2016). Edible insects are the future? Proceedings of the Nutrition Society, 75, 294-305.

Van Huis, A., Dicke, M., \& van Loon, J. J. A. (2015). Insects to feed the world. Journal of Insects as Food and Feed, 1, 3-5.

Van Huis, A., Van Itterbeeck, J., Klunder, H., Mertens, E., Halloran, A., Muir, G., \& Vantomme, P. (2013). Edible insects: future prospects for food and feed security (No. 171). Rome: Food and Agriculture Organization.

Van Huis, A., \& Vantomme, P. (2014). Conference report: insects to feed the world. Food Chain, 4, 184-192.

Wang, Y. S., \& Shelomi, M. (2017). Review of black soldier fly (Hermetia illucens) as animal feed and human food. Foods, 6, 91.

Wong, C. Y., Rosli, S. S., Uemura, Y., Ho, Y. C., Leejeerajumnean, A., Kiatkittipong, W., . . Lim, J. W. (2019). Potential protein and biodiesel sources from black soldier fly larvae: Insights of larval harvesting instar and fermented feeding medium. Energies, 12, 1570.

Wu, G. (2014). Dietary requirements of synthesizable amino acids by animals: a paradigm shift in protein nutrition. Journal of Animal Science and Biotechnology, 5, 34.

Yang, S. (2019). Why is the calcium in our black soldier fly larvae so important? Symton black soldier fly. Retrieved from: https://symtonbsf.com/blogs/blog/why-is-the-calcium-inour-black-soldier-fly-larvae-so-important, July 2, 2019.

Zotte, A. D., Singh, Y., Michiels, J., \& Cullere, M. (2019). Black soldier fly (Hermetia illucens) as dietary source for laying quails: Live performance, and egg physico-chemical quality, sensory profile and storage stability. Animals, 9, 115. 


\section{Chapter 7}

\section{Effect of dietary replacement of fishmeal by insect meal on growth performance, blood profiles and economics of growing pigs in Kenya}

Shaphan Y. Chia, Chrysantus M. Tanga, Isaac M. Osuga, Alphonce O. Alaru, David M. Mwangi, Macdonald Githinji, Sevgan Subramanian, Komi K. M. Fiaboe, Sunday Ekesi, Joop J. A. van Loon and Marcel Dicke

Published in Animals (2019)

9:705, doi:10.3390/ani9100705 


\section{Abstract}

Pig production is one of the fastest growing livestock sectors. Development of this sector is hampered by rapidly increasing costs of fishmeal (FM), which is a common protein source in animal feeds. Here, we explored the potential of substituting FM with black soldier fly larval meal (BSFLM) on growth and blood parameters of pigs as well as economic aspects. At weaning, 40 hybrid pigs, i.e., crossbreeds of purebred Large White and Landrace were randomly assigned to five iso-nitrogenous and iso-energetic dietary treatments: Control (0\% BSFLM and 100\% FM (T0)), and FM replaced at 25\% (T25), 50\% (T50), 75\% (T75) and 100\% (T100) with BSFLM. Average daily feed intake (ADFI), average daily gain (ADG), body weight gain (BWG) and feed conversion ratio (FCR) were calculated for the whole trial. Hematological and serum biochemical parameters, the cost-benefit ratio (CBR) and return on investment (RoI) were evaluated. No significant effect of diet type was observed on feed intake and daily weight gain. Red or white blood cell indices did not differ among diets. Pigs fed T25, T75 and T100, had lower platelet counts compared to T0 and T50. Dietary inclusion of BSFLM did not affect blood total cholesterol, triglycerides, low-density lipoprotein and high-density lipoprotein. CBR and RoI were similar for the various diets. In conclusion, BSFLM is a suitable and cost-effective alternative to FM in feed for growing pigs.

Keywords: growing pigs; blood parameters; insect larval meal; alternative protein; animal feeds; cost benefit analysis; return on investment 


\section{Introduction}

Pig production is one of the fastest growing livestock sectors globally, with most of the growth occurring in the developing countries (Githigia et al., 2012). Pigs are of socio-economic value to smallholder farmers and provide a safety net in times of financial crisis (Githigia et al., 2012). A short breeding cycle, high fecundity, high feed conversion efficiency and increasing demand are major drivers of growth in this sector. In communities currently experiencing a shift from ruminant to non-ruminant livestock production, pig farming is becoming relevant (Githigia et al., 2012; Serem et al., 2017). However, expansion and profitability are constrained by increasing feed costs, especially the protein ingredients (Githigia et al., 2012). Feed costs represent $60 \%-70 \%$ of total costs in intensive pig production, which is especially due to costs of protein. In East Africa, major protein ingredients such as fishmeal (FM) and soybean meal are increasingly unavailable and expensive for smallholder farmers (Onsongo et al., 2018). Consequently, farmers resort to alternative feed sources considered to be cheaper without knowledge of their influence on the physiological response and animal growth (Etim et al., 2014a; Etim et al., 2014b; Etim et al., 2014c; Serem et al., 2017). Considering the importance of pig production in livelihoods of smallholder farmers and the growing scarcity of protein ingredients as well as the environmental implications of producing these resources (Masuda \& Goldsmith, 2009; Tacon \& Metian, 2008), dependence on FM and soybean meal is not sustainable (Van Huis et al., 2013).

Insects have high protein and fat content and have been considered promising high-quality feed components (Bosch et al., 2014; Rumpold \& Schluter, 2013; Veldkamp et al., 2012). Insects could replace $25 \%$ to $100 \%$ of FM or soybean meal in feeds for livestock and aquaculture, depending on the insect, livestock and fish species (Makkar et al., 2014). The black soldier fly (BSF) Hermetia illucens L. (Diptera: Stratiomyidae) is distributed worldwide in the tropics and warm temperate regions (Sheppard et al., 1994). BSF larvae feed on organic resources such as fruit remains, animal manure, vegetables and brewers' spent grains (Chia et al., 2018; Li et al., 2011; Makkar et al., 2014; Meneguz et al., 2018; Myers et al., 2008; Nguyen et al., 2013; Pinotti et al., 2019; Rehman et al., 2017; Salomone et al., 2017) and convert these resources into high-quality insect protein and fat. In contrast to other dipteran species such as the house fly Musca domestica, BSF is not considered a pest and its larvae can reduce populations of harmful bacteria (Erickson et al., 2004; Liu et al., 2008). On a dry matter basis, BSF larvae contain 37\% to $63 \%$ crude protein, $7 \%$ to 39\% fat (Barragan-Fonseca et al., 2017; Bosch et al., 2014), $8 \%$ calcium, $1 \%$ to $2 \%$ phosphorus, $0.1 \%$ to $0.3 \%$ sodium and $0.4 \%$ to $1 \%$ magnesium (Barragan-Fonseca et al., 2017; Dierenfeld \& King, 2008; Finke, 2013; Newton et al., 2005a). BSF larval meal has been used as an ingredient in feed for fish (Cummins Jr et al., 2017; Devic et al., 2018; Dumas et al., 2018; Kroeckel et al., 2012; Li et al., 2016; 
Magalhaes et al., 2017; Sealey et al., 2011; Zarantoniello et al., 2018), poultry (Maurer et al., 2016; Onsongo et al., 2018; Schiavone et al., 2017) and pigs (Biasato et al., 2019; Driemeyer, 2016; Newton et al., 1977; Spranghers et al., 2018), with promising results. However, there is no exhaustive information on the influence of BSF larval meal (BSFLM) on performance and health response of growing pigs. The few studies on the inclusion of BSFLM in pig feeds have focused on piglets, replacing either FM or soybean meal with low (less than 10\%) levels of BSFLM over short (10-40 days) periods of feeding (Biasato et al., 2019; Driemeyer, 2016; Newton et al., 1977; Spranghers et al., 2018). The short experimental periods do not allow for a complete growth phase under the dietary supplementation and, therefore, do not reflect the common practice of pig feeding. In addition, higher levels of BSFLM inclusion in pig feed have not been assessed. In the present study, we subjected growing pigs to feeds with higher $(25 \%-100 \%)$ dietary replacement levels of FM with BSFLM over an extended period (>60 days) of feeding, covering the complete pig grower phase and measured the effect of diet on performance and economics of pig feeding.

Hematological and biochemical parameters are affected by several factors, including diet (Etim et al., 2014a). Nutritional deficiencies and diseases influence clinical health status of animals (Wilson et al., 1972). In the case of nutritional deficiencies, blood profiling can provide an indication of the clinical health status as well as the extent to which dietary deficiencies impact physiological status of the animal, which allows farmers to adjust the diets of the animals to ensure that they receive adequate feed ingredients for optimal production (Ameen et al., 2007; Etim et al., 2014a; Shanmugam et al., 2017). BSF larvae represent a novel protein source in animal feed. Studies have reported unaffected growth performance, blood parameters, nutrient digestibility, gut morphology and histological features of piglets as well as gut antimicrobial potential of the inclusion of full-fat or partially defatted BSFLM in piglet feed at the rate of $4 \%-10 \%$ to replace soybean meal or FM (Biasato et al., 2019; Driemeyer, 2016; Spranghers et al., 2018), but there is little information on the effect of complete replacement of FM by full-fat BSFLM in pig feed. Utilization of insect meal as an animal feed ingredient is attracting interest from researchers because conventional feed ingredients are increasingly becoming unaffordable to resource-poor farmers due to rapidly rising costs. This requires us to search for alternative protein ingredients that can economically supplement conventional feed ingredients used in feed formulation without adverse effects on the health and performance of the animals. The inclusion of ingredients in feed formulation does not only aim at a balanced nutrient content for optimal growth performance, but also considers profitability of the production process (Spring, 2013). Therefore, the present study aimed at evaluating the effect of substituting FM with BSFLM on (a) growth performance, (b) hematological and serum biochemical indices and (c) economic implications of BSFLM inclusion in growing pig diets. 


\section{Materials and Methods}

The present study was conducted at the pig rearing facility of the Non-ruminant Research Institute (NRI) of the Kenya Agricultural and Livestock Research Organization (KALRO), Naivasha, Kenya. The general care and management of the animals followed accepted guidelines as described by the Federation of Animal Science Societies (FASS, 2010).

\section{BSF larval meal (BSFLM) and experimental diets}

Diets were formulated to meet growing pig requirements (NRC, 1979). Isonitrogenous and isoenergetic diets were prepared by replacing the FM content of a control diet (T0) at 25\%,50\%,75\% and 100\% (T25, T50, T75 and T100, respectively) with BSFLM, as experimental diets (Table 1). Maize meal, wheat pollard and rice polishing were included as energy sources. BSFLM and FM served as major protein sources. Vitamin and mineral premix, salt, limestone and bone meal served as vitamin and mineral sources (Table 1). FM, maize meal, rice polishing, salt, limestone, vitamin and mineral premix, lysine, methionine and bone meal were purchased from commercial animal feed retailers. BSF larvae were obtained from the International Centre of Insect Physiology and Ecology (icipe), reared following the BSF rearing procedure of the Animal Rearing and Containment Unit (ARCU), icipe. BSF larvae were reared on a mixture of brewers' spent grains (BSGs) obtained from Kenya Breweries Limited (KBL). After harvest, larvae were sterilized by washing in warm water $\left(84^{\circ} \mathrm{C}\right)$ for 10 minutes and then oven-dried using a commercial stainless-steel fruit/vegetable/meat/fish drying machine model (CT-C-III Series hot air circulating drying oven, Henan Forchen Machinery Co., Ltd., Henan, China). The machine can dry $360 \mathrm{~kg} / \mathrm{batch}$ of fresh insects for $2.5 \mathrm{~h}$ at $120{ }^{\circ} \mathrm{C}$. Dried larvae were ground into larval meal using a hammer mill (Newton et al., 1977).

\section{Proximate, amino acids and mineral composition of experi- mental diets}

The dry matter content of formulated feed samples was gravimetrically determined after the loss of water. The samples were heated to $103 \pm 2{ }^{\circ} \mathrm{C}$ for $3 \mathrm{~h}$ to constant weight. Ash content was determined by ignition of samples at $550{ }^{\circ} \mathrm{C}$ in a muffle furnace. Dried and ground samples were exposed to an electromagnetic scan in the absorbance mode using near infrared (NIR) spectroscopy (CROPNUTS, Nairobi, Kenya). The crude protein, fat, starch, oil, acid detergent fiber, neutral detergent fiber, sugar and digestibility (NCGD) values were determined following standard laboratory procedures and energy values were calculated (Núñez-Sánchez et al., 2012; Rosales et al., 2011). Essential and non-essential amino acid contents of BSF larvae and experimental diets (Table 1) were analyzed by AMINOLab® (Evonik Industries, Hanau, Germany) using an amino acid 
analyzer (Biochrom 30 plus, Biochrom Ltd. Cambridge, UK) (Al Sagan et al., 2018; Llames \& Fontaine, 1994; Powell et al., 2017; Windham, 1995; Zampiga et al., 2018). Feed samples were homogenously ground with an Ultra Centrifugal Mill RETSCH-ZM 200 to pass through a $0.5 \mathrm{~mm}$ sieve. Finely ground samples were weighed using an analytical balance, display accuracy $\pm 0.01 \mathrm{mg}$ into $50 \mathrm{~mL}$ laboratory bottles, with thread of DURAN glass (Schott, Mainz, Germany), red polybutylene terephthalate (PBTP) caps with silicone/Teflon seal. Then, $25 \mathrm{~mL}$ of hydrochloric-phenol reagent was added to the sample in the bottles and the mixture was introduced into a thermostatically controlled heating oven (UT 6060 AR, Thermo Electron LED, Langenselbold, Germany) at $110{ }^{\circ} \mathrm{C}$, with loose screw tops for one hour and then with tightened screw tops for $23 \mathrm{~h}$ to complete the sample hydrolysis. Methionine and cystine samples were prepared through performic acid oxidation procedures followed by the acid hydrolysis-sodium metabisulfite method (Slump \& Bos, 1985; Windham, 1995). The resulting hydrolysate solutions were then introduced into the amino acid analyzer and the sample aminograms were detected at $570 \mathrm{~nm}$ and $440 \mathrm{~nm}$. Amino acid concentrations in the samples were determined in duplicate.

The mineral content of feed samples (Table 2) was analyzed by inductively coupled plasma-atomic emission spectrometry (ICP-OES; CROPNUTS, Nairobi, Kenya). Sample preparation involved microwave-assisted acid digestion. Aliquots of ground feed samples were transferred to a glass tube of the microwave system. Then, a mixture of nitric acid and hydrochloric acid was added to the sample and allowed to digest. The resulting solution was filtered into a volumetric flask and used for ICP-OES analysis to determine the following minerals: Boron, molybdenum, iron, copper, zinc, cobalt, manganese, sodium, sulphur, magnesium, potassium, phosphorus and calcium (Barałkiewicz et al., 2007; Płotka-Wasylka et al., 2018; Santos et al., 2012; Sreenivasulu et al., 2017). 
Table 1. Ingredients, composition of black soldier fly larval meal and experimental diets

\begin{tabular}{|c|c|c|c|c|c|c|}
\hline \multirow{2}{*}{ Parameter } & \multirow[b]{2}{*}{ BSFLM } & \multicolumn{5}{|c|}{ Diets } \\
\hline & & T0 & $\mathrm{T} 25$ & T50 & $\mathrm{T} 75$ & T100 \\
\hline \multicolumn{7}{|c|}{ Ingredient $(\mathrm{kg})$} \\
\hline Maize meal & - & 12.0 & 14.0 & 14.0 & 14.0 & 15.0 \\
\hline Wheat pollard & - & 52.0 & 35.0 & 33.0 & 35.2 & 34.2 \\
\hline Rice polishing & - & 22.0 & 30.5 & 32.0 & 29.8 & 28.3 \\
\hline Fishmeal & - & 10.0 & 7.5 & 5.0 & 2.5 & - \\
\hline BSFLM & - & - & 9.0 & 12 & 14.5 & 18.5 \\
\hline Lysine & - & 1.0 & 1.0 & 1.0 & 1.0 & 1.0 \\
\hline Methionine & - & 1.0 & 1.0 & 1.0 & 1.0 & 1.0 \\
\hline Salt & - & 0.2 & 0.2 & 0.2 & 0.2 & 0.2 \\
\hline Bone meal & - & 0.8 & 0.8 & 0.8 & 0.8 & 0.8 \\
\hline Limestone & - & 0.8 & 0.8 & 0.8 & 0.8 & 0.8 \\
\hline $\begin{array}{l}\text { Vitamin and mineral } \\
\text { premix }^{a}\end{array}$ a & - & 0.2 & 0.2 & 0.2 & 0.2 & 0.2 \\
\hline Dry matter (DM) $(\%)$ & 94.9 & 92.6 & 94.0 & 92.4 & 93.2 & 94.0 \\
\hline Crude protein (\% DM) & 46.6 & 15.4 & 15.3 & 15.0 & 15.7 & 14.8 \\
\hline \multicolumn{7}{|c|}{ Essential amino acids (\% DM) } \\
\hline Lysine & 2.9 & 1.0 & 0.8 & 0.9 & 1.0 & 0.9 \\
\hline Methionine & 0.8 & 0.5 & 0.4 & 0.5 & 0.5 & 0.5 \\
\hline Methionine + Cystine & 1.1 & 0.7 & 0.6 & 0.8 & 0.7 & 0.7 \\
\hline Isoleucine & 1.8 & 0.5 & 0.5 & 0.5 & 0.5 & 0.5 \\
\hline Leucine & 2.9 & 1.0 & 1.1 & 0.9 & 1.0 & 0.9 \\
\hline Threonine & 1.7 & 0.5 & 0.5 & 0.5 & 0.5 & 0.5 \\
\hline Phenylalanine & 2.2 & 0.6 & 0.6 & 0.5 & 0.6 & 0.6 \\
\hline Valine & 2.6 & 0.7 & 0.7 & 0.7 & 0.7 & 0.7 \\
\hline Arginine & 2.2 & 0.9 & 0.9 & 0.8 & 0.8 & 0.8 \\
\hline Histidine & 1.3 & 0.3 & 0.4 & 0.3 & 0.3 & 0.3 \\
\hline \multicolumn{7}{|c|}{ Nonessential amino acids (\% DM) } \\
\hline Alanine & 3.0 & 0.8 & 0.9 & 0.8 & 0.9 & 0.8 \\
\hline Aspartic acid & 3.9 & 1.1 & 1.2 & 1.1 & 1.1 & 1.0 \\
\hline Cystine & 0.4 & 0.3 & 0.3 & 0.2 & 0.2 & 0.2 \\
\hline Glutamic acid & 4.9 & 2.3 & 2.3 & 2.0 & 2.1 & 2.0 \\
\hline Glycine & 2.5 & 0.8 & 0.8 & 0.7 & 0.8 & 0.7 \\
\hline Proline & 2.4 & 0.8 & 0.9 & 0.8 & 0.8 & 0.8 \\
\hline Serine & 1.8 & 0.6 & 0.6 & 0.6 & 0.6 & 0.6 \\
\hline
\end{tabular}

BSFLM $=$ black soldier fly larval meal. T0 $=0 \%$ (control), T25 $=25 \%$, T50 $=50 \%$, T75 $=75 \%$ and T100 $=100 \%$ levels of replacement of fishmeal with BSFLM. DM = dry matter. Amino acid values are means of

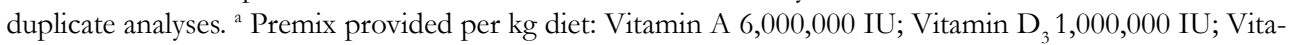
min E 5,000 IU; Vitamin $\mathrm{K}_{3}$ - KASTAB 3,000 mg; Vitamin $\mathrm{B}_{2}$-riboflavin 4,500 mg; Vitamin $\mathrm{B}_{3}$ - nicotinic acid 22,000 mg; Vitamin $B_{5}$ - pantothenic acid 16,000 mg; Vitamin $B_{6}$ - pyridoxine 2,250 mg; Vitamin $B_{9}-$ folic acid $350 \mathrm{mg}$; Vitamin $\mathrm{H}$ - biotin $50 \mathrm{mg}$, Vitamin $\mathrm{B}_{12}$ - cobalamin $22 \mathrm{mg}$; choline chloride 150,000 mg; antioxidant 125,000 mg; iron (Fe) 40,000 mg, manganese (Mn) 40,000 mg; zinc (Zn) 100,000 mg, copper (Cu) 25,000 mg; iodine (I) 1,000 mg, cobalt (Co) $250 \mathrm{mg}$, selenium (Se) $100 \mathrm{mg}$. 
Table 2. Mineral and proximate composition of experimental diets

\begin{tabular}{llllll}
\hline \multirow{2}{*}{ Parameter } & \multicolumn{5}{c}{ Diets } \\
\cline { 2 - 6 } & T0 & T25 & T50 & T75 & T100 \\
\hline Boron (ppm) & 4.2 & 2.8 & 2.3 & 2.7 & 3.1 \\
Molybdenum (ppm) & 1.3 & 1.1 & 0.5 & 1.0 & 1.2 \\
Iron (ppm) & 750.5 & 731.0 & 632.6 & 518.4 & 529.2 \\
Copper (ppm) & 22.6 & 501.1 & 80.5 & 16.7 & 22.8 \\
Zinc (ppm) & 121.4 & 110.6 & 114.1 & 102.3 & 112.6 \\
Cobalt (ppm) & 3.4 & 0.5 & 0.4 & 0.5 & 0.4 \\
Manganese (ppm) & 295.4 & 257.0 & 264.1 & 243.0 & 222.9 \\
Sodium (ppm) & 2439.8 & 1648.6 & 1097.8 & 1138.8 & 998.9 \\
Sulphur (\%) & 0.4 & 0.6 & 0.3 & 0.3 & 0.3 \\
Magnesium (\%) & 0.8 & 0.7 & 0.7 & 0.6 & 0.6 \\
Potassium (\%) & 0.9 & 0.9 & 0.9 & 0.9 & 0.9 \\
Phosphorus (\%) & 0.9 & 0.7 & 0.8 & 0.8 & 0.7 \\
Calcium (\%) & 2.5 & 2.8 & 2.1 & 1.7 & 1.8 \\
Sugar (\%) & 4.5 & 5.1 & 6.2 & 6.5 & 8.7 \\
Starch (\%) & 29.2 & 25.3 & 27.6 & 20.7 & 26.9 \\
Ash (\%) & 10.5 & 10.6 & 10.1 & 10.1 & 8.9 \\
Acid detergent fiber (\%) & 15.3 & 19.0 & 17.0 & 20.7 & 15.4 \\
Neutral detergent fiber (\%) & 37.7 & 42.8 & 41.6 & 47.0 & 39.7 \\
Digestibility (NCGD) (\%) & 79.3 & 73.5 & 75.0 & 70.0 & 76.9 \\
Oil (\%) & 5.0 & 8.1 & 8.9 & 9.8 & 12.2 \\
Net energy (MJ/kg) & 9.5 & 9.8 & 10.5 & 9.9 & 12.0 \\
\hline
\end{tabular}

$\mathrm{T} 0=0 \%$ (control), $\mathrm{T} 25=25 \%, \mathrm{~T} 50=50 \%, \mathrm{~T} 75=75 \%$ and $\mathrm{T} 100=100 \%$ levels of replacement of fishmeal with BSFLM. NCGD = neutral cellulase gammanase digestibility, $\mathrm{ppm}=$ parts per million.

\section{Experimental animals and housing}

Before the commencement of the experiment, forty (20 male and 20 female) hybrid pig weaners, which consisted of a cross between purebred Large White and the Landrace with mean body weight of $18.25 \pm 0.34 \mathrm{~kg}$ were sourced from Farmer's Choice Limited, Nairobi, Kenya. The pigs were randomly assigned to five dietary treatments, each replicated four times per sex (four males and four females). Pigs were housed in concrete floor pens $(3.65 \mathrm{~m} \times 1.85 \mathrm{~m})$ each containing two pigs (one male and one female). Each pen was provided with a one-sided self-feeder $(1.80 \mathrm{~m} \times 0.20 \mathrm{~m} \times 0.18 \mathrm{~m})$. Pigs were adapted to the pens for 14 days before the start of the experiment, during which they were fed a commercial starter feed. At the start of the experiment, each pen was labeled with a number and diet type while each animal was identified with a unique number by ear tattooing. A layer ( $\sim 0.25 \mathrm{~m}$ thick) of dry wood shavings was carefully placed at one corner of the floor of each pen, which served as bedding for the pig and provided warmth. Pig pens were cleaned every day by scrubbing the floor using Teepee straight brooms (c27, Chandarana Foodplus, Nairobi, Kenya) and water. Each pen was provided with a nipple drinker fitted to the wall and the distance between the nipple and floor was adjusted as the pigs increased in height. Experimental animals were allowed ad libitum access to feed and water throughout the experiment. 


\section{Growth performance}

Individual pig body weight was recorded on a weekly basis using a $150 \mathrm{~kg} \times 500 \mathrm{~g}$ suspended weighing scale (Salter, model 235, Bilston, England), with the sides covered with a wire mesh to prevent uncontrolled exit of the animal. The entry gate of the weighing cage was opened sideward and the animal was led into a stable, non-moving floor after which the gate was closed. Once inside the cage, the animal was allowed to settle, and the weight value read on an analogue display screen above the weighing cage. After every reading, the pig was released from the weighing cage into its pen and the scale was moved to the next pen on two wheels fitted on the front end of the cage. On the day of weighing, pigs were only provided with feed after recording their body weight. The weekly body weights were used to calculate average daily weight gain (ADG). Feed offered to the pigs and unconsumed portions were weighed daily using a digital platform weighing scale (XK3190-A12, >300 kg, Gromy Scale Co., Ltd., Hangzhou, China) to calculate average daily feed intake (ADFI). The trial lasted nine weeks. Total body weight gain and feed consumed were used to calculate feed conversion ratio (FCR) for each dietary treatment.

\section{Blood characteristics}

At the end of the growing pig phase, three randomly selected pigs from each dietary treatment were starved for $12 \mathrm{~h}$, with access to drinking water only. After this period, two blood samples $(5 \mathrm{~mL}$ each) were drawn from the peripheral ear vein using flashback blood collection needles and $9 \mathrm{~mL}$ vacutainer blood collection tubes (VP4082, Sunphoria Co., Ltd., Taipei, Taiwan). One of the samples was treated with the anticoagulant ethylene diamine tetra acetic acid (K2EDTA) and the other with serum clot activator. These samples were transported immediately to the laboratory for further analysis.

\section{Hematological and serum lipid parameters}

A 5-part white blood cell (WBC) differential and complete blood cell count was performed using the automated IDEXX ProCyte DxTM Hematology analyzer (IDEXX, Westbrook, ME, USA) by laser flow cytometry, optical fluorescence and laminar flow impedance. Each ethylene diamine tetra acetic acid (EDTA)-anticoagulated whole blood sample was mixed thoroughly for seven minutes on a sample rocker. Once the processing was over, the sample details were entered and the type of analysis to be carried out was indicated. Thereafter, the blood samples were loaded into the analyzer and automatically run to generate the following parameters: Red blood cells (RBC), hemoglobin concentration $(\mathrm{Hb})$, hematocrit $(\mathrm{Hct})$, mean corpuscular volume (MCV), mean corpuscular hemoglobin (MCH), mean corpuscular hemoglobin concentration (MCHC), red cell distribution width (RDW), platelet count, total white blood cell count 
(WBC), neutrophil percentage, lymphocyte percentage, monocyte percentage, eosinophil percentage and basophil percentage. The WBC differential counts were qualitatively verified through Romanowsky-stained thin blood smear examination using a light microscope at the oil immersion objective $(100 \times)$. Clotted blood samples were centrifuged at 4000 revolutions per minute (rpm) for 10 minutes. The serum lipoprotein (HDL), triglyceride and low-density lipoprotein (LDL) levels in the samples were measured on an automatic Cobas Integra 400 plus Chemistry Analyzer (Roche, Rotkreuz, Switzerland) using enzymatic colorimetry.

\section{Economic analysis}

Two key parameters, the cost-benefit analysis (CBA) and return on investment (RoI) (Onsongo et al., 2018) were used to evaluate the economic implication of replacing FM in pig diets with BSFLM. The cost-benefit ratio (CBR), as an indicator in CBA, was used to summarize the economic value of replacing FM with BSFLM in pig diets. Here, it was assumed that all other costs of production were constant for all dietary treatments, except the cost of the feed, which was considered in the CBR and RoI calculations. Feed costs were calculated from the ingredient prices based on quantities of each item incorporated in the dietary treatments. The total revenue from the pigs was estimated by considering 3.0 US $\$ / \mathrm{kg}$ of pig's live body weight, assumed to represent all the benefits that would be received from the production. The ratio between the production revenue and the production cost represents the CBR. A CBR value greater than one suggests that the benefits of the production exceeded the production costs and vice versa. RoI is a measure of gain/loss generated from an investment relative to the money invested. The higher the RoI value the better the returns of the project under consideration (Aok, 2012; Onsongo et al., 2018).

\section{Statistical Analysis}

General linear modeling was used to assess the effect of diet on growth performance, blood parameters and economic parameters of pigs fed BSFLM-based diets and a control diet over a nine-week period. Collinearity of variables was checked to obtain independent covariates. The model for each analysis included all independent variables, which were removed one by one until the Akaike information criterion (AIC) was at a minimal level. For growth performance, diet, sex and their interaction effect were included for the analysis of ADG, body weight gain (BWG) and final body weight (FBW). For weekly body weight (BW), diet, sex, time (week) and their interaction effects were included in the model. Two pigs (female and male) per replicate were provided with feed in the same trough. Hence, ADFI analysis by sex was not possible. Three randomly selected pigs per dietary treatment were used for the blood parameter assessment, with diet as the explanatory variable. Similarly, the economic analysis was based on ADFI, 
hence, diet was included as the explanatory variable in the model. Mean effects were considered statistically significant at $\mathrm{P}<0.05$, with a least significant difference test (LSD) as the post-hoc test. All statistical analyses of the data were implemented using $\mathrm{R}$ software (version 3.5.1).

\section{Ethical approval}

Ethical approval for the study was provided by the Institutional Animal Care and Use Committee (IACUC) of Kenya Agricultural and Livestock Research Organization (KALRO)-Veterinary Science Research Institute (VSRI); approval Code No.: KALRO-VSRI/IACUC019/30082019.

\section{Results}

\section{Growth performance and feed conversion}

Pigs readily accepted experimental diets and no mortality was recorded. Neither diet nor sex affected initial weight, final body weight (FBW) or average daily weight gain (ADG); the interaction between diet and sex was also not significant (Table 3). Weekly body weight $(\mathrm{BW})$ differed significantly among diets $\mathrm{P}<0.001)$ and sexes $(\mathrm{P}=0.005)$. $\mathrm{BW}$ increased significantly $(\mathrm{P}<0.001)$ from week 1 to week 9 for male and female pigs (Figure 1). The interaction between diet and sex on BW was significant $(\mathrm{P}<0.001)$. There was no significant interaction between diet and week $(\mathrm{P}=0.110)$ or between sex and week on BW $(\mathrm{P}=0.388)$. Furthermore, the interaction between diet, sex and week on $\mathrm{BW}$ was also not significant $(\mathrm{P}=0.345)$. Body weight gain for the entire experimental period (BWG) was neither affected by diet $(\mathrm{P}=0.351$; Figure 2$)$ nor by sex $(\mathrm{P}=0.486)$ and neither was the interaction between diet and sex $(\mathrm{P}=0.340)$. ADFI did not differ among diets (Figure 3). FCR differed significantly among diets $(\mathrm{P}=0.011)$. When fed T75 or T100, FCR of the pigs was significantly higher compared to T25 (Figure 4). 
Table 3. Effects of dietary BSFLM inclusion on growth performance of growing pigs.

\begin{tabular}{|c|c|c|c|c|c|c|c|c|c|}
\hline \multirow{2}{*}{ Parameter } & \multirow{2}{*}{ Sex } & \multicolumn{5}{|c|}{ Diets } & \multicolumn{3}{|c|}{$\mathrm{P}$ value (GLM) } \\
\hline & & T0 & T25 & $\mathrm{T} 50$ & $\mathrm{~T} 75$ & T100 & Diet & Sex & Diet $x$ Sex \\
\hline \multirow{3}{*}{$\begin{array}{l}\text { Initial } \\
\text { weight, kg }\end{array}$} & F & $19.5 \pm 1.73$ & $16.8 \pm 0.63$ & $17.1 \pm 0.66$ & $17.0 \pm 0.87$ & $18.5 \pm 0.71$ & & & \\
\hline & M & $18.8 \pm 1.56$ & $17.1 \pm 0.85$ & $18.5 \pm 0.89$ & $18.5 \pm 0.79$ & $20.8 \pm 0.83$ & & & \\
\hline & Overall & $19.1 \pm 1.09$ & $17.0 \pm 0.49$ & $17.8 \pm 0.57$ & $17.8 \pm 0.61$ & $19.6 \pm 0.66$ & 0.080 & 0.152 & 0.628 \\
\hline \multirow{3}{*}{$\begin{array}{l}\text { Final } \\
\text { weight, } \mathrm{kg}\end{array}$} & F & $56.3 \pm 4.3$ & $50.8 \pm 2.65$ & $56.3 \pm 1.45$ & $47.8 \pm 1.76$ & $50.0 \pm 1.43$ & & & \\
\hline & M & $53.8 \pm 3.56$ & $53.5 \pm 3.68$ & $53.9 \pm 4.90$ & $53.0 \pm 1.97$ & $56.9 \pm 0.99$ & & & \\
\hline & Overall & $55.0 \pm 2.63$ & $52.1 \pm 2.16$ & $55.1 \pm 2.41$ & $50.4 \pm 1.58$ & $53.4 \pm 1.53$ & 0.474 & 0.295 & 0.395 \\
\hline \multirow{3}{*}{$\begin{array}{l}\text { Average } \\
\text { daily gain, } \\
\text { kg }\end{array}$} & F & $0.61 \pm 0.04$ & $0.56 \pm 0.04$ & $0.62 \pm 0.04$ & $0.50 \pm 0.03$ & $0.54 \pm 0.03$ & & & \\
\hline & M & $0.59 \pm 0.04$ & $0.57 \pm 0.04$ & $0.62 \pm 0.04$ & $0.57 \pm 0.04$ & $0.59 \pm 0.03$ & & & \\
\hline & Overall & $0.60 \pm 0.03$ & $0.57 \pm 0.02$ & $0.62 \pm 0.02$ & $0.53 \pm 0.02$ & $0.57 \pm 0.02$ & 0.126 & 0.408 & 0.641 \\
\hline
\end{tabular}

BSFLM = black soldier fly larval meal. General linear model (GLM) $\mathrm{P}<0.05$. For each diet, $\mathrm{N}=4 ; \mathrm{F}=$ female; $\mathrm{M}=$ male. Overall $=$ data for female and male pigs pooled together. $\mathrm{T} 0=0 \%$ (control), $\mathrm{T} 25=25 \%$, $\mathrm{T} 50=50 \%, \mathrm{~T} 75=75 \%$ and $\mathrm{T} 100=100 \%$ levels of replacement of fishmeal with BSFLM.
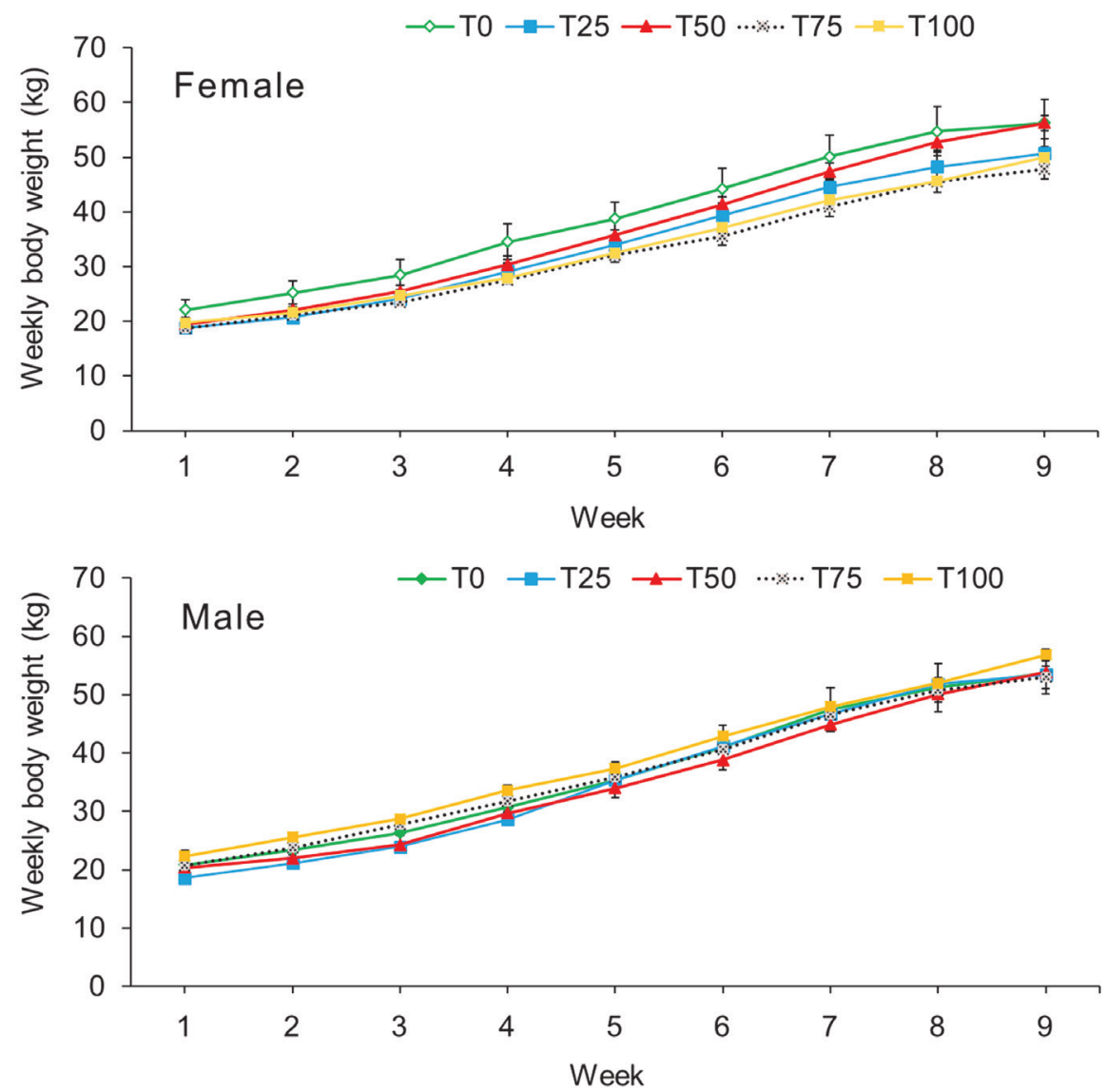

Figure 1. Mean $( \pm$ SE) weekly body weight of pigs fed BSFLM-based diets and a control diet. BSFLM = black soldier fly larval meal. T0 $=0 \%$ (control), T25 $=25 \%$, T50 $=50 \%$, T75 $=75 \%$ and $\mathrm{T} 100=100 \%$ levels of replacement of fishmeal with BSFLM. For each diet, 4 males and 4 females were investigated. 


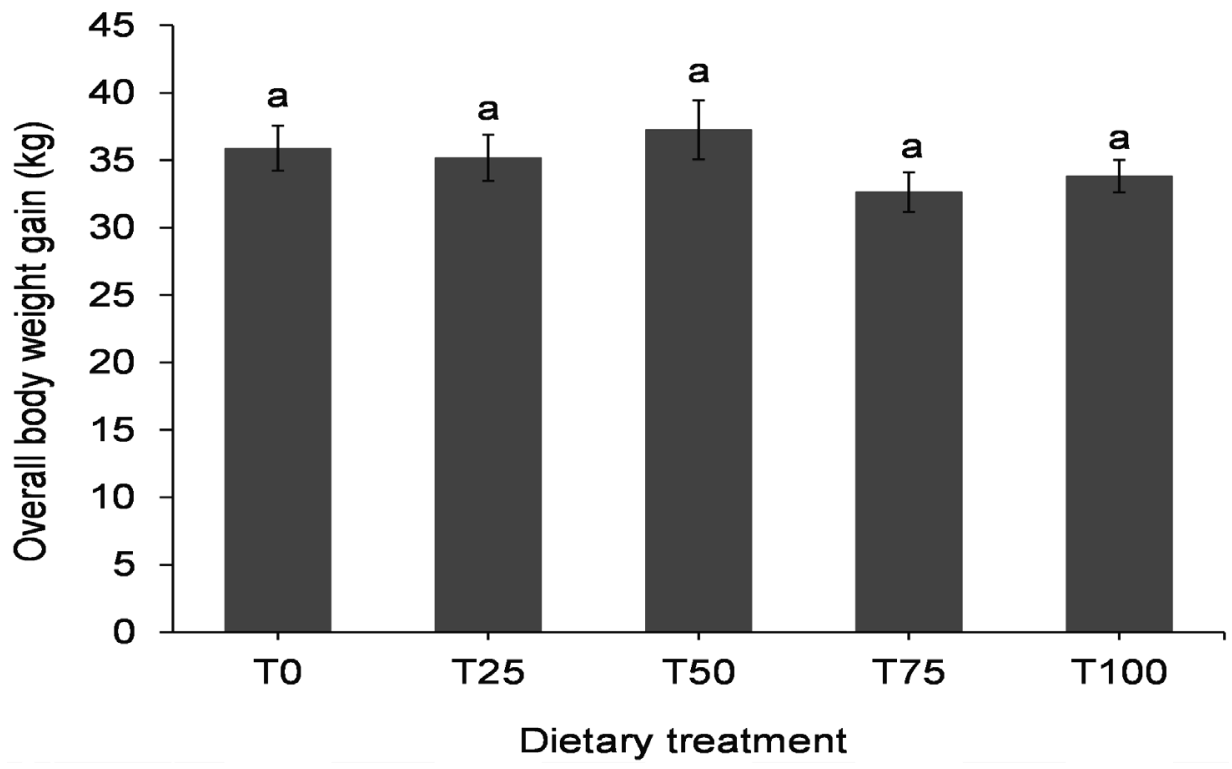

Figure 2. Body weight gain (mean \pm SE) of pigs fed BSFLM-based diets and a control diet for the whole trial. Bars followed by the same letter are not significantly different: $\alpha=0.05$, general linear model (GLM, LSD). BSFLM $=$ black soldier fly larval meal. T0 $=0 \%$ (control), T25 $=25 \%$, T50 $=50 \%$, T75 $=75 \%$ and T100 $=100 \%$ levels of replacement of fishmeal with BSFLM. For each diet, 4 males and 4 females were investigated. Data for female and male pigs pooled together because there is no significant effect of sex. $\mathrm{N}=8$ per bar.

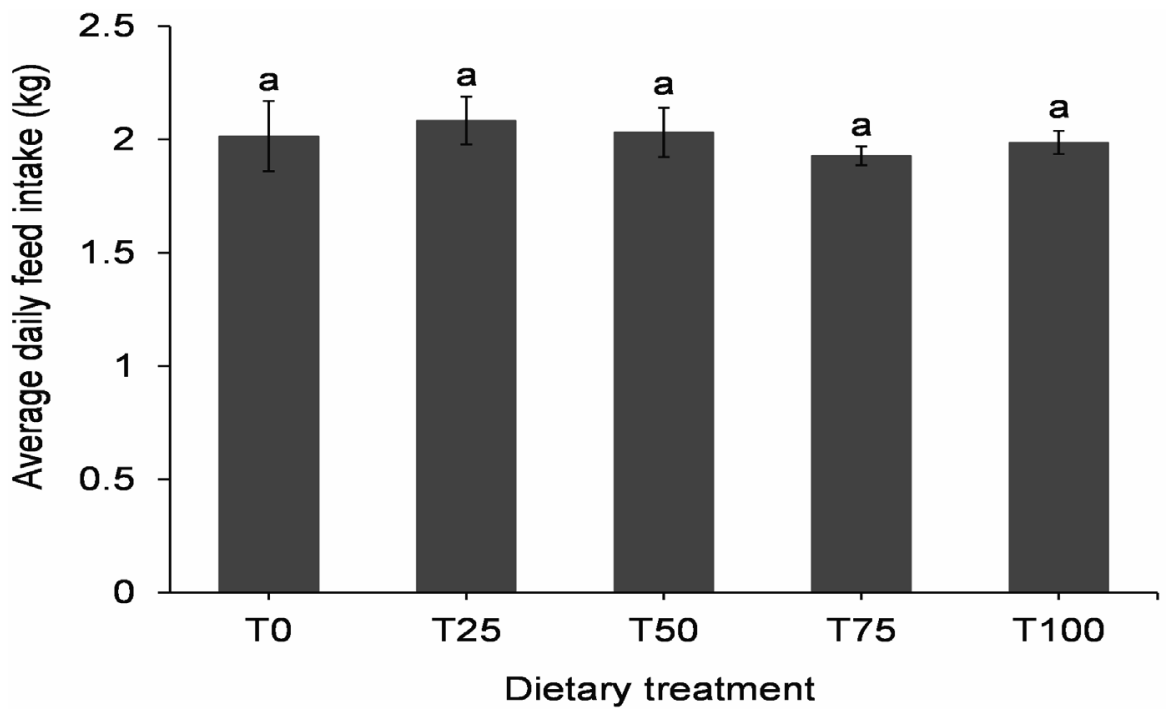

Figure 3. Average daily feed intake $( \pm \mathrm{SE})$ in pigs fed BSFLM-based diets and a control diet. Bars with same letters are not significantly different: $\alpha=0.05$, general linear model (GLM), BSFLM $=$ black soldier fly larval meal. T0 $=0 \%$ (control), T25 $=25 \%$, T50 $=50 \%$, T $75=75 \%$ and T100 $=100 \%$ levels of replacement of fishmeal with BSFLM. $\mathrm{N}=8$ per bar. 


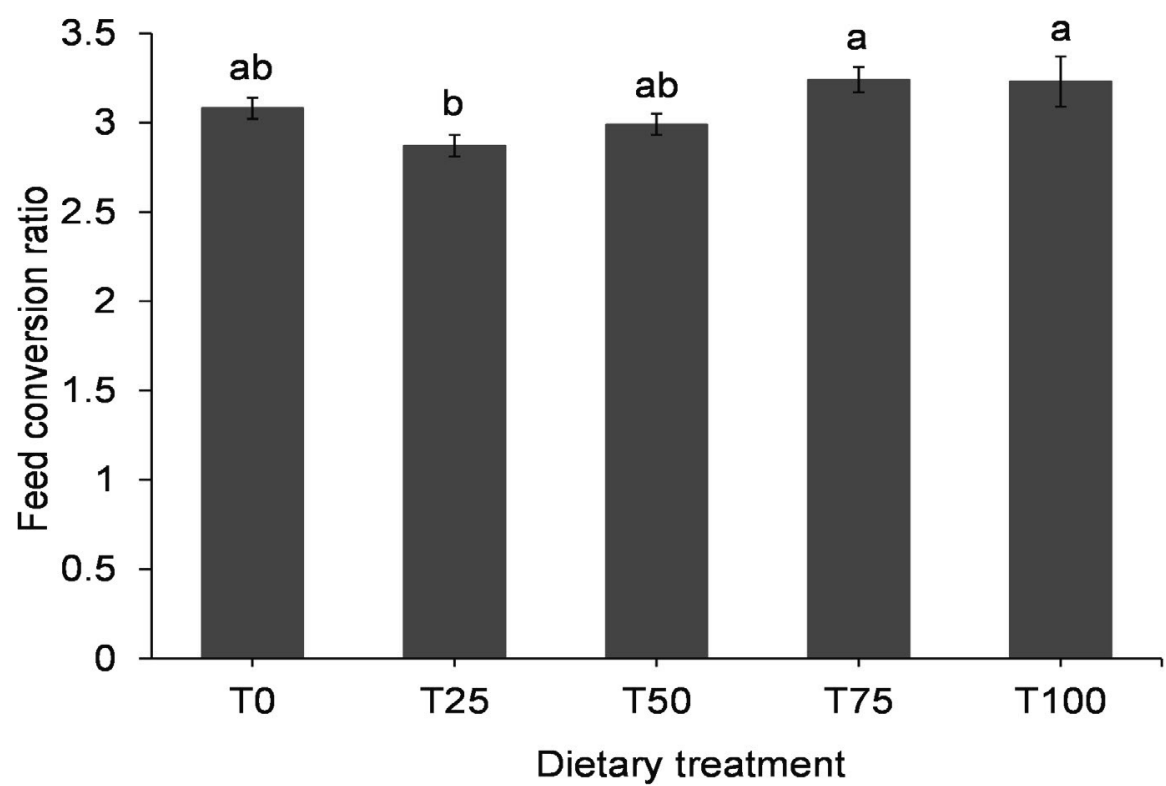

Figure 4. Feed conversion ratio (mean \pm SE) for pigs fed BSFLM-based diets and a control diet. Bars with different letters are significantly different: $\mathrm{P}<0.05$; general linear model $(\mathrm{GLM}), \mathrm{LSD}$. BSFLM $=$ black soldier fly larval meal. T0 $=0 \%$ (control), T25 $=25 \%$, T50 $=50 \%$, T75 $=75 \%$ and T100 $=100 \%$ levels of replacement of fishmeal with BSFLM. $\mathrm{N}=8$ per bar.

\section{Hematological and serum lipid parameters}

Red blood cell indices did not differ among dietary treatments (Table 4). Hb at T25-T100 was within the normal range, whereas at $\mathrm{T} 0, \mathrm{Hb}$ was slightly below the normal range. MCHC values at T25-T100 were below the normal range compared to T0. Platelet count differed significantly among diets (Table 4). At T0, platelet count was and within the normal range compared to treatments T25, T75 and T100 (Table 4).

WBC count did not differ among pigs fed with different diets $(\mathrm{P}=0.463)$. At T0 and T50, WBC counts were within the normal range, whereas the WBC counts of pigs from the other dietary groups were slightly above the normal range (Table 5). Diet significantly affected neutrophil counts (Table 5). At T75 and T100, neutrophil counts were significantly higher and within the normal range compared to T0 and T25 (Table 5). Lymphocyte counts did not differ among diets (Table 5). At T100, lymphocyte count was within the normal range, whereas at T0 - T75 the values were above the normal range. Monocyte, eosinophil and basophil counts did not differ among diets and were all within the normal range (Table 5). Serum lipid parameters did not differ among diets. All serum lipid parameters investigated were within the normal range (Table 5). 
Table 4. Effects of dietary BSFLM inclusion on red blood cell indices and platelet count of growing pigs

\begin{tabular}{|c|c|c|c|c|c|c|c|}
\hline \multirow{2}{*}{ Parameter } & \multicolumn{5}{|c|}{ Diets } & \multirow{2}{*}{$\begin{array}{l}\text { P value } \\
\text { (GLM) }\end{array}$} & \multirow{2}{*}{$\begin{array}{l}\text { Normal } \\
\text { range }\end{array}$} \\
\hline & T0 & $\mathrm{T} 25$ & $\mathrm{~T} 50$ & $\mathrm{~T} 75$ & T100 & & \\
\hline $\mathrm{RBC}\left(\mathrm{x} 10^{12} / \mathrm{L}\right)$ & $5.4 \pm 2.3$ & $7.0 \pm 0.2$ & $7.4 \pm 0.1$ & $6.8 \pm 0.6$ & $6.9 \pm 0.1$ & 0.725 & $5.0-8.00$ \\
\hline $\mathrm{Hb}(\mathrm{g} / \mathrm{dL})$ & $10.2 \pm 4.3$ & $13.3 \pm 0.2$ & $13.8 \pm 0.4$ & $12.8 \pm 1.0$ & $13.5 \pm 0.3$ & 0.719 & $10.7-16.7$ \\
\hline Hct $(\%)$ & $35.5 \pm 15$ & $48.0 \pm 1.0$ & $47.6 \pm 1.7$ & $45.2 \pm 3.2$ & $47.0 \pm 2.1$ & 0.704 & $32.0-50.0$ \\
\hline MCV (fl) & $64.4 \pm 1.7$ & $69.1 \pm 3.0$ & $64.4 \pm 3.2$ & $66.5 \pm 1.8$ & $68.1 \pm 2.4$ & 0.593 & $50.0-68.0$ \\
\hline $\mathrm{MCH}(\mathrm{pg})$ & $19.3 \pm 0.5$ & $19.1 \pm 0.8$ & $18.6 \pm 0.8$ & $18.8 \pm 0.4$ & $19.6 \pm 0.3$ & 0.803 & $17.0-21.0$ \\
\hline $\mathrm{MCHC}(\mathrm{g} / \mathrm{dL})$ & $30.0 \pm 1.5$ & $27.8 \pm 0.1$ & $28.9 \pm 0.2$ & $28.3 \pm 0.8$ & $28.8 \pm 0.7$ & 0.449 & $30.0-34.0$ \\
\hline $\mathrm{RDW}(\%)$ & $20.5 \pm 1.7$ & $21.8 \pm 0.2$ & $22.0 \pm 0.5$ & $21.6 \pm 1.0$ & $22.2 \pm 0.4$ & 0.706 & $15.0-27.0$ \\
\hline Platelet (K/uL) & $382 \pm 7.0^{1} \mathrm{a}$ & $209 \pm 49 c$ & $328 \pm 33 \mathrm{ab}$ & $229 \pm 27 b c$ & $251 \pm 28 b c$ & 0.042 & $300-700$ \\
\hline
\end{tabular}

BSFLM = black soldier fly larval meal. $\mathrm{RBC}=$ red blood cell, $\mathrm{Hb}=$ haemoglobin, Hct = haematocrit, $\mathrm{MCV}$ $=$ mean corpuscular volume, $\mathrm{MCH}=$ mean corpuscular haemoglobin, $\mathrm{MCHC}=$ mean corpuscular haemoglobin concentration, $\mathrm{RDW}=$ red cell distribution width. $\left({ }^{1}\right) \mathrm{n}=2$. Means $( \pm \mathrm{SE})$ within a row followed by different letters are significantly different: $\mathrm{P}<0.05$, general linear model (GLM), LSD. T0 $=0 \%$ (control), $\mathrm{T} 25=25 \%$, T50 $=50 \%, \mathrm{~T} 75=75 \%$ and $\mathrm{T} 100=100 \%$ levels of replacement of fishmeal with BSFLM. For each diet, 3 pigs were investigated.

Table 5. Effects of dietary BSFLM inclusion on white blood cell and serum biochemical indices of growing pigs

\begin{tabular}{|c|c|c|c|c|c|c|c|}
\hline \multirow{2}{*}{ Parameter } & \multicolumn{5}{|c|}{ Diets } & \multirow{2}{*}{$\begin{array}{l}\text { P value } \\
\text { (GLM) }\end{array}$} & \multirow{2}{*}{$\begin{array}{c}\text { Normal } \\
\text { range }\end{array}$} \\
\hline & T0 & $\mathrm{T} 25$ & T50 & $\mathrm{T} 75$ & T100 & & \\
\hline WBC $(\mathrm{k} / \mathrm{L})$ & $17.3 \pm 1.6$ & $24.5 \pm 2.7$ & $20.6 \pm 2.5$ & $24.0 \pm 3.6$ & $24.8 \pm 5.0$ & 0.463 & $11.0-22.0$ \\
\hline \multicolumn{8}{|c|}{ Differential count $(\%)$} \\
\hline Neutrophils & $24.2 \pm 1.0 \mathrm{c}$ & $24.7 \pm 0.4 \mathrm{c}$ & $27.1 \pm 1.1 \mathrm{bc}$ & $29.9 \pm 2.9 \mathrm{ab}$ & $31.8 \pm 0.4 \mathrm{a}$ & 0.019 & $28.0-51.0$ \\
\hline Lymphocytes & $69.4 \pm 1.4$ & $66.8 \pm 0.8$ & $64.8 \pm 1.2$ & $62.4 \pm 4.0$ & $60.9 \pm 1.2$ & 0.092 & $39.0-62.0$ \\
\hline Monocytes & $3.5 \pm 0.7$ & $5.6 \pm 0.5$ & $4.8 \pm 0.9$ & $4.1 \pm 0.8$ & $4.3 \pm 1.2$ & 0.496 & $2.00-10.0$ \\
\hline Eosinophils & $2.8 \pm 0.5$ & $3.0 \pm 0.1$ & $3.3 \pm 0.3$ & $3.5 \pm 0.3$ & $2.9 \pm 0.5$ & 0.684 & $0.50-11.0$ \\
\hline Basophils & $0.13 \pm 0.03$ & $0.08 \pm 0.01$ & $0.07 \pm 0.03$ & $0.15 \pm 0.03$ & $0.10 \pm 0.0$ & 0.585 & $0.00-2.00$ \\
\hline \multicolumn{8}{|c|}{ Blood serum indices $(\mathrm{mmol} / \mathrm{L})$} \\
\hline Total Chol & $1.90 \pm 0.16$ & $2.11 \pm 0.13$ & $2.11 \pm 0.20$ & $2.50 \pm 0.12$ & $2.19 \pm 0.12$ & 0.185 & $1.68-5.81$ \\
\hline Total Trig & $0.69 \pm 0.08$ & $1.03 \pm 0.23$ & $0.99 \pm 0.17$ & $0.89 \pm 0.03$ & $0.89 \pm 0.07$ & 0.479 & $0.11-1.13$ \\
\hline LDL & $0.67 \pm 0.11$ & $0.88 \pm 0.08$ & $0.75 \pm 0.12$ & $0.71 \pm 0.11$ & $0.65 \pm 0.04$ & 0.50 & $<3.00$ \\
\hline $\mathrm{HDL}$ & $1.23 \pm 0.09$ & $1.23 \pm 0.07$ & $1.37 \pm 0.09$ & $1.77 \pm 0.23$ & $1.53 \pm 0.09$ & 0.066 & $>1.00$ \\
\hline
\end{tabular}

BSFLM = black soldier fly larval meal. WBC $=$ White Blood Cell. Means within a row followed by different letters are significantly different: $\mathrm{P}<0.05$, general linear model $(\mathrm{GLM}), \mathrm{LSD}$. BSFLM = Black soldier fly larval meal. $\mathrm{Chol}=$ cholesterol, Trig $=$ triglycerides, $\mathrm{LDL}=$ Low density lipoproteins, $\mathrm{HDL}=$ High density lipoproteins. T0 $=0 \%$ (control), T25 $=25 \%$, T50 $=50 \%$, T75 $=75 \%$ and T100 $=100 \%$ levels of replacement of fishmeal with BSFLM. For each diet, 3 pigs were investigated. 


\section{Economic analyses of the inclusion of black soldier fly larval meal in pig diets}

Replacing fish meal by BSFLM in pig diet did not affect the profit accrued from the sale of pigs (Table 6 ). Cost benefit ratio and return on investment did not differ among diets (Table 6).

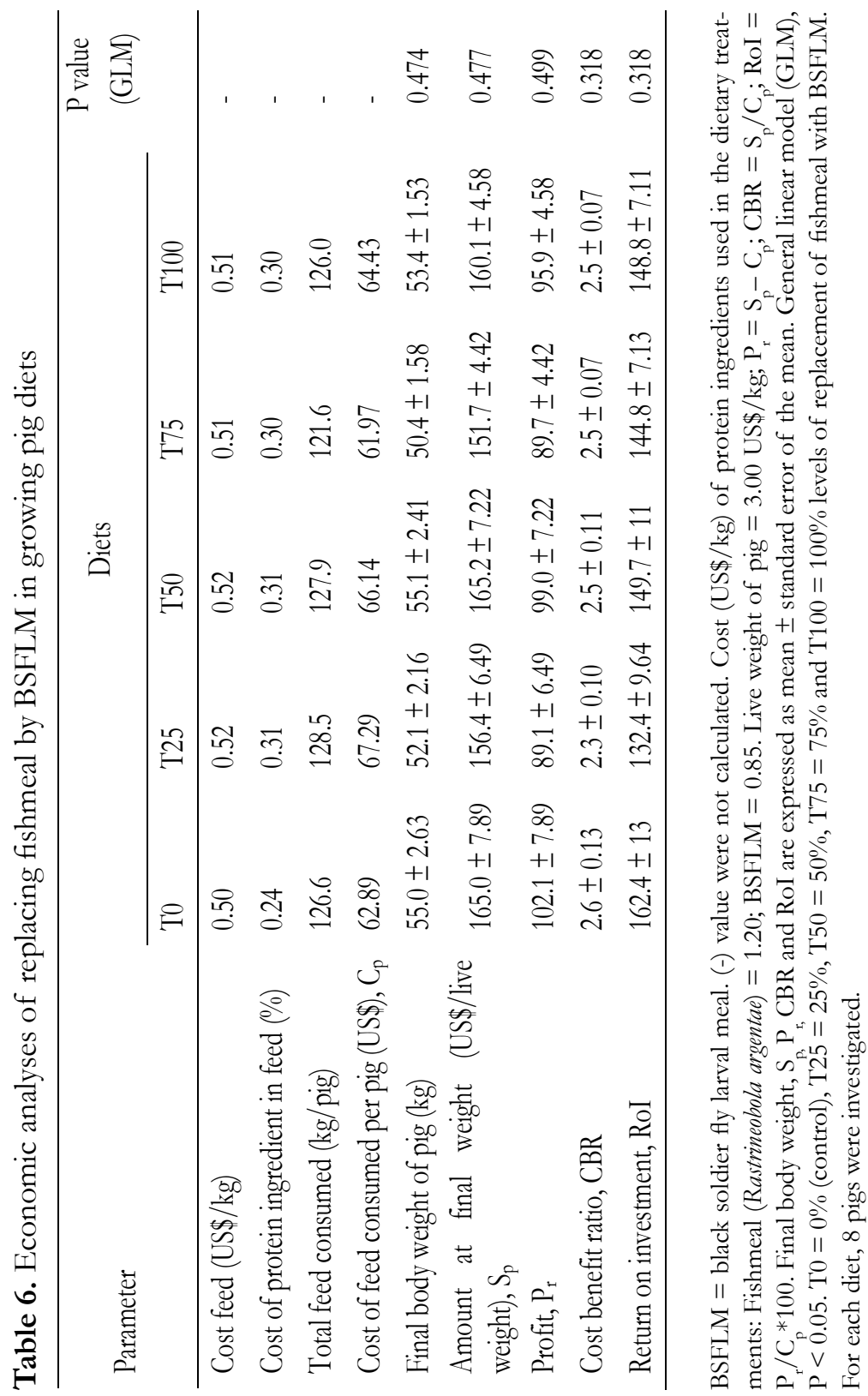




\section{Discussion}

In Africa, to the best of our knowledge, the current study is the first to report the positive impact of non-defatted BSF larvae as a protein-rich ingredient in pig feeds. Protein is an important component of animal feeds required for growth and development. The source of protein is crucial because it affects availability and utilization of the essential amino acids (Wallace et al., 2017). The crude protein (CP) content of BSF larvae largely depends on the substrate used to rear the larvae and varies from 39\% to 44\% (Lalander et al., 2019), which is comparable or superior to that of the commonly used soybean and FM (Onsongo et al., 2018). BSFLM is a suitable ingredient in pig feed (Makkar et al., 2014) and feeds containing BSFLM are as palatable as those containing soybean meal (Newton et al., 1977). Our results agree with earlier studies in which partially defatted or full-fat BSF inclusion levels of only $4 \%-10 \%$ in partial replacement of either FM or soybean meal did not result in a significant difference in growth performance of the piglets (Biasato et al., 2019; Driemeyer, 2016; Spranghers et al., 2018), when compared to the conventional FM / soybean diets. The present study shows that much higher replacement levels, up to $100 \%$ were acceptable and well tolerated by the pigs. No significant decline in growth parameters or mortality was recorded. Acceptability and suitability of BSFLM has also been successfully recorded for fish and chicken (Pieterse et al., 2018; Sealey et al., 2011). Thus, our study shows that BSFLM can successfully replace FM as a sustainable protein-rich ingredient in growing pig diet as reflected in the growth performance and feed conversion rate, which were similar for all the treatment and control diet groups of pigs. Rejection of feed due to texture, palatability or inclusion of BSFLM was not observed, which is in line with the observations by Ramos-Elorduy et al. (2002) for broiler chickens.

In animal production, ADG is a critical index of growth performance (Wu et al., 2018). We did not observe a significant effect of dietary treatment on ADG of the pigs, which is a clear indication of adequate nutrient supply by the different formulated diets. Tolerance of insect-based protein-rich diets for pigs has been documented in other studies (Coll et al., 1992; Medhi, 2011; Medhi et al., 2009a; Medhi et al., 2009b; Newton et al., 2005b). In India, silkworm meal was used to completely replace FM in the diet of growing and finishing pigs without altering carcass and meat quality and blood parameters (Medhi, 2011; Medhi et al., 2009a; Medhi et al., 2009b). Similarly, in Nigeria, feeding early weaned pigs with a 3:1 mixture of dried rumen content and maggot meal in the diet replacing 10\% wheat offal did not have adverse effects on performance (Adeniji, 2008). The inclusion of $10 \%$ and $15 \%$ of defatted BSFLM in the diet of growing quails (from 10 to $28 \mathrm{~d}$ of age) led to comparable production performances and carcass traits with those of quails fed conventional soybean meal and oil-based diets (Cullere et al., 2016). The suitability of BSFLM for the growing pigs in our experiments can be attributed to the high level of digestibility, which is consistent with other studies on pigs fed with 
BSF larvae (Newton et al., 1977), and broilers fed with housefly pupal meal (Pretorius, 2011).

In contrast to the current study, Newton et al. (2005b) reported that a complete replacement of dried plasma with BSF pre-pupal meal in the diet of early weaned pigs reduced performance of the pigs by 3\%-13\%. Poor performance of weaner pigs fed on pre-pupal meal might be attributed to the higher chitin levels in the pre-pupae than in larvae as used in our study, which has been reported to contribute to decreased digestibility resulting in reduced nutrient utilization and growth performance in animals when higher substitution rates are used (Alegbeleye et al., 2012; Newton et al., 2005b). Low digestibility of BSF pre-pupal protein in animal feeds is also supported by Bosch et al. (2014), who attributed this to higher cuticular protein-sclerotization in the pupae. The similarity in feed intake and average daily weight gain recorded for all the treatment groups in the current study can be attributed to utilization of the 5th instar larval meal instead of the pre-pupal meal, which contributes sufficient nutrients in the diets with high level of digestibility. BSFLM has also been shown to be of good nutrient composition for reptiles (Klaphake, 2010).

In the present study, the values of the hematological parameters $\mathrm{RBC}, \mathrm{Hb}, \mathrm{Hct}, \mathrm{MCH}$, $\mathrm{MCV}, \mathrm{MCHC}$ and RDW for pigs fed BSFLM were not significantly influenced by the replacement levels. The values for $\mathrm{RBC}, \mathrm{Hb}, \mathrm{Hct}, \mathrm{MCH}$ and RDW fell within the physiological range for pigs, which is a clear indication of a good health status of the animals, implying that the quality of the test diets was adequate to maintain good health of the pigs. Dietary replacement of FM with BSFLM at the rates of $25 \%, 50 \%, 75 \%$ and $100 \%$ in pig diet improved RBC, Hb, Hct and RDW, which had higher values compared to the control FM diet group of pigs. The RBC counts and $\mathrm{Hb}$ concentration in blood increased to a level of $37 \%$ and $35.3 \%$, respectively, at a FM replacement level of 50\% with BSFLM. These results are consistent with the reports by Marono et al. (2017) and Loponte et al. (2017), who reported that dietary BSFLM inclusion positively affected the blood profile of laying hens and Barbary partridges, in terms of higher globulin levels. Our results may be attributed to high digestibility of insect-based protein and high levels of minerals such as iron, which is required for the formation of haemoglobin in the pigs. The higher the haemoglobin concentration, the better the oxygen circulation in the body, hence, better performance of the animal (Olugbemi et al., 2010).

The results of the present study show that the composition of the various treatments significantly affected platelet count in pigs. The replacement of FM with BSFLM at rates of $25 \%, 75 \%$ and $100 \%$ in the feed was associated with significantly lower blood platelet counts out of the normal range than observed with $50 \%$ replacement of FM with BSFLM or with the control diet without BSFLM. This implies that diet composition in the present study significantly influenced the developing hematological system with some unknown factors suppressing the normal developmental increase in platelet 
counts in growing pigs. Low platelet concentration implies that blood clotting might be impaired, resulting in blood loss in case of injury (Etim et al., 2014a). According to Martin et al. (1983), bleeding time largely depends on both platelet counts and mean platelet volume.

The largely similar WBC count obtained in this study implies that the ability of the pigs to respond to and eliminate infection was not compromised with the inclusion of BSFLM to replace FM in the diets. The normal monocyte levels may indicate that the pigs did not react to any infections during the experimental period. Furthermore, the similarity in basophil levels indicates that the pigs showed no hypersensitivity reaction to the inclusion of BSFLM in diets while the normal levels of eosinophils might indicate that the pigs did not suffer from parasitic infections during the experimental period (AACC, 2019; Konlan et al., 2012). However, higher (75\% and 100\%) levels of replacement of FM with BSFLM significantly improved the neutrophil count to the normal physiological range compared to the control FM diet. Neutrophils play an important role in immune responses, especially in wound healing through microbial sterilization and macrophage attraction (Nathan, 2006). BSF larval fat contains medium-chain saturated fatty acids with antimicrobial properties (Skřivanová et al., 2006; Spranghers et al., 2018). For instance, lauric acid has been identified as the most predominant medium chain saturated fatty acid found in BSF larvae. It has been shown that inclusion of coconut oil, which contains medium-chain saturated fatty acids in rabbit feeds significantly increases leucocytes and neutrophil counts (Ahlante et al., 2010). The increase in neutrophil count in the present study could be an indication of the antimicrobial response in pigs fed high BSFLM-based diets. According to (Ahlante et al., 2010), increased mobilization of leucocytes and neutrophils in animals fed with coconut oil-based feed resulted from the stimulation of the pluripotent haemopoietic stem cells from which leucocytes are produced in the presence of a growth inducer and differentiation inducer, which are proteins. Neutropenia is a consequence of reduced neutrophil and leucocyte levels, which leads to reduced body immunity. Therefore, the inclusion of BSFLM in pig feed is highly recommended due to the valuable nutrients available to the growing pigs. The lymphocyte counts of pigs fed 100\% FM diet, 25\%, 50\% and 75\% BSFLM diets were higher and out of the normal range. This implies that these diets might have stimulated both cellular and humoral immune response systems of the pigs to protect against intracellular and extracellular pathogens such as Mycobacterium, Listeria, Brucella, Pasteurella or Salmonella, viruses and fungi (Dudek et al., 2006).

The replacement of FM by BSFLM up to $100 \%$ did not affect the serum biochemical indices that are indicators of pig health. It is worth noting that although the use of hematological and biochemical indices have been considered as a fast means of assessing nutritional and health status of farmed animals, this has rarely been used in pig veterinary practices (Biasato et al., 2019). The observation that replacing FM by BSFLM does 
not affect serum biochemical indices in pigs supports the conclusion that BSFLM could form the basis of a valuable component in grower pig diets.

The cost-benefit analysis, which assesses whether an investment is sound and if-and by how much-profits outweigh costs, allows for comparing costs and benefits of alternative investments (David et al., 2013) as in the present study. The similarity in results obtained for the 'control' (100\% FM diet) and BSFLM-based diets indicate that BSFLM is not only a valuable component of pig feed from a performance perspective but also from an economic perspective. This supports the need to further investigate the economic prospects of using BSFLM in large-scale pig feed formulation and feeding programs. A key advantage of insects as a feed ingredient, especially the BSF larvae over other conventional protein sources is their ability to convert waste into high-value biomass and closing nutrient cycles as they reduce pollution and costs of managing organic waste (Wang \& Shelomi, 2017).

\section{Conclusion}

Dietary replacement of FM up to $100 \%$ with full-fat BSFLM did not adversely affect growth, blood characteristics or economic parameters. Although some changes in blood cell counts were observed, values were largely similar among diets. Pigs did not show visual signs of illness or abnormal behavior. Moreover, serum biochemical parameters were all within normal range for pigs. The present study indicates that a complete replacement of FM with full-fat BSFLM as an ingredient in growing pig feed is feasible, with reduced predisposition to heart diseases associated with high total cholesterol and LDL. Cost-benefit analysis results of the present study indicate that the inclusion of BSFLM in pig feed is a worthwhile investment for pig farmers. Finally, there is little evidence to suggest that adverse health effects should be expected in pigs following BSFLM consumption. Further studies are required to assess the effect of feeding BSFLM to pigs on meat sensory attributes and consumer perceptions.

\section{Acknowledgements}

We thank Ogetonto Wycliffe for help during data collection. We thank Isaiah E. Rachami, Nyamu Faith Wamurango, Ondiaka Shem and Joshua Wambua for providing dried black soldier fly larvae produced at International Centre of Insect Physiology and Ecology (icipe). We thank the Non-ruminant Research Institute staff for technical support. This study was financially supported by the Netherlands Organization for Scientific Research, WOTRO Science for Global Development (NWO-WOTRO) (ILIPA - W 08.250.202). Authors declare no conflicts of interest. 


\section{References}

AACC-American Association for Clinical Chemistry. (2019). White blood cell (WBC) differential. Lab tests online. Retrieved from https://labtestsonline.org/tests/white-blood-cellwbc-differential, July 11, 2019.

Adeniji, A. A. (2008). The feeding value of rumen content-maggot meal mixture in the diets of early weaned piglets. Asian Journal of Animal and Veterinary Advances, 3, 115-119.

Ahlante, B., Afiukwa, J., \& Ajayi, O. (2010). The dietary effects of coconut oil on tiie leucocytes and neutrophils count in rabbits. Journal of Ecophysiology and Occupational Health, 10, 143-148.

Al Sagan, A. A., Khalil, S., \& Smith, M. P. (2018). The benefit of L-threonine supplementation on growth performance, carcass characteristics, intestinal morphology and litter quality of broilers. Brazilian Journal of Poultry Science, 20, 753-758.

Alegbeleye, W. O., Obasa, S. O., Olude, O. O., Otubu, K., \& Jimoh, W. (2012). Preliminary evaluation of the nutritive value of the variegated grasshopper (Zonocerus variegatus L.) for African catfish Clarias gariepinus (Burchell. 1822) fingerlings. Aquaculture Research, 43, 412-420.

Ameen, S., Adedeji, O., Akingbade, A., Olayemi, T., Oyedapo, L., \& Aderinola, A. (2007). The effect of different feeding regimes on haematological parameters and immune status of commercial broilers in derived savannah zone of Nigeria. Paper presented at the Proceedings of the 32nd Annual Conference Nigerian Society Animal Production (NSAP). University of Calabar, Nigeria.

Aok, Y. M. D. (2012). Effect of feed enzymes and energy level on broiler chicken (Gallus domesticus) performance in Kenya. Master of Science, University of Nairobi, Nairobi, Kenya.

Barałkiewicz, D., Kanecka-Hanc, A., \& Gramowska, H. (2007). ICP slurry introduction for simple and rapid determination of $\mathrm{Pb}, \mathrm{Mg}$ and $\mathrm{Ca}$ in plant roots. Central European Journal of Chemistry, 5, 1148-1157.

Barragan-Fonseca, K. B., Dicke, M., \& van Loon, J. J. A. (2017). Nutritional value of the black soldier fly (Hermetia illucens L.) and its suitability as animal feed-a review. Journal of Insects as Food and Feed, 3, 105-120.

Biasato, I., Renna, M., Gai, F., Dabbou, S., Meneguz, M., Perona, G., . . Gasco, L. (2019). Partially defatted black soldier fly larva meal inclusion in piglet diets: effects on the growth performance, nutrient digestibility, blood profile, gut morphology and histological features. Journal of Animal Science and Biotechnology, 10, 12.

Bosch, G., Zhang, S., Oonincx, D. G., \& Hendriks, W. H. (2014). Protein quality of insects as potential ingredients for dog and cat foods. Journal of Nutritional Science, 3, E29.

Chia, S. Y., Tanga, C. M., Osuga, I. M., Mohamed, S. A., Khamis, F. M., Salifu, D., . . Ekesi, S. (2018). Effects of waste stream combinations from brewing industry on performance of Black Soldier Fly, Hermetia illucens (Diptera: Stratiomyidae). PeerJ, 6, e5885.

Coll, J., Crespi, M., Itagiba, M., Souza, J., Gomes, A., \& Donatti, F. (1992). Utilization of silkworm pupae meal (Bombyx mori L.) as a source of protein in the diet of growing-finishing pigs. Revista da Sociedade Brasileira de Zootecnia, 21, 378-383.

Cullere, M., Tasoniero, G., Giaccone, V., Miotti-Scapin, R., Claeys, E., De Smet, S., \& Zotte, A. D. (2016). Black soldier fly as dietary protein source for broiler quails: apparent digestibility, excreta microbial load, feed choice, performance, carcass and meat traits. Animal, 10, 1923-1930.

Cummins Jr, V. C., Rawles, S. D., Thompson, K. R., Velasquez, A., Kobayashi, Y., Hager, J., \& 
Webster, C. D. (2017). Evaluation of black soldier fly (Hermetia illucens) larvae meal as partial or total replacement of marine fish meal in practical diets for Pacific white shrimp (Litopenaeus vannamei). Aquaculture, 473, 337-344.

David, R., Dube, A., \& Ngulube, P. (2013). A cost-benefit analysis of document management strategies used at a financial institution in Zimbabwe: A case study. South African Journal of Information Management, 15, 1-10.

Devic, E., Leschen, W., Murray, F., \& Little, D. C. (2018). Growth performance, feed utilization and body composition of advanced nursing Nile tilapia (Oreochromis niloticus) fed diets containing Black Soldier Fly (Hermetia illucens) larvae meal. Aquaculture Nutrition, 24, 416-423.

Dierenfeld, E. S., \& King, J. (2008). Digestibility and mineral availability of Phoenix worms, Hermetia illucens, ingested by mountain chicken frogs, Leptodactylus fallax. Journal of Herpetological Medicine and Surgery, 18, 100-105.

Driemeyer, H. (2016). Evaluation of black soldier fly (Hermetia illucens) larvae as an alternative protein source in pig creep diets in relation to production, blood and manure microbiology parameters. Master of Science, Stellenbosch University, Stellenbosch.

Dudek, K., Sliwa, E., \& Tatara, M. R. (2006). Changes in blood leukocyte pattern in piglets from sows treated with garlic preparations. Bulletin of Veterinary Institute in Pulawy, 50, 263.

Dumas, A., Raggi, T., Barkhouse, J., Lewis, E., \& Weltzien, E. (2018). The oil fraction and partially defatted meal of black soldier fly larvae (Hermetia illucens) affect differently growth performance, feed efficiency, nutrient deposition, blood glucose and lipid digestibility of rainbow trout (Oncorbynchus mykiss). Aquaculture, 492, 24-34.

Erickson, M. C., Islam, M., Sheppard, C., Liao, J., \& Doyle, M. P. (2004). Reduction of Escherichia coli $\mathrm{O} 157$ : $\mathrm{H} 7$ and Salmonella enterica serovar enteritidis in chicken manure by larvae of the black soldier fly. Journal of Food Protection, 67, 685-690.

Etim, N., Offiong, E. E., Williams, M. E., \& Asuquo, L. E. (2014a). Influence of nutrition on blood parameters of pigs. American Journal of Biology and Life Sciences, 2, 46-52.

Etim, N., Williams, M. E., Akpabio, U., \& Offiong, E. E. (2014b). Haematological parameters and factors affecting their values. Agricultural Science, 2, 37-47.

Etim, N. A. N., Akpabio, U., Okpongete, R. O., \& Offiong, E. E. (2014c). Do diets affect haematological parameters of poultry. British Journal of Applied Science \& Technology, 4, 1952-1965.

FASS. (2010). Guide for the Care and Use of Agricultural Animals in Agricultural Research and Teaching (3rd ed.). Champaign, IL, USA: Federation of Animal Science Societies (FASS).

Finke, M. D. (2013). Complete nutrient content of four species of feeder insects. Zoo Biology, 32, 27-36.

Githigia, S. M., Okuthe, S., \& Diop, B. (2012). Pig Sector Kenya. FAO Animal Production and Health Livestock Country Reviews. No. 3 (No. 3). Rome. Food and Agriculture Organization (FAO). Retrieved from: www.fao.org/3/a-i2566e.pdf, June 10, 2019.

Klaphake, E. (2010). A fresh look at metabolic bone diseases in reptiles and amphibians. Veterinary Clinics: Exotic Animal Practice, 13, 375-392.

Konlan, S., Karikari, P., \& Ansah, T. (2012). Productive and blood indices of dwarf rams fed a mixture of rice straw and groundnut haulms alone or supplemented with concentrates containing different levels of shea nut cake. Pakistan Journal of Nutrition, 11, 566-571.

Kroeckel, S., Harjes, A.-G., Roth, I., Katz, H., Wuertz, S., Susenbeth, A., \& Schulz, C. (2012). When a turbot catches a fly: Evaluation of a pre-pupae meal of the black soldier fly (Hermetia illucens) as fish meal substitute-Growth performance and chitin degradation in 
juvenile turbot (Psetta maxima). Aquaculture, 364, 345-352.

Lalander, C., Diener, S., Zurbrugg, C., \& Vinneras, B. (2019). Effects of feedstock on larval development and process efficiency in waste treatment with black soldier fly (Hermetia illucens). Journal of Cleaner Production, 208, 211-219.

Li, Q., Zheng, L., Cai, H., Garza, E., Yu, Z., \& Zhou, S. (2011). From organic waste to biodiesel: Black soldier fly, Hermetia illucens, makes it feasible. Fuel, 90, 1545-1548.

Li, S. L., Ji, H., Zhang, B. X., Tian, J. J., Zhou, J. S., \& Yu, H. B. (2016). Influence of black soldier fly (Hermetia illucens) larvae oil on growth performance, body composition, tissue fatty acid composition and lipid deposition in juvenile Jian carp (Cyprinus carpio var. Jian). Aquaculture, 465, 43-52.

Liu, Q., Tomberlin, J. K., Brady, J. A., Sanford, M. R., \& Yu, Z. (2008). Black soldier fly (Diptera: Stratiomyidae) larvae reduce Escherichia coli in dairy manure. Environmental Entomology, 37, 1525-1530.

Llames, C. R., \& Fontaine, J. (1994). Determination of Amino-Acids in Feeds - Collaborative Study. Journal of Association of Official Analytical Chemists, 77, 1362-1402.

Loponte, R., Nizza, S., Bovera, F., De Riu, N., Fliegerova, K., Lombardi, P., . . . Moniello, G. (2017). Growth performance, blood profiles and carcass traits of Barbary partridge (Alectoris barbara) fed two different insect larvae meals (Tenebrio molitor and Hermetia illucens). Research in Veterinary Science, 115, 183-188.

Magalhaes, R., Sanchez-Lopez, A., Leal, R. S., Martinez-Llorens, S., Oliva-Telesa, A., \& Peres, H. (2017). Black soldier fly (Hermetia illucens) pre-pupae meal as a fish meal replacement in diets for European seabass (Dicentrarchus labrax). Aquaculture, 476, 79-85.

Makkar, H. P. S., Tran, G., Henze, V., \& Ankers, P. (2014). State-of-the-art on use of insects as animal feed. Animal Feed Science and Technology, 197, 1-33.

Marono, S., Loponte, R., Lombardi, P., Vassalotti, G., Pero, M. E., Russo, F., . . Bovera, F. (2017). Productive performance and blood profiles of laying hens fed Hermetia illucens larvae meal as total replacement of soybean meal from 24 to 45 weeks of age. Poultry Science, 96, 17831790.

Martin, J. F., Trowbridge, E. A., Salmon, G., \& Plumb, J. (1983). The biological significance of platelet volume: its relationship to bleeding time, platelet thromboxane B2 production and megakaryocyte nuclear DNA concentration. Thrombosis Research, 32, 443-460.

Masuda, T., \& Goldsmith, P. D. (2009). World soybean production: Area harvested, yield, and long-term projections. International Food and Agribusiness Management Review, 12, 143-161.

Maurer, V., Holinger, M., Amsler, Z., Früh, B., Wohlfahrt, J., Stamer, A., \& Leiber, F. (2016). Replacement of soybean cake by Hermetia illucens meal in diets for layers. Journal of Insects as Food and Feed, 2, 83-90.

Medhi, D. (2011). Effects of enzyme supplemented diet on finishing crossbred pigs at different levels of silk worm pupae meal in diet. Indian Journal of Field Veterinarians, 7, 24-26.

Medhi, D., Math, N., \& Sharma, D. (2009a). Effect of silk worm pupae meal and enzyme supplementation on blood constituents in pigs. Indian Veterinary Journal, 86, 433-434.

Medhi, D., Nath, N., Gohain, A., \& Bhuyan, R. (2009b). Effect of silk worm pupae meal on carcass characteristics and composition of meat in pigs. Indian Veterinary Journal, 86, 816-818.

Meneguz, M., Schiavone, A., Gai, F., Dama, A., Lussiana, C., Renna, M., \& Gasco, L. (2018). Effect of rearing substrate on growth performance, waste reduction efficiency and chemical composition of black soldier fly (Hermetia illucens) larvae. Journal of the Science of Food and 
Agriculture, 98, 5776-5784.

Myers, H. M., Tomberlin, J. K., Lambert, B. D., \& Kattes, D. (2008). Development of black soldier fly (Diptera: Stratiomyidae) larvae fed dairy manure. Environmental Entomology, 37, $11-15$.

Nathan, C. (2006). Neutrophils and immunity: challenges and opportunities. Nature Reviews Immunology, 6, 173-182.

National Research Council. (1979). Nutrient requirements of swine: Eighth revised edition, 1979. Washington, DC: The National Academies Press.

Newton, G. L., Booram, C. V., Barker, R. W., \& Hale, O. M. (1977). Dried Hermetia illucens larvae meal as a supplement for swine. Journal of Animal Science, 44, 395-400.

Newton, L., C. Sheppard, D., W. Watson, D., Burtle, G., R. Dove, C., Tomberlin, J., \& E. Thelen, E. (2005a). The black soldier fly, Hermetia illucens, as a manure management/resource recovery tool Retrieved from: https://pdfs.semanticscholar.org/5aa5/81bf66145ee15551c0a86df6436b9183fd05.pdf.

Newton, L., Sheppard, C., Watson, D. W., Burtle, G., \& Dove, R. (2005b). Using the black soldier fly, Hermetia illucens, as a value-added tool for the management of swine manure Retrieved from: www.organicvaluerecovery.com/studies/studies_htm_files/bsf_value_added.pdf.

Nguyen, T. T., Tomberlin, J. K., \& Vanlaerhoven, S. (2013). Influence of resources on Hermetia illucens (Diptera: Stratiomyidae) larval development. Journal of Medical Entomology, 50, 898906.

Núñez-Sánchez, N., Marín, A. L. M., Hernández, M. P., Carrion, D., Castro, G. G., \& Alba, L. M. P. (2012). Faecal near infrared spectroscopy (NIRS) as a tool to asses rabbit's feed digestibility. Livestock Science, 150, 386-390.

Olugbemi, T., Mutayoba, S., \& Lekule, F. (2010). Effect of Moringa (Moringa oleifera) inclusion in cassava based diets fed to broiler chickens. International Journal of Poultry Science, 9, 363-367.

Onsongo, V. O., Osuga, I. M., Gachuiri, C. K., Wachira, A. M., Miano, D. M., Tanga, C. M., . . . Fiaboe, K. K. M. (2018). Insects for income generation through animal feed: Effect of dietary replacement of soybean and fish meal with black soldier fly meal on broiler growth and economic performance. Journal of Economic Entomology, 111, 1966-1973.

Pieterse, E., Erasmus, S. W., Uushona, T., \& Hoffman, L. C. (2018). Black soldier fly (Hermetia illucens) pre-pupae meal as a dietary protein source for broiler production ensures a tasty chicken with standard meat quality for every pot. Journal of the Science of Food and Agriculture, 99, 893-903.

Pinotti, L., Giromini, C., Ottoboni, M., Tretola, M., \& Marchis, D. (2019). Review: Insects and former foodstuffs for upgrading food waste biomasses/streams to feed ingredients for farm animals. Animal, 13, 1365-1375.

Płotka-Wasylka, J., Frankowski, M., Simeonov, V., Polkowska, Ż., \& Namieśnik, J. (2018). Determination of metals content in wine samples by inductively coupled plasma-mass spectrometry. Molecules, 23, e2886.

Powell, C. D., Chowdhury, M. K., \& Bureau, D. P. (2017). Assessing the bioavailability of L-methionine and a methionine hydroxy analogue (MHA-Ca) compared to DL-methionine in rainbow trout (Oncorbynchus mykiss). Aquaculture Research, 48, 332-346.

Pretorius, Q. (2011). The evaluation of larvae of Musca domestica (common house fly) as protein source for broiler production. Master of Science, Stellenbosch University, Stellenbosch.

Ramos-Elorduy, J., Gonzalez, E. A., Hernandez, A. R., \& Pino, J. M. (2002). Use of Tenebrio 
molitor (Coleoptera: Tenebrionidae) to recycle organic wastes and as feed for broiler chickens. Journal of Economic Entomology, 95, 214-220.

Rehman, K. u., Cai, M., Xiao, X., Zheng, L., Wang, H., Soomro, A. A., . . . Zhang, J. (2017). Cellulose decomposition and larval biomass production from the co-digestion of dairy manure and chicken manure by mini-livestock (Hermetia illucens L.). Journal of Environmental Management, 196, 458-465.

Rosales, A., Galicia, L., Oviedo, E., Islas, C., \& Palacios-Rojas, N. (2011). Near-infrared reflectance spectroscopy (NIRS) for protein, tryptophan, and lysine evaluation in quality protein maize (QPM) breeding programs. Journal of Agricultural and Food Chemistry, 59, 1078110786.

Rumpold, B. A., \& Schluter, O. K. (2013). Nutritional composition and safety aspects of edible insects. Molecular Nutrition \& Food Research, 57, 802-823.

Salomone, R., Saija, G., Mondello, G., Giannetto, A., Fasulo, S., \& Savastano, D. (2017). Environmental impact of food waste bioconversion by insects: Application of life cycle assessment to process using Hermetia illucens. Journal of Cleaner Production, 140, 890-905.

Santos, É. J. d., Baika, L. M., Herrmann, A. B., Kulik, S., Sato, C. S., Santos, A. B. d., \& Curtius, A. J. (2012). Fast assessment of mineral constituents in grass by inductively coupled plasma optical emission spectrometry. Brazilian Archives of Biology and Technology, 55, 457-464.

Schiavone, A., Cullere, M., De Marco, M., Meneguz, M., Biasato, I., Bergagna, S., . . Zotte, A. D. (2017). Partial or total replacement of soybean oil by black soldier fly larvae (Hermetia illucens L.) fat in broiler diets: effect on growth performances, feed-choice, blood traits, carcass characteristics and meat quality. Italian Journal of Animal Science, 16, 93-100.

Sealey, W. M., Gaylord, T. G., Barrows, F. T., Tomberlin, J. K., McGuire, M. A., Ross, C., \& St-Hilaire, S. (2011). Sensory analysis of rainbow trout, Oncorbynchus mykiss, fed enriched black soldier fly pre-pupae, Hermetia illucens. Journal of the World Aquaculture Society, 42, 34-45.

Serem, J., Wahome, R., Gakuya, D., Kiama, S., Gitao, G., \& Onyango, D. (2017). Growth performance, feed conversion efficiency and blood characteristics of growing pigs fed on different levels of Moringa oleifera leaf meal. Journal of Veterinary Medicine and Animal Health, 9, 327-333.

Shanmugam, A. A., Muliya, S. K., Deshmukh, A., Suresh, S., Nath, A., Kalaignan, P., . . Jose, L. (2017). Baseline hematology and serum biochemistry results for Indian leopards (Panthera pardus fusca). Veterinary World, 10, 818-824.

Sheppard, D. C., Newton, G. L., Thompson, S. A., \& Savage, S. (1994). A value added manure management system using the black soldier fly. Bioresource Technology, 50, 275-279.

Skřivanová, E., Marounek, M., Benda, V., \& Březina, P. (2006). Susceptibility of Escherichia coli, Salmonella sp and Clostridium perfringens to organic acids and monolaurin. Veterinarni Medicina, 51, 81-88.

Slump, P., \& Bos, K. D. (1985). Determination of methionine in feed concentrates. Poultry Science, 64, 705-707.

Spranghers, T., Michiels, J., Vrancx, J., Ovyn, A., Eeckhout, M., De Clercq, P., \& De Smet, S. (2018). Gut antimicrobial effects and nutritional value of black soldier fly (Hermetia illucens L.) prepupae for weaned piglets. Animal Feed Science and Technology, 235, 33-42.

Spring, P. (2013). The challenge of cost effective poultry and animal nutrition: optimizing existing and applying novel concepts. Lobmann Information, 48, 38-46.

Sreenivasulu, V., Kumar, N. S., Dharmendra, V., Asif, M., Balaram, V., Zhengxu, H., \& Zhen, Z. 
(2017). Determination of boron, phosphorus, and molybdenum content in biosludge samples by microwave plasma atomic emission spectrometry (MP-AES). Applied Sciences-Basel, $7,264$.

Tacon, A. G. J., \& Metian, M. (2008). Global overview on the use of fish meal and fish oil in industrially compounded aquafeeds: Trends and future prospects. Aquaculture, 285, 146-158.

Van Huis, A., Van Itterbeeck, J., Klunder, H., Mertens, E., Halloran, A., Muir, G., \& Vantomme, P. (2013). Edible insects: future prospects for food and feed security (No. 171). Rome: Food and Agriculture Organization.

Veldkamp, T., Van Duinkerken, G., van Huis, A., Lakemond, C., Ottevanger, E., Bosch, G., \& Van Boekel, T. (2012). Insects as a sustainable feed ingredient in pig and poultry diets: a feasibility study; Report 638. Wageningen. Wageningen UR Livestock Research. Retrieved from: http://library.wur.nl/WebQuery/wurpubs/fulltext/234247, March 24, 2019.

Wallace, P. A., Nyameasem, J. K., Adu-Aboagye, G. A., Affedzie-Obresi, S., Nkegbe, E. K., Karbo, N., . . Maquart, P. (2017). Impact of black soldier fly larval meal on growth performance, apparent digestibility, haematological and blood chemistry indices of guinea fowl starter keets under tropical conditions. Tropical Animal Health and Production, 49, 1163-1169.

Wang, Y. S., \& Shelomi, M. (2017). Review of black soldier fly (Hermetia illucens) as animal feed and human food. Foods, 6, 91.

Wilson, G. D., Harvey, D. G., \& Snook, C. R. (1972). A review of factors affecting blood biochemistry in the pig. British Veterinary Journal, 128, 596-610.

Windham, W. R. (1995). AOAC official method 994.12, amino acids in feeds, alternative III, acid hydrolysis method. In P. Cunniff (Ed.), Official methods of analysis of AOAC Intemational (16th ed., Vol. 1). Rockville, MD, USA: AOAC International.

Wu, X., Xie, C., Long, C., Li, J., Zhou, X., Fan, Z., . . Yin, Y. (2018). Effects of a daily three-meal pattern with different dietary protein contents on pig growth performance, carcass and muscle quality traits. Journal of the Science of Food and Agriculture, 98, 415-421.

Zampiga, M., Laghi, L., Petracci, M., Zhu, C., Meluzzi, A., Dridi, S., \& Sirri, F. (2018). Effect of dietary arginine to lysine ratios on productive performance, meat quality, plasma and muscle metabolomics profile in fast-growing broiler chickens. Journal of Animal Science and Biotechnology, 9, 79.

Zarantoniello, M., Bruni, L., Randazzo, B., Vargas, A., Gioacchini, G., Truzzi, C., . . Olivotto, I. (2018). Partial Dietary Inclusion of Hermetia illucens (black soldier fly) full-fat prepupae in Zebrafish feed: Biometric, histological, biochemical, and molecular implications. Zebrafish, 15, 519-532. 


\section{Chapter 8}

Black soldier fly larval meal in feed enhances growth performance, carcass yield and meat quality of finishing pigs

Shaphan Y. Chia, Chrysantus M. Tanga, Isaac M. Osuga, Alphonce O. Alaru, David M. Mwangi, Macdonald Githinji,

Sunday Ekesi, Joop J. A. van Loon and Marcel Dicke 


\section{Abstract}

The price of protein ingredients (soybean and fishmeal - FM) commonly used in feed for meat production has increased drastically due to reduced availability. Black soldier fly (BSF) larvae are a novel source of animal protein whose use in animal feeds rapidly increases. Yet, little is known about the effect of dietary inclusion of BSF larval meal (BSFLM) on finishing pig growth, carcass yield and meat quality. The present study evaluated the effect of replacing FM with BSFLM on growth performance, carcass traits and meat quality of pigs. A control diet (including FM: 0\% BSFLM) was compared with four dietary levels of replacement of FM with BSFLM at 25, 50, 75 or 100\%. Forty hybrid pigs (crossbreeds of purebred Large White and Landrace) were randomly allocated to the five different dietary treatments. Feed intake, body weight gain and feed conversion ratio were measured. After 98 days of feeding, all eight pigs per treatment were slaughtered for the evaluation of carcass and nutritional content of the organ and muscle tissues. The results show that diet significantly affected average daily weight gain, final body weight, average daily feed intake, and feed conversion ratio. Fasted weight and carcass weight of pigs fed diets with $50-100 \%$ of FM replaced with BSFLM were significantly greater than in the control group. Back fat depth was significantly greater in the 75 and 100\% replacement groups than in the $0-50 \%$ replacement groups. Belly, ham and loin cuts weighed significantly more in the $50-100 \%$ replacement groups than in the control group. The crude protein content of pork tissues on dry matter basis (DM) was high, ranging between 65 - 93\% across all dietary groups. BSFLM proves to be a suitable feed ingredient in finishing pig feed and can completely replace FM with beneficial consequences on growth, carcass and nutritional quality of edible pork by-products. These findings are relevant for commercial pig feed production and provide for the first time a nutritional perspective on pork derived from pigs raised on insect-based feeds.

Keywords: insect meal, finishing pigs, market weight, pork, novel nutrient source, fat, mineral 


\section{Introduction}

Approximately one third of global meat production is represented by pig meat (Bruinsma, 2003). In Sub-Saharan Africa, pig production has a great potential for raising household income of millions of resource-poor smallholder farmers especially women in the rural and peri-urban communities (Ouma et al., 2014; Pezo et al., 2014). The production and consumption of pork has recently increased in many countries in Sub-Saharan Africa. Further studies revealed that with the growing per capita income, population and urbanization, this trend is predicted to continue, surpassing the increase in demand for cereals and root tubers (Pica-Ciamarra \& Otte, 2009).

In Kenya, pig production is an important source of household income for pig farmers (Kagira et al., 2010a; Kagira et al., 2010b; Mutua et al., 2010). Although 70\% of the producers are small-holder farmers (Githigia et al., 2012; Mbuthia et al., 2015), pig meat ranked the second highest livestock export earner for Kenya at USD \$1,122,000 in 2002 (Kagira et al., 2010a). However, a major barrier for producers is the lack of quality feed ingredients, especially the major protein sources such as fishmeal (FM) and soybean meal. The reduced availability of these common protein sources in the market throughout the year has led to an increase in feed costs, representing $60-70 \%$ of the total costs of pig production. Thus, cheaper and sustainable sources of protein for inclusion in animal feed to substitute FM are urgently needed (Ardjosoediro \& Neven, 2008; Fiaboe \& Nakimbugwe, 2017; Githigia et al., 2012). Although FM has a good amino acid profile and minerals that can positively impact nutrition and meat quality of farmed animals (Cho \& Kim, 2011), it is mainly obtained from silver cyprinid fish Rastrineobola argentea, which constitutes the largest catch by weight of fishery in Lake Victoria (Kolding et al., 2014). The high demand for this fish has led to excessive fishing activities in Lake Victoria, prompting the lake regulatory authorities to institute periodic fishing bans. As a result, FM is not available in sufficient quantities throughout the year, leading to increased prices (Ardjosoediro \& Neven, 2008). Therefore, novel protein sources, including edible insects are needed to supplement the current sources of protein (Van Krimpen \& Hendriks, 2019).

Insects contain high-quality protein, fats and minerals, and are suitable alternatives to FM or soybean meal in animal feed (Makkar et al., 2014). The black soldier fly (BSF) Hermetia illucens L. (Diptera: Stratiomyidae) is widespread in the tropics and warm temperate regions of the world (Sheppard et al., 1994). BSF larvae (BSFL) feed on a variety of substrates including organic side streams (Chia et al., 2018a; Chia et al., 2018b; Meneguz et al., 2018; Rehman et al., 2017), converting residual nutrients into high-quality insect biomass (Barragan-Fonseca et al., 2017; Barragan-Fonseca et al., 2018; Diener et al., 2009; Lalander et al., 2015). BSF larval meal (BSFLM) has been used extensively in fish (Belghit et al., 2019; Xiao et al., 2018; Zarantoniello et al., 2018) and poultry feeds 
(Moula et al., 2018; Onsongo et al., 2018), but its use in pig feed formulation has only been assessed occasionally (Biasato et al., 2019; Newton et al., 1977; Yu et al., 2019).

A pig production cycle produces mature pigs either for slaughter or reproduction and feed is the most critical input in every growth phase (piglet-grower-finisher) in commercial pig production. The finishing phase of pigs, a growth phase which typically precedes slaughter or market stage of pigs, is marked by considerable lean growth (Kim et al., 2005). The inclusion of BSFLM in pig feed has not yet been extensively assessed and has thus far been focused on the piglet stage. Yu et al. (2019) replaced soybean meal with BSFLM in finishing pig feeds at the rate of 4 and $8 \%$ and investigated the colonic microbiota and bacterial metabolite production in the animals. They report that the inclusion of BSFL in pig feed may enhance mucosal immune homeostasis of pigs through altering bacterial composition in the intestinal (colon) mucosa and the bacterial metabolite profile. In the present study, we replaced FM with BSFLM in feed that was provided to finishing pigs until market weight, and assessed their growth performance, as well as carcass traits and meat quality. Market weight is an important economic factor in pig production, impacting pork quality and profit. Furthermore, the values of different cuts of pig carcasses are different; hence, information on the proportion of primal cuts can be important in assessing carcass yield to optimize profit (Kim et al., 2005).

Body weight gain in pigs and feed composition are important factors in pork production (Muns et al., 2018). About 80\% of feed used in a farrow-finish operation is consumed in the grower-finisher phase (Njoku et al., 2015). Inadequate feed intake affects growth performance, thus impacting the cost of production. Reduced carcass fat content, especially in animal carcasses set for the consumer market is preferred ( $\mathrm{Zak}$ \& Pieszka, 2009).

Edible meat by-products including internal organs such as liver, lungs, heart, spleen and kidneys are generated through slaughter of pigs. These by-products make up an important portion of the animal's live weight and can provide essential nutrients to consumers who are limited in meat and meat products (Alao et al., 2017; Fayemi et al., 2018; Irshad $\&$ Sharma, 2015). However, their consumption is limited and varies among cultures and economic status (Seong et al., 2014). The commercial value of these by-products is also low and limited information on their nutritional quality may be responsible for their low consumption rates (Seong et al., 2014). Information on the nutritional composition of edible pork by-products when fed insect-based feeds, can influence the consumer's decision to accept these by-products. This information can also promote the use of edible pork by-products and can contribute to ensuring the widespread use of insect meal in pig feed formulation.

Farmed animals are often assessed for growth on farm or at the market gate based on live body weight (Birteeb et al., 2015). However, weighing heavier animals is challenging 
to resource-poor farmers because they cannot afford the expensive weighing scales. Simple linear body measurements can therefore provide a basic assessment of the animal in smallholder farms. The present study aimed at evaluating the effect of replacing FM with BSFLM on growth performance and carcass yield of finishing pigs as well as the nutritional composition of some major pork by-products. The study also established the correlation between live body weight and linear body measurements using principal component analysis (PCA).

\section{Materials and Methods}

\section{Study site}

The experiment was conducted at the Non-ruminant Research Institute (NRI) of the Kenya Agricultural and Livestock Research Organization (KALRO) located in Naivasha, Kenya.

\section{Insect meal and experimental diets}

Black soldier fly larvae used in the study were obtained from the Animal Rearing and Containment Unit (ARCU), icipe, Nairobi, Kenya. The larvae were reared on a mixture of brewers' spent grains (BSGs) from Kenya Breweries Limited. BSF larvae were sterilized by washing in warm water $\left(84^{\circ} \mathrm{C}\right)$ for 10 minutes and then oven-dried using a stainless-steel fruit/vegetable/meat/fish drying machine model (CT-C-III Series hot air circulating drying oven, Henan Forchen Machinery Co., Ltd, China). Dried larvae were ground into larval powder meal using a hammer mill (Newton et al., 1977). Diets were prepared to partially or completely replace FM with BSFLM and were formulated to be isonitrogenous and isoenergetic to meet requirements for finishing pigs (National Research Council, 1979). FM content of a control (D0) diet was replaced at 25, 50, 75 and $100 \%$ with BSFLM to obtain: D25, D50, D75 and D100, respectively, as experimental diets (Table 1).

\section{Proximate, amino acid and mineral composition of experimen- tal diets}

The dry matter content of formulated feed samples was gravimetrically determined after loss of water. The samples were heated to $103 \pm 2{ }^{\circ} \mathrm{C}$ for $3 \mathrm{~h}$ until constant weight, when the weight of samples was constant for two consecutive readings. Ash content was determined by ignition of samples at $550{ }^{\circ} \mathrm{C}$ in a muffle furnace. Dried, ground samples were exposed to an electromagnetic scan in the absorbance mode using near infrared (NIR) spectroscopy (Cropnuts, Nairobi, Kenya). The crude protein, fat, starch, oil, acid detergent fibre, neutral detergent fibre, sugar and digestibility (NCGD) values 
were determined following standard laboratory procedures (Núñez-Sánchez et al., 2012; Rosales et al., 2011). The amino acid composition of experimental diets (Table 1) was analyzed by AMINOLab® (Evonik Industries, Hanau, Germany) using an amino acid analyzer (Biochrom 30 plus, Biochrom Ltd. Cambridge, UK) (Al-Sagan et al., 2018; Llames \& Fontaine, 1994; Powell et al., 2017; Windham, 1995; Zampiga et al., 2018). Feed samples were homogeneously ground with an Ultra Centrifugal Mill RETSCHZM 200 to pass through a $0.5 \mathrm{~mm}$ sieve. Finely ground samples were weighed using an analytical balance, display accuracy $\pm 0.01 \mathrm{mg}$ into $50 \mathrm{ml}$ laboratory bottles, with thread of DURAN glass (Schott), red PBTP caps with silicone/Teflon seal. Then, $25 \mathrm{ml}$ of hydrochloric-phenol reagent was added to the sample in the bottles and the mixture was introduced into a thermostatically controlled heating oven (UT 6060 AR, Thermo Electron LED, Langenselbold, Germany) at $110^{\circ} \mathrm{C}$, with loose screw tops for one hour and then with tightened screw tops for 23 hours to complete sample hydrolysis. Methionine and cysteine samples were prepared through performic acid oxidation procedures followed by acid hydrolysis-sodium metabisulfite method (Powell et al., 2017; Slump $\&$ Bos, 1985). The resulting hydrolysate solutions were then introduced into the amino acid analyzer and the sample aminograms were analyzed at $570 \mathrm{~nm}$ and $440 \mathrm{~nm}$. Amino acid concentrations in the samples were determined in duplicate.

Mineral composition of feed samples (Table 2) was analyzed by Inductively Coupled Plasma-Optical Emission spectrometry (ICP-OES) (Cropnuts, Nairobi, Kenya). Ground feed samples were transferred to a microwave digestion system. Then, a mixture of nitric acid and hydrochloric acid was added to the sample and allowed to digest the sample. The resulting solution was filtered into a volumetric flask and used for ICP-OES analysis to determine the following minerals: boron, molybdenum, iron, copper, zinc, cobalt, manganese, sodium, sulphur, magnesium, potassium, phosphorus and calcium (Barałkiewicz et al., 2007; Płotka-Wasylka et al., 2018; Santos et al., 2012; Sreenivasulu et al., 2017).

\section{Animals and Housing}

Hybrid grower pigs (crossbreeds of purebred Large White and Landrace) comprising of 20 boars and 20 gilts, with mean body weight (BW) of $54.3 \pm 0.93 \mathrm{~kg}$ were randomly assigned to the five dietary treatments, with eight replicate pigs (four boars and four gilts) per treatment. Pigs were placed individually in pens $(3.7 \mathrm{~m} \times 1.9 \mathrm{~m})$ with concrete floors. Each pen was provided with a one-sided feeding trough $(1.8 \times 0.2 \times 0.2 \mathrm{~m})$ and a nipple drinker. Each pen was labelled with a number and diet type while each animal was identified with a unique number by ear tattooing. Pig pens were cleaned every day by scrubbing the floor using Teepee straight brooms with handle (c27, Chandarana Foodplus, Nairobi, Kenya) and water. Pigs were allowed ad libitum access to feed and water throughout the experiment. 


\section{Growth performance}

Initial body weight of the pigs was recorded at the start of the experiment and subsequently the pigs were weighed on a weekly basis using a $150 \mathrm{~kg}$ x $500 \mathrm{~g}$ suspended weighing scale (model 235, England, Salter). The sides of the scale were covered with a wire mesh to prevent uncontrolled exit of the animal. The entry gate of the weigh cage was opened sideward and the animal was led into a stable, unmoving floor after which the gate was closed. Once inside the cage, the animal was allowed to settle, and the weight value read on an analogue display screen above the weigh cage. Pigs were only provided with feed after recording their body weight if this coincided with the weekly body weight measurement. The experiment lasted 14 weeks and the weekly body weight values were used to calculate average daily weight gain (ADG). Feed offered to the pigs and the unconsumed portions were weighed daily using a digital platform weighing scale (XK3190-A12, Gromy Scale Co., Ltd, Hangzhou, China) to calculate average daily feed intake (ADFI). Feed conversion ratio (FCR) was calculated as total feed consumed divided by the body weight gain at the end of the experiment. 
Table 1. Composition of experimental diets

\begin{tabular}{|c|c|c|c|c|c|}
\hline \multirow{2}{*}{ Parameter } & \multicolumn{5}{|c|}{ Diets } \\
\hline & D0 & D25 & D50 & D75 & D100 \\
\hline \multicolumn{6}{|c|}{ Ingredient $(\mathrm{kg})$} \\
\hline Maize meal & 13.0 & 14.0 & 14.5 & 14.0 & 14.0 \\
\hline Wheat pollard & 46.5 & 35.0 & 34.0 & 32.3 & 36.0 \\
\hline Rice polishing & 27.5 & 33.8 & 33.0 & 34.0 & 30.0 \\
\hline Fishmeal & 7.0 & 5.3 & 3.5 & 1.8 & 0.0 \\
\hline BSFLM & 0.0 & 6.0 & 9.0 & 12.0 & 14.0 \\
\hline L-Lysine & 1.0 & 1.0 & 1.0 & 1.0 & 1.0 \\
\hline DL-Methionine & 1.0 & 1.0 & 1.0 & 1.0 & 1.0 \\
\hline $\begin{array}{l}\text { Vitamin and mineral } \\
\text { premix }^{*}\end{array}$ & 1.0 & 1.0 & 1.0 & 1.0 & 1.0 \\
\hline Bone meal & 1.3 & 1.3 & 1.3 & 1.3 & 1.3 \\
\hline Salt & 0.5 & 0.5 & 0.5 & 0.5 & 0.5 \\
\hline Limestone & 1.3 & 1.3 & 1.3 & 1.3 & 1.3 \\
\hline Dry matter (DM) $(\%)$ & 92.6 & 93.1 & 93.6 & 92.2 & 94.1 \\
\hline Crude protein $(\% \mathrm{DM})$ & 12.9 & 14.9 & 15.3 & 14.8 & 16.3 \\
\hline \multicolumn{6}{|c|}{ Essential amino acids (\% DM) } \\
\hline Lysine & 1.1 & 1.2 & 1.3 & 1.2 & 1.3 \\
\hline Methionine & 0.6 & 0.7 & 0.7 & 0.5 & 0.5 \\
\hline Methionine + Cystine & 0.9 & 0.9 & 0.9 & 0.7 & 0.8 \\
\hline Isoleucine & 0.4 & 0.4 & 0.5 & 0.4 & 0.5 \\
\hline Leucine & 0.8 & 0.9 & 0.9 & 0.9 & 1.0 \\
\hline Threonine & 0.4 & 0.5 & 0.5 & 0.4 & 0.5 \\
\hline Phenylalanine & 0.5 & 0.6 & 0.6 & 0.5 & 0.6 \\
\hline Valine & 0.6 & 0.6 & 0.7 & 0.6 & 0.8 \\
\hline Arginine & 0.8 & 0.8 & 0.8 & 0.7 & 0.9 \\
\hline Histidine & 0.3 & 0.3 & 0.3 & 0.3 & 0.4 \\
\hline \multicolumn{6}{|c|}{ Nonessential amino acids ( $\% \mathrm{DM})$} \\
\hline Alanine & 0.7 & 0.8 & 0.8 & 0.8 & 0.9 \\
\hline Aspartic acid & 0.9 & 1.0 & 1.1 & 1.0 & 1.2 \\
\hline Cystine & 0.2 & 0.2 & 0.2 & 0.2 & 0.2 \\
\hline Glutamic acid & 1.9 & 2.0 & 2.0 & 1.8 & 2.1 \\
\hline Glycine & 0.7 & 0.7 & 0.8 & 0.7 & 0.8 \\
\hline Proline & 0.7 & 0.8 & 0.8 & 0.8 & 0.9 \\
\hline Serine & 0.5 & 0.6 & 0.6 & 0.5 & 0.6 \\
\hline
\end{tabular}

BSFLM $=$ black soldier fly larval meal. D0 $=0 \%$ (control), D25 $=25 \%$, D50 $=50 \%$, D $75=75 \%$, D100 $=100 \%$ levels of replacement of fishmeal with BSFLM. DM, crude protein, essential and non-essential amino acids are results of chemical analysis of feed samples. Amino acid values presented are mean values of two subsamples analyzed. * Premix contained per $2 \mathrm{~kg}$ : Vitamin A 3,000,000 IU; Vitamin D3 500,000 IU; Vitamin E 2,500 IU; Vitamin K3 - KASTAB 2,000 mg; Vitamin B2 -riboflavin 2,500 mg; Vitamin B3 - nicotinic acid 20,000 mg; Vitamin B5 - pantothenic acid 10,000 mg; Vitamin B6 - pyridoxine 500 mg; Vitamin B12 - cobalamin $12 \mathrm{mg}$; choline chloride 100,000 mg; zinc bacitracin 10,000 mg; antioxidant 125,000 mg; iron (Fe) 40,000 mg, manganese (Mn) 25,000 mg; zinc ( $\mathrm{Zn})$ 80,000 mg, copper (Cu) 25,000 mg; iodine (I) $500 \mathrm{mg}$, cobalt (Co) $250 \mathrm{mg}$, selenium (Se) $100 \mathrm{mg}$. 
Table 2. Mineral and proximate composition (dry matter basis) of experimental diets

\begin{tabular}{llllll}
\hline \multirow{2}{*}{ Parameter } & \multicolumn{5}{c}{ Diets } \\
\cline { 2 - 5 } & D0 & D25 & D50 & D75 & D100 \\
\hline Boron (ppm) & 2.6 & 3.7 & 2.6 & 2.6 & 1.68 \\
Molybdenum (ppm) & 1.1 & 1.0 & 0.8 & 0.8 & 10.5 \\
Iron (ppm) & 374.2 & 522.9 & 404.4 & 433.1 & 499 \\
Copper (ppm) & 13.2 & 11.6 & 13.7 & 10.7 & 24.4 \\
Zinc (ppm) & 66.3 & 92.6 & 82.4 & 74.8 & 123 \\
Cobalt (ppm) & 0.1 & 0.2 & 0.2 & 0.1 & 0.44 \\
Manganese (ppm) & 159.7 & 232.5 & 203.3 & 200.2 & 209 \\
Sodium (ppm) & 2833.7 & 3744.5 & 3049.2 & 3384.1 & 942 \\
Sulphur (\%) & 0.4 & 0.4 & 0.3 & 0.3 & 0.3 \\
Magnesium (\%) & 0.5 & 0.6 & 0.5 & 0.5 & 0.58 \\
Potassium (\%) & 0.8 & 1.1 & 0.9 & 0.9 & 0.93 \\
Phosphorus (\%) & 0.8 & 1.0 & 1.0 & 0.9 & 0.64 \\
Calcium (\%) & 2.5 & 3.0 & 2.6 & 2.1 & 1.58 \\
Sugar (\%) & 2.5 & 3.6 & 6.2 & 5.6 & 8.66 \\
Starch (\%) & 32.3 & 17.1 & 25.5 & 25.4 & 29.8 \\
Ash (\%) & 8.5 & 12.3 & 8.3 & 9.3 & 9.53 \\
Acid detergent fiber (\%) & 16.8 & 25.7 & 19.8 & 20.7 & 18.1 \\
Neutral detergent fiber (\%) & 39.1 & 50.1 & 41.1 & 42.3 & 40.2 \\
Digestibility (\%) & 77.8 & 67.9 & 75.4 & 75.0 & 72.9 \\
Oil (\%) & 4.7 & 6.5 & 8.6 & 8.6 & 11.3 \\
Net energy (MJ/Kg) & 9.3 & 7.6 & 10.2 & 10.0 & 13.4 \\
\hline
\end{tabular}

D0 $=0 \%$ (control), D25 $=25 \%$, D $50=50 \%$, D $75=75 \%$, D $100=100 \%$ levels of replacement of fishmeal with black soldier fly larval meal; ppm $=$ parts per million. Values presented in the table are results of single analyses

\section{Linear and live body measurements}

Body measurements studied included: rump height (RH), distance from the highest point of rump to the ground; heart girth (HG), length of body circumference just behind the forelegs; body length (BL), distance between the middle point of the shoulder blade and the base of the tail, measured on the midline along the back; ear width (EW), measured at the widest part of the ear; head width ( $\mathrm{HdW})$, measured at the widest point of the head; body height $(\mathrm{BH})$, distance from the top of the mid-point of the trunk to the ground; Fore limb (Flb), length from the point of attachment of the foreleg to the tip of the foreleg; hind limb ( $\mathrm{Hlb}$ ), length from the point of attachment of the hind leg to the tip of the hind leg; Trunk depth (TD), measured from the mid-point of the trunk (at the top of the back) to the lowest point of the stomach; Shoulder width (SW), distance from left to right upper arm at the widest point of the shoulder; Hip width (HW), distance from left to right at the widest point of the hip; flank circumference (FC), 
measured immediately in front of the hind legs; back height $(\mathrm{BaH})$, measured from the middle point of the upper hips to the floor; neck circumference (NC), and the live body weight $(\mathrm{BW})$ of each pig. Each pig was restrained while taking the body measurements. The linear body traits were recorded using a measuring tape in centimeters (Adeola et al., 2013; Zaragoza, 2009).

\section{Slaughter and Carcass Characteristics}

Forty pigs, consisting of eight ( 4 boars and 4 gilts) pigs per dietary treatment were slaughtered and analyzed for carcass yield, cut-up parts, organ weight, and composition of muscle, bone, fat and skin in primal cuts at the end of the experiment. All pigs were slaughtered at the slaughter facility of the Non-Ruminant Institute, Kenya Agricultural and Livestock Research Organization, Naivasha, Kenya where the feeding trial on pigs was conducted. Pigs were weighed and fasted for about 18 hours after which the fasted weight of each pig was recorded before it was stunned. Pigs were carefully slaughtered following prescriptions according to the Kenya Society for the Protection and Care of Animals (KSPCA), Naivasha, Kenya. Pigs were immobilized by head stunning, using a stunning gun and bled by incision, cutting through the jugular vein between the skull and the atlas after which complete dehairing was done. Following dehairing, the stomach of each pig was opened along the greater curvature and eviscerated. After evisceration, the remaining part was weighed within $45 \mathrm{~min}$ postmortem to determine the hot carcass weight $(\mathrm{HCW})$ and later expressed as percentage of the ending live weight to obtain the dressing percentage (DP). The head was removed by cutting through the occipito-atlas joint. The trotters were removed by sawing through the hock joint at a right angle to the long axis of the leg.

The carcass was split longitudinally by sawing along the dorsal midline and the right half of each carcass was dissected into main cuts (ham, shoulder, loin and belly) and into other parts (collar butt, tenderloin and rump). The ham was separated by locating the division between the second and third sacral vertebrae and then sawing perpendicularly to the long axis of the carcass. The shoulder was separated from the loin and belly by a straight cut between the second and third ribs. The shoulder cut was further separated into the shoulder picnic (portion closest to the knee) and collar butt (portion closest to the spine of the pig). The middle portion of the carcass side was divided into the loin and belly by a straight cut from the edge of the tenderloin muscle on the ham end through the front rib tight against the protruding edge of the split backbone. The rump is the portion posterior to the loin and anterior to the tail and was separated by cutting just below the exposed pelvic or aitchbone (Njoku et al., 2015; Sheridan et al., 1991). For each cut, the weight was recorded using a digital weighing scale. The four main cuts (ham, shoulder picnic, loin and belly) were deboned and the skin plus subcutaneous fat 
removed. The weight of the dissected lean (muscle), bone, skin plus fat of each of the main cuts was recorded and expressed as a percentage of the weight of the cut.

The unskinned loin portion of the half carcass was sectioned between the $10^{\text {th }}$ and $11^{\text {th }}$ rib and after exposing the loin eye of the Longissimus dorsi muscle (LELD), the surface of the LELD was covered with a transparent plastic grid $(20 \times 15 \mathrm{~cm})$ marked out into squares of one centimeter $\left(\mathrm{cm}^{2}\right)$ and the number of squares covered by the grid counted to obtain the loin eye area (LEA).

The $10^{\text {th }}$ rib back fat depth (TRFD) was measured at three quarters of the distance of the lumber muscle from the dorsal process of the vertebral column (Lowell et al., 2018), using a digital venier caliper (VonHaus 6" $150 \mathrm{~mm}$ Digital Caliper Micrometer Vernier Gauge Tool, UK).

The fat-free index (FFI) was estimated using the following equation, described in procedure 1 for ribbed carcasses (Burson, 2010) and used by Lowell et al. (2018).

$\left.\mathrm{FFI}=\left(8.588+(0.465 \times \mathrm{HCW}, \mathrm{lb})-(21.896 \times \mathrm{TRFD}, \mathrm{in})+\left(3.005 \times \mathrm{LEA}, \mathrm{in}^{2}\right)\right) / \mathrm{HCW}, \mathrm{lb}\right) \times 100$

Where FFI $=$ fat free index, $\mathrm{HCW}=$ hot carcass weight, $\mathrm{TRFD}=10^{\text {th }}$ rib fat depth, LEA = loin eye area.

\section{Proximate and mineral composition of pork tissues}

The heart, kidney, liver, Longissimus dorsi (LM), lung and spleen tissues from slaughtered pigs reared on five different diets (D0-D100) were freeze-dried using a Benchtop Freeze Dryer (VirTis AdVantage 2.0, SP Scientific, New York, USA). Dried tissue samples were crushed into powder using a blender (Preethi Trio Mixer Grinder 500W, India). Samples were analyzed following the procedures described by AOAC (1990). The nitrogen content (\%) was determined using the Kjeldahl method. The crude protein (CP) was then determined by multiplying the nitrogen content by the factor 6.25 . Fat content was determined using the Velp solvent extractor (SER 148/6) with ethyl ether as extractant. Ash content was determined by heating at $550{ }^{\circ} \mathrm{C}$ overnight. The organic matter (OM) was then determined by subtracting ash content from 100.

Pork tissues samples were microwave-digested using a mixture of $65 \%$ nitric acid, $37 \%$ hydrochloric acid and 30\% hydrogen peroxide-ACS grade, (Sigma-Aldrich, USA) (Mohammed et al., 2017). Minerals including calcium $(\mathrm{Ca})$, copper $(\mathrm{Cu})$, iron $(\mathrm{Fe})$, potassium $(\mathrm{K})$, magnesium $(\mathrm{Mg})$, manganese $(\mathrm{Mn})$, sodium $(\mathrm{Na})$, phosphorus $(\mathrm{P})$, sulphur $(\mathrm{S})$, and zinc $(\mathrm{Zn})$ in the digested samples were determined by inductively coupled plasma atomic emission spectrometry (ICP-AES). 


\section{Statistical Analysis}

Statistical analyses of the data were performed with R software (version 3.5.1) by using a general linear model, which included: diet, sex and their interaction as independent variables for the analysis of ADG, ADFI, FCR, body weight gain (BWG) and final body weight (FBW), fasted body weight, carcass weight, DP, LEA and FFI. For the cut up parts, visceral organs and composition of primal cuts, diet was included in the model as the independent variable. The model for each analysis included all independent variables which were removed one by one until the Akaike Information Criterion (AIC) was at a minimal level. Mean effects were considered statistically significant at $\mathrm{P}<0.05$, with least significant difference test (LSD) as post-hoc test.

\section{Ethical approval}

Ethical approval for the study was provided by the Institutional Animal Care and Use Committee (IACUC) of Kenya Agricultural and Livestock Research Organization (KALRO) - Veterinary Science Research Institute (VSRI); approval Code No.: KALRO-VSRI/ IACUC019/30082019.

\section{Results}

\section{Growth performance}

All pigs showed healthy growth throughout the experimental period. Diet significantly affected ADG (Figure 1). At higher levels of replacement of FM with BSFLM, ADG was higher than obtained for lower levels of replacement of FM with BSFLM. Sex did not affect $\mathrm{ADG}(\mathrm{P}=0.30)$ and the interaction between diet and sex was not significant $(\mathrm{P}=0.90)$. Diet significantly affected BWG (Figure B1). At higher levels of replacement of FM with BSFLM, BWG was higher than obtained at lower levels of BSFLM. Sex significantly affected $\mathrm{BWG}(\mathrm{P}=0.027)$, but the interaction between diet and sex was not significant $(\mathrm{P}=0.37)$.

Neither diet nor sex affected ADFI and also the interaction between diet and sex was not significant (Table 3). FBW differed significantly among diets (Figure 2). At higher levels of replacement of FM with BSFLM, FBW was higher than at a lower levels. FBW differed significantly between boars and gilts $(\mathrm{P}=0.014)$, but the interaction of diet and sex on FBW was not significant $(\mathrm{P}=0.13$ ). Diet significantly affected FCR (Figure 3). At higher levels of replacement of FM with BSFLM, FCR was lower compared to the lower levels of replacement of FM. Sex did not affect FCR $(P=0.07)$ and there was no interaction effect of diet and sex on FCR $(\mathrm{P}=0.72)$. 


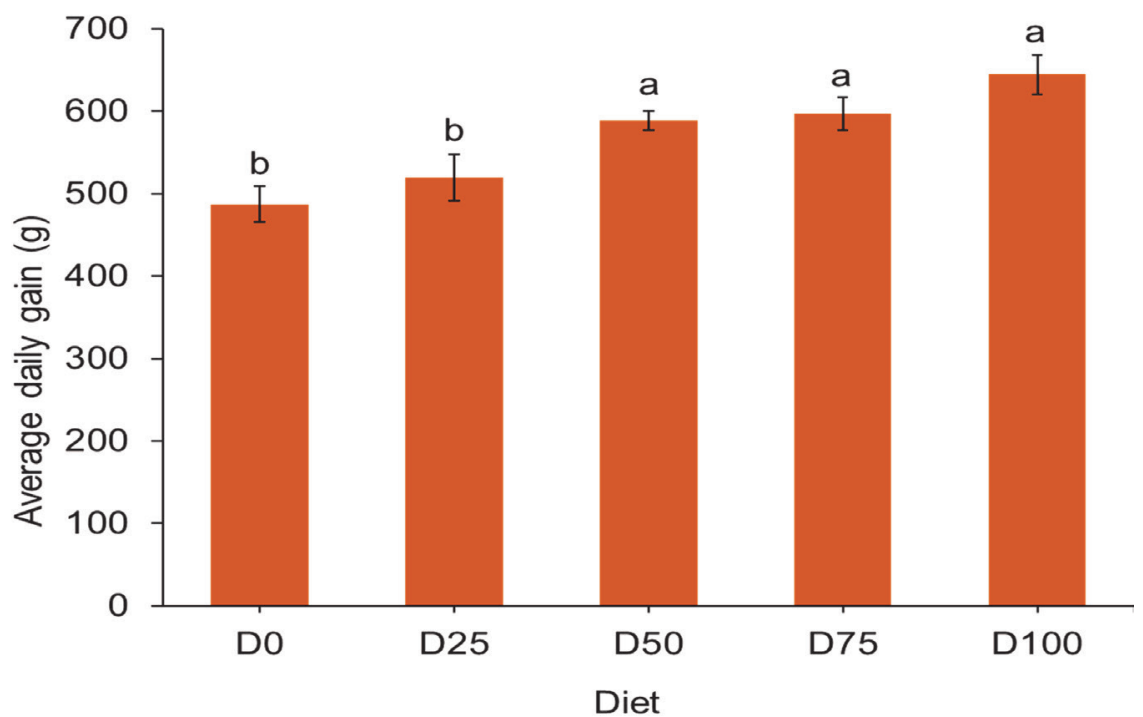

Figure 1. Average daily body weight gain (ADG) in finishing pigs fed BSFLM-based diets and a control diet. Means followed by different letters are significantly different (GLM, P < 0.05; LSD). BSFLM = black soldier fly larval meal. D0 $=0 \%$ (control), D25 $=25 \%$, D50 $=50 \%$, D75 $=75 \%$, D100 $=100 \%$ levels of replacement of fishmeal with BSFLM. LSD = Least Significant Difference test. For each diet, $\mathrm{N}=8$.

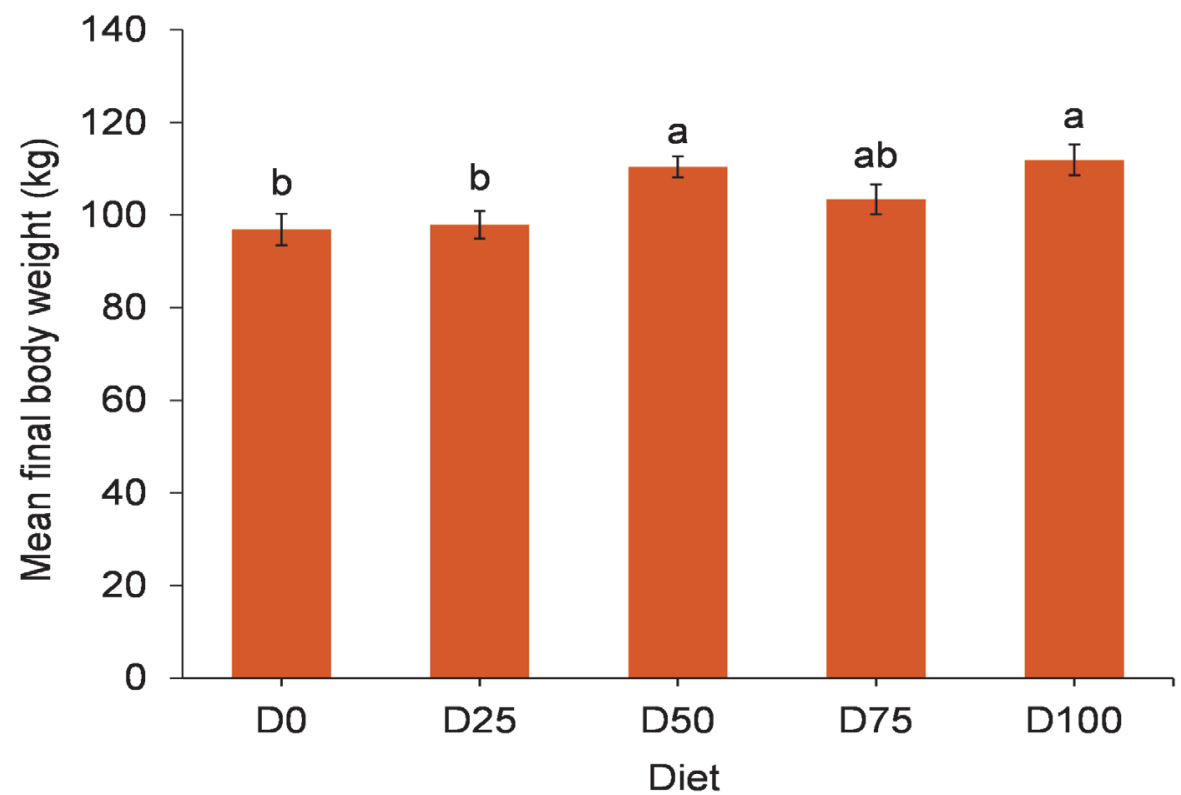

Figure 2. Mean ( \pm SE) final body weight of finishing pigs fed BSFLM-based diets and a control diet. Means followed by different letters are significantly different (GLM, P < 0.05; LSD). BSFLM = black soldier fly larval meal, D0 $=0 \%$ (control), D25 $=25 \%$, D $50=50 \%$, D $75=75 \%$, D100 $=100 \%$ levels of replacement of fishmeal with BSFLM. For each diet, $\mathrm{N}=8$. 


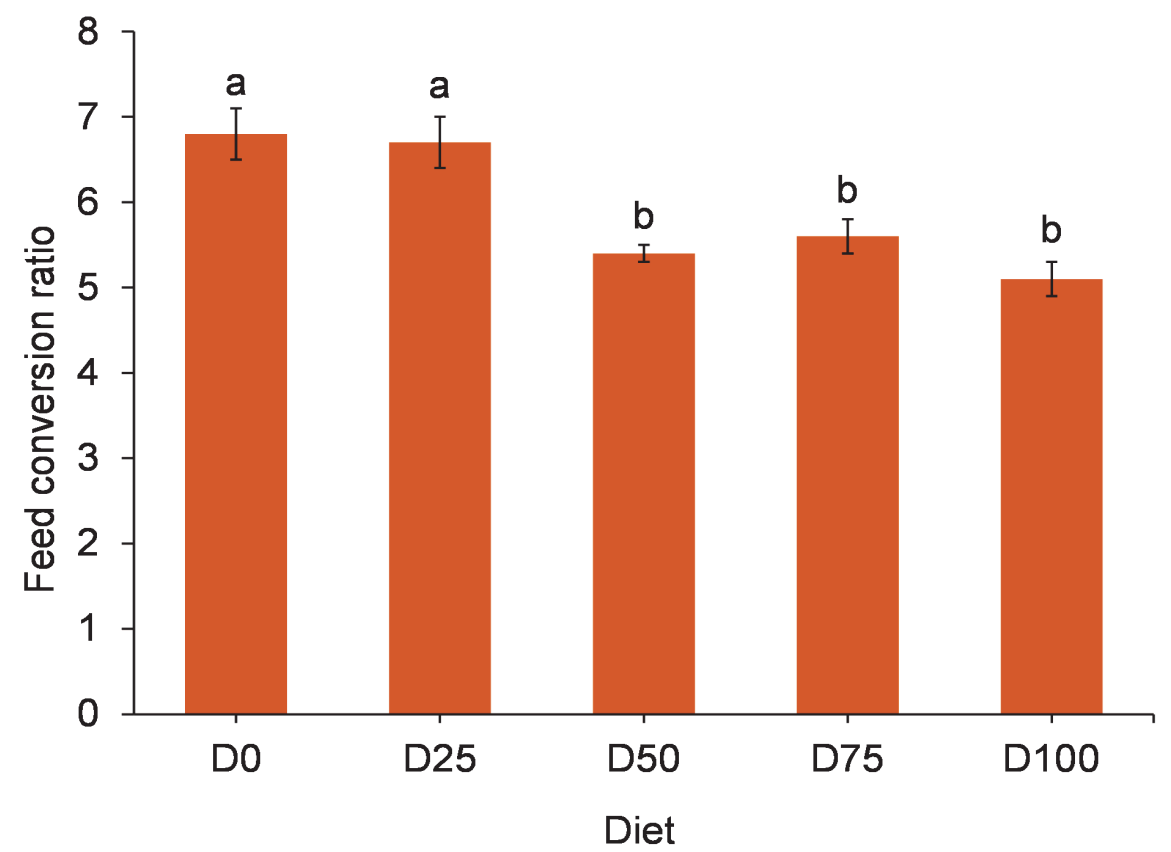

Figure 3. Mean $( \pm$ SE) feed conversion ratio (FCR) for finishing pigs fed BSFLM-based diets and a control diet. Means followed by different letters are significantly different (GLM, P < 0.05; LSD). BSFLM $=$ black soldier fly larval meal, D0 $=0 \%$ (control), D25 $=25 \%$, D $50=50 \%$, D75 $=75 \%$, D $100=100 \%$ levels of replacement of fishmeal with BSFLM. For each diet, $\mathrm{N}=8$.

\section{Carcass yield}

Fasted weight and carcass weight differed significantly among diets (Table 3). Fasted weight and carcass weight were higher at higher levels of replacement of FM with BSFLM than at lower levels of replacement of FM with BSFLM. Sex significantly affected fasted weight and carcass weight (Table 3). There were significant interactions between the effect of diet and sex on fasted weight and carcass weight (Table 3). Dressed percentage (DP) did not differ among dietary treatments (Table 3). Sex did not affect DP, but there was an interaction effect of diet and sex on DP (Table 3). LEA did not differ among diets. Sex did not affect LEA, and there was no interaction effect of diet and sex on LEA (Table 3). Fat free index (FFI) was significantly lower for boars and gilts at higher levels of replacement of FM with BSFLM (Table 3). Back fat depth measured at the $10^{\text {th }}$ rib increased with increased replacement of FM with BSFLM (Figure 4). Overall, back fat depth differed significantly $(\mathrm{P}=0.004)$ among diets with higher values for higher replacement rates of FM by BSFLM (Figure 4). 


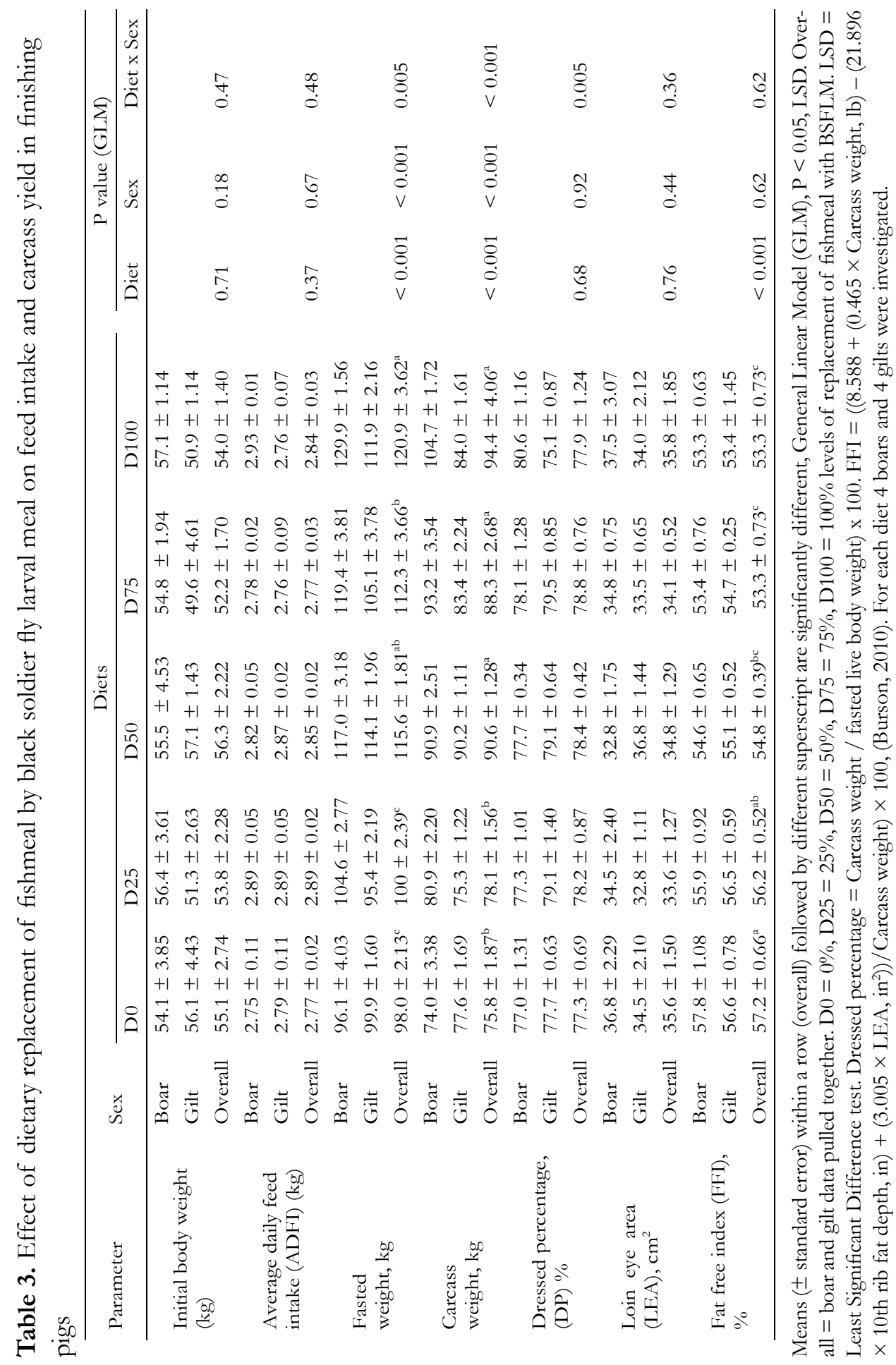




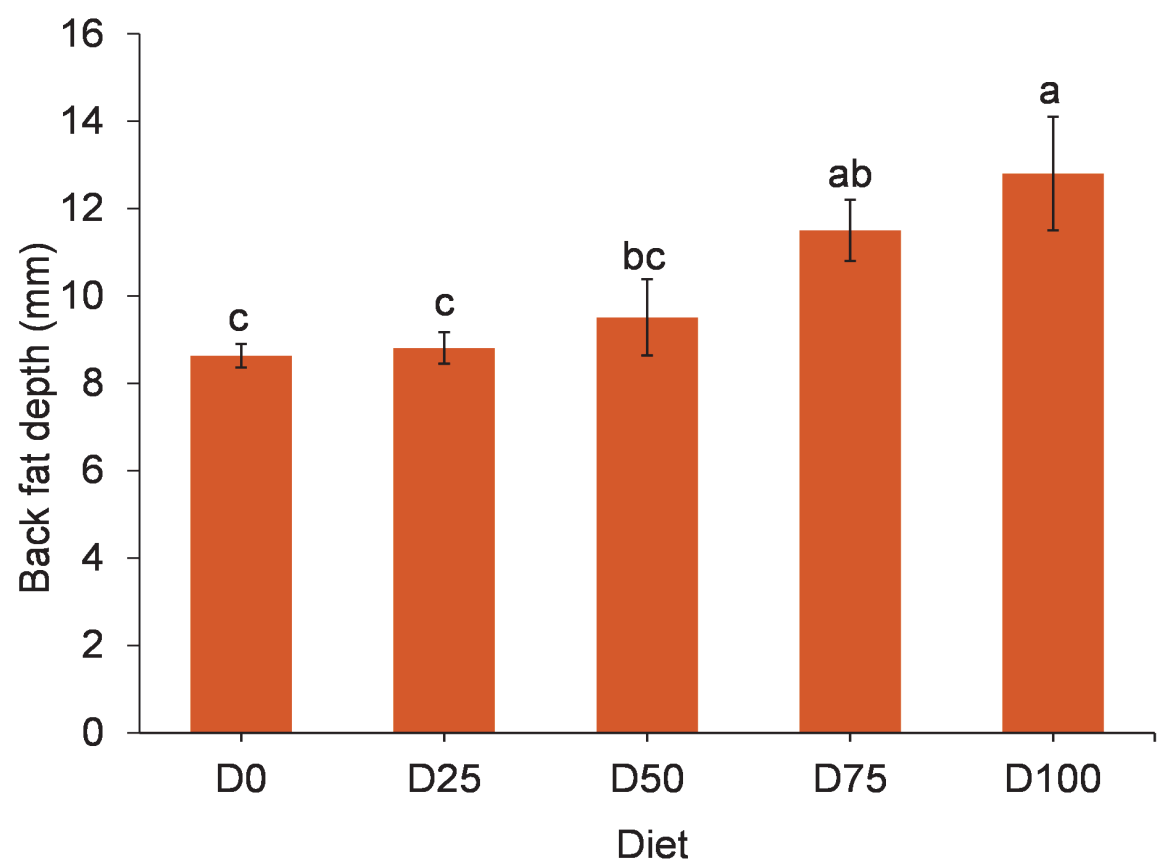

Figure 4. Mean $\left( \pm\right.$ SE) $10^{\text {th }}$ rib back fat depth in carcasses of finishing pigs fed BSFLM-based diets and a control diet. D0 $=0 \%$ (control), D25 $=25 \%$, D $50=50 \%$, D $75=75 \%$, D $100=100 \%$ levels of replacement of fishmeal with BSFLM. Means followed by different letters are significantly different (GLM, P < 0.05 ; LSD). BSFLM = black soldier fly larval meal. For each diet, $\mathrm{N}=8$.

\section{Cut-up parts and organ weight}

The weight of primal cuts (belly, ham and loin) differed significantly among diets (Figure 5). At higher rates of replacement of FM by BSFLM, primal cuts weighed more than for pigs fed lower levels of BSFLM. The head weight, tenderloin weight, rump weight and tail weight differed significantly among dietary treatments (Table 4). Spleen and testes weighed significantly more when pigs were fed higher levels of BSFLM than those fed lower levels of BSFLM, whereas, the heart, liver, kidneys, lungs and ovaries had similar weights across dietary treatments (Table 4). Diet significantly affected the amount of fat-skin in primal cuts (Figure B2). At D100, fat-skin was higher compared to D0, except in the shoulder cut for which similar values were recorded (Figure B2). The ham had the lowest FS (Figure B2). In ham, shoulder, loin and belly, the weight of muscle and bone tissues was similar among diets, except at D100 where bones from the loin weighed less compared to the rest of the dietary treatments (Table B1). 


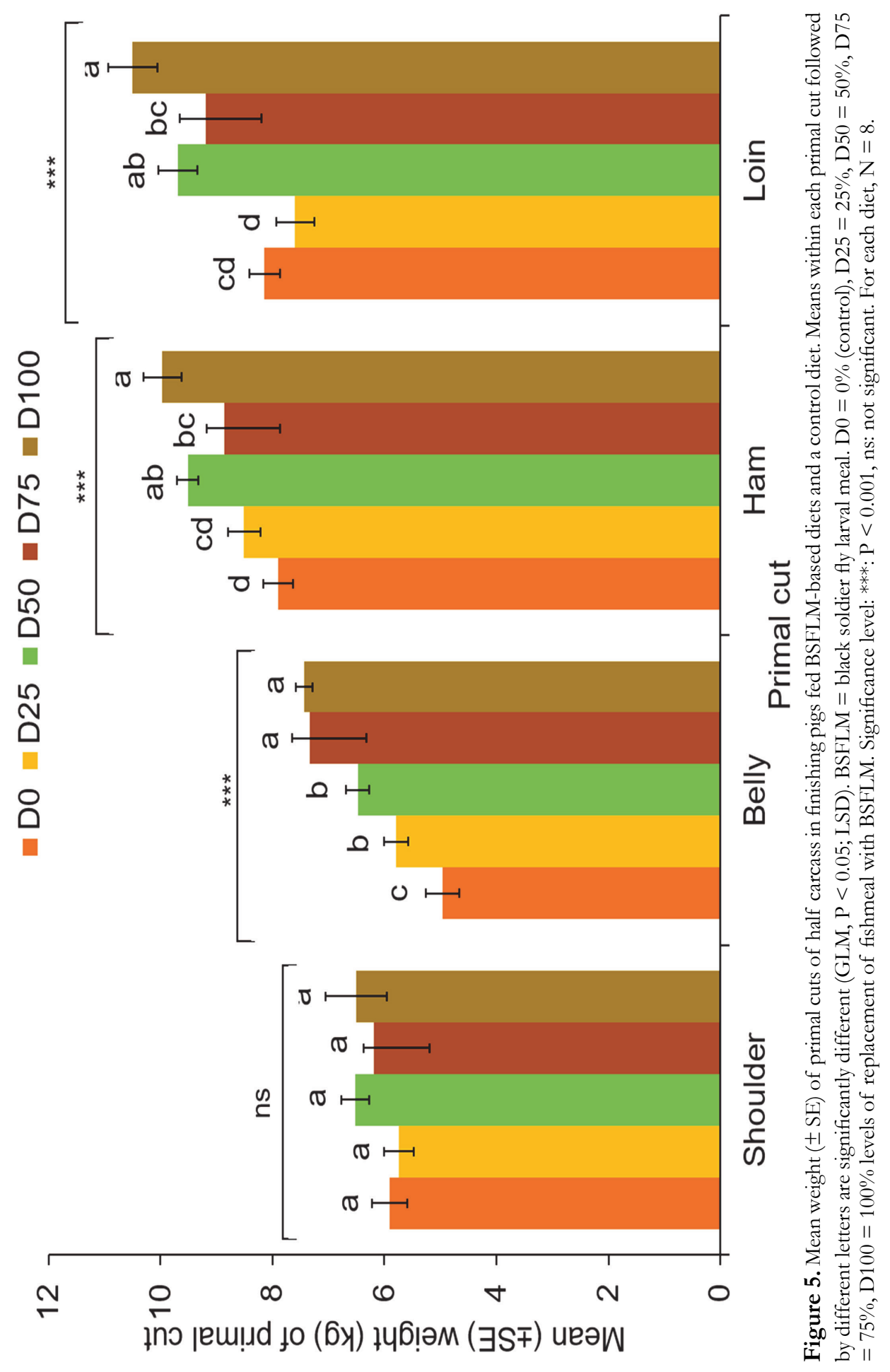




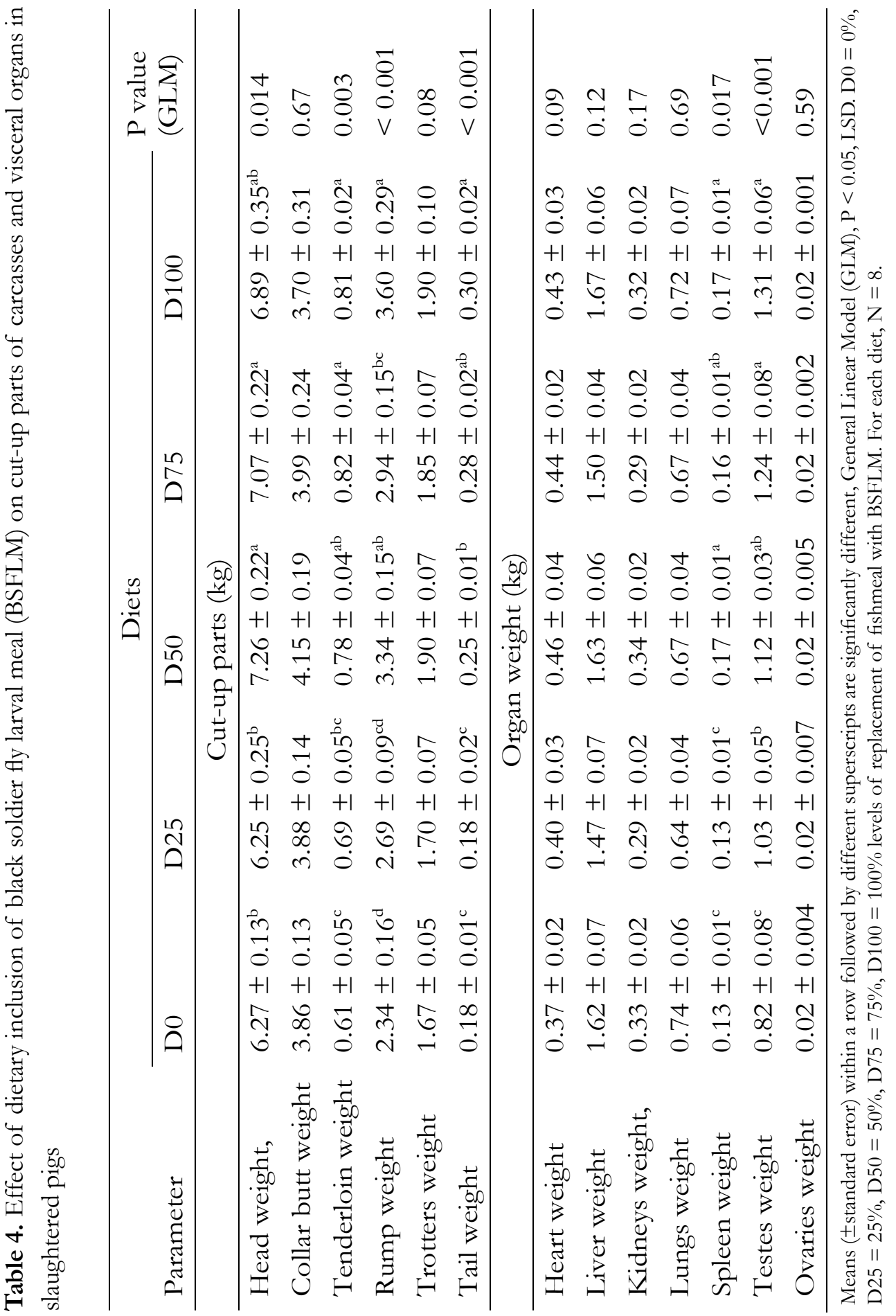




\section{Linear and live body measurements}

The PCA revealed two main groups of highly correlated sets of variables, which explained $53.98 \%$ of the total variance (PC1 $=41.54 \%$, PC2 $=12.44 \%$ ) (Figures B3 and B4). First, the variables $\mathrm{HdW}, \mathrm{BH}, \mathrm{Hlb}, \mathrm{RH}, \mathrm{BaH}, \mathrm{BW}, \mathrm{BL}, \mathrm{FC}, \mathrm{HG}, \mathrm{Flb}, \mathrm{TD}$ and NC were positively correlated. Secondly, HW and SW were positively correlated, but negative correlated with EW. Of all these variables, $\mathrm{RH}, \mathrm{BaH}, \mathrm{BW}, \mathrm{FC}$ and TD showed the highest contribution to the PC, with BW closely related with $\mathrm{BaH}, \mathrm{FC}, \mathrm{RH}$ and $\mathrm{HG}$ (Figure B3). A cluster plot of PC1 and PC2 shows an overlap between pigs fed D0 and those fed D25, D50, D75 and D100, although the degree of overlap between D0 and D100 is smallest (Figure B4).

\section{Proximate and mineral composition of pork tissues}

CP content differed significantly among diets (Figure 6). At D50, overall CP content was higher compared to other dietary treatments investigated. Tissue type significantly affected CP $(\mathrm{P}<0.001)$. The interaction effect of diet and tissue type on CP content was significant $(\mathrm{P}<0.0001)$. The average $\mathrm{CP}$ content ranged between $65 \%$ (heart tissue) and 93\% (lung tissue) (Figure 6). The heart and LM tissues from pigs fed insect-based diets (D25, D50, D75 and D100) had higher crude fat contents than those fed the control diet (D0) (Figure 6). OM content differed significantly among diets (Figure 6). Overall, tissue samples at D100 had higher OM content than the other diets investigated. Tissue type significantly affected OM (P < 0.001). Water content was only slightly affected by diet type. Overall, diet type had no significant effect $(\mathrm{P}=0.554)$ on water content of tissues, whereas there was a significant effect $(\mathrm{P}<0.0001)$ of tissue type on water content. Liver and LM tissues from pigs fed D25, D50, D75 and D100 had significantly higher $(\mathrm{P}<0.0001$ and $\mathrm{P}=0.012$, respectively) water contents than samples from pigs fed D0, whereas the water content of heart, kidney, lung and spleen tissue samples were not influenced by diet type $(\mathrm{P}=0.141, \mathrm{P}=0.592, \mathrm{P}=0.462$ and $\mathrm{P}$ $=0.289$, respectively) (Figure 6). There was no significant interaction between diet and tissue type on water content $(\mathrm{P}=0.167)$.

$\mathrm{K}, \mathrm{P}, \mathrm{S}$ and $\mathrm{Na}$ were the major macro-minerals detected in all tissues across all diets. In heart, lung, LM and spleen tissues, $\mathrm{K}$ was the most abundant macro-mineral followed by $\mathrm{P}$ and $\mathrm{S}$. Kidney tissues exhibited similar levels of $\mathrm{K}$ and $\mathrm{P}$, while in liver tissues, $\mathrm{P}$ was the most abundant mineral (Figure 7). Spleen, liver and LM tissues from pigs fed BSFLM-based diets had higher concentrations of $\mathrm{K}$ than those from pigs fed the control diet (D0), except in the heart where D25 and D100 had lower K contents (Figure 7). In all tissues, $\mathrm{Ca}$ had the lowest concentrations among the macro-minerals detected. Among micro-minerals, Fe was most abundant in all tissues, except LM in which $\mathrm{Zn}$ had the highest concentration. 
Overall, Fe and $\mathrm{Zn}$ were the most abundant micro-minerals folowed by $\mathrm{Cu}$ (Figure 8). The LM tissue from pigs fed D100 contained higher concentrations of Fe and Zn than those fed D0 (Figure 8).
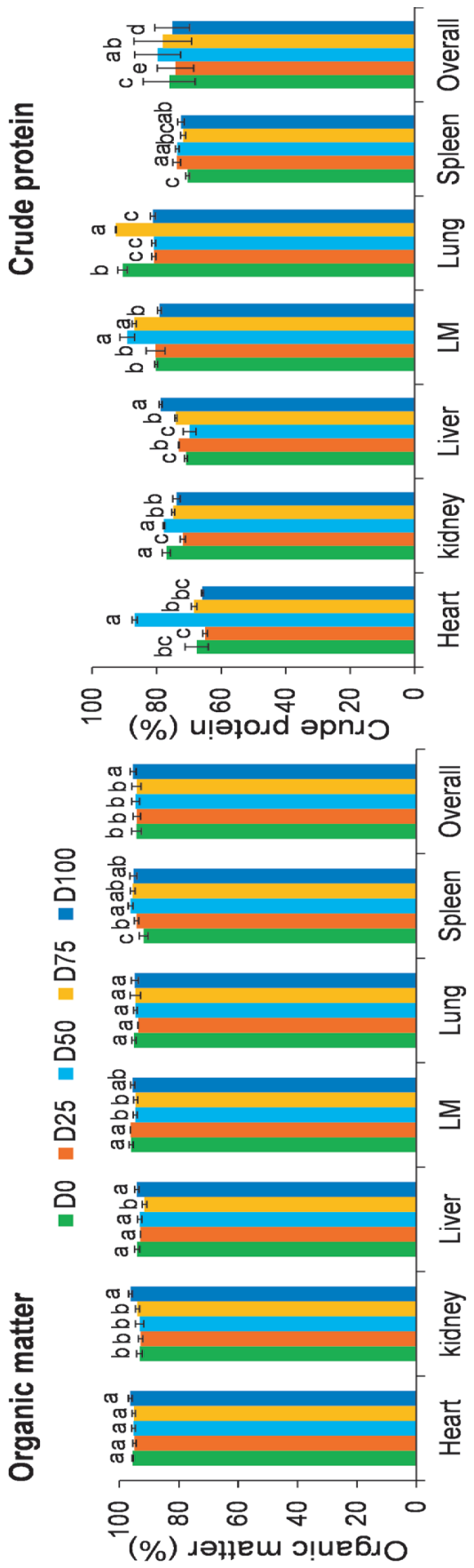

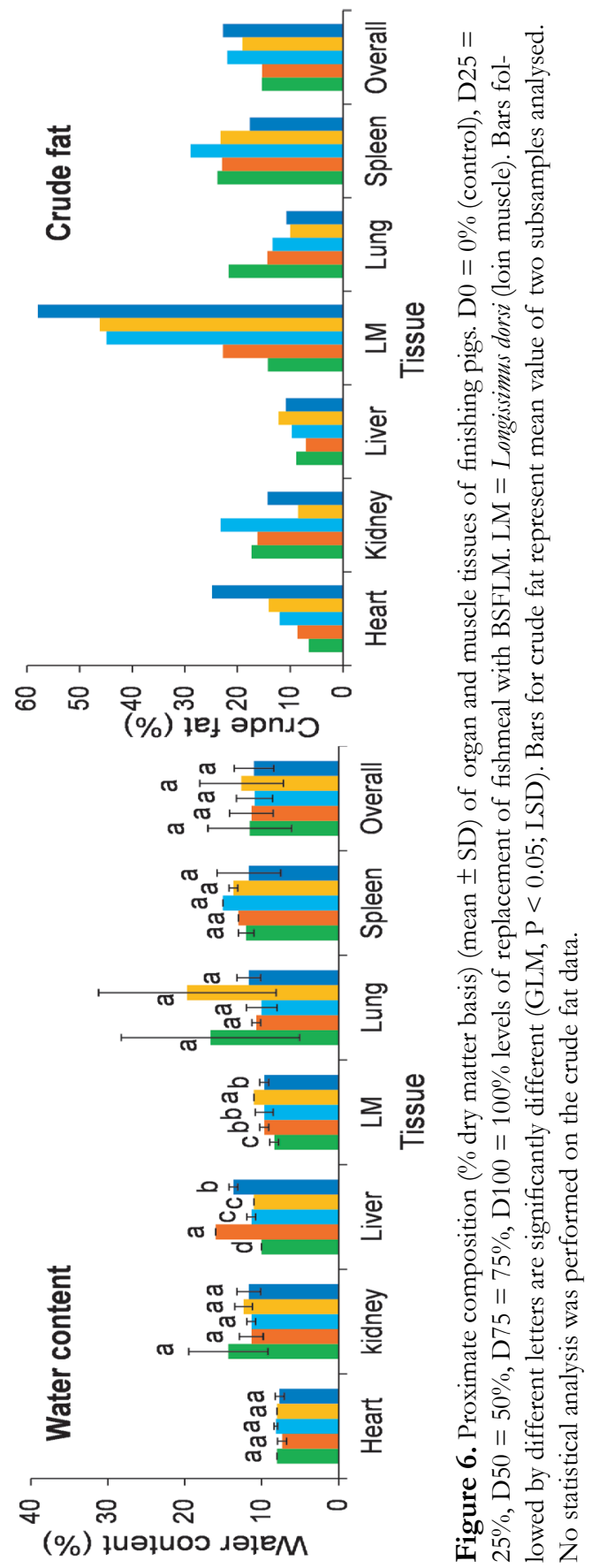



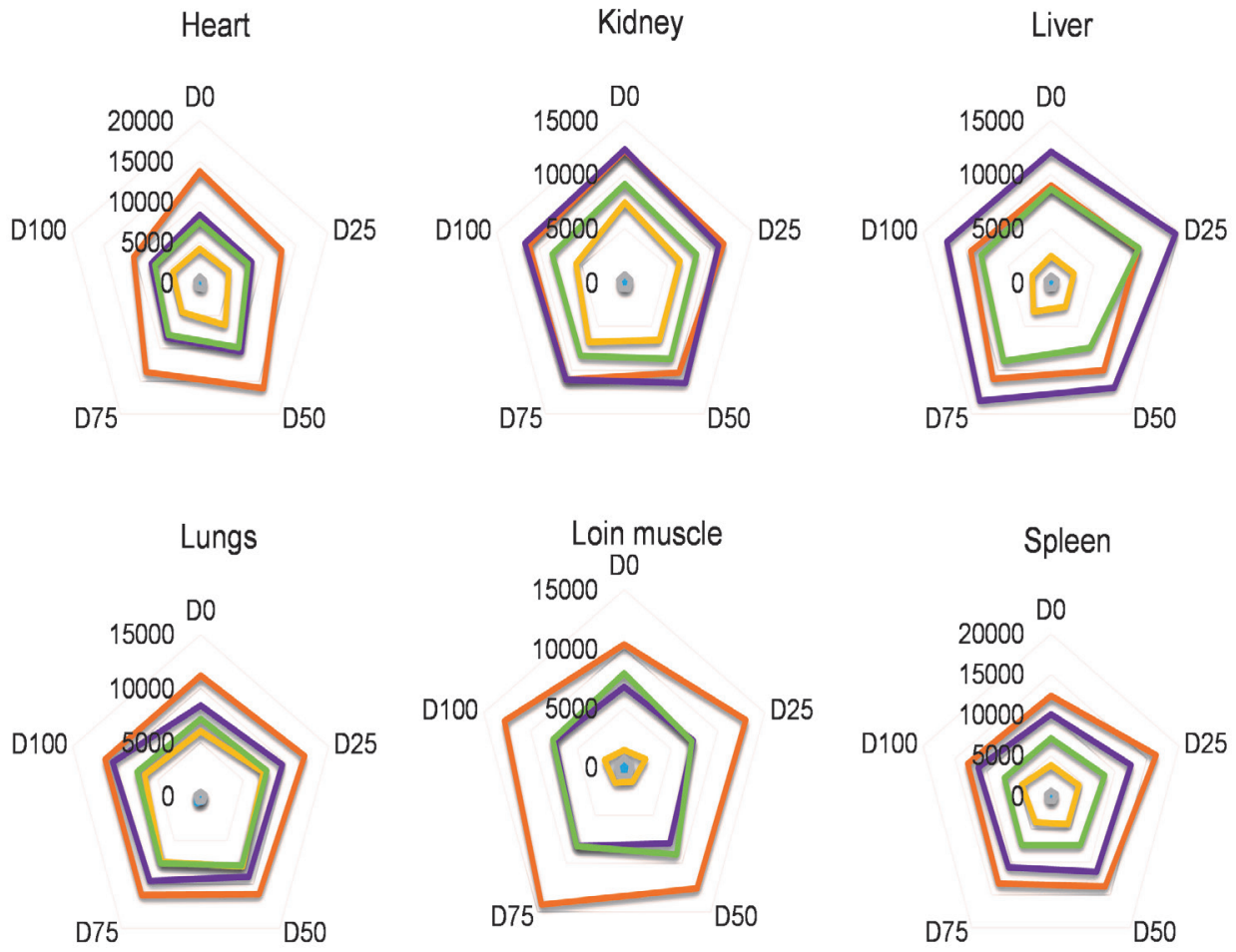

\section{$-\mathrm{Ca}-\mathrm{K}-\mathrm{Mg}-\mathrm{Na}-\mathrm{P}-\mathrm{S}$}

Figure 7. Composition $(\mathrm{mg} / \mathrm{kg})$ of macro-minerals in muscle and organ tissues of slaughtered pigs fed BSFLM-based diets and a control diet. BSFLM = black soldier fly larval meal. D0 $=0 \%$ (control), D25 $=25 \%, \mathrm{D} 50=50 \%, \mathrm{D} 75=75 \%, \mathrm{D} 100=100 \%$ levels of replacement of fishmeal with BSFLM. Ca $=$ calcium, $\mathrm{K}=$ potassium, $\mathrm{Mg}=$ magnesium, $\mathrm{Na}$ = sodium, $\mathrm{P}=$ phosphorus, $\mathrm{S}=$ sulphur. Values presented are results of single analyses. Loin muscle $=$ Longissimus dorsi. 


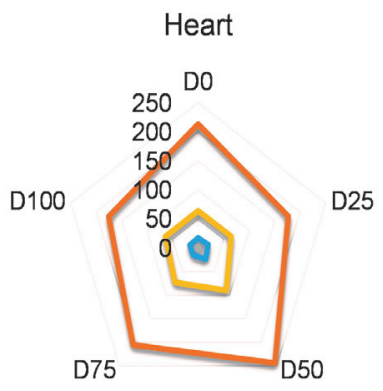

Lungs

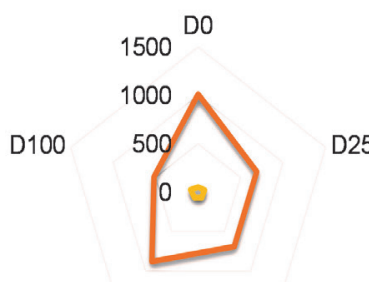

D75

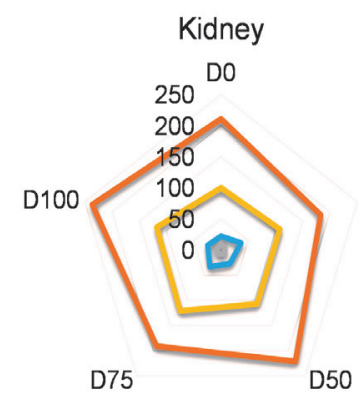

Loin muscle

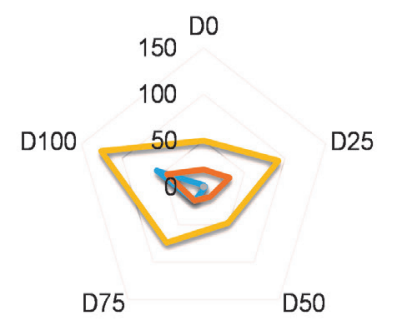

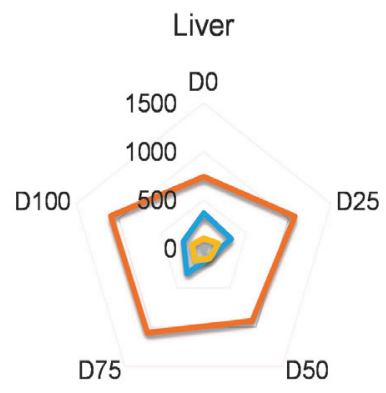

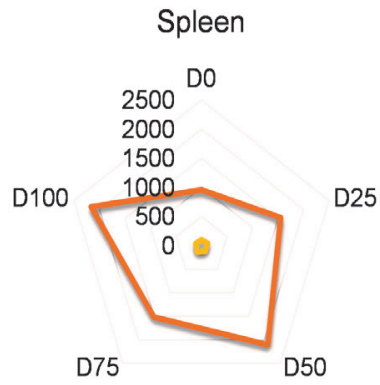$$
-\mathrm{Cu}-\mathrm{Fe}-\mathrm{Mn}-\mathrm{Zn}
$$

Figure 8. Composition ( $\mathrm{mg} / \mathrm{kg}$ ) of micro-minerals in the muscle and organ tissues of pigs fed BSFLMbased diets and a control diet. BSFLM = black soldier fly larval meal. D0 $=0 \%$ (control), D25 $=25 \%$, $\mathrm{D} 50=50 \%, \mathrm{D} 75=75 \%, \mathrm{D} 100=100 \%$ levels of replacement of fishmeal with BSFLM. Values presented are results of single analyses. $\mathrm{Cu}=$ copper, $\mathrm{Fe}=$ iron, $\mathrm{Mn}=$ manganese, zinc $(\mathrm{Zn})$. Values presented are results of single analyses. Loin muscle $=$ Longissimus dorsi.

\section{Discussion}

Black soldier fly larvae are an alternative source of animal protein and have been used in aquaculture, poultry and piglet feeds to replace either FM or soybean meal (Makkar et al., 2014). The present study used partial or complete dietary replacement of FM by BSFLM to demonstrate for the first time the value of BSFLM on growth performance, carcass traits and nutritional value of finishing pigs. Identifying BSFLM as a feed ingredient that guarantees high-quality pork products will not only help to limit dependence on the traditional feed protein sources, but will also provide an alternative protein source for farmers in times of scarcity.

Most importantly, our results have revealed important positive effects of the insect-based diets on growth performance, feed conversion and carcass traits of finishing pigs. Our study shows that higher levels (50-100\%) of replacement of FM with BSFLM, resulted in higher body weight, higher feed conversion and higher carcass yield than the FMbased control diet (D0). Pork by-products had high (65-93\%) CP. The proportion of 
fat in the primal cuts was affected by diet while the muscle and bone tissues were not (except in the loin).

Previous studies had shown that inclusion of dried BSFLM in replacement of soybean meal, FM or dried plasma, either did not affect or positively influenced piglet growth performance parameters (Biasato et al., 2019; Newton et al., 1977; Newton et al., 2005; Spranghers et al., 2018). Moreover, replacing soybean meal by BSFLM in finishing pig feed results in beneficial changes in the microbiota and metabolites of the colonic digesta and mucosal immune gene expression in finisher pigs (Yu et al., 2019). For instance, replacing soybean meal by BSFLM in diet increases the abundance of health-promoting Lactobacillus spp., decreases the abundance of pathogenic Streptococcus $s p p$. and upregulated the expression of anti-inflammatory cytokines in finishing pigs (Yu et al., 2019). Our data provide the first insight into the potential of BSFLM as a nutrient-rich feed ingredient to support maximal lean gain towards attending market weight in finishing pigs. Our data show that BSFLM results in better performance of finishing pigs than when fed with conventional feed based on FM.

The improved performance in the present study is a clear demonstration of feed tolerance in the pigs, a balanced nutrient content and high digestibility of the insect-based diets, which led to optimal feed efficiency and body weight gain. In the literature, studies under other feed regimes showed that pig growth highly depends on the nutrient content of their diet. A protein-rich diet with a balanced amino acid profile leads to high performance (Kim et al., 2005; Nam et al., 1995). Feed intake and quality play essential roles in animal growth performance (Patience et al., 2015). The improved growth performance of pigs with increasing levels of dietary replacement of FM with BSFLM in the present study can be attributed to increased palatability of the diets which resulted in sufficient consumption of digestible nutrients, particularly protein, which support rapid growth (Esonu et al., 2002). This conclusion is supported by the increased ADG, BWG, FBW and low FCR for BSFLM-based diets that we recorded.

Pig market weights vary considerably depending on the region, consumer preference or the processing method of the pig when slaughtered. For instance, in Kenya, the recommended PMW ranges between 90 and $100 \mathrm{~kg}$ live body weights according to Farmer's Choice Ltd., the main pig market provider in the country (http://farmerschoice. co.ke/). In the present study, the average fasted live body weight of pigs at slaughter ranged between 98 and $121 \mathrm{~kg}$. The weight range in our study falls within the recommended ranges for most other countries (Kim et al., 2005). It is worth noting that pigs fed diets with FM fully replaced by BSFLM had the highest fasted live body weight of $121 \mathrm{~kg}$ while pigs fed the control diet without BSFLM had the lowest live fasted body weight of $98 \mathrm{~kg}$ at slaughter. This corresponds to the higher ADG recorded for pigs at $100 \%$ BSFLM and demonstrates that the replacement of FM with BSFLM in pig feed contributes to faster weight gain, which implies that pigs attain the market weight faster 
compared to pigs raised on control diets. This is also supported by the low feed conversion ratio values recorded for BSFLM-based diets in this study.

In Kenya, Farmer's Choice recommends and accepts pigs with market sizes ranging from 40 to $120 \mathrm{~kg}$ cold carcass weight. Carcasses within this range are either consumed locally, processed into other pork products or exported whole to other countries. In the present study, the overall carcass weight of pigs ranged between 76 and $94 \mathrm{~kg}$, which is well within the recommended range for pork in Kenya. In our study, pigs fed BSFLMbased diets produced heavier carcasses than those fed the control FM-based diet. Carcasses from all dietary groups had similarly well-formed loin eye, which is one of the quality control features for commercial pork. Therefore, BSFLM is a suitable alternative to FM in commercial pig feed formulation for the Kenyan and international markets.

Daily fat intake is essential for humans because fat provides energy, enhances food palatability and absorption of vitamins (Seong et al., 2014). The fat content of pork tissues in our study was generally higher than values reported in the literature, which could be due to differences in the feeding regime, breed, body weight at slaughter, or processing method of the meat samples (De Lange et al., 2003; Okrouhla et al., 2009; Park et al., 2012; Seong et al., 2014; Skobrák \& Bodnár, 2012; Valaitiene et al., 2017; Williams, 2007). The full-fat BSFLM used in our study might have contributed to the crude fat content of the pork tissues. For example, the overall result of fat content shows that pork tissues from pigs fed diets with 50-100\% replacement of FM with BSFLM had higher crude fat levels than those from pigs fed diets with 0-25\% replacement of FM with BSFLM. Moreover, the high fat content in the LM is consistent with the significantly higher value of the subcutaneous fat of the loin cuts recorded for pigs fed D100.

Although the pigs in the control group had a significantly higher fat free index than in the D100 group, the fat free index values were generally above 50\% across all dietary groups, which is an indication of the suitability of BSFLM for finishing pig growth and carcass quality. However, it would be necessary to evaluate this parameter under restricted feeding regimes, because unlimited access to feed and high body weight as in this study might have contributed to an increased fat deposition, consequently impacting the fat free index in pigs in the D100 group (Kim et al., 2005).

As mentioned above, a good fat-free index value above $50 \%$ was recorded in the present study, indicating that BSFLM is suitable for both growth and lean quality of pigs, although the 100\% BSFLM diet showed a lower value compared to the FM-control diet. Fat content is one of the desirable attributes of meat quality used to assess suitability of meat for retail or further processing and is mainly affected by feeding strategy (Rosenvold \& Andersen, 2003). In pigs, many dietary components are absorbed from the feed in the intestines into the muscle and fat tissues, which subsequently affect pork quality (Rosenvold \& Andersen, 2003). In the present study, the belly had the highest fat 
content among the primal cuts, which is similar to that reported by Dunshea \& Souza, (2003), who indicated that the belly of pigs is one of the major parts of the body where fat deposition takes place. Furthermore, the back fat depth of pigs fed FM-based diets in the present study was significantly lower than obtained for BSFLM-based diets especially at 75 and $100 \%$ levels of replacement of FM with BSFLM. This may have resulted from the high fat content of the BSFLM-based diets used.

The content and distribution of fat in various primal cuts are important characteristics of meat for various market segments (Dunshea \& D'souza, 2003). In the present study, ham, loin and belly of pigs fed D100 had significantly more fat than in pigs fed the control diet (D0), which can be due to the high fat level of BSF (Wang \& Shelomi, 2017). Furthermore, the subcutaneous adipose tissue is the major site of fat deposition in pigs and fat deposition could result from consuming high-carbohydrate diets or pre-formed fats in diets (Dunshea \& D'souza, 2003). Live body weight is another factor that affects fat deposition in farmed animals (Dunshea \& D'souza, 2003). In the present study, pigs fed D100 had higher fat content in primal cuts and were heavier than pigs fed D0, which is in line with that of the studies described by Dunshea \& D'souza (2003).

In the present study, $\mathrm{K}$ and $\mathrm{P}$ were the most predominant macro-minerals in pork tissues, whose role in human nutrition has been well documented (Gupta \& Gupta, 2014; He \& MacGregor, 2008). Micro-minerals, which are essential for proper cell functioning were also abundant in pork tissues. The high concentration of minerals in pork tissues in the present study indicates that BSFLM can be considered as a valuable component in pig feed formulation with no adverse effects on nutritional quality of the meat.

In pig production, feed represents an important input. The efficiency with which pigs utilize dietary nutrients for growth, maintenance, lean gain and lipid accretion is crucial and has economic implications for individual and industrial production (Patience et al., 2015). Feed conversion ratio is an important measure of feed efficiency in animal production. A low FCR implies that less feed is required to produce a unit of pork weight, thereby leading to less feed required in a production system. This impacts profitability, feed demand and the competitive position of a feed ingredient against other feed sources (Patience et al., 2015). Our data show a significant reduction in FCR at higher levels of replacement of FM with BSFLM, implying that BSFLM-based feed can reduce feed cost in terms of quantity demanded in a finishing pig production. This reduction in FCR positively correlated with body weight gain in the pigs, thus further increasing the value of BSFLM in feed.

Live body weight of farmed animals is the most important growth and economic trait used by livestock producers and processors of animal products in sub-Saharan Africa to inform farm management decisions. Smallholder farmers, however, can barely afford the expensive weight scales, especially for heavier animals (Birteeb et al., 2015). Simple 
linear body measurements are therefore, necessary. In the present study, PCA identified the most important variables which were affected by diet. The correlation between live body weight and the linear body measurements indicates that these body traits can be used to predict body weight of pigs in situations where this parameter cannot be measured directly as has been reported previously for pigs and other livestock (Adeola et al., 2013; Machebe \& Ezekwe, 2010).

\section{Conclusion}

Our study clearly demonstrates that BSFLM is a suitable alternative to FM in feed of finishing pigs. This study is unique in its approach as it presents a comprehensive dataset that combines growth performance, carcass traits and nutritional quality of pigs fed BSFLM-based feeds for the first time. Replacement of FM with BSFLM at $50-100 \%$ in pig feeds clearly demonstrated a significant increase in feed conversion, growth performance (body weight gain), carcass traits and meat quality of finishing pigs. Our results, therefore, do not only provide important information for novel insect-based feeds for pig production industries but also provides information on meat nutritional quality for human consumption. Thus, these research advances hold important opportunities for addressing the increasing scarcity of protein-rich feeds, which is an impediment in the pig value chain. This will facilitate the creation of employment and open new economic opportunities for income generation among the resource-constrained groups such as women and youths.

\section{Acknowledgments}

We thank Ogetonto Wycliffe for help during data collection. We thank Isaiah E. Rachami, Nyamu Faith Wamurango, Ondiaka Shem and Joshua Wambua for providing dried black soldier fly larvae produced at International Centre of Insect Physiology and Ecology (icipe). We thank the Non-ruminant Research Institute staff for technical support. This study was financially supported by the Netherlands Organization for Scientific Research, WOTRO Science for Global Development (NWO-WOTRO) (ILIPA - W 08.250.202). Authors declare no conflicts of interest.

\section{References}

Adeola, A. C., Oseni, S. O., \& Omitogun, O. G. (2013). Morphological characterization of indigenous and crossbred pigs in rural and peri-urban areas of South Western Nigeria. Open Journal of Animal Sciences, 3, 230-235.

Al-Sagan, A. A., Khalil, S., \& Smith, M. P. (2018). The benefit of L-threonine supplementation on growth performance, carcass characteristics, intestinal morphology and litter quality of broilers. Brazilian Journal of Poultry Science, 20, 753-758. 
Alao, B. O., Falowo, A. B., Chulayo, A., \& Muchenje, V. (2017). The potential of animal by-products in food systems: production, prospects and challenges. Sustainability, 9, 1089.

Ardjosoediro, I., \& Neven, D. (2008). The Kenya capture fisheries value chain: An AMAPFSKG value chain finance case study U. United States Agency for International Development (USAID). Retrieved from: https://pdf.usaid.gov/pdf_docs/PNADN416.pdf, March 8, 2019.

Association of Official Analytical Chemists (AOAC). (1990). Official methods of analysis of the AOAC International: Association of Official Analytical Chemists.

Barałkiewicz, D., Kanecka-Hanc, A., \& Gramowska, H. (2007). ICP slurry introduction for simple and rapid determination of $\mathrm{Pb}, \mathrm{Mg}$ and $\mathrm{Ca}$ in plant roots. Central European Journal of Chemistry, 5, 1148-1157.

Barragan-Fonseca, K. B., Dicke, M., \& van Loon, J. J. A. (2017). Nutritional value of the black soldier fly (Hermetia illucens L.) and its suitability as animal feed-a review. Journal of Insects as Food and Feed, 3, 105-120.

Barragan-Fonseca, K. B., Dicke, M., \& van Loon, J. J. A. (2018). Influence of larval density and dietary nutrient concentration on performance, body protein, and fat contents of black soldier fly larvae (Hermetia illucens). Entomologia Experimentalis et Applicata, 166, 761-770.

Belghit, I., Liland, N. S., Gjesdal, P., Biancarosa, I., Menchetti, E., Li, Y. X., . . Lock, E. J. (2019). Black soldier fly larvae meal can replace fish meal in diets of sea-water phase Atlantic salmon (Salmo salar). Aquaculture, 503, 609-619.

Biasato, I., Renna, M., Gai, F., Dabbou, S., Meneguz, M., Perona, G., .. . Gasco, L. (2019). Partially defatted black soldier fly larva meal inclusion in piglet diets: effects on the growth performance, nutrient digestibility, blood profile, gut morphology and histological features. Journal of Animal Science and Biotechnology, 10, 12.

Birteeb, P. T., Tetteh, I. O., \& Salifu, A.-R. S. (2015). Growth performance and weight estimation of large white piglets weaned at different ages. Research \& Reviews: Journal of Veterinary Science and Technology, 4, 15-23.

Bruinsma, J. (2003). World Agriculture: towards 2015/2030-An FAO perspective. . London, USA: Earthscan Publications Ltd.

Burson, D. (2010). Procedures for estimating pork carcass composition. eXtension. Retrieved from: articles.extension.org/pages/27311/procedures-for-estimating-pork-carcass-\%0Acomposition, October 24, 2018.

Chia, S. Y., Tanga, C. M., Khamis, F. M., Mohamed, S. A., Salifu, D., Sevgan, S., . . Ekesi, S. (2018a). Threshold temperatures and thermal requirements of black soldier fly Hermetia illucens: Implications for mass production. PLOS ONE, 13, e0206097.

Chia, S. Y., Tanga, C. M., Osuga, I. M., Mohamed, S. A., Khamis, F. M., Salifu, D., . . Ekesi, S. (2018b). Effects of waste stream combinations from brewing industry on performance of black soldier fly, Hermetia illucens (Diptera: Stratiomyidae). PeerJ, 6, e5885.

Cho, J., \& Kim, I. (2011). Fish meal-nutritive value. Journal of Animal Physiology and Animal Nutrition, 95, 685-692.

De Lange, C., Morel, P., \& Birkett, S. (2003). Modeling chemical and physical body composition of the growing pig. Journal of Animal Science, 81, E159-E165.

Diener, S., Zurbrugg, C., \& Tockner, K. (2009). Conversion of organic material by black soldier fly larvae: establishing optimal feeding rates. Waste Management \& Research, 27, 603-610.

Dunshea, F., \& D’souza, D. (2003). Review: fat deposition and metabolism in the pig. Paper 
presented at the Australasian Pig Science Association meeting: Manipulating pig production IX, November 23, 2003, Werribee, Austrailia. www.researchgate.net/publication/280843800_a_review_fat_deposition_and_metabolism_in_the_pig.

Esonu, B., Iheukwumere, F., Emenalom, O., Uchegbu, M., \& Etuk, E. (2002). Performance, nutrient utilization and organ characteristics of broilers fed Microdesmis puberula leaf meal. Livestock Research for Rural Development, 14, Article \#52. Retrieved from: www.lrrd.org/ lrrd14/6/eson146.htm, July 11, 2019.

Fayemi, P. O., Muchenje, V., Yetim, H., \& Ahhmed, A. (2018). Targeting the pains of food insecurity and malnutrition among internally displaced persons with nutrient synergy and analgesics in organ meat. Food Research International, 104, 48-58.

Fiaboe, K., \& Nakimbugwe, D. (2017). INSFEED: integrating insects in poultry and fish feed in Kenya and Uganda-final technical report. Final technical report. IDRC project number: 107839 I. D. R. C. (IDRC). Retrieved from: http://hdl.handle.net/10625/56858 March 8, 2019.

Githigia, S. M., Okuthe, S., \& Diop, B. (2012). Pig Sector Kenya. FAO Animal Production and Health Livestock Country Reviews. No. 3 (No. 3). Rome. Food and Agriculture Organization (FAO). Retrieved from: www.fao.org/3/a-i2566e.pdf, June 10, 2019.

Gupta, U. C., \& Gupta, S. C. (2014). Sources and deficiency diseases of mineral nutrients in human health and nutrition: A review. Pedosphere, 24, 13-38.

He, F. J., \& MacGregor, G. A. (2008). Beneficial effects of potassium on human health. Physiologia Plantarum, 133, 725-735.

Irshad, A., \& Sharma, B. (2015). Abattoir by-product utilization for sustainable meat industry: a review. Journal of Animal Production Advances, 5, 681-696.

Kagira, J., Maingi, N., Kanyari, P., Githigia, S., \& Gachohi, J. (2010a). Characteristics of pig trade in low income settings in Busia District, Kenya. Tanzania Veterinary Journal, 27, 27-35.

Kagira, J. M., Kanyari, P. W., Maingi, N., Githigia, S. M., Ng'ang’a, J. C., \& Karuga, J. W. (2010b). Characteristics of the smallholder free-range pig production system in western Kenya. Tropical Animal Health and Production, 42, 865-873.

Kim, Y. S., Kim, S. W., Weaver, M. A., \& Lee, C. Y. (2005). Increasing the pig market weight: World trends, expected consequences and practical considerations. Asian-Australasian Journal of Animal Sciences, 18, 590-600.

Kolding, J., Medard, M., Mkumbo, O., \& van Zwieten, P. (2014). Status, trends and management of the Lake Victoria fisheries. In R. L. Welcomme, J. Valbo-Jorgensen, \& A. S. Halls (Eds.), Inland fisheries evolution and management. Case studies from four continents (pp. 49-62). Rome: FAO Fisheries and Aquaculture technical paper no. 579.

Lalander, C. H., Fidjeland, J., Diener, S., Eriksson, S., \& Vinneras, B. (2015). High waste-to-biomass conversion and efficient Salmonella spp. reduction using black soldier fly for waste recycling. Agronomy for Sustainable Development, 35, 261-271.

Llames, C. R., \& Fontaine, J. (1994). Determination of Amino-Acids in Feeds - Collaborative Study. Journal of Association of Official Analytical Chemists, 77, 1362-1402.

Lowell, J., Bohrer, B., Wilson, K., Overholt, M., Harsh, B., Stein, H.-H., . . Boler, D. D. (2018). Growth performance, carcass quality, fresh belly characteristics, and commercial bacon slicing yields of growing-finishing pigs fed a subtherapeutic dose of an antibiotic, a natural antimicrobial, or not fed an antibiotic or antimicrobial. Meat Science, 136, 93-103.

Machebe, N., \& Ezekwe, A. (2010). Predicting body weight of growing-finishing gilts raised in 
the tropics using linear body measurements. Asian Journal of Experimental Biological Sciences, 1, 162-165.

Makkar, H. P. S., Tran, G., Henze, V., \& Ankers, P. (2014). State-of-the-art on use of insects as animal feed. Animal Feed Science and Technology, 197, 1-33.

Mbuthia, J. M., Rewe, T. O., \& Kahi, A. K. (2015). Evaluation of pig production practices, constraints and opportunities for improvement in smallholder production systems in Kenya. Tropical Animal Health and Production, 47, 369-376.

Meneguz, M., Schiavone, A., Gai, F., Dama, A., Lussiana, C., Renna, M., \& Gasco, L. (2018). Effect of rearing substrate on growth performance, waste reduction efficiency and chemical composition of black soldier fly (Hermetia illucens) larvae. Journal of the Science of Food and Agriculture, 98, 5776-5784.

Mohammed, E., Mohammed, T., \& Mohammed, A. (2017). Optimization of an acid digestion procedure for the determination of $\mathrm{Hg}, \mathrm{As}, \mathrm{Sb}, \mathrm{Pb}$ and $\mathrm{Cd}$ in fish muscle tissue. Methods $\mathrm{X}$, 4, 513-523.

Moula, N., Scippo, M. L., Douny, C., Degand, G., Dawans, E., Cabaraux, J. F., . . Detilleux, J. (2018). Performances of local poultry breed fed black soldier fly larvae reared on horse manure. Animal Nutrition, 4, 73-78.

Muns, R., Malak-Rewlikowska, A., Gebska, M., Lokhorst, C., \& Sorensen, T. (2018). Technical reports: Precision Production: Deliverable D3. 9. EU PiG Innovation Group. Retrieved from: https://library.wur.nl/WebQuery/wurpubs/fulltext/443100, March 8, 2019.

Mutua, F., Arimi, S., Ogara, W., Dewey, C., \& Schelling, E. (2010). Farmer perceptions on indigenous pig farming in Kakamega district, Western Kenya. Nordic Journal of African Studies, 19, 43-57.

Nam, D. S., Aherne, F. X., \& Darroch, C. S. (1995). Growth performance of pigs given a choice of natural ingredient diets containing different levels of protein and amino acid(s). Animal Feed Science and Technology, 56, 265-276.

National Research Council. (1979). Nutrient requirements of swine: Eighth revised edition, 1979. Washington, DC: The National Academies Press.

Newton, G. L., Booram, C. V., Barker, R. W., \& Hale, O. M. (1977). Dried Hermetia illucens larvae meal as a supplement for swine. Journal of Animal Science, 44, 395-400.

Newton, L., Sheppard, C., Watson, D. W., Burtle, G., \& Dove, R. (2005). Using the black soldier fly, Hermetia illucens, as a value-added tool for the management of swine manure N. C. S. U. Animal and Poultry Waste Management Center, Raleigh, NC, Retrieved from: www.organicvaluerecovery.com/studies/studies_htm_files/bsf_value_added.pdf, July 11, 2019.

Njoku, C., Adeyemi, O., Sogunle, O., \& Aina, A. (2015). Growth performance, carcass yield and organ weight of growing pigs fed different levels of feed. Slovak Journal of Animal Science, 48, 16-22.

Núñez-Sánchez, N., Marín, A. L. M., Hernández, M. P., Carrion, D., Castro, G. G., \& Alba, L. M. P. (2012). Faecal near infrared spectroscopy (NIRS) as a tool to asses rabbit's feed digestibility. Livestock Science, 150, 386-390.

Okrouhla, M., Stupka, R., Čítek, J., Šprysl, M., Trnka, M., \& Kluzakova, E. (2009). Effect of lean meat proportion on the chemical composition of pork. Czech Journal of Food Sciences, 26, 464-469.

Onsongo, V. O., Osuga, I. M., Gachuiri, C. K., Wachira, A. M., Miano, D. M., Tanga, C. M., .. Fiaboe, K. K. M. (2018). Insects for income generation through animal feed: Effect of 
dietary replacement of soybean and fish meal with black soldier fly meal on broiler growth and economic performance. Journal of Economic Entomology, 111, 1966-1973.

Ouma, E., Dione, M., Lule, P., Roesel, K., \& Pezo, D. (2014). Characterization of smallholder pig production systems in Uganda: constraints and opportunities for engaging with market systems. Livestock research for rural development. Livestock Research for Rural Development, 26. Article \#56. Retrieved from: lrrd26/3/ouma26056.htm, July 11, 2019.

Park, J. C., Kim, S. C., Lee, S. D., Jang, H. C., Kim, N. K., Lee, S. H., . . Choi, B. H. (2012). Effects of dietary fat types on growth performance, pork quality, and gene expression in growing-finishing pigs. Asian-Australasian Journal of Animal Sciences, 25, 1759-1767.

Patience, J. F., Rossoni-Serão, M. C., \& Gutiérrez, N. A. (2015). A review of feed efficiency in swine: biology and application. Journal of Animal Science and Biotechnology, 6, 33.

Pezo, D. A., Ouma, E. A., \& Dione, M. M. (2014). Update on the smallholder pig value chains development in Uganda (SPVCD) project, presented at the more pork by and for the poor project inception and planning workshop, Mukono, Uganda, 27-28 May 2014. Nairobi, Kenya. International Livestock Research Institute (ILRI). Retrieved from: www.slideshare. net/ILRI/spvcd-intro, July 9, 2019.

Pica-Ciamarra, U., \& Otte, J. (2009). The 'Livestock Revolution': Rhetoric and Reality Pro-Poor Livestock Policy Initiative-A Living from Livestock-Research report. Retrieved from: www.fao.org/3/a-bp263e.pdf, July 9, 2019.

Płotka-Wasylka, J., Frankowski, M., Simeonov, V., Polkowska, Ż., \& Namieśnik, J. (2018). Determination of metals content in wine samples by inductively coupled plasma-mass spectrometry. Molecules, 23, 2886.

Powell, C. D., Chowdhury, M. K., \& Bureau, D. P. (2017). Assessing the bioavailability of L-methionine and a methionine hydroxy analogue (MHA-Ca) compared to DL-methionine in rainbow trout (Oncorbynchus mykiss). Aquaculture Research, 48, 332-346.

Rehman, K. u., Cai, M., Xiao, X., Zheng, L., Wang, H., Soomro, A. A., . . Zhang, J. (2017). Cellulose decomposition and larval biomass production from the co-digestion of dairy manure and chicken manure by mini-livestock (Hermetia illucens L.). Journal of Environmental Management, 196, 458-465.

Rosales, A., Galicia, L., Oviedo, E., Islas, C., \& Palacios-Rojas, N. (2011). Near-infrared reflectance spectroscopy (NIRS) for protein, tryptophan, and lysine evaluation in quality protein maize (QPM) breeding programs. Journal of Agricultural and Food Chemistry, 59, 1078110786.

Rosenvold, K., \& Andersen, H. J. (2003). Factors of significance for pork quality—a review. Meat Science, 64, 219-237.

Santos, É. J. d., Baika, L. M., Herrmann, A. B., Kulik, S., Sato, C. S., Santos, A. B. d., \& Curtius, A. J. (2012). Fast assessment of mineral constituents in grass by inductively coupled plasma optical emission spectrometry. Brazilian Archives of Biology and Technology, 55, 457-464.

Seong, P. N., Park, K. M., Cho, S. H., Kang, S. M., Kang, G. H., Park, B. Y., . . Ba, H. V. (2014). Characterization of edible pork by-products by means of yield and nutritional composition. Korean Journal for Food Science of Animal Resources, 34, 297-306.

Sheppard, D. C., Newton, G. L., Thompson, S. A., \& Savage, S. (1994). A value added manure management system using the black soldier fly. Bioresource Technology, 50, 275-279.

Sheridan, J., Allen, P., Ziegler, J., Marinkov, M., Suvakov, M., \& Heinz, G. (1991). Guidelines for slaughtering, meat cutting and further processing (9251029210). Rome. Food and Agriculture Organization. Retrieved from: www.fao.org/3/T0279E/T0279E00.htm 
March 8, 2019.

Skobrák, E. B., \& Bodnár, K. (2012). The main chemical composition parameters of pork. Review on Agriculture and Rural Development, 1, 534-540.

Slump, P., \& Bos, K. D. (1985). Determination of methionine in feed concentrates. Poultry Science, 64, 705-707.

Spranghers, T., Michiels, J., Vrancx, J., Ovyn, A., Eeckhout, M., De Clercq, P., \& De Smet, S. (2018). Gut antimicrobial effects and nutritional value of black soldier fly (Hermetia illucens L.) prepupae for weaned piglets. Animal Feed Science and Technology, 235, 33-42.

Sreenivasulu, V., Kumar, N. S., Dharmendra, V., Asif, M., Balaram, V., Zhengxu, H., \& Zhen, Z. (2017). Determination of boron, phosphorus, and molybdenum content in biosludge samples by microwave plasma atomic emission spectrometry (MP-AES). Applied Sciences, 7, 264.

Valaitiene, V., Stanyte, G., Klementaviciute, J., \& Jankauskas, A. (2017). Nutritional value of and element content in meat from various pig breeds. Animal Science Papers and Reports, 35, 419-428.

Van Krimpen, M., \& Hendriks, W. (2019). 13: Novel protein sources in animal nutrition: considerations and examples. In Poultry and pig nutrition: Challenges of the 21st century (pp. 35-48). Wageningen: Wageningen Academic Publishers.

Wang, Y. S., \& Shelomi, M. (2017). Review of black soldier fly (Hermetia illucens) as animal feed and human food. Foods, 6, 91.

Williams, P. (2007). Nutritional composition of red meat. Nutrition \& Dietetics, 64, S113-S119.

Windham, W. R. (1995). AOAC official method 994.12, amino acids in feeds, alternative III, acid hydrolysis method. In P. Cunniff (Ed.), Official methods of analysis of AOAC Intemational (16th ed., Vol. 1). Rockville, MD, USA: AOAC International.

Xiao, X. P., Jin, P., Zheng, L. Y., Cai, M. M., Yu, Z. N., Yu, J., \& Zhang, J. B. (2018). Effects of black soldier fly (Hermetia illucens) larvae meal protein as a fishmeal replacement on the growth and immune index of yellow catfish (Pelteobagrus fulvidraco). Aquaculture Research, 49, 1569-1577.

Yu, M., Li, Z. M., Chen, W. D., Rong, T., Wang, G., \& Ma, X. Y. (2019). Hermetia illucens larvae as a potential dietary protein source altered the microbiota and modulated mucosal immune status in the colon of finishing pigs. Journal of Animal Science and Biotechnology, 10, 50.

Zak, G., \& Pieszka, M. (2009). Improving pork quality through genetics and nutrition. Annals of Animal Science, 9, 327-339.

Zampiga, M., Laghi, L., Petracci, M., Zhu, C., Meluzzi, A., Dridi, S., \& Sirri, F. (2018). Effect of dietary arginine to lysine ratios on productive performance, meat quality, plasma and muscle metabolomics profile in fast-growing broiler chickens. Journal of Animal Science and Biotechnology, 9, 79.

Zaragoza, L. E. O. (2009). Evaluation of the accuracy of simple body measurements for live weight prediction in growing-finishing pigs. Master of Science, University of Illinois, Urbana, Illinois.

Zarantoniello, M., Bruni, L., Randazzo, B., Vargas, A., Gioacchini, G., Truzzi, C., . . Olivotto, I. (2018). Partial Dietary Inclusion of Hermetia illucens (black soldier fly) full-fat prepupae in Zebrafish feed: Biometric, histological, biochemical, and molecular implications. Zebrafish, 15, 519-532. 


\section{Chapter 9}

General Discussion 


\section{Introduction}

While the global human population is expected to approach 10 billion people by 2050 , more than $50 \%$ of the increase will take place in the developing world, particularly Africa (United Nations, 2017). This growth in the global human population together with rising incomes, urbanization and shifts in diets drive an increasing demand for protein-rich animal products such as meat, eggs, fish, and milk (Van Huis, 2013). Although a growth in the demand for these products is expected to support human health, the aquaculture and livestock industries face challenges related to the availability of feeds and feed ingredients (Ranganathan et al., 2016). As a result, researchers, policy makers and commercial producers are looking for alternative ways to meet this demand, while minimizing adverse impacts on the environment. In this regard, insects which have long been part of the natural diet of humans and animals are increasingly considered as a potential novel protein source for animal feed production (Van Krimpen \& Hendriks, 2019).

The growing interest in insects as feed ingredients can be explained by their high nutritional quality, high reproductive rate, high feed conversion efficiencies and ability to exploit a wide variety of food substrates, including organic side streams (Oonincx et al., 2015; Ortiz et al., 2016; Van Huis, 2013). While several insect species possess these features, the black soldier fly (BSF) Hermetia illucens L. (Diptera: Stratiomyidae) is considered to be the most suitable species for animal feed (Makkar et al., 2014; Van Huis et al., 2013; Veldkamp et al., 2012). As mentioned in Chapters 1 and 2 of this thesis, the $\mathrm{BSF}$ is not a pest, it is not considered to transmit diseases and the larvae can upcycle various organic side streams by converting them into high-quality biomass (Cickova et al., 2015). To exploit the potential of this insect and produce much-demanded sustainable alternative proteins, the capacity to produce the required quantities is crucial. Despite the growing interest in insects as feed, large-scale insect farming is still novel. Insect rearing at industrial scale is the most important means to produce the required quantities (Van Huis et al., 2015). Little is known about availability and suitability of substrates on which insects are reared. An understanding of these aspects is essential for the production of high-quality larvae for feed as well as scalability of the production system (Gold et al., 2018; Ortiz et al., 2016). Insects convert their feed to high-quality biomass more efficiently than livestock animals (Van Huis et al., 2013), but without the right environmental conditions, their feeding, growth and development rates are adversely affected. For example, temperatures below or above the optimum threshold will reduce insect performance and productivity (Ortiz et al., 2016). In captivity, insects are generally unable to locate the right food and maintain optimum ambient temperatures. Therefore, these conditions must be provided to ensure optimal growth and overall farm productivity. Insects are naturally eaten by fish and some livestock, and their high 
nutrient content makes them suitable for animal feed. So far, poultry, fish and to a lesser extent, pigs have been targeted in feeding trials involving insect meal, especially BSF larval meal (BSFLM) (Makkar et al., 2014). Little is known regarding the use of BSFLM on pig performance.

The main objective of this thesis was to assess the potential of BSF larvae as animal feed component and to investigate farmers' willingness to accept insect-based feed for animal production in Kenya. In the following sections, I discuss the possible implications of the results presented in the different chapters of this thesis. As indicated in Chapter 1, the establishment and sustainability of an insect for feed sector will depend on: 1) market acceptance of and demand for insect-based feed, 2) availability of suitable substrates for mass rearing insects as feed, 3) suitable environmental conditions for insect development and reproduction, 4) nutritional quality of the insects to meet nutritional requirements of the consuming animal species and, 5) the effect of insect meal on animal growth performance and resulting animal products.

\section{Willingness to pay for insect-based feeds in Kenya}

Recently, the use of insects as a sustainable alternative to the resource-intensive and increasingly unaffordable fishmeal (FM), and soybean meal in animal feed has received considerable interest due to their high nutritional value, low environmental footprint in terms of land and water requirements and greenhouse gas emission as well as their high conversion efficiencies (Ortiz et al., 2016; Van Huis, 2013; Van Huis et al., 2013). It is worth noting that the development of a new market commodity is conditional upon the acceptance and use by the target consumer (Alemu et al., 2015). Therefore, assessing the willingness to pay (WTP) is important because it provides an indication of the potential demand for a new market product prior to production.

In Chapter 3, we assessed knowledge, attitude and WTP for insect-based feeds among poultry, pig and fish farmers in Kenya. This research demonstrated that in the study areas, farmers are aware of insects as feed and consider insects as a good source of protein. Furthermore, farmers accept and are willing to pay more for insect-based feed. Therefore, the results not only indicate that there is a demand for insect-based feed, but also serve as a baseline for future investigations. The high WTP for insect-based feeds recorded among farmers in this study is in line with a report by Van Huis (2013), who stated that the inclusion of insects in feed for aquaculture and aviculture production will not be considered a problem by consumers. This willingness may be considered as a reflection of the need for suitable alternatives to the conventional protein sources for feed. This finding corresponds to the positive attitudes of the farmers with respect to insects as a good feed ingredient as well as their willingness to pay more for insect-based feed in this study. 
The acceptance of the different insect species in this study shows a similar pattern for poultry, pig and fish farmers and appears to be based upon the common knowledge on insects. For example, the BSF, which is relatively new and considered as a novel insect species for feed had the lowest percentage acceptance compared to termites, grasshoppers and crickets, which are widely known and eaten by humans. To support the implementation of insect-based feed in Kenya and elsewhere in Africa, farmer education on the different insect species for feed and their potential in terms of production and nutritional value is therefore crucial. Furthermore, the high WTP for insect-based feed raises the need for the development of training programs to build farmers' capacity to rear and market insects as a feed ingredient in Kenya. This is highly recommended because farmer participation, including both men and women, will increase local production and availability of insect ingredients and facilitate the establishment of intensive insect-based agribusiness enterprises in Kenya and beyond. Small scale insect farming through inclusive business models can strengthen local economies through income generation from increased production and sell of the insects to local livestock farmers as well as feed millers (Chapter 2).

In future intervention strategies, the incorporation of insect-based feed into aquaculture and livestock nutrition is relevant and will have a greater impact if the government, non-governmental organizations, research organizations and farmer organizations are involved in the awareness technology transfer campaign in Kenya and Africa at large. Most importantly, future intervention strategies must ensure that the demand for insect-based feed can be met, which means that consumers need to know where to obtain insect-based products. This therefore calls for raising general awareness of edible insects as feed to widen the market reach of the new insect-based feed sector.

\section{Agro-industrial by-products as substrates for rearing BSF larvae}

Brewers' spent grains (BSG) are a highly valuable by-product commonly used as feed for ruminant livestock, but have a poor feeding value for growing pigs and poultry (Waldron, 2009). Moreover, the high moisture content of BSG makes it an excellent medium for the growth of bacteria, yeast and fungi. This limits its maximum storage duration to less than a week in warm climates (Heuzé et al., 2017). Alternative uses of these substrates are therefore necessary. On the other hand, insect farming can provide an alternative protein-rich feed resource for aquaculture and non-ruminant livestock production. Artificial diets or feed meant for other livestock have successfully been used to produce BSF larvae (Nguyen et al., 2015; Sheppard et al., 2002). However, sustainab ility in insect-based feed production can only be achieved if insects are reared on 
organic side streams that are no longer fit for human food or livestock feed (Bosch et al., 2019; Veldkamp et al., 2012). Agro-industrial processes generate large quantities of by-products which can support insect production (Meneguz et al., 2018). Therefore, Chapter 4 of this thesis assessed the effect of combining BSG with brewer's yeast, and cane molasses as larval diets on the life-history parameters of the BSF.

The BSF larvae were found to successfully grow and reach the pre-pupal stage in all substrate combinations investigated (Chia et al., 2018b). Most importantly, larval survival was high across substrates and the development time of the larvae was comparable to values reported by Gligorescu et al. (2018) and shorter than values reported by Myers et al. (2008). This shows that these by-products are suitable substrates for rearing BSF larvae.

Larvae reared on substrates supplemented with brewer's yeast at $20-30{ }^{\circ} \mathrm{C}$ (Chia et al., 2018a) had significantly shorter development time and higher larval weight than those reared on un-supplemented substrates at the same temperature. This indicates that brewer's yeast had improved substrate quality such as palatability that led to increased food intake, resulting in faster growth of larvae. Larval food intake was, however, not measured in the present study and is regarded as an important topic for future investigation (Bosch et al., 2019). Furthermore, previous studies showed that nutrient imbalance and low temperatures resulted in slower development of BSF (Barragan-Fonseca et al., 2019; Gligorescu et al., 2018; Harnden \& Tomberlin, 2016; Tomberlin et al., 2009).

These findings have implications in the production of high-quality BSF larvae as an alternative to FM and soybean meal in aquaculture and livestock production. The suitability of BSG for rearing BSF larvae has been reported (Meneguz et al., 2018), but no study has so far assessed the effect of combining BSG with brewers' yeast or molasses. These results therefore demonstrate for the first time that these by-products, which are abundantly generated by the Kenyan brewery and sugar companies are valuable substrates for rearing BSF larvae. These data reveal an innovative strategy in solving important environmental and economic problems. Firstly, BSF larvae can be used in degrading brewery waste streams to reduce unpleasant smells emanating from abandoned solid wastes and composts, thereby reducing environmental pollution. Secondly, the BSF larvae convert these low-grade by-products, which are available throughout the year, accessible, and less competitive for food or feed to nutrient-rich insect larvae as an alternative protein ingredient for animal feed formulation. 


\section{Temperature and insect development and repro- duction}

Temperature is one of the most important abiotic factors that affect cold-blooded organisms, which cannot regulate their body temperature that controls the rate of biological processes. Lower and upper temperature thresholds, and the optimum temperatures have implications for developmental processes, where within a specific range, a temperature change results in an increase or decrease in the rate of development (Mirhosseini et al., 2017; Wagner et al., 1984). An understanding of temperature thresholds has important implications for establishing insect populations, whose activities occur in the context of daily and seasonal fluctuations in temperature (Best et al., 2012).

Insects are cold-blooded animals and their internal body temperature varies depending on the ambient temperature. The normal activity of an insect species occurs within a narrow zone, below or above which the temperatures may become lethal and this varies depending on the species (Dreyer \& Baumgartner, 1996; Infante, 2000; Ju et al., 2011; Ratte, 1984; Taylor, 1981; Yang et al., 1994). Although temperatures below or above the zone of normal activity may not be sufficiently extreme to kill the insect, the surviving insect fails to achieve optimum reproduction to maintain its population (Ju et al., 2011). In the case of farming insects for feed, this will greatly impact productivity. Therefore, Chapter 5 of this thesis studied BSF larvae at nine constant temperatures $\left(10-42{ }^{\circ} \mathrm{C}\right)$ and determined their growth rate and reproductive potential.

The results show that when BSF larvae were reared at $30{ }^{\circ} \mathrm{C}$, the development time was significantly shorter than obtained at lower or higher temperatures. Furthermore, the population growth rate of the $\mathrm{BSF}$ was higher at $30{ }^{\circ} \mathrm{C}$ with higher intrinsic rate of natural increase and shorter doubling time compared to the other temperatures investigated (Chia et al., 2018a). The low intrinsic rate of natural increase, higher doubling time and longer mean generation time of BSF at 20 and $25{ }^{\circ} \mathrm{C}$ might have been caused by reduced metabolic rates which led to a decrease in food intake and, hence, slowing growth and the reproductive potential of the insect (Clarke \& Fraser, 2004; Gligorescu et al., 2018). Temperature affects the rate of metabolism which controls resource uptake from the environment and energy allocation for growth, development, reproduction and excretion (Brown et al., 2004). Threshold and thermal requirements have been determined for crop insect pests to predict their activities in the field and implement control measures that match with target insect life stages (Dahi et al., 2017; Padmavathi et al., 2013; Rao et al., 1989), but little is known about threshold temperatures of BSF. Information on optimal temperature is vital for large scale, year-round production. Therefore, our findings are valuable for colony maintenance and optimization of commercial rearing procedures of BSF under variable temperature conditions. The estimated thermal thresholds could be used to predict BSF growth activity in rearing facilities 
for their effective management.

Our study provides evidence to support the silver-spoon hypothesis, which states that development under favourable conditions will lead to better performing adults under all adult conditions (Minias et al., 2015; Scharf et al., 2015; Song et al., 2018).

\section{Nutritional value of BSF larvae}

One of the reasons for the growing interest on insects as an alternative feed ingredient in animal feed is their favourable nutritional composition (Van Huis et al., 2013; Yin et al., 2017). The nutrient composition of insects varies considerably across species and is influenced by the substrates used in rearing (Meneguz et al., 2018; Spranghers et al., 2017). In Chapter 6, BSG supplemented with brewer's yeast, cane molasses or water were fed to BSF larvae. The nutritional value of edible insects can be assessed by their chemical composition, alongside their digestibility within the consuming species, and their nutrient requirements Makkar et al. (2014). The digestibility of BSF larvae and the nutritional requirements of livestock fulfilled by the larvae were not determined in this thesis, which might be interesting in future investigations. However, larvae were rich in protein and fat, with excellent amino acid and fatty acid profiles respectively, and minerals, all vital nutrients for animal growth performance. The results revealed significant effects of both the BSG and the supplements on the nutrient composition of the larvae. Larvae reared on substrates supplemented with brewer's yeast generally had higher crude protein contents than those reared on substrates supplemented with brewer's yeast plus molasses or supplemented with water. Also, larvae reared on substrates supplemented with brewer's yeast plus molasses were higher in crude fat compared to larvae reared on other substrates investigated in this study. Therefore, the nutritional composition of the BSF larvae can be enhanced through supplementation of BSG to produce protein- and fat-rich BSF larvae. For use as a feed ingredient, the protein content and the amino acid profile of the larvae are important. The crude protein content of BSF larvae ranged between 30 and 46\%, which is comparable to values reported in the literature (Lalander et al., 2019; Liland et al., 2017). The BSF larvae in this study contained the essential amino acids lysine and methionine, which are the major limiting amino acids in livestock diets (Farkhoy et al., 2012). This favours the inclusion of BSF larvae as nutritious and suitable ingredients in animal feed.

Calcium $(\mathrm{Ca})$ and phosphorus $(\mathrm{P})$ constitute the major part of the mineral content of bones such that a deficiency or an excess of one affects the proper utilization of the other. These two often appear in limited quantities in common livestock feedstuffs (Mcdowell, 2003). In this thesis, the $\mathrm{Ca} / \mathrm{P}$ ratio ranged from 0.8 to 2.3 , which largely meets the requirements of poultry, fish and pigs (Andrews et al., 1973; Reinhart \& Mahan, 1986; Sakamoto \& Yone, 1973; Tschirner \& Simon, 2015; Van Krimpen et al., 2013). 
BSF larvae were also rich in micro-minerals including iron and zinc, which complied with the required values for non-ruminants. Therefore, BSF larvae reared on the agro-industrial by-products are a suitable ingredient for farmed animals and can potentially replace minerals contained in the conventional FM in animal feeds.

The larvae of BSF contained both saturated, monounsaturated and polyunsaturated fatty acids. In animal nutrition, fats are as important as proteins and carbohydrates and play important roles in feed conversion and faster growth rate of animals (Çetingül \& Yardımc1, 2008). In Chapter 6 of this thesis, BSF larvae were predominated by saturated fatty acids including lauric acid. This is well in line with reports from other studies in the literature (Belghit et al., 2019; Ushakova et al., 2016). Lauric acid is easily absorbed and oxidized, and therefore yields energy when ingested. However, taken together with other medium chain fatty acids such myristic acid and palmitic acid, lauric acid can be hypercholesterolaemic (Dalle Zotte et al., 2018; Ulbricht \& Southgate, 1991). In a wider context, lauric acid has membrane-disruptive properties and has an antimicrobial effect in the consuming species (Dalle Zotte et al., 2018; Ulbricht \& Southgate, 1991), which can be exploited for novel molecules in the chemical and pharmaceutical industries other than the animal feed industry.

The potential of the agro-industrial by-products to improve the nutritional value of BSF larvae in this thesis confirms their suitability as substrates for rearing BSF larvae (Chapter 4), while valorizing the low-grade by-products into high-quality biomass (Chapter 6). This can particularly be valuable when the supply of these by-products exceeds demand for direct consumption by livestock since their use as substrates for rearing BSF larvae would mean saving the environment from pollution. For instance, molasses, a thick, sticky brown syrupy liquid can cause environmental pollution through aesthetic degradation if it spills. It can also cause water pollution if major spills or factory effluents drain into water bodies (M'Ndegwa, 2016).

\section{Black soldier fly larvae as feed ingredient for pigs}

FM is conventionally used as a major source of high-quality animal protein, with well-balanced amino acid profiles, digestible energy, mineral and vitamin contents in animal feeds. However, ocean fish stocks are being depleted by overfishing and increasing restrictions on unregulated fishing often result in reduced availability of FM (Dobermann et al., 2017). Overall, the scarcity and associated high prices of FM create perverse incentives to increase animal production (Delgado et al., 2003). Therefore, the use of alternative protein sources in animal feed is indispensable. Insects present such an alternative (Merino et al., 2012; Van Huis, 2013; Van Huis, 2016). While several species are being considered for animal feed, BSF is widely considered as the most promising 
fly species because its larvae can convert a wide range of organic side streams, including manure, into high-quality insect protein (Diener et al., 2009; Sheppard et al., 1994). In Chapters 7 and 8, pigs were provided with feeds, in which FM content was replaced at $25,50,75$ or $100 \%$ level of inclusion of BSFLM. The reported feed intake and weight gain in Chapter 7 showed that BSFLM was as suitable in supporting growth of weaning piglets as FM. Furthermore, red or white blood cell indices, as well as the cholesterol levels of pigs were not affected by the replacement of FM by BSFLM in pig feed, which indicates that the health of the animals was not compromised by the inclusion of BSFLM in their feeds.

In Chapter 8, the inclusion of BSFLM resulted in significant weight gain, improved feed conversion, and higher carcass yield of finishing pigs. Nonetheless, higher levels of replacement of FM with BSFLM also resulted in increased backfat depth of pigs, which consequently reduced the fat free lean index of the carcass. However, this is not specific to the BSFLM. Backfat thickness in pigs is reported to show a linear increase with increase in live body weight between 110 and $140 \mathrm{~kg}$, and a decreased percentage fat-free lean (Kim et al., 2005; Wu et al., 2017). The weight of pigs at slaughter in this study ranged from 112-121 kg for pigs reared on diets with 50-100\% levels of replacement of FM with BSFLM, which is within the reported range. Limiting back fat deposition is possible through feed restriction as opposed to unlimited access to feed by finishing pigs (Kim et al., 2005; Nieto et al., 2012; Wu et al., 2017).

While Biasato et al., (2019) reported that a dietary inclusion of up to $10 \%$ of partially defatted BSFLM could be used for weaning pigs without any adverse effects on the growth performance, blood profile, nutrient digestibility, gut morphology or histological features of the piglets, my results show that a complete replacement of FM with BSFLM is possible. Furthermore, pork by-products from pigs fed insect-based feed were rich in protein and essential minerals. This shows that BSFLM is nutritionally a valuable component in pig feed. Moreover, the Kenyan Bureau of Standards has accepted a standard for insects as animal feed, which provides legal approval for the inclusion of insect meal in animal feed in Kenya (Kenya Standard, DKS 2711:2016).

In summary, my results of the inclusion of BSFLM in pig feed are relevant at many levels. To individual farms, this presents a suitable alternative to consider when the supply of FM is limited, without adverse effects on growth or health of animals. The lower FCR, the comparable CBR and RoI estimates in this thesis have economic implications. For instance, low FCR means that less feed is required per unit kilogram of pork produced when BSFLM is included in feed. To the pork sector, higher carcass yields can be obtained when pigs are reared on BSFLM-based feed compared to FM-based feeds. The pork consumer is also assured of meat that is rich in essential nutrients. 


\section{Future perspectives}

The ability of BSF larvae to thrive on organic waste material has inspired commercial applications. Nutritionally, the BSF larvae are a valuable protein source for animal feed. Such quality, combined with the need for affordable and sustainable alternatives to the current protein sources for a global population projected to increase by two billion people in the next three decades (United Nations, 2019), present an opportunity for small and large scale BSF production (Chapter 2). However, to achieve its full potential and effectively compete with the current protein-rich FM and soybean meal, a key challenge to be addressed is the scalability of insect production (IPIFF, 2018). To meet the demand for large quantities of insect biomass, a steady source of safe food substrates will be required. While BSF larvae can exploit a wide range of food sources, accessing substrates with consistent nutritional composition will constitute a major challenge. As shown in this thesis, manipulation of rearing substrates through supplementation with nutrient-rich by-products will be a potential way to stabilize the nutritional composition of insect meal. Furthermore, the current reliance of insect rearing on organic side streams for environmental sustainability may be challenging in the future. For instance, the available organic waste streams today may soon become highly demanded and expensive as insect food as the insect sector grows. An integrated insect-livestock farming approach should be encouraged to ensure regular supply of substrates for insect rearing and competitiveness of the sector.

Consumers demand nutritious, safe and healthy animal products from animal producers. Insect producers are therefore required to produce high-quality insect products that meet nutritional needs of animals (IPIFF, 2018). Moreover, this thesis has shown that farmers in Kenya are willing to use insect-based protein as a feed component in animal production. However, little is known about consumer acceptance of animal products derived from insect-based feed. In the future, therefore, research should investigate the effect of BSF-based feed on sensory attributes of animal products in Kenya. In BSF colonies, studies have shown that feeding adult BSF increases the oviposition period (Bertinetti et al., 2019; Chia et al., 2018b). However, little is known about the number of egg batches an adult BSF can lay in its life time. It is worth investigating if multiple egg laying is possible and whether feeding adult BSF can impact its reproductive capacity. Globally, over $70 \%$ of the poor live in rural areas. An improvement in their livelihoods would substantially contribute towards global food security.

Therefore, policies and interventions seeking to improve rural livelihoods should involve rural farmer groups through inclusive business models, in the production of BSF larvae for their own use and to supply local markets (Chapter 2). Strengthening insect farming initiatives through cooperatives and farmer associations can help famers better organize themselves, and allow more access to opportunities to become less dependent 
on imported feed ingredients, while at same time gaining income from production and sell of insects as a feed component. Insect farming can substantially contribute to meeting the increasing demand for animal sourced food through bioconversion of organic waste streams and closing of nutrient cycles (Van Krimpen \& Hendriks, 2019).

\section{Conclusion}

The results presented in this thesis reveal that livestock farmers in the areas in Kenya studied are aware of insects as feed and are willing to pay for insect-based feed for poultry, pig and fish production. The survival and development of BSF larvae reared on agro-industrial by-products, composed of BSG, brewer's yeast and cane molasses, demonstrated the suitability of these substrates in the mass production of BSF larvae as an alternative protein component in animal feed. The optimum temperature for population growth and reproduction of $\mathrm{BSF}$ is $30^{\circ} \mathrm{C}$. The high nutrient content of BSF larvae reared on the different agro-industrial by-products further confirmed the suitability of these substrates for their mass production. Improved growth performance and carcass yield of pigs as recorded in this thesis support the use of low-cost, insect-based feed as an alternative to the conventional protein sources to achieve better livestock feeding. Generally, the findings from this study favour the production of BSF larvae as an alternative protein source in livestock feed and in the sustainable management of organic waste streams.

\section{Acknowledgements}

I thank Marcel Dicke and Joop J.A. van Loon for helpful comments on an earlier version of this chapter.

\section{References}

Alemu, M. H., Olsen, S. B., Vedel, S. E., Pambo, K. O., \& Owino, V. O. (2015). Consumer acceptance and willingness to pay for edible insects as food in Kenya: the case of white winged termites (IFRO Working Paper 2015/10). Copenhagen. IFRO Working Papers-Department of Food and Resource Economics (IFRO)-University of Copenhagen. Retrieved from: http://okonomi. foi. dk/workingpapers/WPpdf/WP2015/IFRO_WP_2015_10. pdf, August 10, 2019.

Andrews, J. W., Murai, T., \& Campbell, C. (1973). Effects of dietary calcium and phosphorus on growth, food conversion, bone ash and hematocrit levels of catfish. The Journal of Nutrition, 103, 766-771.

Barragan-Fonseca, K. B., Gort, G., Dicke, M., \& van Loon, J. J. A. (2019). Effects of dietary protein and carbohydrate on life-history traits and body protein and fat contents of the black soldier fly Hermetia illucens. Physiological Entomology, 44, 148-159.

Belghit, I., Liland, N. S., Gjesdal, P., Biancarosa, I., Menchetti, E., Li, Y. X., . . Lock, E. J. (2019). 
Black soldier fly larvae meal can replace fish meal in diets of sea-water phase Atlantic salmon (Salmo salar). Aquaculture, 503, 609-619.

Bertinetti, C., Samayoa, A. C., \& Hwang, S. Y. (2019). Effects of feeding adults of Hermetia illucens (Diptera: Stratiomyidae) on longevity, oviposition, and egg hatchability: Insights into optimizing egg production. Journal of Insect Science, 19, 19.

Best, A. R., Lewis, Z., Hurst, G. D. D., \& Lize, A. (2012). Thermal environment during and outside courtship jointly determine female remating rate in Drosophila melanogaster. Animal Behaviour, 83, 1483-1490.

Biasato, I., Renna, M., Gai, F., Dabbou, S., Meneguz, M., Perona, G., .. Gasco, L. (2019). Partially defatted black soldier fly larva meal inclusion in piglet diets: effects on the growth performance, nutrient digestibility, blood profile, gut morphology and histological features. Journal of Animal Science and Biotechnology, 10,12.

Bosch, G., van Zanten, H. H. E., Zamprogna, A., Veenenbos, M., Meijer, N. P., van der FelsKlerx, H. J., \& van Loon, J. J. A. (2019). Conversion of organic resources by black soldier fly larvae: Legislation, efficiency and environmental impact. Journal of Cleaner Production, 222, 355-363.

Brown, J. H., Gillooly, J. F., Allen, A. P., Savage, V. M., \& West, G. B. (2004). Toward a metabolic theory of ecology. Ecology, 85, 1771-1789.

Çetingül, İ. S., \& Yardimci, M. (2008). The importance of fats in farm animal nutrition. Kocatepe Veterinary Journal, 1, 77-81.

Chia, S. Y., Tanga, C. M., Khamis, F. M., Mohamed, S. A., Salifu, D., Sevgan, S., . . Ekesi, S. (2018a). Threshold temperatures and thermal requirements of black soldier fly Hermetia illucens: Implications for mass production. PLOS ONE, 13, e0206097.

Chia, S. Y., Tanga, C. M., Osuga, I. M., Mohamed, S. A., Khamis, F. M., Salifu, D., . . Ekesi, S. (2018b). Effects of waste stream combinations from brewing industry on performance of black soldier fly, Hermetia illucens (Diptera: Stratiomyidae). PeerJ, 6, e5885.

Cickova, H., Newton, G. L., Lacy, R. C., \& Kozanek, M. (2015). The use of fly larvae for organic waste treatment. Waste Management, 35, 68-80.

Clarke, A., \& Fraser, K. (2004). Why does metabolism scale with temperature? Functional Ecology, 18, 243-251.

Dahi, H., Ibrahim, W., Mansour, A., \& Imam, A. (2017). Threshold temperatures and thermal requirements for the development of the olive leaf moth; Palpita unionalis Hbn. (Lepidoptera: Pyralidae). Egyptian Academic Journal of Biological Sciences. A, Entomology, 10, 81-88.

Dalle Zotte, A., Cullere, M., Martins, C., Alves, S. P., Freire, J. P. B., Falcao, E. C. L., \& Bessa, R. J. B. (2018). Incorporation of black soldier fly (Hermetia illucens L.) larvae fat or extruded linseed in diets of growing rabbits and their effects on meat quality traits including detailed fatty acid composition. Meat Science, 146, 50-58.

Delgado, C. L., Wada, N., Rosegrant, M. W., Siet, M., \& Ahmed, M. (2003). Fish to 2020: Supply and demand in changing global markets (Vol. 62): International Food Policy Research Institute and WorldFish Centre.

Diener, S., Zurbrugg, C., \& Tockner, K. (2009). Conversion of organic material by black soldier fly larvae: establishing optimal feeding rates. Waste Management \& Research, 27, 603-610.

Dobermann, D., Swift, J. A., \& Field, L. M. (2017). Opportunities and hurdles of edible insects for food and feed. Nutrition Bulletin, 42, 293-308.

Dreyer, H., \& Baumgartner, J. (1996). Temperature influence on cohort parameters and demographic characteristics of the two cowpea coreids Clavigralla tomentosicollis and $C$ shadabi. Entomologia Experimentalis et Applicata, 78, 201-213. 
Farkhoy, M., Modirsanei, M., Ghavidel, O., Sadegh, M., \& Jafarnejad, S. (2012). Evaluation of protein concentration and limiting amino acids including lysine and met + cys in prestarter diet on performance of broilers. Veterinary Medicine International, 2012, 394189.

Gligorescu, A., Toft, S., Hauggaard-Nielsen, H., Axelsen, J. A., \& Nielsen, S. A. (2018). Development, metabolism and nutrient composition of black soldier fly larvae (Hermetia illucens; Diptera: Stratiomyidae) in relation to temperature and diet. Journal of Insects as Food and Feed, 4, 123-133.

Gold, M., Tomberlin, J. K., Diener, S., Zurbrugg, C., \& Mathys, A. (2018). Decomposition of biowaste macronutrients, microbes, and chemicals in black soldier fly larval treatment: A review. Waste Management, 82, 302-318.

Harnden, L. M., \& Tomberlin, J. K. (2016). Effects of temperature and diet on black soldier fly, Hermetia illucens (L.) (Diptera: Stratiomyidae), development. Forensic Science International, 266, 109-116.

Heuzé, V., Tran, G., Sauvant, D., \& Lebas, F. (2017). Brewer's grains. Feedipedia, a programme by INRA, CIRAD, AFZ and FAO. Retrieved from: www.feedipedia.org/node/74, August $25,2019$.

Infante, F. (2000). Development and population growth rates of Prorops nasuta (Hym., Bethylidae) at constant temperatures. Journal of Applied Entomology, 124, 343-348.

IPIFF. (2018). The European Insect Sector Today: Challenges, opportunities and regulatory landscape. IPIFF vision paper on the future of the insect sector towards 2030. Brussels. International Platform of Insects for Food and Feed (IPIFF). Retrieved from: http:/ / ipiff.org/ipiff-vision-paper/, August 25, 2019.

Ju, R. T., Wang, F., \& Li, B. (2011). Effects of temperature on the development and population growth of the sycamore lace bug, Corythucha ciliata. Journal of Insect Science, 11. Doi. org/10.1673/031.011.0116.

Kim, Y. S., Kim, S. W., Weaver, M. A., \& Lee, C. Y. (2005). Increasing the pig market weight: World trends, expected consequences and practical considerations. Asian-Australasian Journal of Animal Sciences, 18, 590-600.

Lalander, C., Diener, S., Zurbrugg, C., \& Vinneras, B. (2019). Effects of feedstock on larval development and process efficiency in waste treatment with black soldier fly (Hermetia illucens). Journal of Cleaner Production, 208, 211-219.

Liland, N. S., Biancarosa, I., Araujo, P., Biemans, D., Bruckner, C. G., Waagbo, R., . . Lock, E. J. (2017). Modulation of nutrient composition of black soldier fly (Hermetia illucens) larvae by feeding seaweed-enriched media. PLOS ONE, 12, e0183188.

M'Ndegwa, J. (2016). Diversifying the use of molasses towards improving the infrastructure and economy of Kenya Civil and Environmental Research, 8, 37-42.

Makkar, H. P. S., Tran, G., Henze, V., \& Ankers, P. (2014). State-of-the-art on use of insects as animal feed. Animal Feed Science and Technology, 197, 1-33.

Mcdowell, L. (2003). Calcium and phosphorus. In L. Mcdowell (Ed.), Minerals in animal and human nutrition (pp. 33-100). Amsterdam: Elsevier.

Meneguz, M., Schiavone, A., Gai, F., Dama, A., Lussiana, C., Renna, M., \& Gasco, L. (2018). Effect of rearing substrate on growth performance, waste reduction efficiency and chemical composition of black soldier fly (Hermetia illucens) larvae. Journal of the Science of Food and Agriculture, 98, 5776-5784.

Merino, G., Barange, M., Blanchard, J. L., Harle, J., Holmes, R., Allen, I., . . Holt, J. (2012). 
Can marine fisheries and aquaculture meet fish demand from a growing human population in a changing climate? Global Environmental Change, 22, 795-806.

Minias, P., Włodarczyk, R., Surmacki, A., \& Iciek, T. (2015). Silver spoon effects on plumage quality in a passerine bird. Royal Society Open Science, 2, 140459.

Mirhosseini, M. A., Fathipour, Y., \& Reddy, G. V. (2017). Arthropod development's response to temperature: a review and new software for modeling. Annals of the Entomological Society of America, 110, 507-520.

Myers, H. M., Tomberlin, J. K., Lambert, B. D., \& Kattes, D. (2008). Development of black soldier fly (Diptera: Stratiomyidae) larvae fed dairy manure. Environmental Entomology, 37, 11-15.

Nguyen, T. T., Tomberlin, J. K., \& Vanlaerhoven, S. (2015). Ability of black soldier fly (Diptera: Stratiomyidae) larvae to recycle food waste. Environmental Entomology, 44, 406-410.

Nieto, R., Lara, L., Barea, R., Garcia-Valverde, R., Aguinaga, M. A., Conde-Aguilera, J. A., \& Aguilera, J. F. (2012). Response analysis of the Iberian pig growing from birth to $150 \mathrm{~kg}$ body weight to changes in protein and energy supply. Journal of Animal Science, 90, 38093820 .

Oonincx, D., Van Huis, A., \& Van Loon, J. J. A. (2015). Nutrient utilisation by black soldier flies fed with chicken, pig, or cow manure. Journal of Insects as Food and Feed, 1, 131-139.

Ortiz, J. C., Ruiz, A. T., Morales-Ramos, J., Thomas, M., Rojas, M., Tomberlin, J., . . Jullien, R. (2016). Insect mass production technologies. In A. Dossey, J. Morales-Ramos, \& M. Rojas (Eds.), Insects as sustainable food ingredients (pp. 153-201): Academic Press.

Padmavathi, C., Katti, G., Sailaja, V., Padmakumari, A. P., Jhansilakshmi, V., Prabhakar, M., \& Prasad, Y. G. (2013). Temperature thresholds and thermal requirements for the development of the rice leaf folder, Cnaphalocrocis medinalis. Journal of Insect Science, 13, 96.

Ranganathan, J., Vennard, D., Waite, R., Dumas, P., Lipinski, B., \& Searchinger, T. (2016). Shifting diets for a sustainable food future. Creating a sustainable food future, installment eleven. Washington, DC. World Resources Institute. Retrieved from: www.wri.org/publication/ shifting-diets, August 29, 2019.

Rao, G. V. R., Wightman, J. A., \& Rao, D. V. R. (1989). Threshold temperatures and thermal requirements for the development of Spodoptera litura (Lepidoptera, Noctuidae). Environmental Entomology, 18, 548-551.

Ratte, H. T. (1984). Temperature and insect development. In K. H. Hoffmann (Ed.), Environmental physiology and biochemistry of insects (pp. 33-66). Berlin, Heidelberg: Springer.

Reinhart, G., \& Mahan, D. (1986). Effect of various calcium: phosphorus ratios at low and high dietary phosphorus for starter, grower and finishing swine. Journal of Animal Science, 63, 457-466.

Sakamoto, S., \& Yone, Y. (1973). Effect of dietary calcium/phosphorus ratio upon growth, feed efficiency and blood serum Ca and P level in red-sea bream. Bulletin of the Japanese Society of Scientific Fisheries, 39, 343-348.

Scharf, I., Braf, H., Ifrach, N., Rosenstein, S., \& Subach, A. (2015). The effects of temperature and diet during development, adulthood, and mating on reproduction in the red flour beetle. PLOS ONE, 10, e0136924.

Sheppard, D. C., Newton, G. L., Thompson, S. A., \& Savage, S. (1994). A value added manure management system using the black soldier fly. Bioresource Technology, 50, 275-279.

Sheppard, D. C., Tomberlin, J. K., Joyce, J. A., Kiser, B. C., \& Sumner, S. M. (2002). 
Rearing methods for the black soldier fly (Diptera: Stratiomyidae). Journal of Medical Entomology, 39, 695-698.

Song, Z., Zou, Y., Hu, C., Ye, Y., Wang, C., Qing, B., . . Ding, C. (2018). Silver spoon effects of hatching order in an asynchronous hatching bird. Behavioral Ecology, 30, 509-517.

Spranghers, T., Ottoboni, M., Klootwijk, C., Ovyn, A., Deboosere, S., De Meulenaer, B., ... De Smet, S. (2017). Nutritional composition of black soldier fly (Hermetia illucens) prepupae reared on different organic waste substrates. Journal of the Science of Food and Agriculture, 97, 2594-2600.

Taylor, F. (1981). Ecology and evolution of physiological time in insects. American Naturalist, 117, $1-23$.

Tomberlin, J. K., Adler, P. H., \& Myers, H. M. (2009). Development of the black soldier fly (Diptera: Stratiomyidae) in relation to temperature. Environmental Entomology, 38, 930-934.

Tschirner, M., \& Simon, A. (2015). Influence of different growing substrates and processing on the nutrient composition of black soldier fly larvae destined for animal feed. Journal of Insects as Food and Feed, 1, 249-259.

Ulbricht, T., \& Southgate, D. (1991). Coronary heart disease: seven dietary factors. The Lancet, 338, 985-992.

United Nations. (2017). World population prospects: key findings and advance tables. The 2017 revision (Working Paper No. ESA/P/WP/248). New York. U. Nations. Retrieved from: https://population.un.org/wpp/Publications/Files/WPP2017_KeyFindings.pdf.

United Nations, Department of Economic and Social affairs-Population Division. (2019). World Population Prospects 2019: Highlights (ST/ESA/SER.A/423). New York. United Nations. Retrieved from: https://population.un.org/wpp/Publications/Files/WPP2019_ Highlights.pdf, September 3, 2019.

Ushakova, N., Brodskii, E., Kovalenko, A., Bastrakov, A., Kozlova, A., \& Pavlov, D. (2016). Characteristics of lipid fractions of larvae of the black soldier fly Hermetia illucens. Doklady Biochemistry and Biophysics, 468, 209-212.

Van Huis, A. (2013). Potential of insects as food and feed in assuring food security. Annual Review of Entomology, 58, 563-583.

Van Huis, A. (2016). Edible insects are the future? Proceedings of the Nutrition Society, 75, 294-305.

Van Huis, A., Dicke, M., \& van Loon, J. J. A. (2015). Insects to feed the world. Journal of Insects as Food and Feed, 1, 3-5.

Van Huis, A., Van Itterbeeck, J., Klunder, H., Mertens, E., Halloran, A., Muir, G., \& Vantomme, P. (2013). Edible insects: future prospects for food and feed security (No. 171). Rome: Food and Agriculture Organization.

Van Krimpen, M., \& Hendriks, W. (2019). 13: Novel protein sources in animal nutrition: considerations and examples. In Poultry and pig nutrition: Challenges of the 21 st century (pp. 35-48). Wageningen: Wageningen Academic Publishers.

Van Krimpen, M., Van Diepen, J. T. M., Van Wikselaar, P., Bikker, P., \& Jongbloed, A. W. (2013). Effects of available phosphorus $(\mathrm{aP})$, calcium/aP ratio, and growth rate on $\mathrm{P}$ deposition, $\mathrm{P}$ digestibility, performance and leg quality in broilers (1570-8616). Wageningen. W. U. L. Research. Retrieved from: http://library.wur.nl/WebQuery/wurpubs/fulltext/284889, August 27, 2019.

Veldkamp, T., Van Duinkerken, G., van Huis, A., Lakemond, C., Ottevanger, E., Bosch, G., \& Van Boekel, T. (2012). Insects as a sustainable feed ingredient in pig and poultry diets: 
a feasibility study; Report 638. Wageningen. Wageningen UR Livestock Research. Retrieved from: http://library.wur.nl/WebQuery/wurpubs/fulltext/234247, September 2, 2019.

Wagner, T. L., Wu, H. I., Sharpe, P. J. H., Schoolfield, R. M., \& Coulson, R. N. (1984). Modeling insect development rates - a literature-review and application of a biophysical model. $A n$ nals of the Entomological Society of America, 77, 208-225.

Waldron, K. W. (2009). Handbook of waste management and co-product recovery in food processing (K. W. Waldron Ed.): Elsevier.

Wu, F., Vierck, K., DeRouchey, J., O’Quinn, T., Tokach, M., Goodband, R., . . W Woodworth, J. (2017). 122 Heavy weight market pigs: Status of knowledge and future needs assessment. Journal of Animal Science, 95, 57-58.

Yang, P. J., Carey, J. R., \& Dowell, R. V. (1994). Temperature influences on the development and demography of Bactrocera dorsalis (Diptera, Tephritidae) in China. Environmental Entomology, 23, 971-974.

Yin, W., Liu, J., Liu, H., \& Lv, B. (2017). Nutritional value, food ingredients, chemical and species composition of edible insects in China. In H. Mikkola (Ed.), Future Foods (pp. 27-53). 


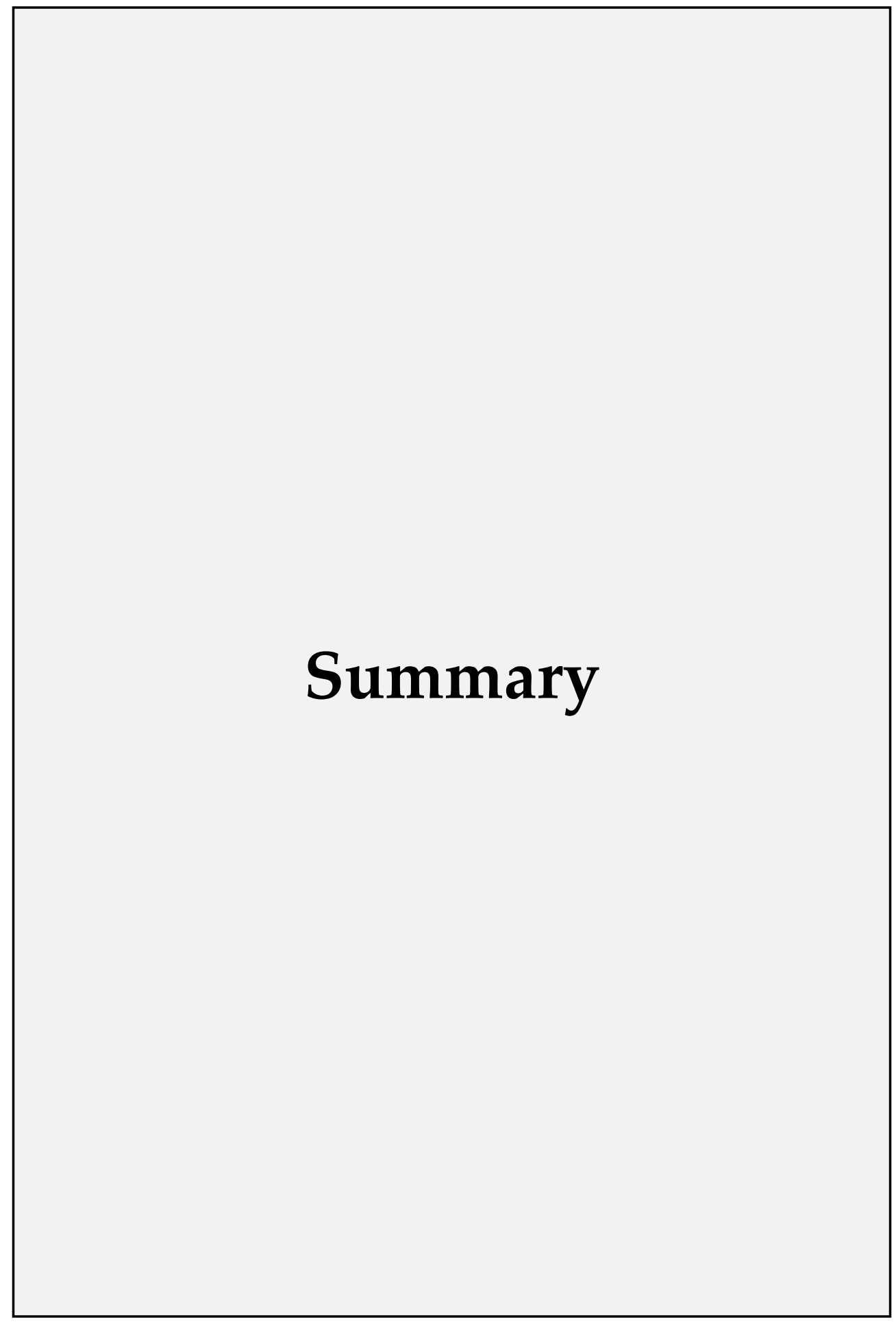


Current trends predict a global population increase to about 10 billion people by 2050 , forcing an increased food or feed production, which exerts pressure on the environment for resources. With the increasing human population, increased urbanization and income rise, there is an increased demand for animal-based foods such as beef, dairy, pork, chicken, eggs and fish. Efficient animal production requires adequate feeding to produce high-quality animal products. Aquaculture and livestock industries face challenges related to the availability of sustainable and affordable feed ingredients. Fishmeal (FM) and soybean meal are the major protein sources in animal feed, which are increasingly becoming scarce and unaffordable, thereby increasing the total cost of production. High costs of production adversely affect growth of production and livelihood of smallholder producers, particularly in developing countries. Currently, interest in using insects as an alternative nutrient source is growing and the need to establish an insect sector has become important, but for insect-based feed to make a substantial contribution in substituting the conventional protein-rich FM and soybean meal, large quantities of insect biomass are required, which makes insect mass rearing an inevitable step. Knowledge on sources of substrates for rearing insects, suitability of insect meal as feed ingredient, as well as acceptance and demand by end users is therefore important for a sustainable insect-based feed sector. The study described in this thesis focused on the potential of black soldier fly (BSF) larvae as a feed ingredient and farmers' willingness to pay (WTP) for insect-based feed in Kenya.

Chapter 2 presents an overview of the current literature on the potential of insects as an alternative animal feed ingredient and the role insect farming can play in inclusive business models for smallholder farmers, with a focus on the BSF. Insects are highly nutritious, with protein contents comparable to FM and soybean meal. The BSF is the most suitable insect species reared for animal feed because it is not considered as a pest or vector of diseases and can its larvae exploit a wide range of food substrates, including organic side streams such as manure. The larvae can upgrade low value organic side streams to a high-quality feed ingredient. Moreover, insect farming fits well into the concept of a circular economy and has great prospects for animal feed and waste management, with valuable consequences for many societal aspects, which align with various Sustainable Development Goals, including reduction of poverty, hunger and food waste.

In Chapter 3, farmers' knowledge of and attitude towards insects as feed, and their WTP for insect-based feed were assessed using a contingent valuation method. We found that poultry and fish farmers are aware that insects can be used as a feed ingredient. Famers have a positive attitude that insects are a nutritious feed ingredient for animals. Furthermore, farmers are willing to pay for insect-based feed. In addition, factors such as age of farmer, gender, education level, marital status, distance to feed trader, awareness of insects as feed, attitude towards insects as feed, acceptance of insect species, 
availability of agricultural inputs, training, and market information affect farmers' W'TP for insect-based feed. These findings imply that there is a potential demand for insect-based feed in Kenya and suggest that the implementation of extension programmmes to educate famers on the nutritional value of insects as well as provide market information may improve farmers attitude towards insects, create more awareness and enhance W'TP for insect-based feed. Our findings also highlight the need for increased training programmes towards capacity building of local insect producers in order to increase local production and availability of insects for the animal feed value chain, which is currently recognized by the Kenyan government.

Availability and accessibility of suitable substrates is key to a successful insect mass rearing operation. In Chapter 4, we explored the potential of rearing BSF larvae on a combination of agro-industrial by-products composed of brewers' spent grains (BSG) and brewer's yeast from beer brewing, and molasses from cane sugar production. Immature and adult life history parameters including: larval development, survival, adult emergence, adult longevity and fecundity of the BSF were assessed. Our results show that BSF larvae successfully developed to pre-pupae in all substrate combinations, with $86-99 \%$ larval survival. When provided with water or a sugar solution upon emergence, adult BSF lived 2-3 times longer than adults BSF that were not fed. Unfed female BSF died without ovipositing, whereas the water- or sugar- female BSF successfully oviposited. These findings imply that the BSG are a suitable substrate for rearing BSF larvae. Supplementing BSG with brewer's yeast or a combination of brewer's yeast and molasses supports larval growth and, therefore, is a valuable strategy to manage brewer's yeast and cane molasses. These findings are valuable in the production of BSF larvae as feed as well as in the management of organic waste streams through bioconversion of substrates. The results also provide insight into the management of adult BSF colonies to achieve optimal performance.

The time taken for most insects to complete a specified growth stage is largely dependent on temperature and food. In Chapter 5, BSF larvae were reared on BSG supplemented with brewer's yeast or un-supplemented at nine constant temperatures. Our results show that supplementing BSG with brewer's yeast resulted in higher weight of BSF larvae compared to the un-supplemented substrates. Furthermore, the population growth rate of $\mathrm{BSF}$ was most favourable at $30{ }^{\circ} \mathrm{C}$ with a higher intrinsic rate of natural increase and shorter doubling time compared to the other temperatures evaluated. These findings are valuable for the optimization of rearing conditions of the BSF under various environmental conditions and the prediction of population dynamics.

The BSF larvae convert organic material into high-quality insect biomass that can be used as a feed ingredient. The nutrient composition of the larvae may vary depending on the substrates on which the larvae are reared. In Chapter 6, we therefore assessed the nutritional quality of BSF larvae reared on agro-industrial by-products composed 
of BSG, brewer's yeast and molasses (Chapter 4) for animal feed. Our results show that larvae reared on all the substrates investigated were rich in protein, with a balanced amino acid profile, fats, predominated by saturated fatty acids, as well as macro- and micro-minerals. Furthermore, supplementing BSG with brewer's yeast resulted in higher crude protein content of the BSF larvae than obtained on substrates without brewer's yeast. The BSF larvae contained 30-46\% crude protein, which is comparable to values recorded for BSF larvae reared on other substrates such as fruit and vegetable wastes in other studies. These findings imply that BSF larvae reared on these agro-industrial by-products are nutritionally suitable for animal feed.

FM is the major source of protein in animal feed, but its rapidly reducing availability leads to increased prices. Alternative sources of protein are therefore needed for animal feed production. The BSF larvae are a novel protein source widely used in aquaculture and poultry feeds, but little is known about the effect of substituting FM with black soldier fly larval meal (BSFLM) on growing and finishing pigs. In Chapters 7 and $\mathbf{8}$, the potential of a partial or complete replacement of FM by BSFLM on growth and economic performance, carcass yield and nutritional quality of pigs was investigated. Pigs were fed different diet types: control (no BSFLM: 0\%), 25, 50, 75 and 100\% replacement of FM by BSFLM for the grower and finisher phases of the pigs. Our results show that the replacement of FM by BSFLM did not affect feed intake, daily weight gain, red or white blood cell counts as wells as serum lipid indices of pigs in the grower phase (Chapter 7). Moreover, the inclusion of BSFLM in feed for growing pigs did not affect the value of return on investment (RoI) estimated, but the cost benefit ratio showed a value greater than 1.0, which means that BSFLM can be considered as an ingredient in commercial production of pig feed.

In the finishing phase (Chapter 8), the inclusion of BSFLM greatly improved feed conversion and daily weight gain of the pigs. Replacing FM with 50-100\% levels of inclusion of BSFLM in feed led to higher carcass weights than at lower levels of BSFLM. Furthermore, pork tissues were rich in crude protein and minerals across all diet types tested. BSFLM proves to be a suitable ingredient in finishing pig feed and can completely replace FM with beneficial consequences for growth, carcass and nutritional quality of edible pork by-products. These findings are valuable for the production of insect-based feed for pigs. In Chapter 9, the key findings of this research and the implications for BSF production in Kenya are addressed and recommendations for future investigations are provided.

In conclusion, the results of the research described in this thesis show that farmers are aware that insects can be used as a feed component and are willing to pay for insect-based feed in Kenya. The combination of agro-industrial by-products, composed of BSG, brewer's yeast and molasses is suitable for rearing BSF larvae. Moreover, the addition of brewer's yeast to BSG leads to higher protein content of the BSF larvae. 
Furthermore, the inclusion of BSFLM in pig feed improves pig growth and carcass quality. Farmer sensitization on the nutritional value of the different insect species, especially the BSF is necessary to increase awareness and enhance WTP for insect-based feed among farmers. Organoleptic studies are recommended on pork derived from pigs raised on insect-based feed to investigate consumers' perceptions with regards to sensory characteristics of the meat. The findings presented in this thesis are relevant to animal feed producers seeking to include insect meal in their feed formulae, to smallholder BSF farmers and to livestock producers. Additionally, these findings are valuable to non-governmental organizations, policy makers and intergovernmental bodies seeking to implement policies to improve livelihoods of smallholder farmers, and enhance access to alternative sources of high-quality protein ingredients for animal feeds. 


\section{Appendix A}

\section{Nutritional composition of black soldier fly larvae feeding on agro-indus- trial by-products}

Shaphan Y. Chia, Chrysantus M. Tanga, Isaac M. Osuga, Xavier Cheseto, Sunday Ekesi, Joop J. A. van Loon and Marcel Dicke

Submitted 


\section{Analysis of amino acids}

Column conditions: The chromatographic separation was achieved on the Agilent 1260 Infinity Binary Liquid Chromatograph system (Agilent Technologies, Inc., Santa Clara, CA, USA) fitted with a ZORBAX SB-C18, $4.6 \times 250 \mathrm{~mm}, 3.5 \mu \mathrm{m}$ column with a heater turned at $40{ }^{\circ} \mathrm{C}$ and an auto sampler tray maintained at room temperature. As the mobile phases, LC grade water (A) and LC grade methanol (B) each containing $0.1 \%$ formic acid were used. The flow rate is maintained at $0.5 \mathrm{ml} / \mathrm{min}$ and the gradient is programmed as shown in the following Table A1. Free amino acids were identified using a Mass Selective Detector Agilent 6120 quadrupole LC/MS operating on ESI-positive mode at a mass range of $\mathrm{m} / \mathrm{z} 70-600$ and $70 \mathrm{eV}$ cone voltage.

Table A1. Flow rate of liquid chromatography

\begin{tabular}{|l|l|l|}
\hline Time (minutes) & $\% \mathrm{~A}$ & $\% \mathrm{~B}$ \\
\hline 0 & 90 & 10 \\
\hline 8 & 90 & 10 \\
\hline 14 & 0 & 100 \\
\hline 19 & 0 & 100 \\
\hline 21 & 90 & 10 \\
\hline 25 & 90 & 10 \\
\hline
\end{tabular}

Table A2. Calibration equations for external quantification of amino acids in black soldier fly larvae reared on substrates composed of agro-industrial by-products

\begin{tabular}{|l|c|c|c|}
\hline Amino Acid & \multicolumn{1}{|c|}{ Equation (y) } & $\mathrm{R}^{2}$ & $\begin{array}{c}\text { Calibration curve range } \\
\text { (microgram) }\end{array}$ \\
\hline Alanine & $3 \mathrm{E}+07 \ln (\mathrm{x})+1 \mathrm{E}+08$ & 0.9946 & 0.0223 to 0.4455 \\
\hline Arginine & $7 \mathrm{E}+07 \ln (\mathrm{x})+2 \mathrm{E}+08$ & 0.9507 & 0.0436 to 0.8710 \\
\hline Aspartic Acid & $7 \mathrm{E}+06 \ln (\mathrm{x})+3 \mathrm{E}+07$ & 0.9915 & 0.0333 to 0.6655 \\
\hline Cystine & $9 \mathrm{E}+06 \ln (\mathrm{x})+4 \mathrm{E}+07$ & 0.9965 & 0.0300 to 0.6008 \\
\hline Glutamic Acid & $1 \mathrm{E}+07 \ln (\mathrm{x})+5 \mathrm{E}+07$ & 0.994 & 0.0368 to 1.1033 \\
\hline Glycine & $2 \mathrm{E}+07 \ln (\mathrm{x})+1 \mathrm{E}+08$ & 0.9894 & 0.0188 to 0.5630 \\
\hline Histidine & $4 \mathrm{E}+07 \ln (\mathrm{x})+1 \mathrm{E}+08$ & 0.9898 & 0.0388 to 1.9400 \\
\hline Isoleucine & $3 \mathrm{E}+08 \ln (\mathrm{x})+9 \mathrm{E}+08$ & 0.9129 & 0.0328 to 1.6400 \\
\hline Leucine & $6 \mathrm{E}+07 \ln (\mathrm{x})+2 \mathrm{E}+08$ & 0.9472 & 0.0328 to 1.6400 \\
\hline Lysine & $8 \mathrm{E}+07 \ln (\mathrm{x})+2 \mathrm{E}+08$ & 0.9894 & 0.0366 to 1.8275 \\
\hline Methionine & $2 \mathrm{E}+08 \ln (\mathrm{x})+5 \mathrm{E}+08$ & 0.9405 & 0.0376 to 1.8650 \\
\hline Phenylalanine & $3 \mathrm{E}+08 \ln (\mathrm{x})+8 \mathrm{E}+08$ & 0.9025 & 0.0413 to 1.6520 \\
\hline Proline & $6 \mathrm{E}+07 \ln (\mathrm{x})+2 \mathrm{E}+08$ & 0.9917 & 0.0863 to 1.4388 \\
\hline Serine & $1 \mathrm{E}+07 \ln (\mathrm{x})+5 \mathrm{E}+07$ & 0.994 & 0.0263 to 0.5255 \\
\hline Threonine & $1 \mathrm{E}+07 \ln (\mathrm{x})+6 \mathrm{E}+07$ & 0.9956 & 0.0298 to 1.4888 \\
\hline Tyrosine & $2 \mathrm{E}+08 \ln (\mathrm{x})+4 \mathrm{E}+08$ & 0.9675 & 0.1359 to 2.2650 \\
\hline Valine & $1 \mathrm{E}+08 \ln (\mathrm{x})+4 \mathrm{E}+08$ & 0.9676 & 0.0293 to 1.4650 \\
\hline
\end{tabular}


Table A3. Amino acid concentration ( $\mathrm{mg} / \mathrm{g}$ dry matter) of black soldier fly larvae reared on substrates composed of agro-industrial by-products

\begin{tabular}{|c|c|c|c|c|c|c|c|c|c|c|c|c|}
\hline \multirow[t]{3}{*}{ Amino acid } & \multicolumn{12}{|c|}{ Treatment } \\
\hline & \multicolumn{3}{|c|}{ B } & \multicolumn{3}{|c|}{ MB } & \multicolumn{3}{|c|}{$\mathrm{MC}$} & \multicolumn{3}{|c|}{ SB } \\
\hline & W & $\bar{Y}$ & YM & W & $\mathrm{Y}$ & YM & W & $\mathrm{Y}$ & YM & W & $\mathrm{Y}$ & YM \\
\hline \multicolumn{13}{|c|}{ Essential amino acids } \\
\hline \multicolumn{13}{|l|}{ subsample 1} \\
\hline Lysine & 6.6 & 7.2 & 5.15 & 7.6 & 5.9 & 4.88 & 9.5 & 6.09 & 5.491 & 6.67 & 5.86 & 7.4 \\
\hline Histidine & 6.6 & 6.75 & 4.84 & 5.96 & 6.97 & 4.60 & 7.03 & 7.05 & 4.88 & 5.52 & 3.4 & 5.75 \\
\hline Arginine & 5.9 & 6.43 & 4.333 & 4.23 & 5.3 & 3.11 & 4.99 & 5.77 & 3.9 & 4.28 & 3.48 & 3.97 \\
\hline Methionine & 3.140 & 3.025 & 3.052 & 2.867 & 3.194 & 2.75 & 3.31 & 3.241 & 2.846 & 2.947 & 3.155 & 3.32 \\
\hline Phenylalanine & 3.24 & 3.15 & 2.985 & 2.774 & 3.11 & 2.66 & 4.4 & 3.11 & 2.74 & 2.681 & 3.150 & 3.62 \\
\hline Isoleucine & 2.221 & 2.17 & 2.12 & 2.28 & 2.22 & 2.02 & 3.00 & 2.278 & 2.048 & 1.925 & 2.376 & 2.605 \\
\hline Leucine & 2.95 & 2.86 & 2.570 & 3.04 & 2.70 & 2.62 & 4.86 & 2.969 & 2.56 & 1.94 & 3.13 & 3.8 \\
\hline Threonine & 0.097 & 0.096 & 0.098 & 0.092 & 0.103 & 0.087 & 0.113 & 0.107 & 0.092 & 0.092 & 0.100 & 0.102 \\
\hline Valine & 1.240 & 1.21 & 1.12 & 1.32 & 1.21 & 1.06 & 2.01 & 1.236 & 1.144 & 1.128 & 1.244 & 1.6 \\
\hline \multicolumn{13}{|l|}{ subsample 2} \\
\hline Lysine & 5.4 & 8.75 & 4.90 & 5.6 & 7.4 & 5.30 & 8.1 & 6.91 & 5.400 & 5.93 & 6.19 & 5.72 \\
\hline Histidine & 6.24 & 7.41 & 5.49 & 5.61 & 7.24 & 5.38 & 6.7 & 7.84 & 5.57 & 5.66 & 6.0 & 4.89 \\
\hline Arginine & 4 & 7.3 & 4.356 & 3.67 & 6.68 & 3.98 & 4.51 & 6.27 & 4.33 & 4.16 & 4.10 & 3.43 \\
\hline Methionine & 3.064 & 3.060 & 2.956 & 2.817 & 3.163 & 2.90 & 3.07 & 3.158 & 2.915 & 2.890 & 3.071 & 3 \\
\hline Phenylalanine & 3.04 & 3.71 & 2.914 & 2.735 & 2.99 & 3.22 & 3.74 & 3.46 & 2.96 & 2.763 & 3.200 & 2.91 \\
\hline Isoleucine & 2.132 & 2.37 & 2.02 & 1.98 & 2.37 & 1.92 & 2.56 & 2.357 & 2.134 & 1.957 & 2.319 & 2.167 \\
\hline Leucine & 2.66 & 2.58 & 2.493 & 2.42 & 3.26 & 2.93 & 4.04 & 3.051 & 2.75 & 1.77 & 2.86 & 2.7 \\
\hline Threonine & .099 & 0.100 & 0.094 & 0.090 & 0.102 & 0.088 & 0.098 & 0.109 & 0.102 & 0.088 & 0.100 & 0.092 \\
\hline Valine & 1.158 & 1.5 & 1.0 & 1.09 & 1.38 & 1.2 & 1.59 & 1.311 & 1.131 & 1.137 & 1.326 & 1.2 \\
\hline \multicolumn{13}{|c|}{ Non-essential amino acids } \\
\hline \multicolumn{13}{|l|}{ subsample 1} \\
\hline Tyrosine & 5.520 & 5.61 & 5.255 & 5.60 & 5.81 & 5.01 & 4.9 & 6.03 & 5.213 & 5.41 & 5.12 & 6.29 \\
\hline Alanine & 1.478 & 1.39 & 1.392 & 1.352 & 1.476 & 1.253 & 1.539 & 1.517 & 1.33 & 1.341 & 1.435 & 1.57 \\
\hline Aspartic acid & 0.725 & 0.72 & 0.682 & 0.636 & 0.73 & 0.603 & 0.94 & 0.79 & 0.63 & 0.595 & 0.627 & 0.8 \\
\hline Cystine & 0.472 & 0.470 & 0.421 & 0.418 & 0.473 & 0.397 & 0.42 & 0.498 & 0.433 & 0.421 & 0.450 & 0.453 \\
\hline Glutamic acid & 0.254 & 0.239 & 0.246 & 0.240 & 0.258 & 0.226 & 0.255 & 0.265 & 0.228 & 0.237 & 0.264 & 0.265 \\
\hline Glycine & 1.748 & 1.70 & 1.16 & 1.59 & 1.14 & 1.247 & 1.575 & 1.87 & 1.22 & 1.314 & 1.11 & 1.51 \\
\hline Proline & 2.679 & 2.65 & 2.631 & 2.49 & 2.49 & 2.55 & 3.47 & 2.564 & 2.67 & 2.084 & 2.099 & 2.56 \\
\hline Serine & 0.664 & 0.67 & 0.542 & 0.519 & 0.65 & 0.479 & 0.581 & 0.783 & 0.58 & 0.495 & 0.371 & 0.535 \\
\hline \multicolumn{13}{|l|}{ subsample 2} \\
\hline Tyrosine & 5.608 & 5.90 & 5.347 & 5.10 & 6.06 & 5.45 & 6.0 & 6.24 & 5.293 & 5.29 & 5.73 & 5.47 \\
\hline Alanine & 1.437 & 1.50 & 1.316 & 1.309 & 1.528 & 1.307 & 1.497 & 1.526 & 1.53 & 1.348 & 1.478 & 1.33 \\
\hline Aspartic acid & 0.668 & 0.92 & 0.639 & 0.622 & 0.90 & 0.573 & 0.77 & 0.782 & 0.79 & 0.675 & 0.669 & 0.61 \\
\hline Cystine & 0.447 & 0.410 & 0.438 & 0.410 & 0.464 & 0.406 & 0.430 & 0.505 & 0.431 & 0.431 & 0.457 & 0.437 \\
\hline Glutamic acid & 0.243 & 0.251 & 0.237 & 0.229 & 0.256 & 0.230 & 0.245 & 0.263 & 0.241 & 0.232 & 0.264 & 0.237 \\
\hline Glycine & 1.673 & 1.93 & 0.99 & 1.30 & 1.72 & 1.168 & 1.596 & 1.62 & 1.63 & 1.322 & 1.32 & 1.17 \\
\hline Proline & 2.648 & 3.09 & 2.666 & 2.04 & 2.73 & 3.04 & 2.91 & 2.642 & 2.91 & 2.036 & 2.091 & 2.01 \\
\hline Serine & 0.568 & 0.78 & 0.561 & 0.472 & 0.78 & 0.541 & 0.517 & 0.714 & 0.70 & 0.489 & 0.438 & 0.449 \\
\hline
\end{tabular}

$\mathrm{B}=$ spent barley; $\mathrm{MB}=$ spent malted barley; $\mathrm{MC}=$ spent malted corn; $\mathrm{SB}=$ spent sorghum and barley;

$\mathrm{W}=$ water; $\mathrm{Y}=$ residual brewer's yeast; $\mathrm{YM}=$ brewer's yeast plus molasses. Values presented in the table are duplicate concentrations (subsamples 1 and 2) of amino acids for black soldier fly larvae for each substrate. 


\section{Appendix B}

Black soldier fly larval meal in feed enhances growth performance, carcass yield and meat quality of finishing pigs

Shaphan Y. Chia, Chrysantus M. Tanga, Isaac M. Osuga, Alphonce O. Alaru, David M. Mwangi, Macdonald Githinji, Sunday Ekesi, Joop J.A. van Loon and Marcel Dicke 


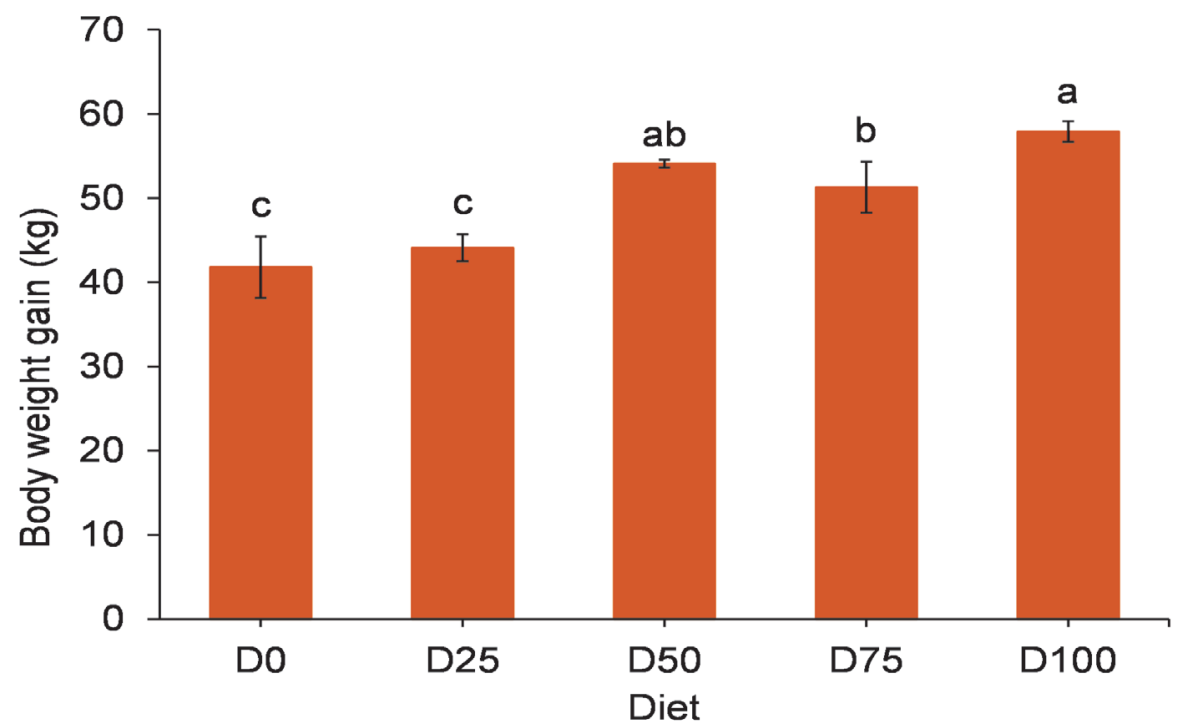

Figure B1. Overall mean body weight gain in finishing pigs fed BSFLM-based diets and a control diet. Means $( \pm$ SE) followed by different lowercase letters are significantly different (GLM, P < 0.05; LSD). BSFLM $=$ black soldier fly larval meal, D0 $=0 \%$ (control), D25 $=25 \%$, D $50=50 \%$, D $75=75 \%$, D100 $=$ $100 \%$ levels of replacement of fishmeal with BSFLM. For each diet, $\mathrm{N}=8$.

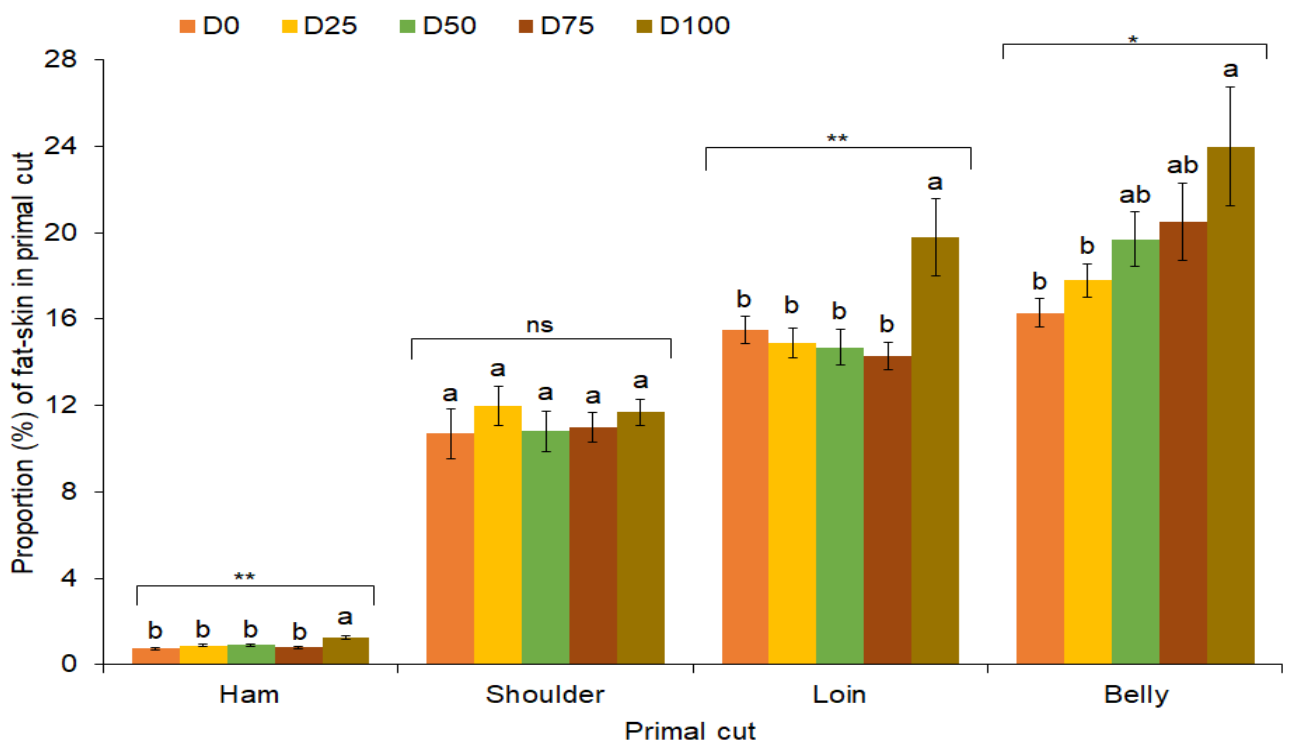

Figure B2. Composition of fat and skin in primal cuts of half carcasses of finishing pigs fed BSFLM-based diets and a control diet. Means $( \pm$ SE) within each primal cut followed by different letters are significantly different (GLM, P < 0.05 ; LSD). D0 $=0 \%$ (control), D25 $=25 \%$, D $50=50 \%$, D $75=75 \%$, D $100=100 \%$ levels of replacement of fishmeal with BSFLM. Significance level: **: P $<0.01, *$ : $<0.05$, ns: not significant. 


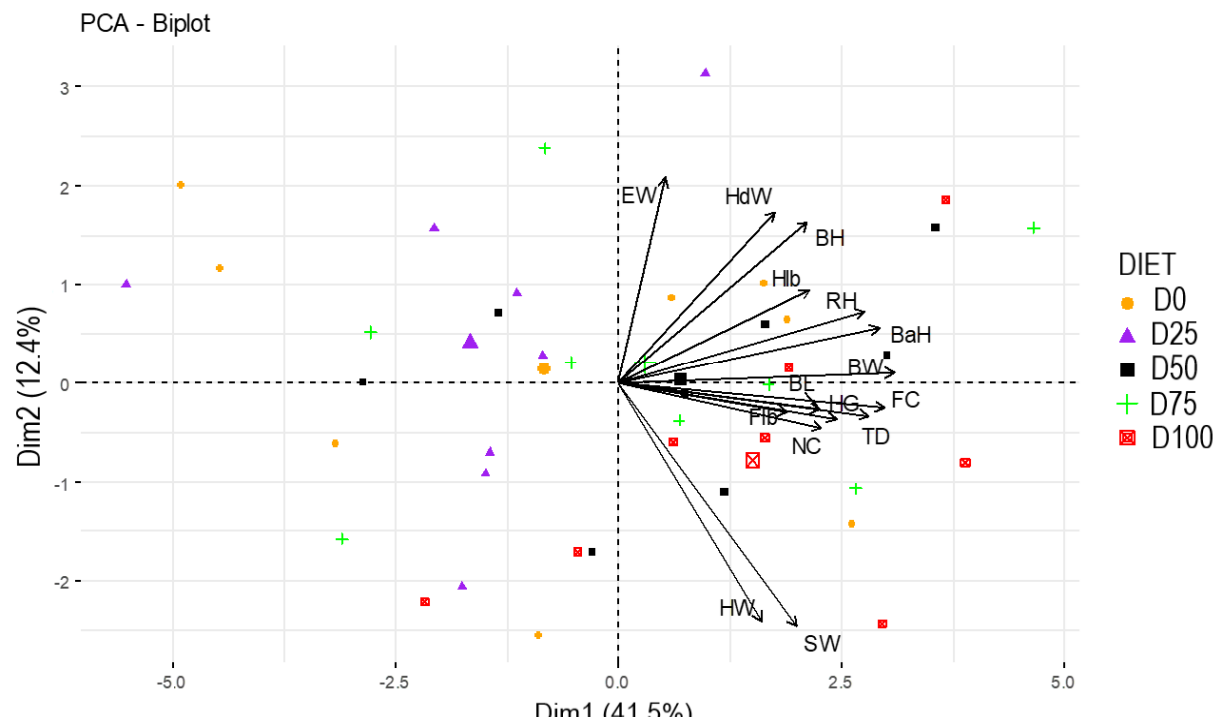

Figure B3. Principal component analysis (PCA) for pig traits assessed for the five diets. The factor map identifies clusters of correlated variables. Principal components 1 and 2 (Dim1 and Dim2) show the space where variables are expressed ( $>50 \%$ of variance). Variables (vectors) close to the center of the plot are less represented in the first two PCs. Variables analyzed: BW = live body weight of pig, $\mathrm{BL}=$ body length, $\mathrm{BH}=$ body height, $\mathrm{RH}=$ rump height, $\mathrm{HG}$ = heart girth, Flb = fore limb, Hlb = hind limb, EW = ear width, TD = trunk depth, SW = shoulder width, HW = hip width, $\mathrm{FC}=$ flank circumference, $\mathrm{BaH}=$ back height, $\mathrm{HdW}=$ head width, $\mathrm{NC}=$ neck circumference. Diets: $\mathrm{D} 0=0 \%$ (control), D25 $=25 \%$, D50 $=50 \%$, D75 $=75 \%$, D100 $=100 \%$ levels of replacement of fishmeal with BSFLM.

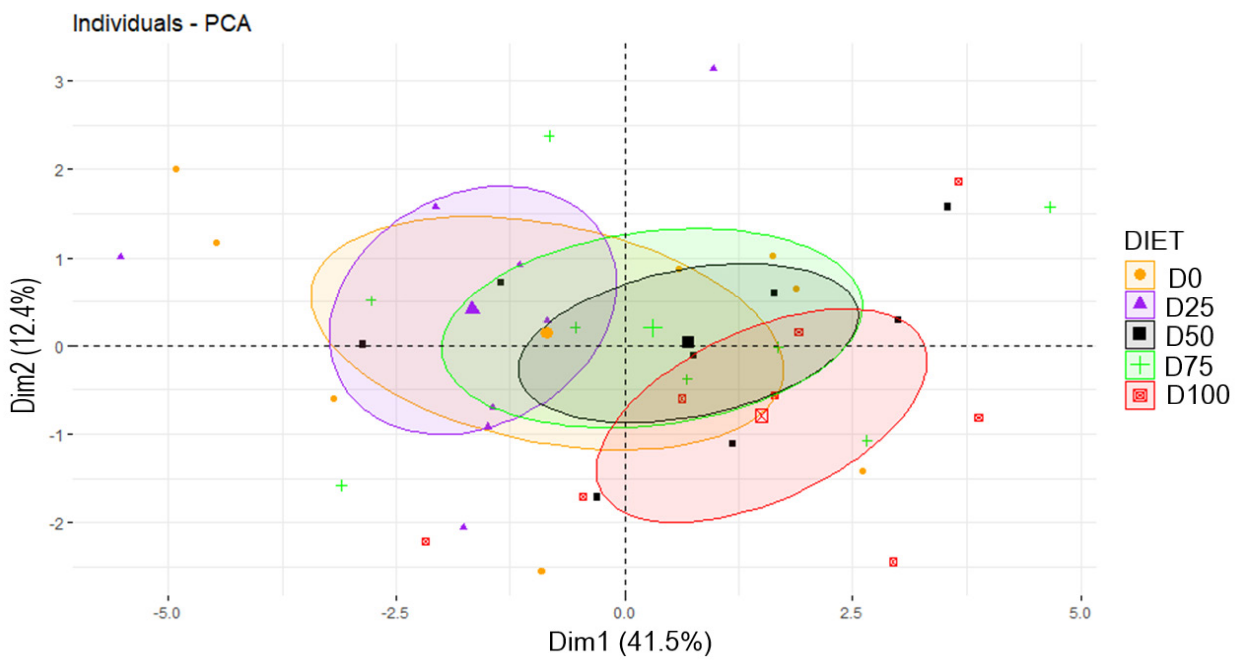

Figure B4. Principal component analysis (PCA). The ellipses represent the treatment groups and show the overlap between the control diet and the BSFLM-based diets. Principal components 1 and 2 (Dim1 and 2 ) show the space where variables are expressed ( $>50 \%$ of variance). Diet: D0 $=0 \%$ (control), D25 = $25 \%$, D $50=50 \%$, D $75=75 \%$, D $100=100 \%$ levels of replacement of fishmeal with BSFLM. 
Table B1. Proportion of muscle and bone in primal cuts of half carcasses in pigs fed diets with different levels of black soldier fly larval meal (BSFLM)

\begin{tabular}{lllrlll}
\hline $\begin{array}{l}\text { Parameter } \\
(\%)\end{array}$ & \multicolumn{5}{c}{ Diet } & P value, GLM \\
\cline { 2 - 6 } & D0 & D25 & D50 & D75 & D100 & \\
\hline Muscle & $75.1 \pm 0.51$ & $73.4 \pm 0.52$ & $74.6 \pm 0.90$ & $73.3 \pm 1.07$ & $71.9 \pm 1.05$ & 0.09 \\
Bone & $15.0 \pm 0.50$ & $15.2 \pm 0.52$ & $14.3 \pm 0.57$ & $15.5 \pm 0.83$ & $13.5 \pm 0.52$ & 0.13 \\
& & & Shoulder & & & \\
Muscle & $72.7 \pm 1.29$ & $68.8 \pm 1.04$ & $71.7 \pm 0.92$ & $71.1 \pm 0.83$ & $71.9 \pm 0.79$ & 0.09 \\
Bone & $16.5 \pm 0.67$ & $18.0 \pm 0.52$ & $17.1 \pm 0.69$ & $17.3 \pm 0.48$ & $15.8 \pm 0.51$ & 0.11 \\
& & & Loin & & & \\
Muscle & $58.6 \pm 1.47$ & $57.9 \pm 1.46$ & $58.5 \pm 1.16$ & $57.7 \pm 0.67$ & $56.9 \pm 1.57$ & 0.91 \\
Bone & $25.3 \pm 1.23 \mathrm{ab}$ & $26.4 \pm 0.63^{\mathrm{a}}$ & $25.9 \pm 0.92^{\mathrm{a}}$ & $27.6 \pm 1.05^{\mathrm{a}}$ & $23.0 \pm 0.84 \mathrm{~b}$ & 0.022 \\
& & & Belly & & & \\
Muscle & $62.9 \pm 2.96$ & $64.6 \pm 1.08$ & $63.0 \pm 1.13$ & $60.5 \pm 1.84$ & $60.4 \pm 2.26$ & 0.52 \\
Spare ribs & $20.5 \pm 2.97$ & $16.98 \pm 0.79$ & $16.75 \pm 0.95$ & $17.5 \pm 0.78$ & $15.1 \pm 0.72$ & 0.16 \\
\hline
\end{tabular}

Means $( \pm$ SE) within a row followed by different superscripts are significantly different, General Linear Model (GLM), P < 0.05, LSD. D0 $=0 \%$ (control), D25 $=25 \%$, D50 $=50 \%$, D75 $=75 \%$, D $100=100 \%$ levels of replacement of fishmeal with BSFLM. For each diet, $\mathrm{N}=8$. 
Acknowledgements 
The completion of this work represents a unique achievement in my academic life and gives me a great feeling of accomplishment, which would not have been possible without the immense contribution and support of many people and institutions. It would have been very pleasant to mention the name of everyone who helped me during my $\mathrm{PhD}$ work. Due to space constraints, this is not possible but their invaluable support does not in any way go unacknowledged.

Firstly, I would like to express sincere gratitude to my supervisors: Prof. Marcel Dicke, Prof. Joop J.A. van Loon and Dr. Chrysantus M. Tanga: Thank you for your invaluable support and mentorship during my PhD studies. Your constructive suggestions and guidance were very helpful in my studies and the completion of this work. I cannot thank you enough. Your timely feedback and insightful comments and suggestions were valuable incentives for me to improve on my academic and research pursuits. You made learning and work joyful to me through your encouragement and friendly interactions. I am particularly grateful to my two promotors: Prof. Marcel Dicke, Prof. Joop J.A. van Loon who, apart from academics also ensured that I had a place to stay by organizing an accommodation for me, even before I arrived in Wageningen. I remain indebted to your kind gestures. I am very grateful to my co-promotor, Dr. Chrysantus M. Tanga and his family for their continuous encouragement during this academic journey.

Besides my two promotors and co-promotor, I thank Drs. Sunday Ekesi, Komi K.M. Fiaboe, Sevgan Subramanian, Isaac M. Osuga, David M. Miano, Evans D. Ilatsia, and Prof. Baldwyn Torto for their invaluable contributions in terms of logistics, technical and administrative support during my work.

I would like to extend my profound gratitude to Wageningen University \& Research, The Netherlands for giving me the opportunity and academic support to pursue my PhD studies. I gratefully acknowledge the International Centre of Insect Physiology and Ecology (icipe), Nairobi, Kenya for the academic training and the facilities provided to me to carry out my research. I am also grateful to the Kenyan Agricultural and Livestock Research Organization (KALRO), Naivasha, Kenya and most especially, the Non-ruminant Research Institute (NRI), Naivasha, Kenya for providing the animal rearing facility and technical assistance during my pig feeding trials. I acknowledge Drs. Melita and Wilfred for their frequent visits to check on the wellbeing of my experimental animals. To Jacinter, Ochieng, Gikonyo, Sarem, Peter Alaro, and Esther for their continuous support at KALRO.

I am grateful to Dr. Daisy Salifu, John Macharia and Daan Mertens for their guidance in statistical analysis of my data. To Macdonald Githinji, I am thankful for his continuous support and encouragement during my pig feeding trials. You provided me with food and a place to spend the night when I first arrived in Naivasha to start up my experiment.

I thank Njowe Kieran and David Mutegi, Rachami Eric, Joshua Wambua, Ondiaka Shem and Faith Wamurango for their substantial contribution and technical support during 
my data collection process at icipe. I thank Alexandre Villela for his continued support in processing my amino acid and fatty acid data. I am deeply grateful to Wycliffe Ogetonto, who tirelessly supported me throughout the pig feeding trials. I am thankful to all the farmers from the four counties in Kenya, who participated in the household survey study and to the enumerators for their substantial contribution during the data collection process. I thank: Kentos, Njoroge, Muema and Joseph for helping me out during pig feed preparation and transport to and from Nakuru. I am grateful to Dr. Skilton, Margret Ochanda, Carolyn Akal, Cynthia Opana, Vivian Otieno, Lillian Igweta-Tonnang, Esther Ndung'u, and Lisa Omondi for their administrative assistance at icipe. I am thankful to Angelique Bosch and Tanja Schultz for their administrative assistance at Wageningen University \& Research. I thank Petra Cornelissen and Edith van de Horst for organizing my travel to The Netherlands. I am grateful to Hans Smid for helping out with the design of my thesis cover. Thank you Claudius and Lennart for organizing the $\mathrm{PhD}$ weekend meetings, which were very useful to me.

To my colleagues and friends at the Laboratory of Entomology, Wageningen University \& Research: Alessia, Alexander, Antonio, Bram, Davy, Els, Filippo, Gabriela, Jeanine, Jeroen, Jessica, Julia, Julian, Julien, Karol, Katherine, Kay, Luuk, Margaret, Maite, Marieke, Marilyn, Max, Monicah, Mitchel, Peter, Pieter, Quint, Sandeep, Simone, Sivaprakaham, Steve, Stijn, Tessa, Thibault and Yidong; thank you for your help in diverse ways. The PhD lunch meetings, the food, drinks and moments we shared together always inspired interesting and enriching discussions. You created 'home away from home' for me in Wageningen. I am grateful to Davy and Daan for being my paranymphs.

I would like to thank all my colleagues and friends at icipe, particularly: Akua, Olabimpe, Owusu, Abdelmutalab, Seydou Diabate, Steve Baleba, Joseph Gachuhi, Cheseto, Mawufe, Beatrice, Sheila Agha, Ritter, Inusa Ajene, Levi Ombura and Maureen Adhiambo, who in diverse ways contributed to my happy stay and work in Kenya. I enjoyed the various discussions we had, particularly during the science club, dry run and departmental meetings. These were great moments of learning to me. To the icipe scholars association (IScA), thank you for the opportunity to serve and learn.

To the Kenyan community and the united community of African students (UCAS) groups at Wageningen University \& Research, and the Cameroon students association in Nairobi, Kenya: thank you for the get-together moments we had, which always made me feel at home. To my fellow Cameroonian and friend, Urcil whom I met in Wageningen: thank you for your hospitality and great company during lunch. To my friends and corridor mates at Asserpark: Joy, Isaac, Aron, and Christella, whom I met at Wageningen, thank you for the warm reception, dinners, lunches and discussions we shared. The discussions always reminded me of the tasks I had to accomplish in my PhD work. Dear Honorine, thank you for your endless calls and messages of encouragement. To my friends Joshua (Kenya) and Bernard (Zambia), thank you for 
organizing and hosting the get-togethers in Wageningen, which were always refreshing. To my family: thank you for your continuous encouragement. I am particularly thankful to my mother Judith Ndisi, who has supported and encouraged me at every phase of my academic life. I am thankful to my siblings and cousins: Maurice, Faith, Diligence, Derrick, Kestine, Emmanuel, Winifred, Clement, Margret, Mary, Doris, Levy, Laura, Larisa, Philemon, for their continuous encouragements. To my uncles and aunts: Nkwaa Primus, Nkwaa Frida, Nwenfor Patrick and Nwenfor Felicia, thank you for your encouragement, which kept me going even when it seemed difficult at times. 


\section{Curriculum vitae $\&$ Publications}




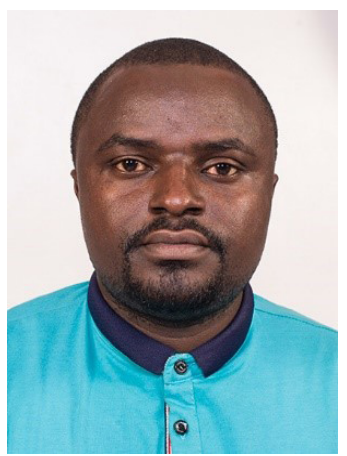

Shaphan Yong Chia was born on 10 June 1987 in Baingo, Cameroon. After completing his primary and secondary education, he enrolled in Government High School, in Wum and obtained his Advanced Level (AL) certificate in 2007. Shaphan then joined the University of Buea, Cameroon from 2008 to 2011, where he pursued a Bachelor of Science (BSc) degree in Zoology (major) and medical laboratory technology (minor). Later on, from 2013 to 2015, Shaphan did a Master of Philosophy (MPhil.) degree in Agricultural Entomology at the University of Ghana, Accra, Ghana, under the African Postgraduate Programme in Insect Science (ARPPIS), sponsored by the German Academic Exchange Service (DAAD). During his MPhil, he assessed the species composition and host association of thrips in the Eastern and Greater Accra Regions, Ghana. After completing his MPhil, he joined the Institute of Research and Agricultural Development (IRAD), Bambui-Bamenda, Cameroon as a research volunteer. In 2016, Shaphan enrolled for a Sandwich PhD program between Wageningen University \& Research, and the International Centre of Insect Physiology and Ecology (icipe), Nairobi, Kenya. His research focused on black soldier fly larvae as a sustainable animal feed ingredient. The results of this research are presented in this thesis. He was actively involved in and led the icipe scholars association (IScA) (2016-2017), which seeks to advance student interest in science through participation in academic exchange programmes as well as promote social interaction among scholars at icipe. Shaphan's ambition is to continue conducting research on the sustainable production of high-quality insects as a novel feed component for animal production and improvement of livelihood. 


\section{List of publications}

\section{In peer-reviewed journals}

Chia S.Y., Tanga C.M., van Loon J.J.A. and Dicke M. (2019). Insects for sustainable animal feed: inclusive business models involving smallholder farmers. Current Opinion in Environmental Sustainability 41:23-30 (chapter 2 in this thesis)

Chia S.Y., Tanga C.M., Osuga I.M., Mohamed S.A., Khamis F.M., Salifu D., Sevgan S., Fiaboe K.K.M., Niassy S., van Loon J.J.A., Dicke M. and Ekesi S. (2018). Effects of waste stream combinations from brewing industry on performance of black soldier fly Hermetia illucens (Diptera: Stratiomyidae). Peer 6:e5885 (Chapter 4 in this thesis)

Chia S.Y., Tanga C.M, Khamis F.M., Mohamed S.A, Salifu D, Sevgan S., Fiaboe K.K., Niassy S., van Loon J.J.A., Dicke M. and Ekesi S. (2018). Threshold temperatures and thermal requirements of black soldier fly Hermetia illucens: Implications for mass production. PLOS ONE 13:e0206097 (Chapter 5 in this thesis)

Chia, S. Y., Tanga, C. M., Osuga, I. M., Alaru, A. O., Mwangi, D. M., Githinji, M., Subramanian S., Fiaboe K.K.M., Ekesi S., van Loon J.J.A. and Dicke, M. (2019). Effect of dietary replacement of fishmeal by insect meal on growth performance, blood profiles and economics of growing pigs in kenya. Animals, 9, 705. (Chapter 7 in this thesis)

\section{Submitted}

Chia S.Y., Tanga C.M, Osuga I.M., Cheseto X., Ekesi S., van Loon J.J.A. and Dicke M. Nutritional composition of black soldier fly larvae feeding on agro-industrial by-products (chapter 6 in this thesis)

Chia S.Y., Tanga C.M., Macharia J., Diiro G.M., Ekesi S., van Loon J.J.A. and Dicke M. Knowledge and willingness of smallholder farmers in Kenya to pay for insect-based feeds (Chapter 3 in this thesis)

\section{In preparation}

Chia S.Y., Tanga C.M., Isaac M. Osuga, Alphonce O. Alaru, David M. Mwangi, Macdonald Githinji, Ekesi S., van Loon J.J.A. and Dicke M. Black soldier fly larval meal in feed enhances growth performance, carcass yield and meat quality of finishing pigs (Chapter 8 in this thesis) 


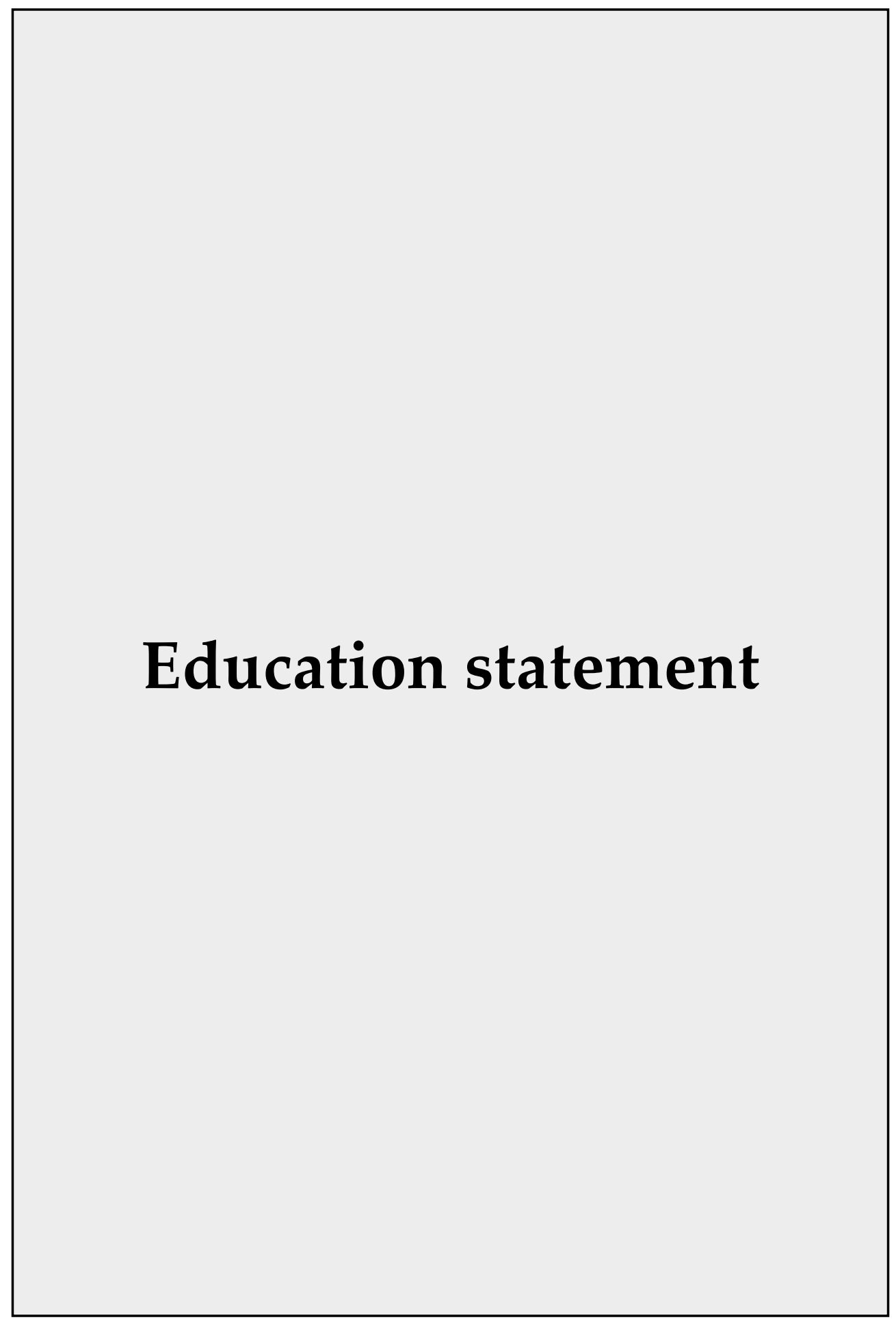




\section{PE\&RC Training and Education Statement}

With the training and education activities listed below the $\mathrm{PhD}$ candidate has complied with the requirements set by the C.T. de Wit Graduate School for Production Ecology and Resource Conservation (PE\&RC) which comprises of a minimum total of 32 ECTS (= 22 weeks of activities)

\section{Review of literature (4.5 ECTS)}

Insects as high quality protein ingredient for poultry, fish and pig feed industries

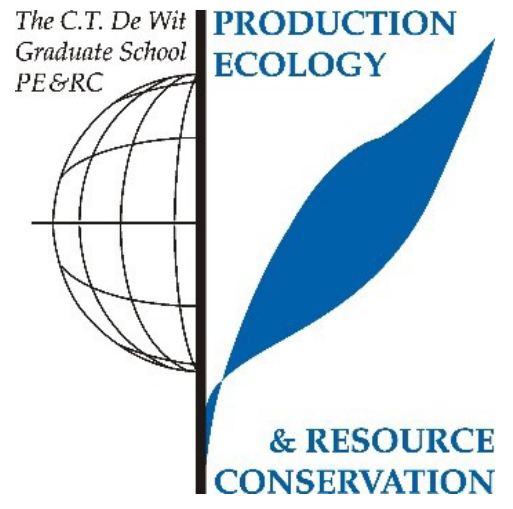

\section{Writing of project proposal (4.5 ECTS)}

Assessing the potential of black soldier fly as protein subsidy in poultry, fish and pig feed in Kenya

\section{Post-graduate courses (12.6 ECTS)}

Introduction to insect taxonomy, identification and insect photography;

International centre of insect physiology and ecology (ICIPE), Nairobi, Kenya (2016)

- Introduction to GIS and remote sensing; ICIPE (2016)

- Introduction to behavioural and chemical ecology; ICIPE (2016)

- Introduction to molecular biology and bioinformatics; ICIPE (2016)

Principles of biostatistical reasoning: an introduction to statistical methods in biological research; ICIPE (2016)

- Ecological modelling; ICIPE (2016)

- Biostatistics: introduction to R software; ICIPE (2016)

\section{Laboratory training and working visits (4.5 ECTS)}

Effect of insect meal on pig performance; Non ruminant Research Institute (NRI)- Kenya Agricultural and Livestock Research Organization (KALRO), Naivasha, Kenya (2018)

\section{Competence strengthening / skills courses (6.8 ECTS)}

Introduction to research ethics; ICIPE (2016)

Health and safety; ICIPE (2016)

Introduction to GIS and remote sensing; ICIPE (2017) 
- $\quad$ Scientific writing and publishing; ICIPE (2017)

- Information literacy training, reference management; ICIPE/WUR (2017-2018)

- Communication with the media and the general public; WUR (2018)

- Interpersonal communication for PhDs; WUR (2018)

- Critical thinking and argumentation; WUR (2018)

- Reviewing a scientific paper; WUR (2018)

\section{PE\&RC Annual meetings, seminars and the PE\&RC weekend (1.5 ECTS)}

PE\&RC Day (2018)

PE\&RC Midterm weekend (2018)

PE\&RC Last years weekend (2019)

\section{Discussion groups / local seminars / other scientific meetings (7.5 ECTS)}

- Plant health theme monthly meetings; ICIPE (2016-2017)

- ICIPE Scholars association-science club meetings; ICIPE (2016-2017)

- $\quad$ Student dry run programme; ICIPE (2016-2017)

- $\quad$ PhD Lunch meetings; WUR (2018-2019)

\section{International symposia, workshops and conferences (9.3 ECTS)}

International conference on legislation and policy on the use of insect as food and feed in East Africa; Kisumu, Kenya (2016)

- $\quad 22^{\text {nd }}$ Meeting and conference of the African association of insect scientists: towards securing human welfare through management of insect diversity in a changing world; Wad Medani, Sudan (2017)

- Annual general meeting of ICIPE governing council; poster presentation; Nairobi, Kenya (2017)

- The $2^{\text {nd }}$ International conference: Insects to Feed the World (IFW); oral and poster presentation; Wuhan, China (2018)

- $\quad 30^{\mathrm{e}}$ Nederlandse entomologendag; poster presentation; Ede, the Netherlands (2018)

- Symposium earth futures; WUR, the Netherlands (2018)

- Annual general meeting of ICIPE governing council; poster presentation; Nairobi, Kenya (2018) 
The research described in this thesis was financially supported by The Netherlands Organisation for Scientific Research, WOTRO Science for Global Development (NWO-WOTRO).

Cover design by Hans Smid

Thesis layout by Shaphan Yong Chia

Printed by GVO Printers \& Designers, Ede, The Netherlands. 


\section{Propositions}

1. Dietary replacement of fishmeal by black soldier fly larval meal enhances growth and carcass yield in finishing pigs.

(this thesis)

2. Predominance of saturated fatty acids in black soldier fly larvae reduces their nutritional value.

(this thesis)

3. Pest outbreaks in crops can be prevented by increasing biodiversity in and around agricultural land.

4. Market access and trade interactions involving livestock enhance the spread of HIV/AIDS.

5. Multidisciplinary approaches are vital in assessing gut health of animals in feeding trials.

6. Mosquito vector control is more justified by instrumental value than by intrinsic value of the organism.

7. The key to sound leadership is service.

Propositions belonging to the thesis, entitled:

"Black soldier fly larvae as a sustainable animal feed ingredient in Kenya"

Shaphan Yong Chia

Wageningen, 20 December 2019 